$\frac{12}{3 / 18.96850}$

UCRL-ID- 122673

\title{
Environmental Measurements for \\ Project Overview
}

\author{
David H. Chambers \\ Douglas L. Ravizza
}

September 28, 1995

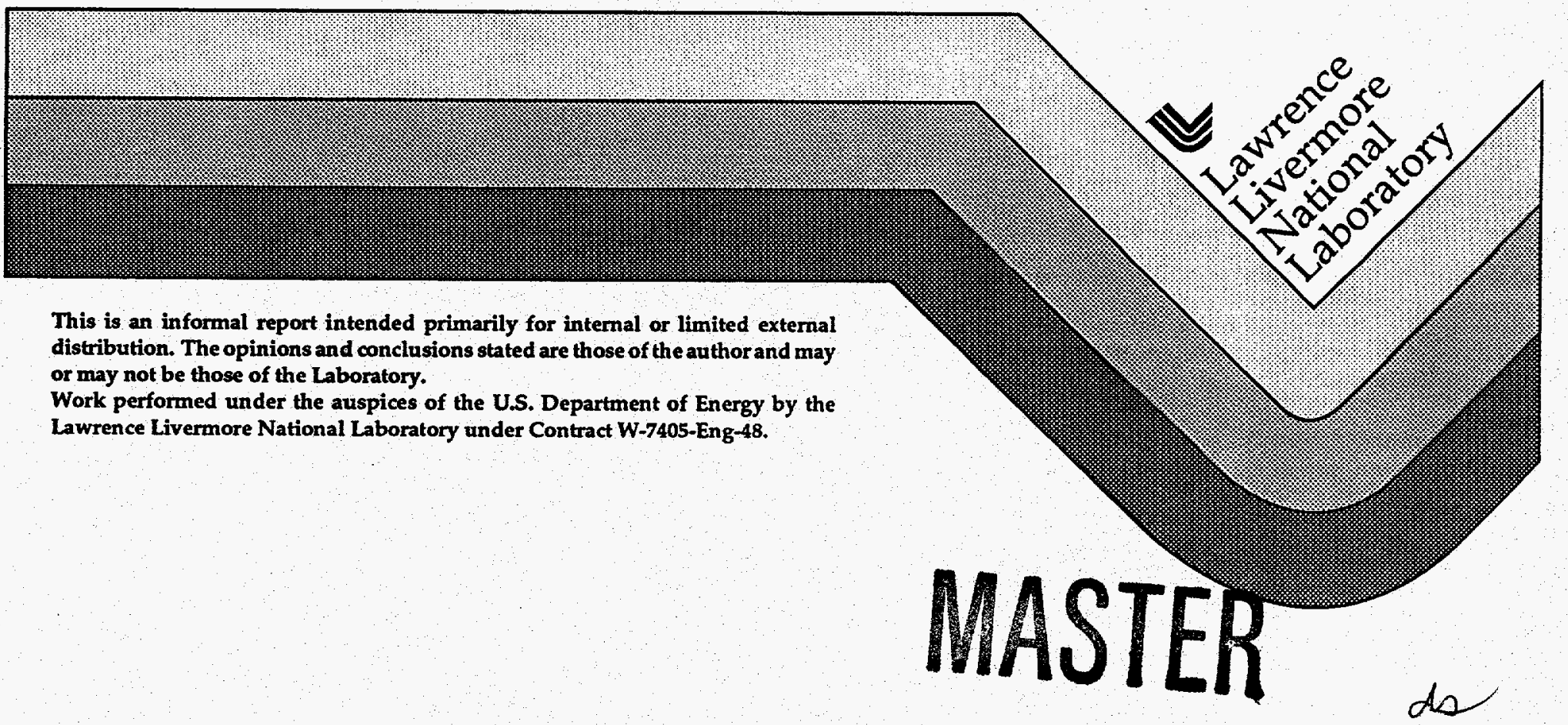




\section{DISCLAIMER}

This document was prepared as an account of work sponsored by an agency of the United States Government. Neither the United States Government nor the University of California nor any of their employees, makes any warranty, express or implied, or assumes any legal liability or responsibility for the accuracy, completeness, or usefulness of any information, apparatus, product, or process disclosed, or represents that its use would not infringe privately owned rights. Reference herein to any specific commercial product, process, or service by trade name, trademark, manufacturer, or otherwise, does not necessarily constitute or imply its endorsement, recommendation, or favoring by the United States Government or the University of California. The views and opinions of authors expressed herein do not necessarily state or reflect those of the United States Government or the University of California, and shall not be used for advertising or product endorsement purposes.

This report has been reproduced directly from the best available copy.

Available to DOE and DOE contractors from the Office of Scientific and Technical Information P.O. Box 62, Oak Ridge, TN 37831

Prices available from (615) 576-8401, FTS 626-8401

Available to the public from the

National Technical Information Service

U.S. Department of Commerce

5285 Port Royal Rd.,

Springfield, VA 22161 


\section{DISCLAMMER}

Portions of this document may be illegible in electronic image products. Images are produced from the best available original document. 


\section{Introduction}

From July 10 to July 17, 1995, Project Overview was conducted at the Atlantic Undersea Test and Evaluation Center (AUTEC) at Andros Island, Bahamas. Part of the project was the collection and analysis of environmental data including wind measurements and ocean temperature and salinity profiles. This report describes these environmental measurements and presents the results of analysis performed in the field. The goal of the analysis was to calculate the Brunt-Väisälä (BV) profile during operations, and provide operational recommendations from solutions of the Taylor-Goldstein (T-G) equation using the measured BV profile. Part 1 is a description of the sensors and their deployment. Part 2 discusses the analysis done in the field. Part 3 presents a summary of the wind measurements. Part 4 summarizes the ocean profiling results. Part 5 presents overall conclusions and recommendations for future experiments. The appendices include all of the ocean profiling results and wind measurements obtained in the field.

\section{Part 1: Sensors and deployment}

In Project Overview three ocean profiling sensors were used and one meteorological station was deployed from the AUTEC research ship Range Rover. The met station was identical to that used in the Loch Linnhe 1994 experiments. Data recorded include wind speed, direction, air temperature, and relative humidity, of which wind speed and direction was most important. The anemometer for measuring the wind was mounted at the top of a 10 meter tower secured to the deck of Range Rover. A notebook computer was set up to continuously monitor the met data. The met station was set up to record 10 minute averages of each quantity which were periodically dumped to the computer.

The primary ocean profiling sensor was an STD Plus, Model STD-12, Conductivity-Temperature-Depth (CTD) instrument manufactured by Applied Microsystems, Ltd. This was lowered by winch from the Range Rover to depths of at least 200 meters. The instrument was configured to record water temperature, conductivity, and salinity sampled every $10 \mathrm{~cm}$ in depth. Casts using this sensor attained a maximum depth of 250 meters typically. Two 
deep casts were done, one at the beginning and the other near the end of the experiment, attaining depths greater than 500 meters.

In addition to the STD Plus, an S4 current meter equipped with extra CTD sensors was deployed occasionally as a back up sensor. The S4, manufactured by InterOcean Systems, also measures horizontal water velocity. It has the capability of recording temperature, pressure (depth), salinity, two horizontal velocities, sensor tilt, and sensor orientation (compass). It also calculates water density using the UNESCO 80 equation of state for sea water. During deployment, the S4 was attached to the same rigging as the STD Plus. The profiles from each instrument could then be compared.

The STD Plus and S4 profiling sensors were fielded by LLNL during Overview. A third profiling sensor system, the XBT profilers, was fielded by the crew of the Range Rover. These expendable sensors recorded temperature and depth to roughly 500 meters. They were typically deployed simultaneously with the STD Plus and provided another cross check for the CTD temperature measurements.

The profiling sensors were deployed periodically during each serial as boat and radar operations permitted. During serial 1 the sensors were deployed roughly every two hours. After it was determined that the BV profile was fairly stable the deployment interval was increased for later serials. Early in the experiment it became apparent that the operational requirements of the VLGA radar mounted on the Range Rover were incompatible with the profiling operations. The radar required the Range Rover to stationkeep using the thrusters. During thruster operation no profiling could be done since the sensor line would be in danger of entanglement with the thrusters. Profiling operations could be done only during brief periods between radar data collection times. This restricted profiling but did not affect weather data collection during the first half (serials 1 through 4) of the experiment. For the latter half of the experiment (serials 5 through 8), the Range Rover was continually running racetrack patterns which prevented both profiling and wind data collection. Thus wind and profile data for serial 5 through 8 were restricted to periods just before or just after the serial data collection periods.

\section{Part 2: On-site data analysis}

The primary on-site analysis was done using a Macintosh IIci installed on the Range Rover. In addition, a Macintosh Powerbook 
was used for data backups and for interfacing with the S4 and STD Plus. The primary data products were plots of temperature, density, and BV frequency as functions of depth for each cast. In addition, for each S4 cast plots of the two components of horizontal velocity were made. These components were parallel (along track) and perpendicular (cross track) to the target track for run 1 of each serial. Whenever two or more profiling instruments were used, plots comparing the profiles from each instrument were produced. At least once per serial, the Taylor-Goldstein equation was solved for a profile (usually the first in a serial). This produces plots of the dispersion relation, phase and group speeds, and sensitivity functions required for determining target operation parameters. Almost all of the analysis was performed using MATLAB, an interactive matrix algebra and signal processing environment developed by Mathworks, Inc. The one exception was the Taylor-Goldstein solver which was a Fortran program written by Dr. Harry Robey. MATLAB proved to be a particularly efficient and flexible environment for data analysis. Much of the routine processing and analysis was automated after a short development period.

As described above, the met data consisted of 10 minute averages of wind speed and direction as well as other meteorological quantities (temperature, relative humidity, etc.). The only analysis applied to this data was averaging and display.

The profile data was processed more extensively. The STD Plus CTD data was smoothed using a 9 point running average, then density at STD was calculated using the UNESCO (1979) equation of state for sea water. The S4 sensor calculates density automatically using a slightly different formula that includes pressure variations. Thus the S4 density is the actual physical density at depth while the STD Plus density is the equivalent density at atmospheric pressure. This leads to a divergence of the two density profiles with increasing depth. The derivative of the density profile with depth is calculated for both sensors then smoothed in order to obtain the BV frequency profile.

The velocity data from the $\mathrm{S} 4$ is recorded as a magnitude and compass heading in the sensor. This is then resolved into cross track and along track velocity components in the usual way.

\section{Part 3: Wind data summary}

The wind data consists of time histories of wind direction and speed for serials 1 through 4 when the Range Rover was stationary 


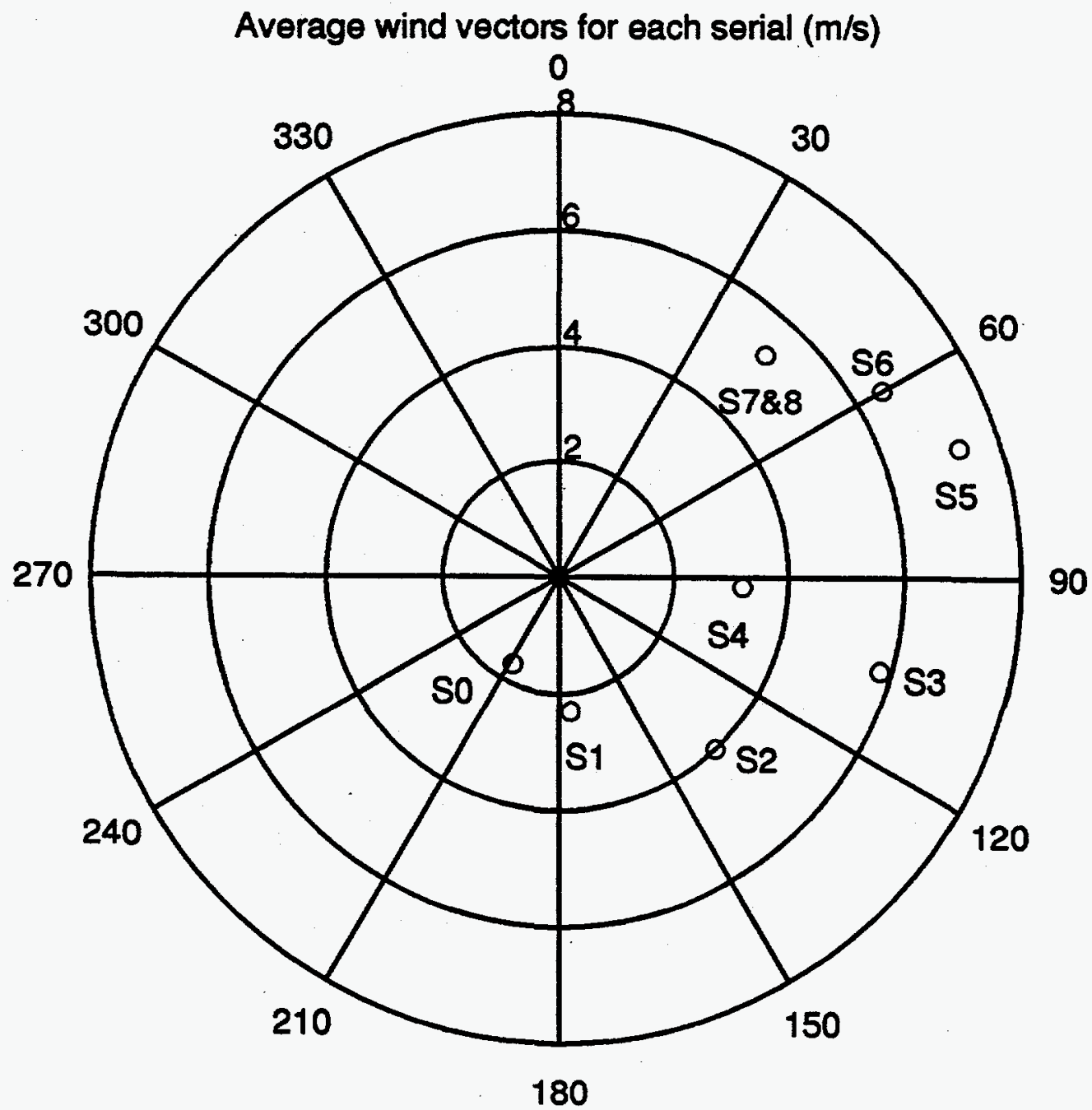


and average values for serials 5 through 8 . No time histories are available for the latter serials because the Range Rover was continually moving. The average wind speeds and directions for serials 5 through 8 are based on time series of wind data for roughly an hour before commencement of each serial. The following table and figure shows the overall average for wind speed and direction for each serial. Note serial 0 refers to the test day on July 10, 1995. The actual time history of the wind for serials 1 through 4 are shown in Appendix 1. The wind was light for the first two serials, coming predominantly from the south. For the remainder of the experiment it blew from a more easterly direction.

$\begin{array}{llc}\text { Serial } & \text { Wind speed }(\mathrm{m} / \mathrm{s}) & \text { Wind direction } \\ 0 & 1.7 & 208 \\ 1 & 2.3 & 175 \\ 2 & 4.0 & 137 \\ 3 & 5.8 & 106 \\ 4 & 3.2 & 93 \\ 5 & 7.3 & 72 \\ 6 & 6.5 & 60 \\ 7 & 5.3 & 43 \\ 8 & 5.3 & 43\end{array}$

Table 3.1 Wind summary

Figure 3.1

Average wind speed and direction for each serial.

\section{Part 4: Profile summary}

A total of 24 casts were performed during the experiment. Of these, all involved the STD Plus (CTD), 5 were joint casts with the S4, and 19 were joint casts with the XBT sensor. Table 4.1 lists all of the casts by serial, date and time. Note that serial number 0 refers to the test day before the start of operations. The results from each cast are presented in Appendix 2.

For the STD Plus and S4, two profiles are obtained for each cast, one as the instruments are lowered, and one as they are raised. Due to the placement of the temperature and conductivity sensors on each instrument, only the downcast was used for the STD Plus, and 
the upcast for the S4. The STD Plus was set to record data in $10 \mathrm{~cm}$ depth increments. The $S 4$ could only be set to record at a given time rate $(10 \mathrm{~Hz})$ and consequently the resolution of the S4 data was much greater. Each instrument stored data internally during a cast. This data was then downloaded to the analysis computer after the cast. A MATLAB function was used to strip the appropriate cast (up or down) from the data, median filter ( 7 point window) to eliminate wild points, derive the BV profile, then display the results. In the case of the STD Plus data, the density was calculated from the temperature and salinity using the UNESCO equation of state. The incorporation of both editing and display operations into one function made the initial analysis of the data quick and reliable. The calculation of the BV profile requires the derivative of the density profile. A simple first order difference combined with smoothing (9 point moving average) was used to approximate the derivative.

\begin{tabular}{|c|c|c|c|c|c|}
\hline Serial & GMT date & GMT time & STD Plus & S4 & XBT \\
\hline 0 & July 10 & $17: 32$ & $\mathrm{x}$ & & \\
\hline 1 (deep) & July 11 & $00: 32$ & $\mathrm{x}$ & & $\mathbf{x}$ \\
\hline 1 & July 11 & $03: 54$ & $\mathrm{x}$ & $\mathrm{x}$ & \\
\hline 1 & July 11 & $06: 38$ & $\mathrm{x}$ & & \\
\hline 1 & July 11 & $09: 55$ & $\mathbf{x}$ & & \\
\hline 2 & July 12 & 01:39 & $\mathrm{x}$ & & $\mathbf{x}$ \\
\hline 2 & July 12 & $06: 34$ & $\mathrm{x}$ & & $\mathbf{x}$ \\
\hline 2 & July 12 & $10: 08$ & $\mathrm{x}$ & & $\mathbf{x}$ \\
\hline 3 & July 13 & $00: 31$ & $\mathrm{x}$ & $\mathrm{x}$ & $\mathbf{x}$ \\
\hline 3 & July 13 & $05: 25$ & $\mathrm{x}$ & & \\
\hline 3 & July 13 & 09:35 & $\mathrm{x}$ & & $\mathrm{x}$ \\
\hline 4 & July 13 & $17: 40$ & $\mathrm{x}$ & & $\mathrm{x}$ \\
\hline 4 & July 14 & $01: 20$ & $\mathrm{x}$ & & $\mathbf{x}$ \\
\hline 4 & July 14 & $04: 35$ & $\mathrm{x}$ & & $\mathbf{x}$ \\
\hline 5 & July 15 & $00: 47$ & $\mathrm{x}$ & $\mathrm{x}$ & $\mathbf{x}$ \\
\hline 5 & July 15 & $10: 04$ & $\mathrm{x}$ & & $\mathbf{x}$ \\
\hline 6 & July 15 & $18: 54$ & $\mathrm{x}$ & $\mathbf{x}$ & $\mathbf{x}$ \\
\hline 6 & July 16 & $01: 44$ & $x$ & & $\mathrm{x}$ \\
\hline 6 & July 16 & $06: 30$ & $\mathrm{x}$ & & $\mathbf{x}$ \\
\hline 7 & July 16 & $14: 22$ & $\mathrm{x}$ & & $\mathbf{x}$ \\
\hline 7 (deep) & July 16 & $18: 22$ & $\mathbf{x}$ & $\mathbf{x}$ & $\mathrm{x}$ \\
\hline 8 & July 16 & $21: 19$ & $x$ & & $\mathrm{x}$ \\
\hline 8 & July 17 & $00: 36$ & $\mathrm{x}$ & & $\mathrm{x}$ \\
\hline 8 & July 17 & $06: 26$ & $\mathrm{x}$ & & $\mathrm{x}$ \\
\hline
\end{tabular}

Table 4.1 Profile summary 
Appendix 2 shows all of the results from the profiles listed above. A comparison between instruments shows that all of the instruments generally agree in their measurements of temperature and salinity. The STD Plus (CTD) temperature and the $S 4$ temperature profiles agree to within $0.1 \mathrm{C}$. The XBT temperature is typically $0.5 \mathrm{C}$ lower than the CTD. The salinity recorded by the $S 4$ is typically 0.1 psu higher than the CTD. This offset plus the difference between the internal density formula of the $\mathrm{S} 4$ and the formula provided for the CTD accounts for the difference between the S4 and CTD density profiles. The $\mathrm{S} 4$ density formula includes the effect of increasing pressure (compressibility) while the CTD formula is the adiabatic density (density at 1 atmosphere). For the purpose of calculating the BV profile, it is more correct to use the adiabatic density because the buoyancy force on a displaced fluid parcel is proportional to the density difference after pressure equilibration. The derived BV profiles generally agree between the $S 4$ and CTD. The increased variability of the $\mathrm{S} 4 \mathrm{BV}$ profile results from the greater depth resolution of the $S 4$ profiles. The $\mathrm{BV}$ profiles also diverge slightly at greater depth due to the difference in density profiles.

As noted before, the S4 also measures the two horizontal components of water velocity. By profiling the $S 4$, the depth distribution of current could, in theory, be measured. These are recorded in the form of magnitude and compass direction for each depth. Using the known target track the data can be transformed into along-track and cross track current velocities. Before this experiment it was not clear how much the boat motion, and the act of profiling would contaminate the current measurements. Each cast using the S4 gives two current profiles: one while the instrument is lowered (downcast), and the other when it is raised (upcast). After comparing these two profiles for a cast it was found that the boat motion significantly contaminates the velocity profile measurements. The boat cannot use its thrusters to maintain position during a cast because of the danger of line entanglement. This leaves the boat to drift during a cast. Profiling the $\mathrm{S} 4$ for current distributions requires a stable platform, either a permanent structure, or a multi-point mooring.

The water characteristics were remarkably stable over the duration of the experiment. Except for the July 10 profile and the first 2 profiles on July 11 , the upper 200 meters of the BV profile stayed within a range of $2 \mathrm{cph}$. The peak of the BV profile was around 80 meters. However, the BV profile decayed slowly with depth below the peak. Since the salinity varies only slightly with 


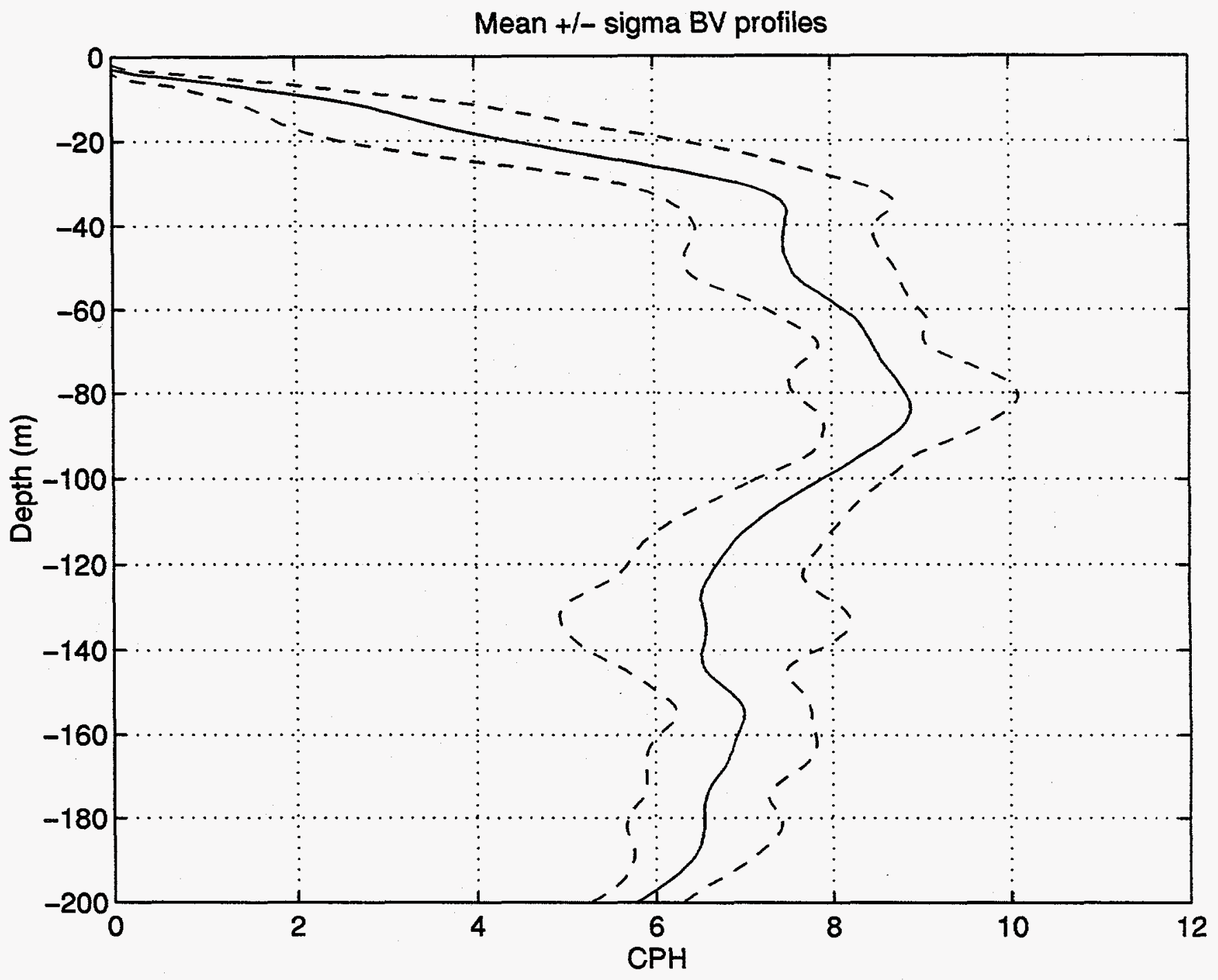



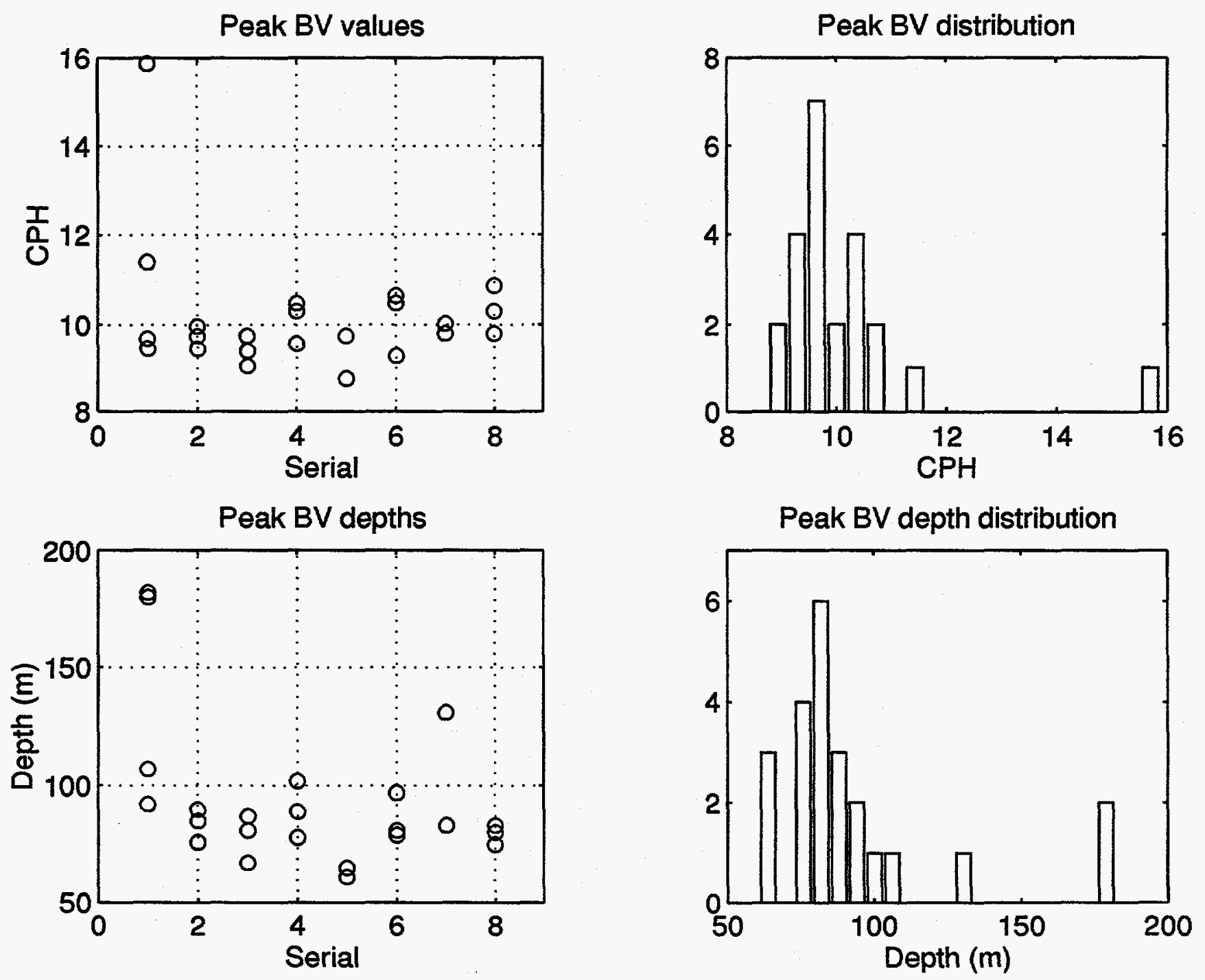
depth, the temperature is the main cause of the density variation with depth. The XBT data and the two deep profiles noted in Table 4.1 show that the temperature gradient is still significant down to 1000 meters depth and thus the BV frequency is still nearly $50 \%$ of the peak value for the deep cast July 11, 00:32 GMT. The zero value of the BV frequency at maximum depth in the shallow profiles is an artifact of the smoothing algorithm.

At the end of the experiment each BV profile derived from the CTD (STD Plus) was interpolated onto a uniform grid from 0 to 200 meters with 1 meter resolution. The resulting profiles were then averaged and standard deviations calculated excluding the first two profiles from the first day and the profile from the test day, July 10 . These excluded profiles were significantly different from the rest. This average profile with one $\sigma$ bounds is shown in Figure 4.1. The peak BV values and peak depths for each profile are summarized in Figure 4.2 for each serial. Note the exceptionally high values of peak BV and peak depth obtained from the first two casts in serial 1. This is one indication of the atypical nature of these two profiles. However, the peak value and peak depth are remarkably stable over the remainder of the experiment.

Figure 4.1

Average $\mathrm{BV}$ profile with $\pm \sigma$ bounds

Figure 4.2

Peak BV values and depths for each serial

For each serial one BV profile, typically the first, was used to find the dispersion relations and mode functions by solving the Taylor-Goldstein (TG) equation using a shooting method developed by Dr. Harry Robey. The frequencies, phase speeds, group speeds, and sensitivity functions for the lowest two modes were displayed as functions of the wave number $k$ (see Appendix 3 ). The typical value of the limit of phase speed as $k$ approaches zero was $1 \mathrm{~m} / \mathrm{s}$. The sensitivity function for a given $k$ value and mode is the product of the derivative of the eigenfunction with the derivative value at the surface $(\mathrm{z}=0)$, i.e. $S(z)=\phi^{\prime}(0) \phi^{\prime}(z)$. This function governs the amplitude of the surface current response to a source at depth $z$. Since $\phi(z)$ depends on wave number $k$, the sensitivity function $S(z)$ 
Phase speed variations, modes 1 and 2

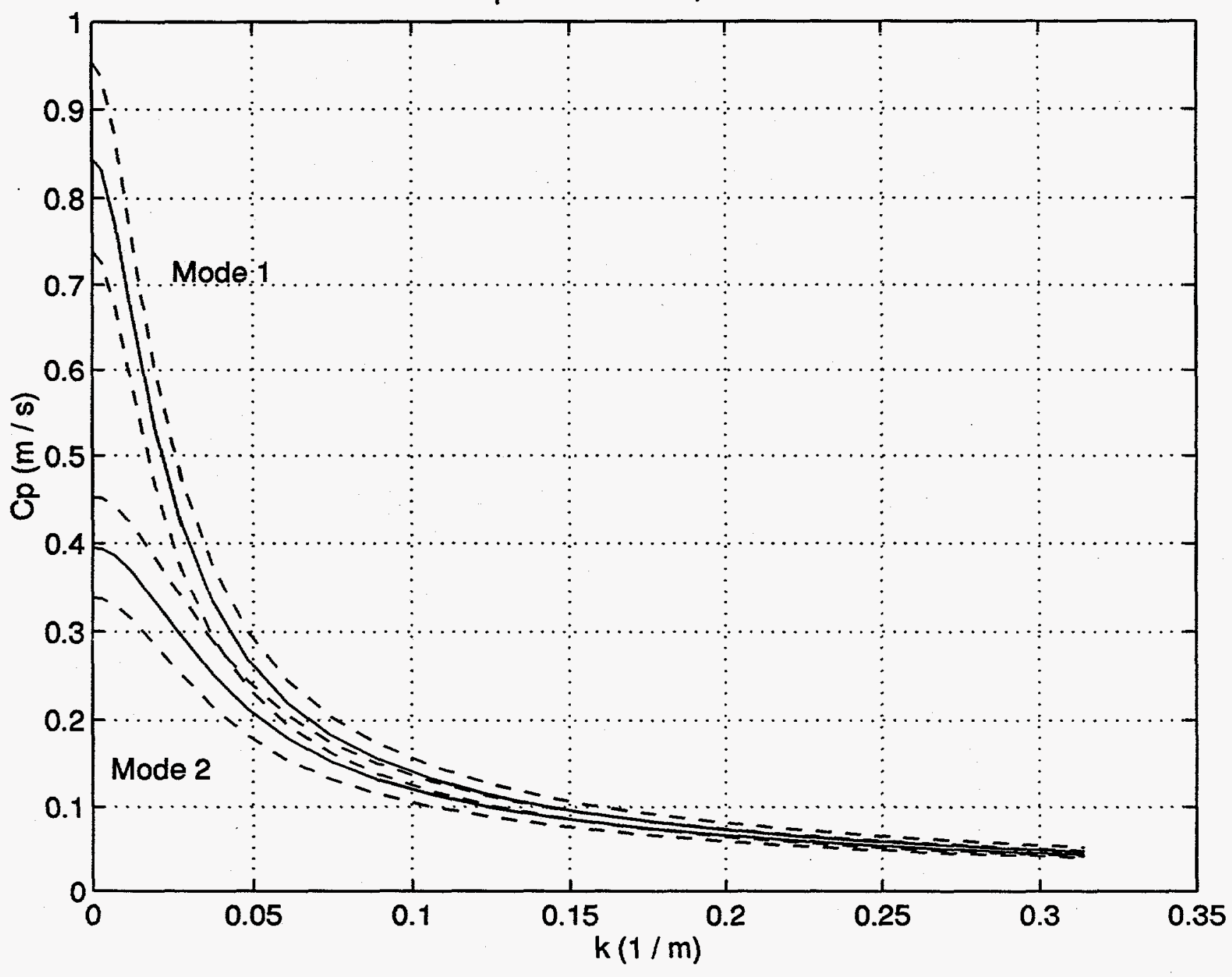




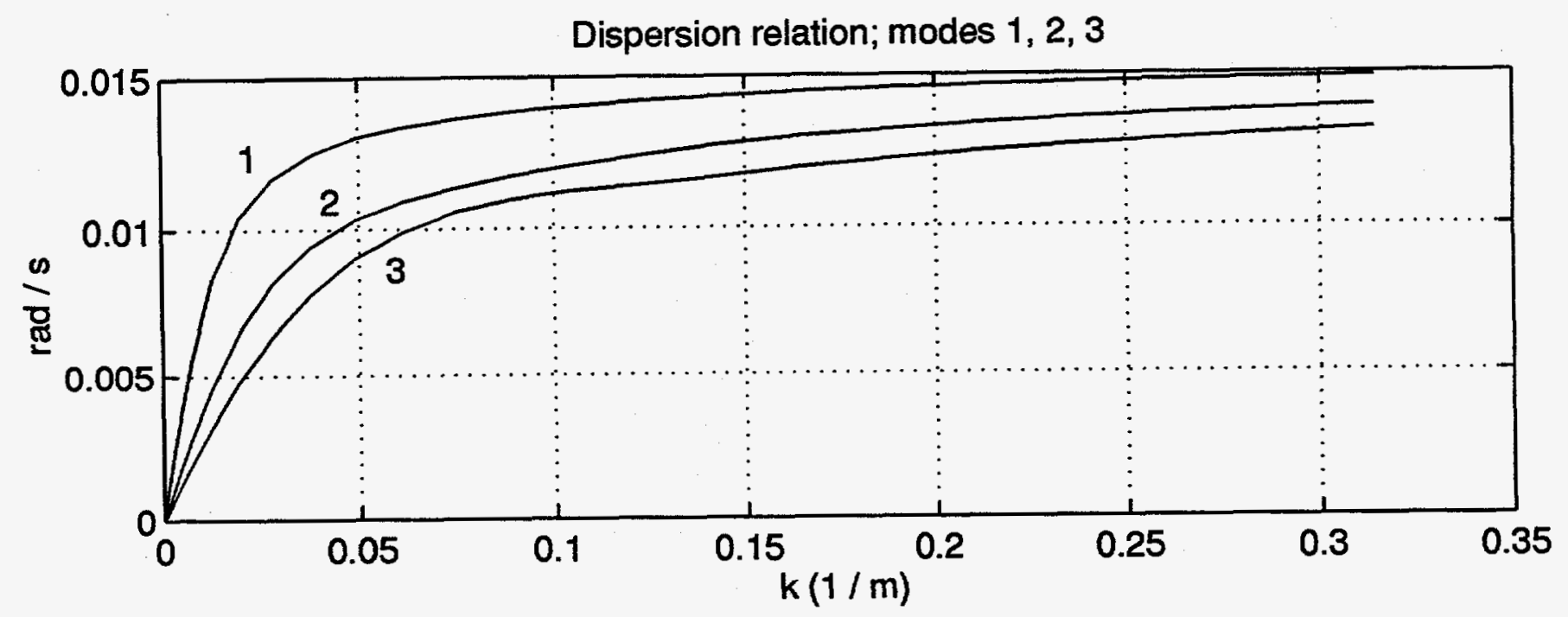

Phase (-) and group (--) speeds; modes 1, 2, 3

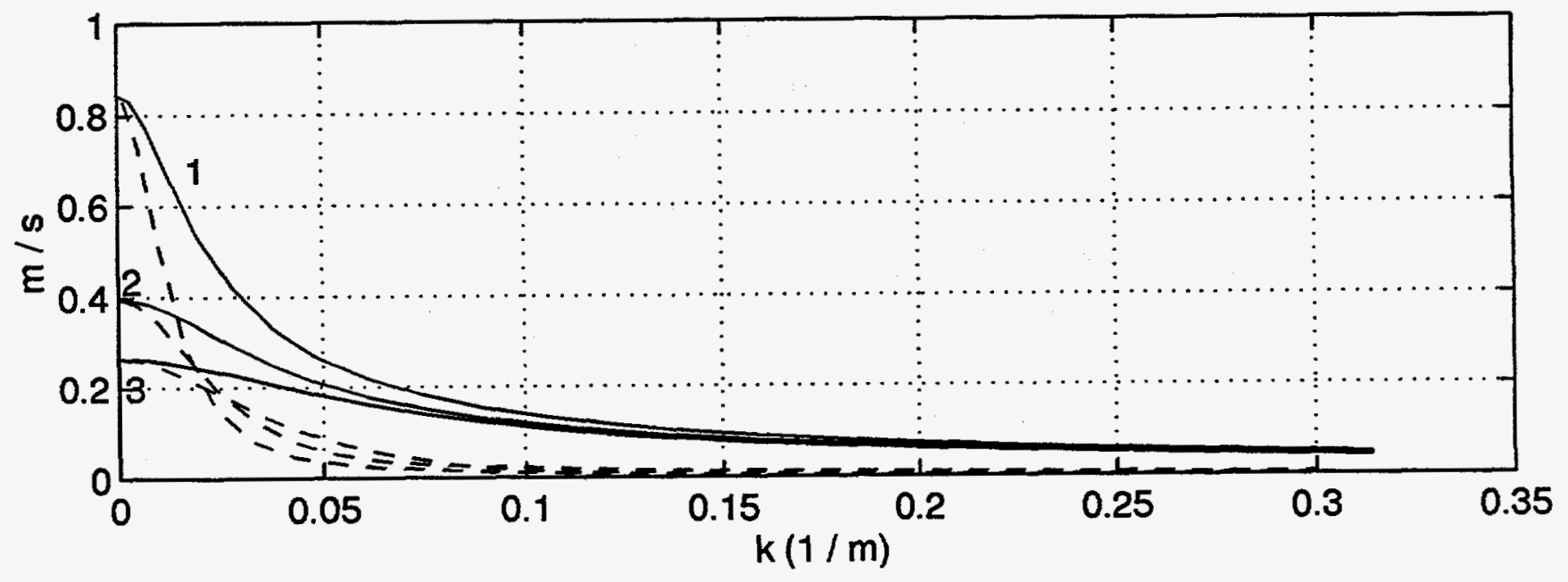



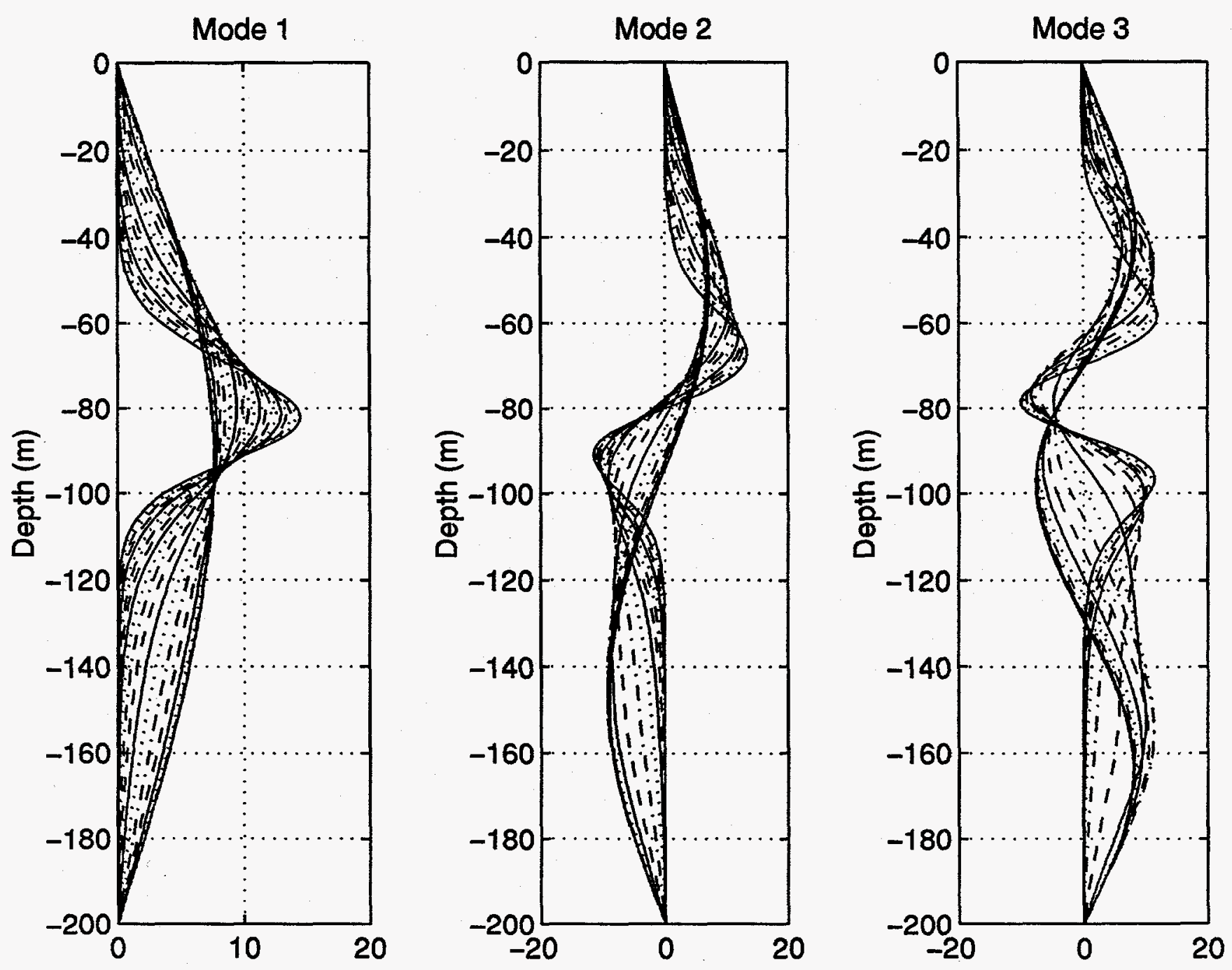
also depends on the wave number of the source. The sensitivity function profiles were used in the field to select the optimum source depth for each serial.

Using a shooting method developed with MATLAB by one of the authors (DHC), the $T-G$ equation for the average profile and the $\pm \sigma$ profiles was solved. The phase speeds for modes 1 and 2 are shown in Figure 4.3. The solid line represents the phase speed for the average profile, and the dashed lines represent the phase speeds obtained from the $\pm \sigma$ profiles. This shows that the greatest variation between profiles occurs for long waves (low $\mathbf{k}$ values). The variation of the phase speeds for short waves is minimal. The full dispersion relation and the phase and group speeds for the mean profile are shown in Figure 4.4 for the lowest three modes. The normalized eigenfunctions for the mean profile are shown in Figure 4.5 for the same range of $\mathrm{k}$ values in Figure 4.3. One sees the typical clustering of the eigenfunctions around the peak of the BV profile for higher $k$ values. The lower $k$ eigenfunctions extend to the bottom of the domain and are thus expected to be sensitive to the cut-off depth of the profile. This is true for all derived results using the shallower profiles.

Figure 4.3

Phase speeds, modes 1 and 2 , for average and $\pm \sigma \mathrm{BV}$ profiles

Figure 4.4

Dispersion relation (top), and phase and group speeds for average BV profile, modes 1,2 , and 3 .

Figure 4.5

Eigenfunctions for modes 1,2 , and 3 for the average profile. Wave number values correspond to the range in figure 4.4 . 


\section{Part 5: Conclusions}

Environmental measurements and on-site analysis were performed from the AUTEC vessel Range Rover during Project Overview. These included basic meteorological measurements, of which the most relevant to radar are wind speed and direction, and water profiling measurements, from which the Brunt-Väisälä (BV) frequency profile was calculated. Additional on-site analysis included solving the Taylor-Goldstein equation for a single BV profile at the beginning of each serial in order to determine the optimal source depth. The BV profile proved quite stable during the experiment with a peak value of nearly $9 \mathrm{cph}$ at a depth near 80 meters. The long wave phase speed was typically $1 \mathrm{~m} / \mathrm{s}$. Wind speeds varied from 1.7 to $7.3 \mathrm{~m} / \mathrm{s}$ with directions from east to south. On-site analysis of data proved quite feasible and was critical to operational decisions during the experiment.

The main difficulty experienced during the experiment was the incompatibility between environmental data collection and the radar mounted on the Range Rover. In subsequent experiments, we recommend separating the radar and environmental collection. 
APPENDIX 1 

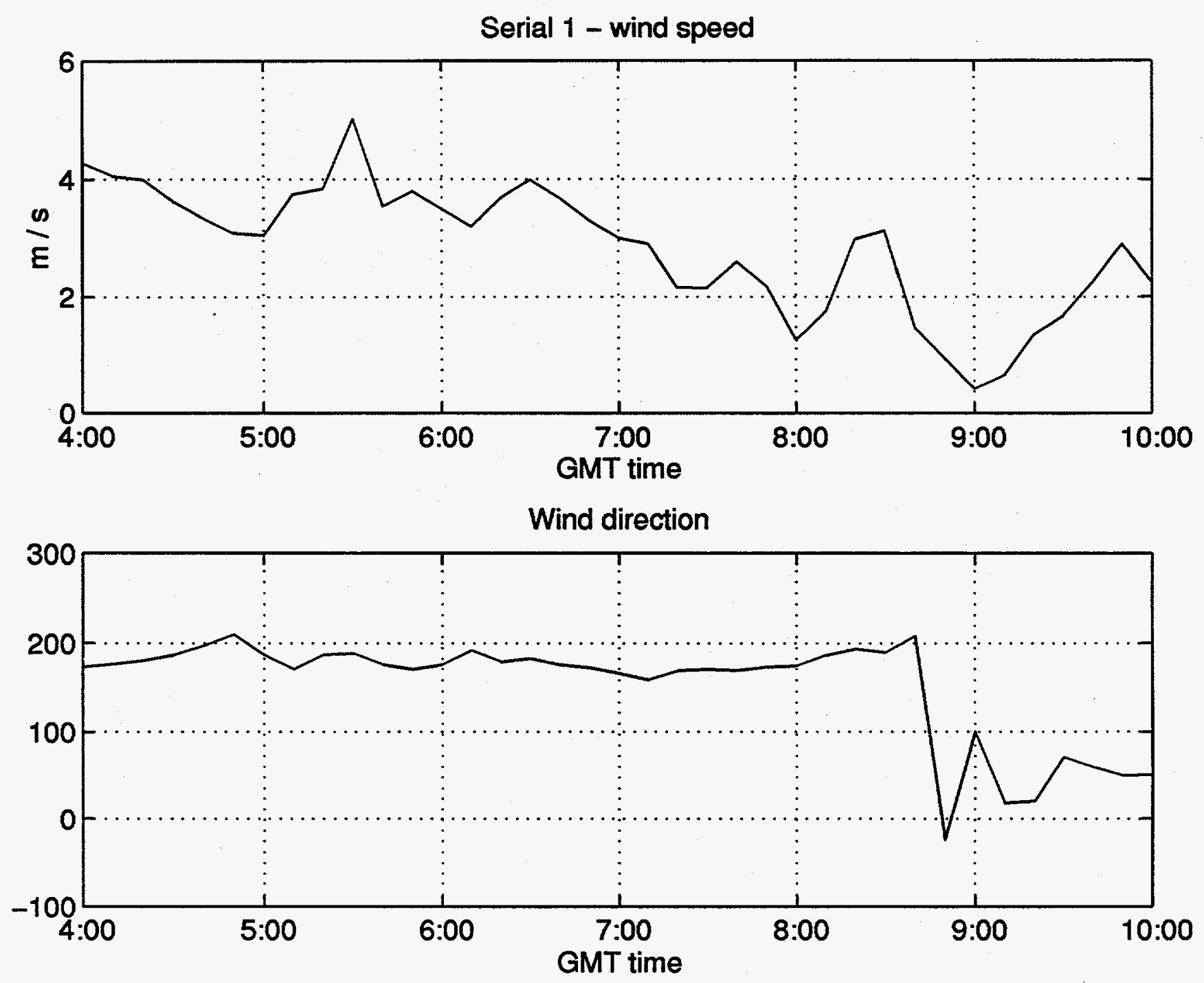


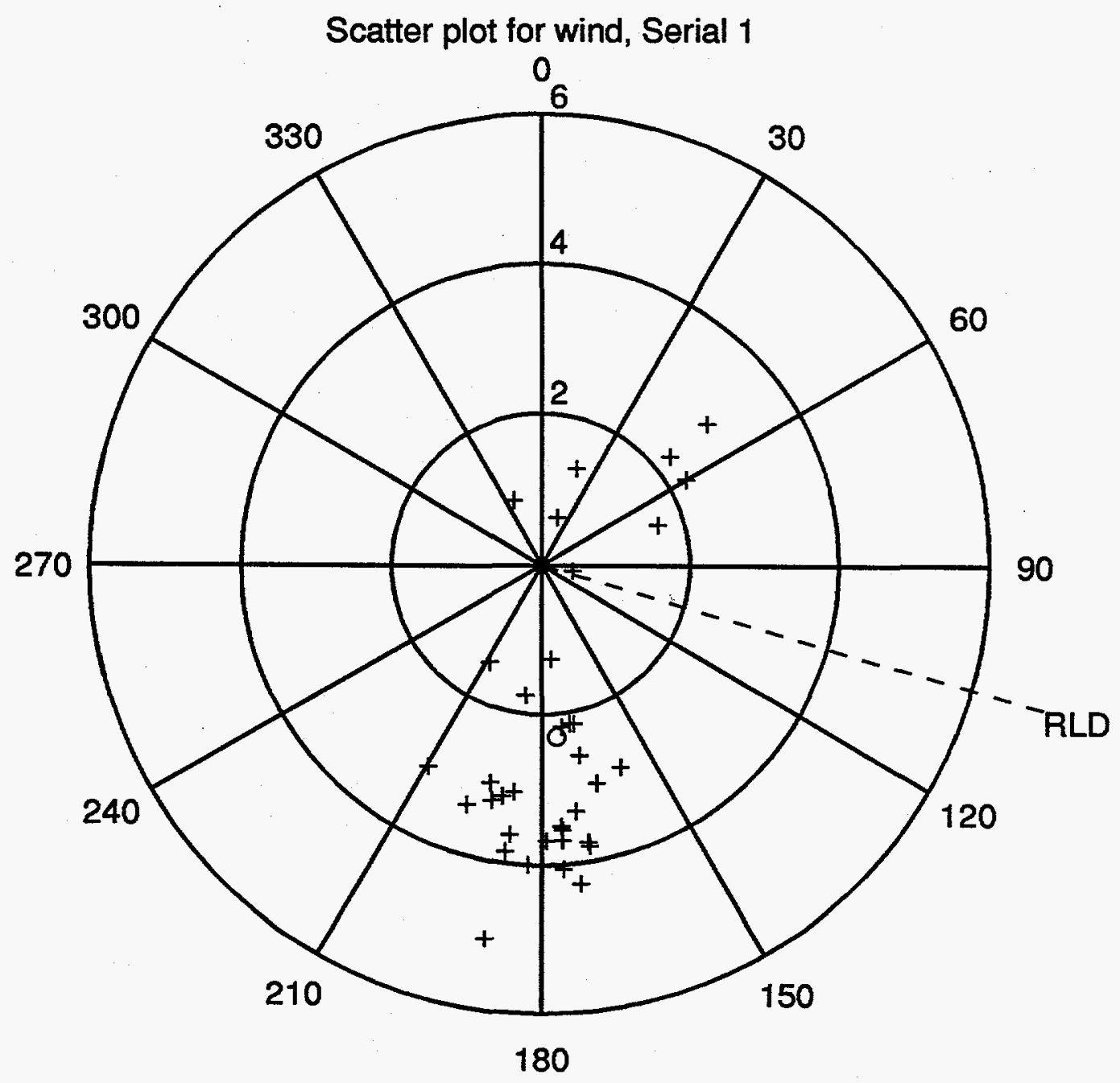




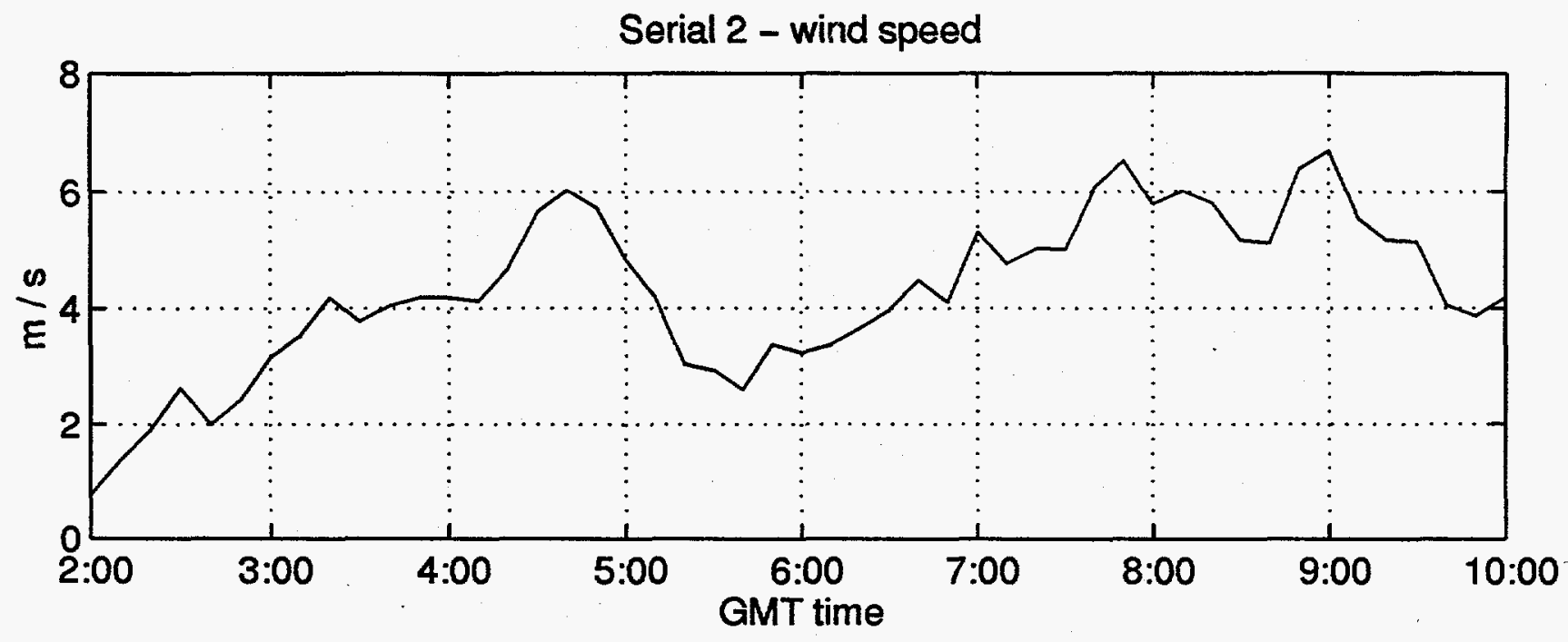

Wind direction

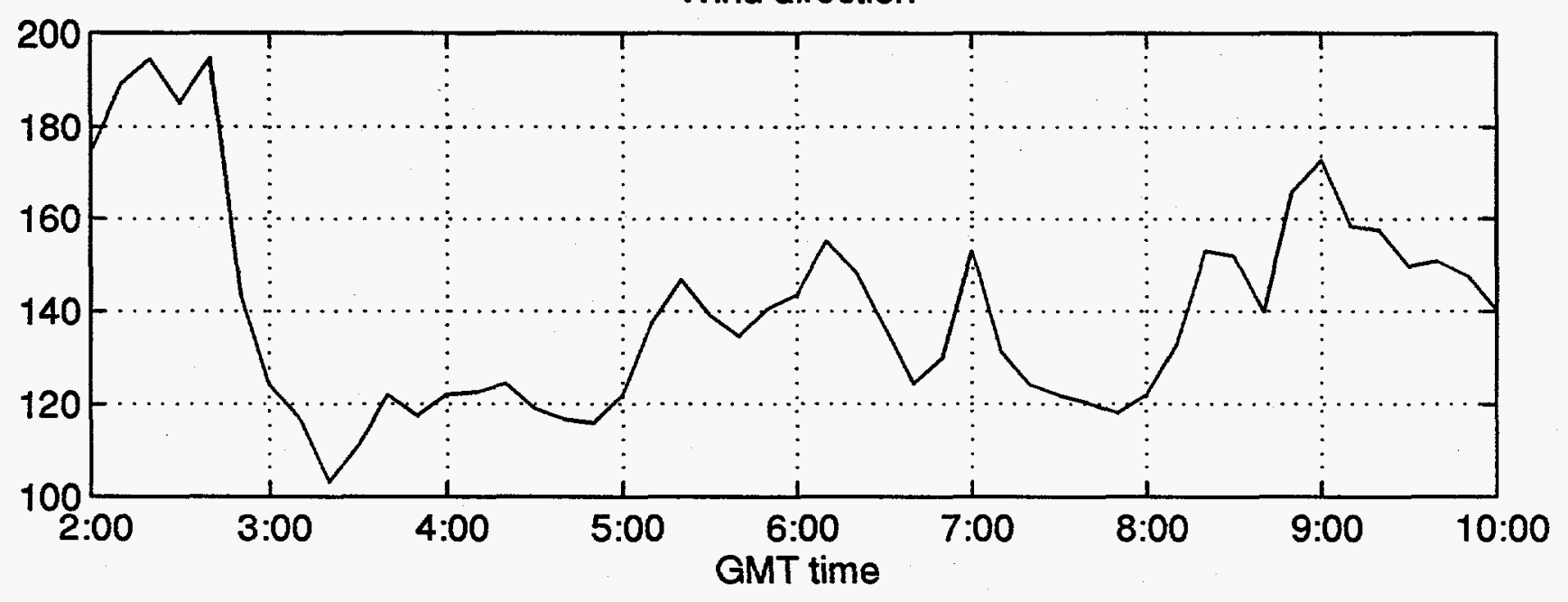




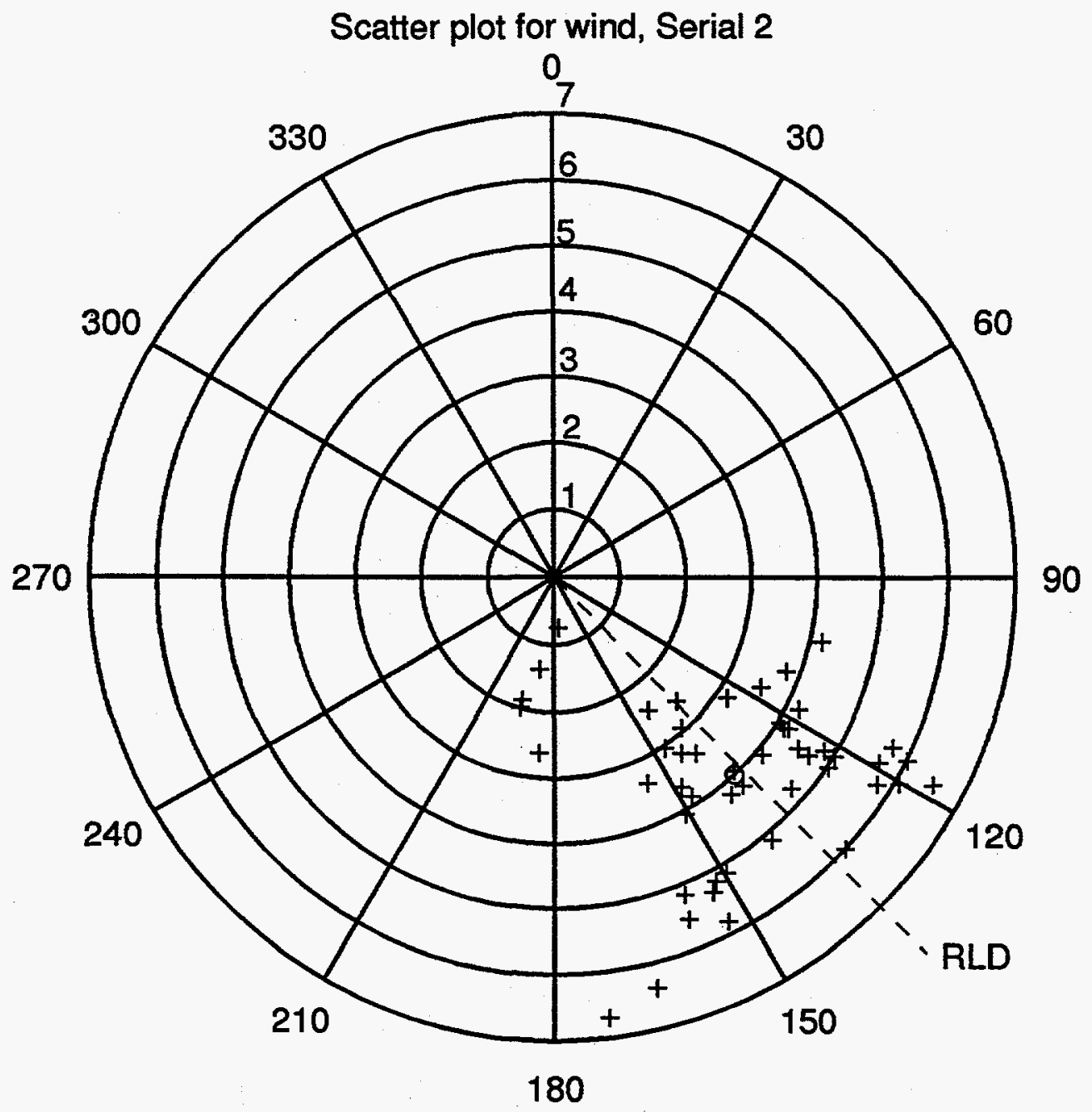



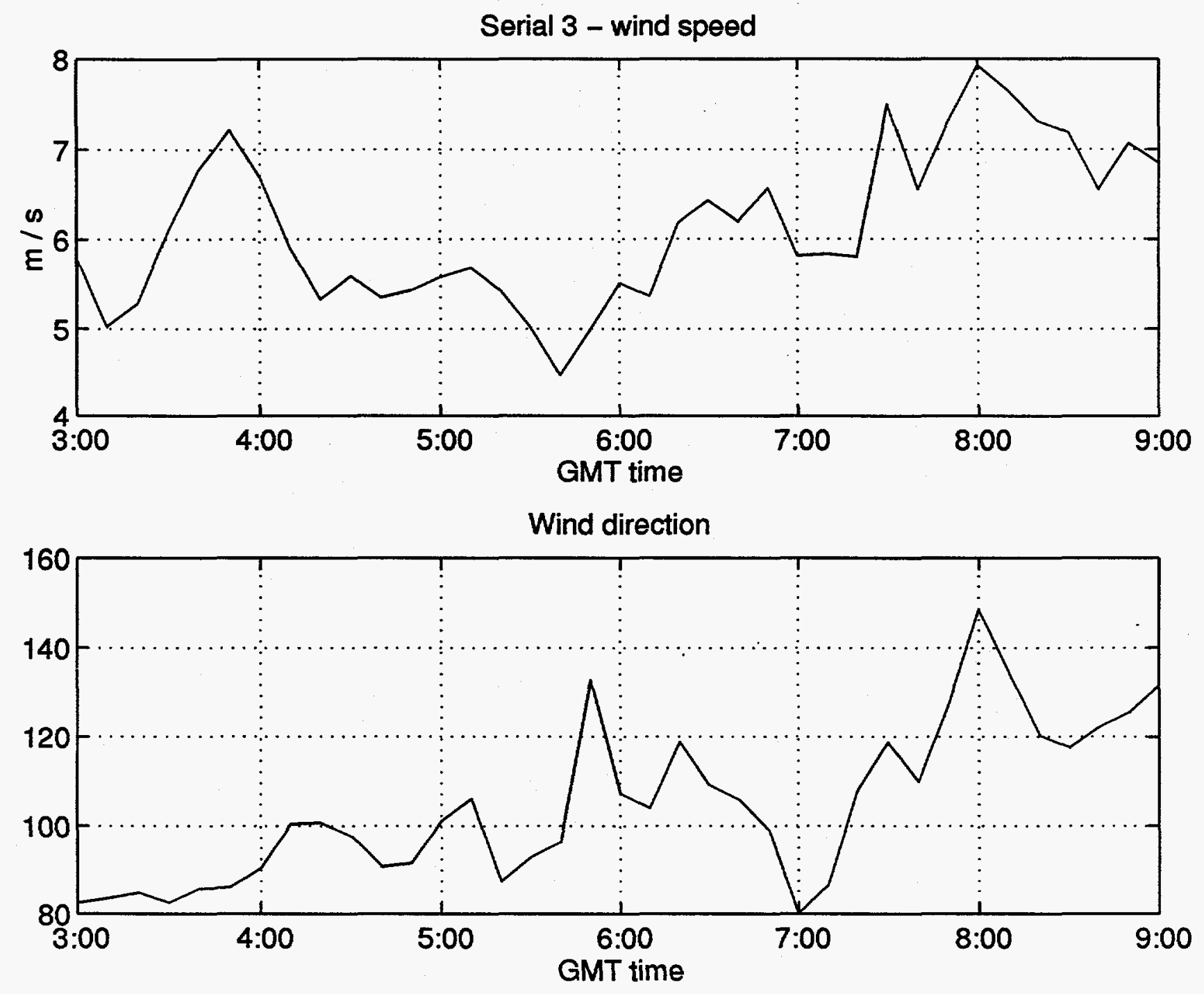


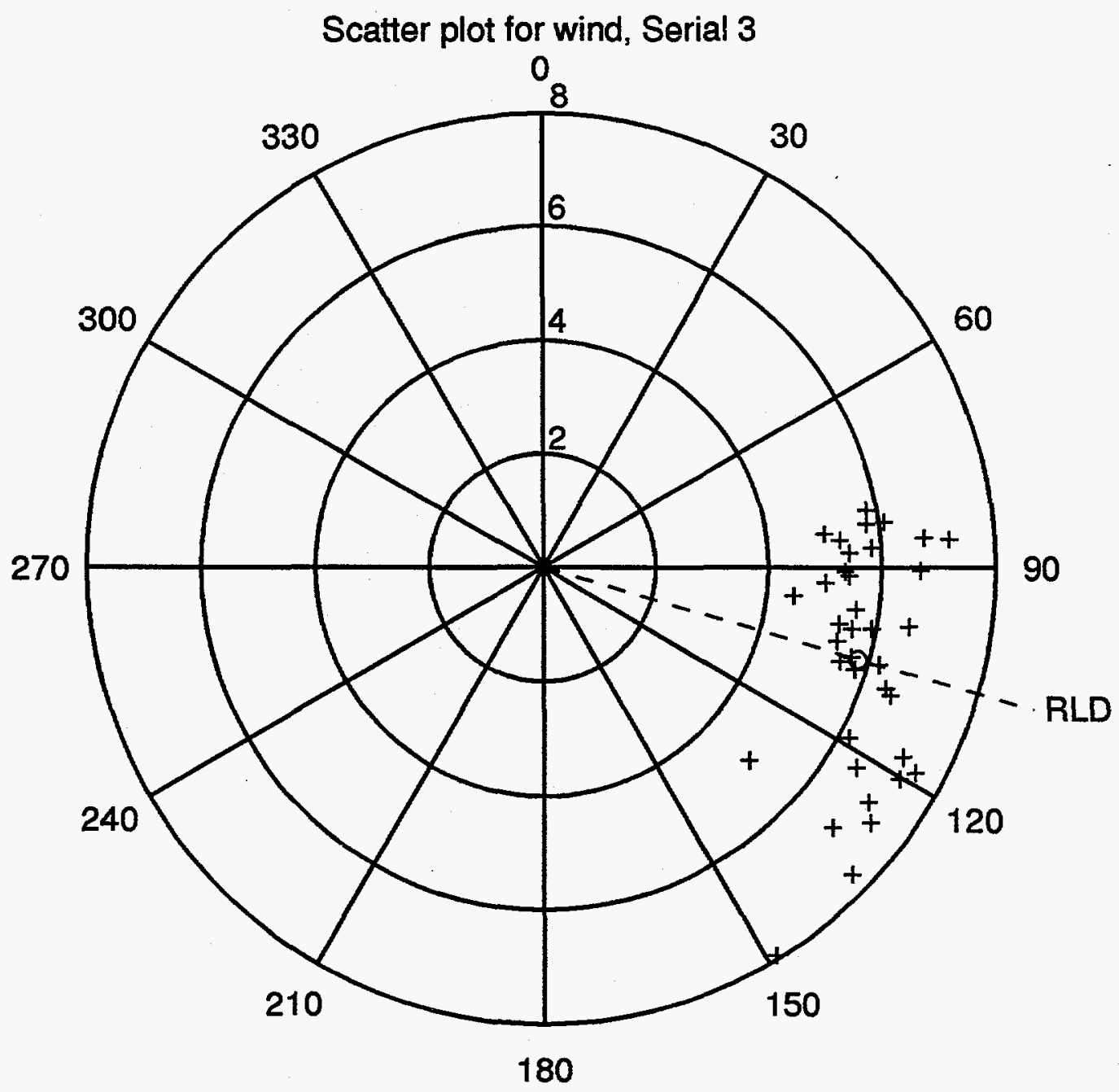




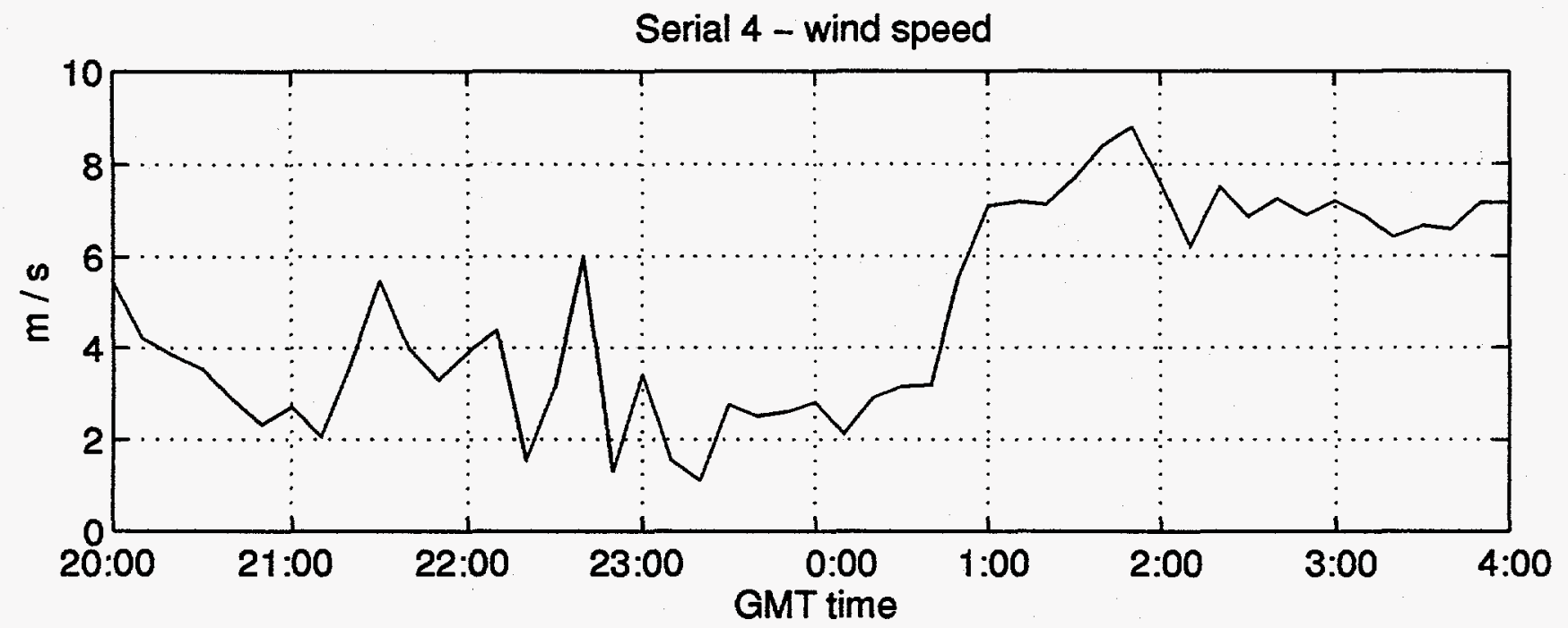

Wind direction

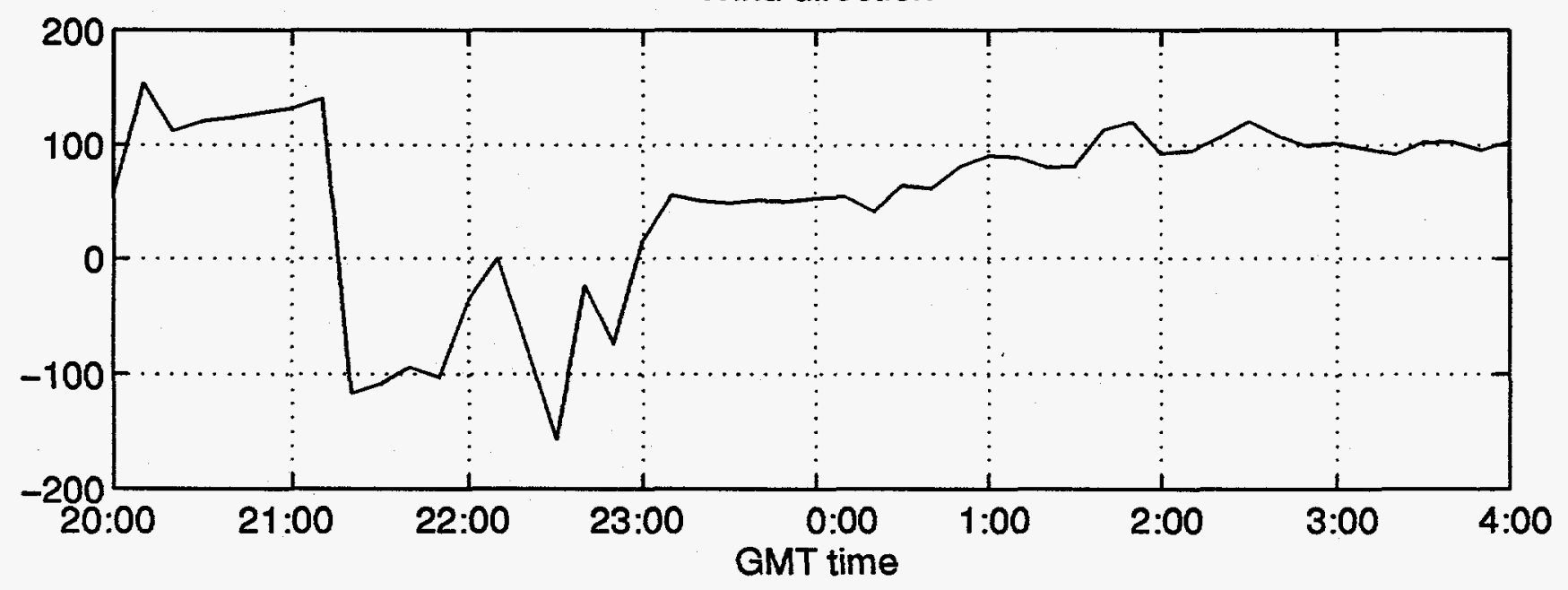




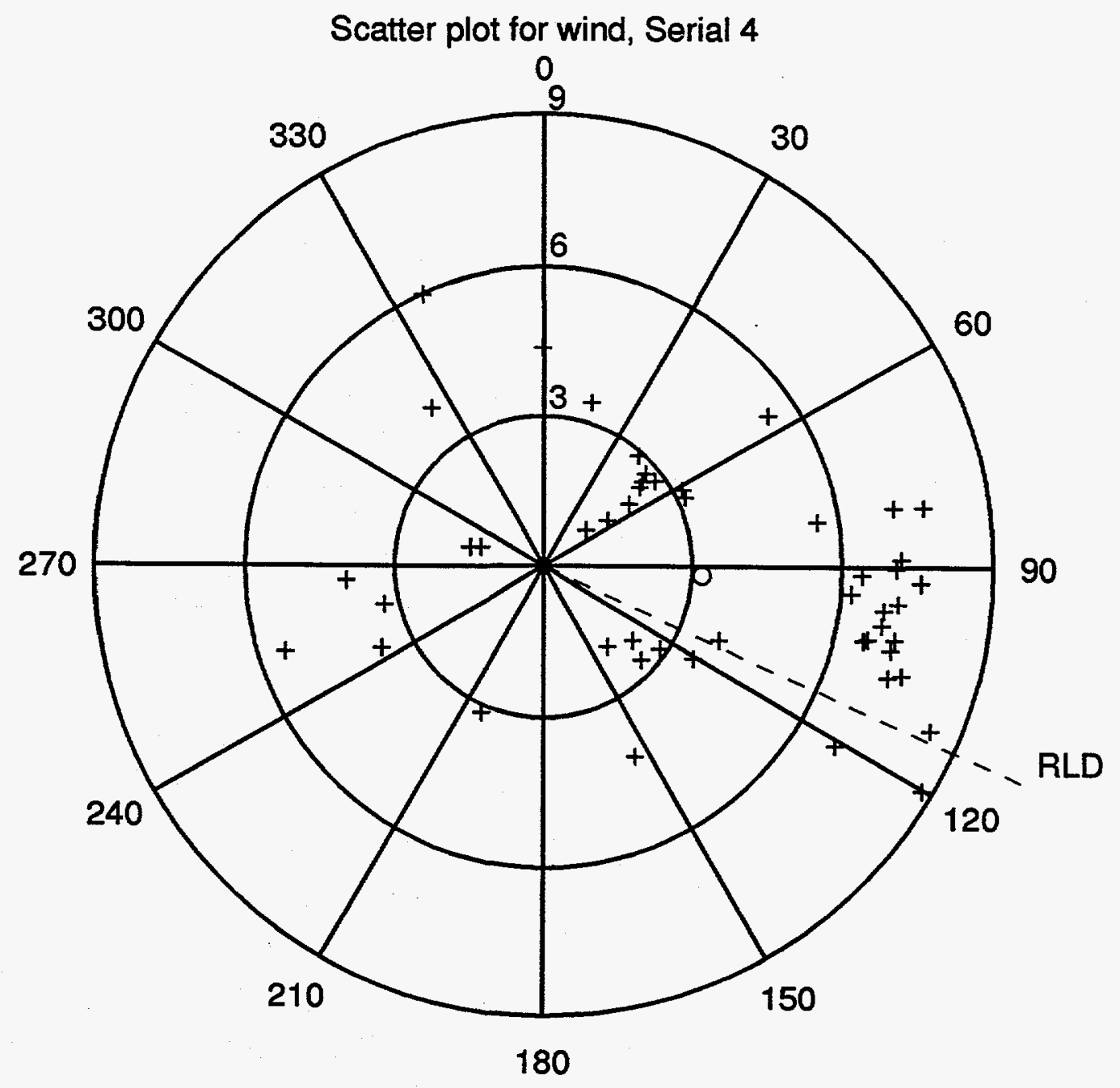


APPENDIX 2 

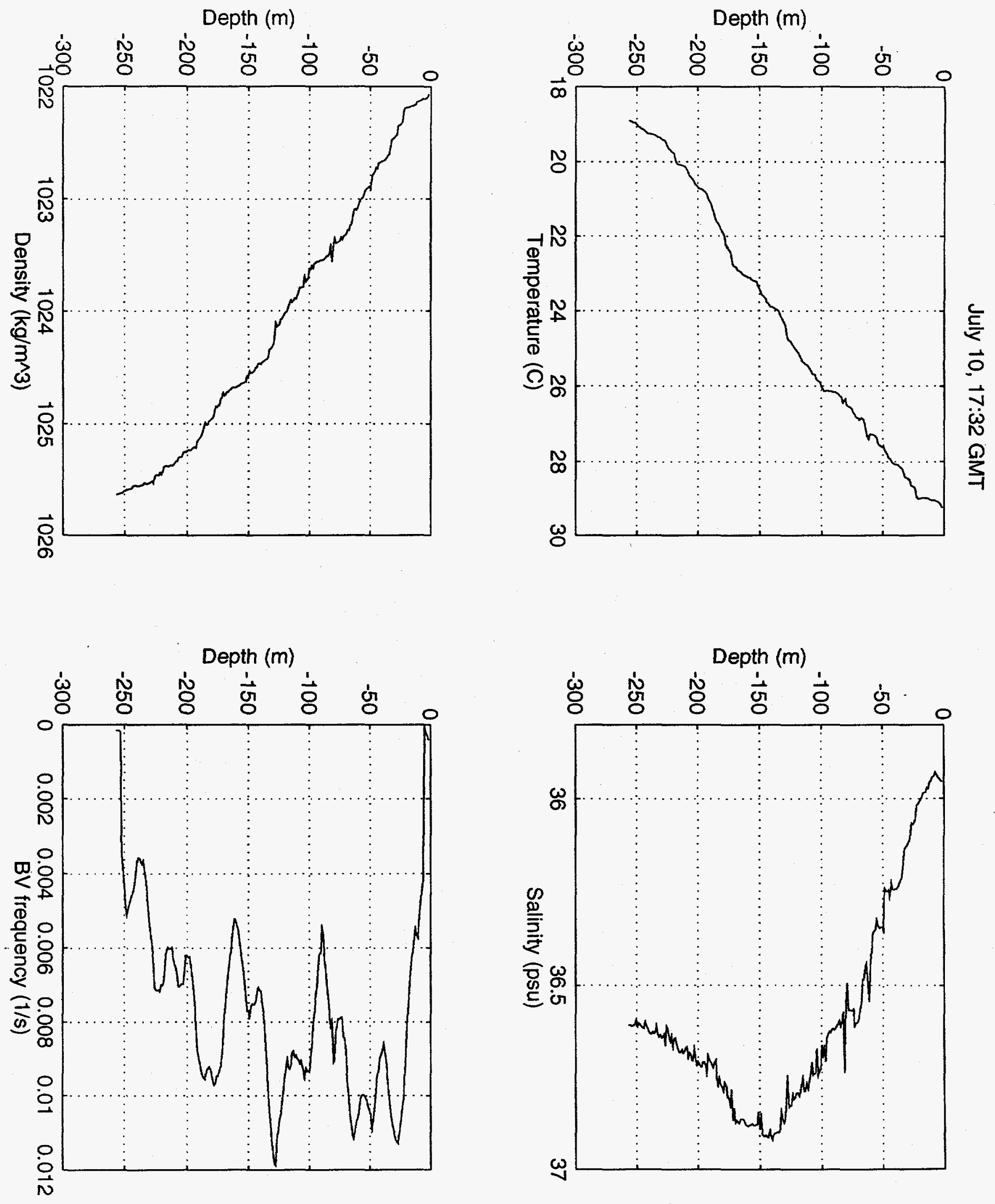
Deep cast, July $11,00: 32$ GMT
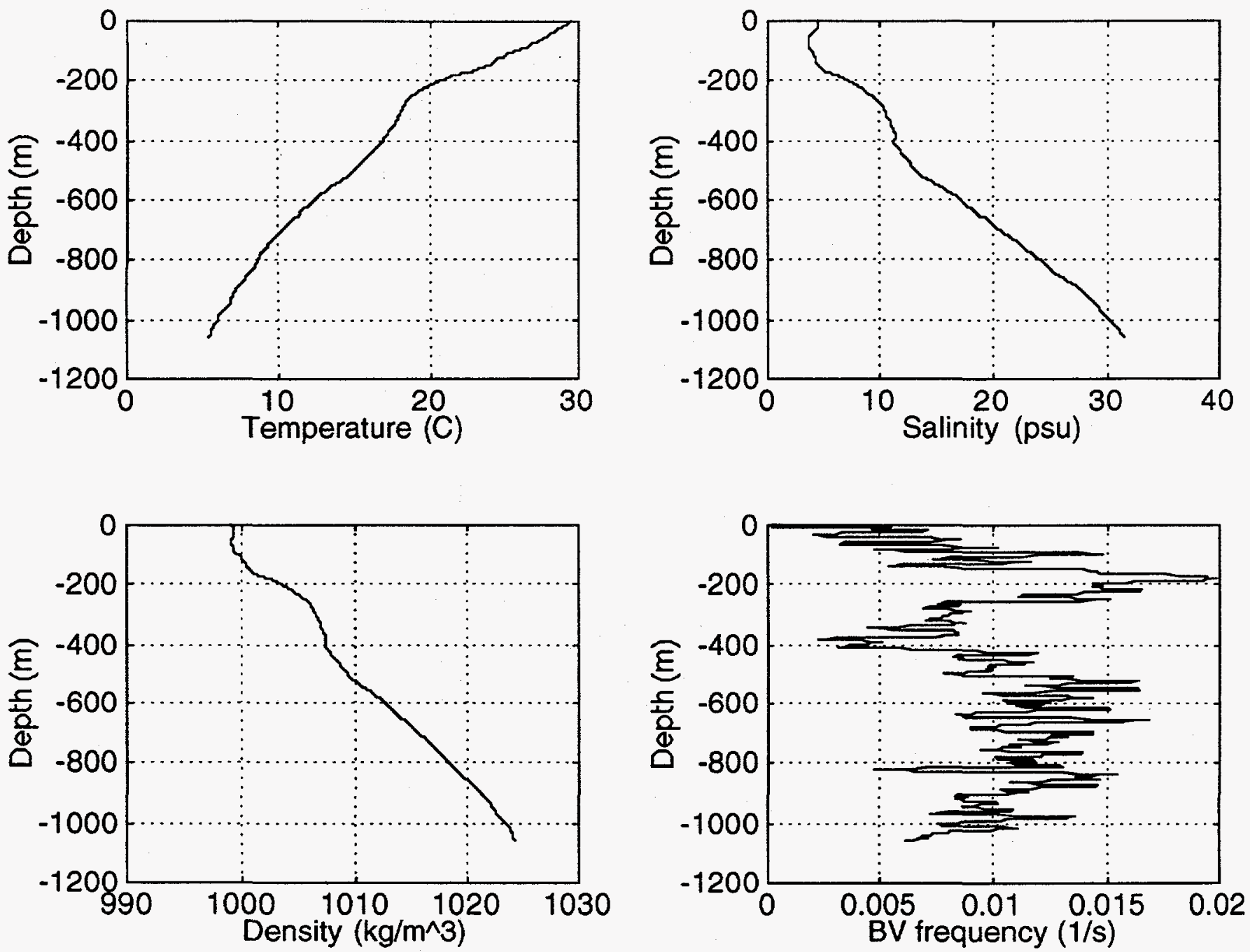


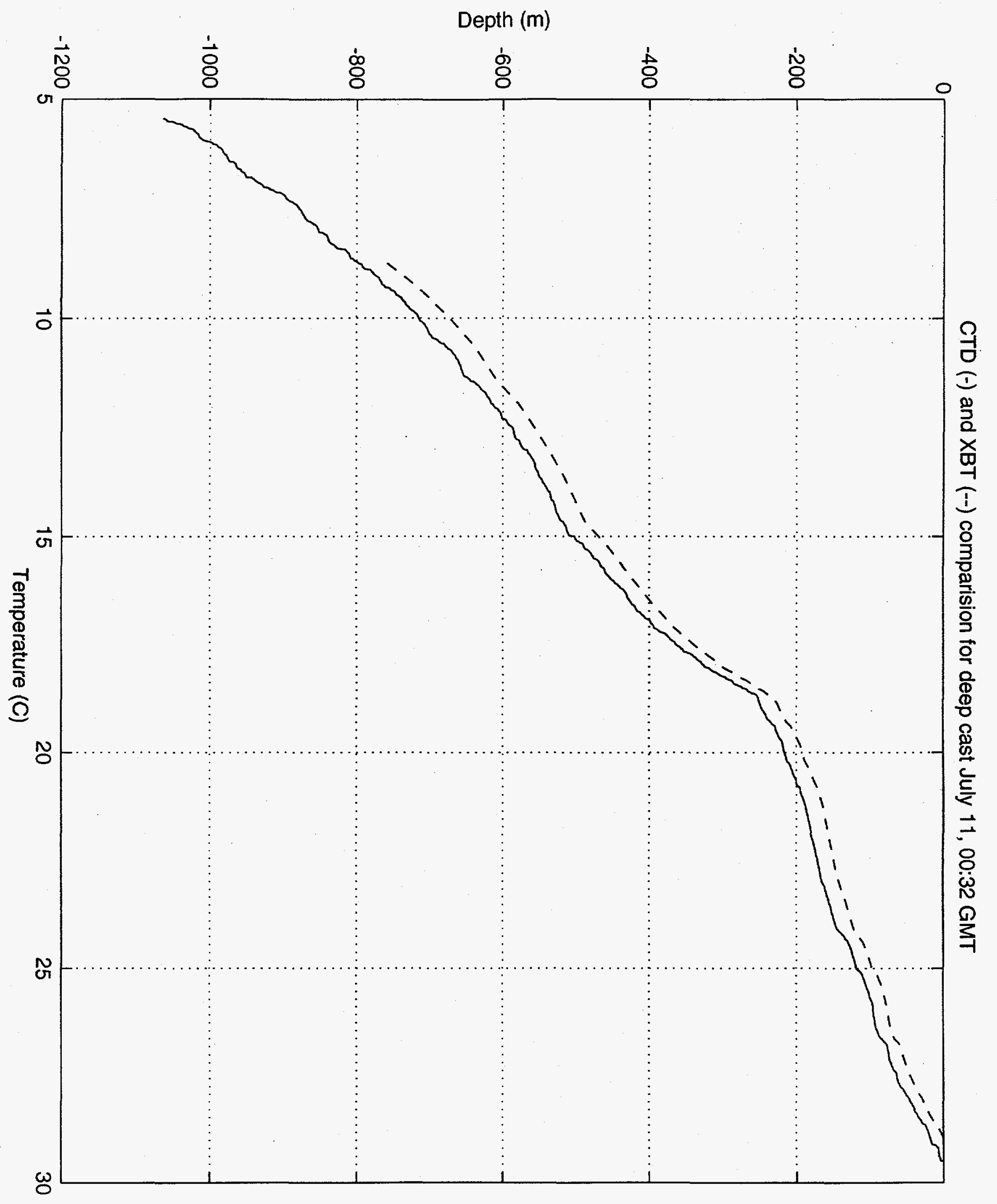



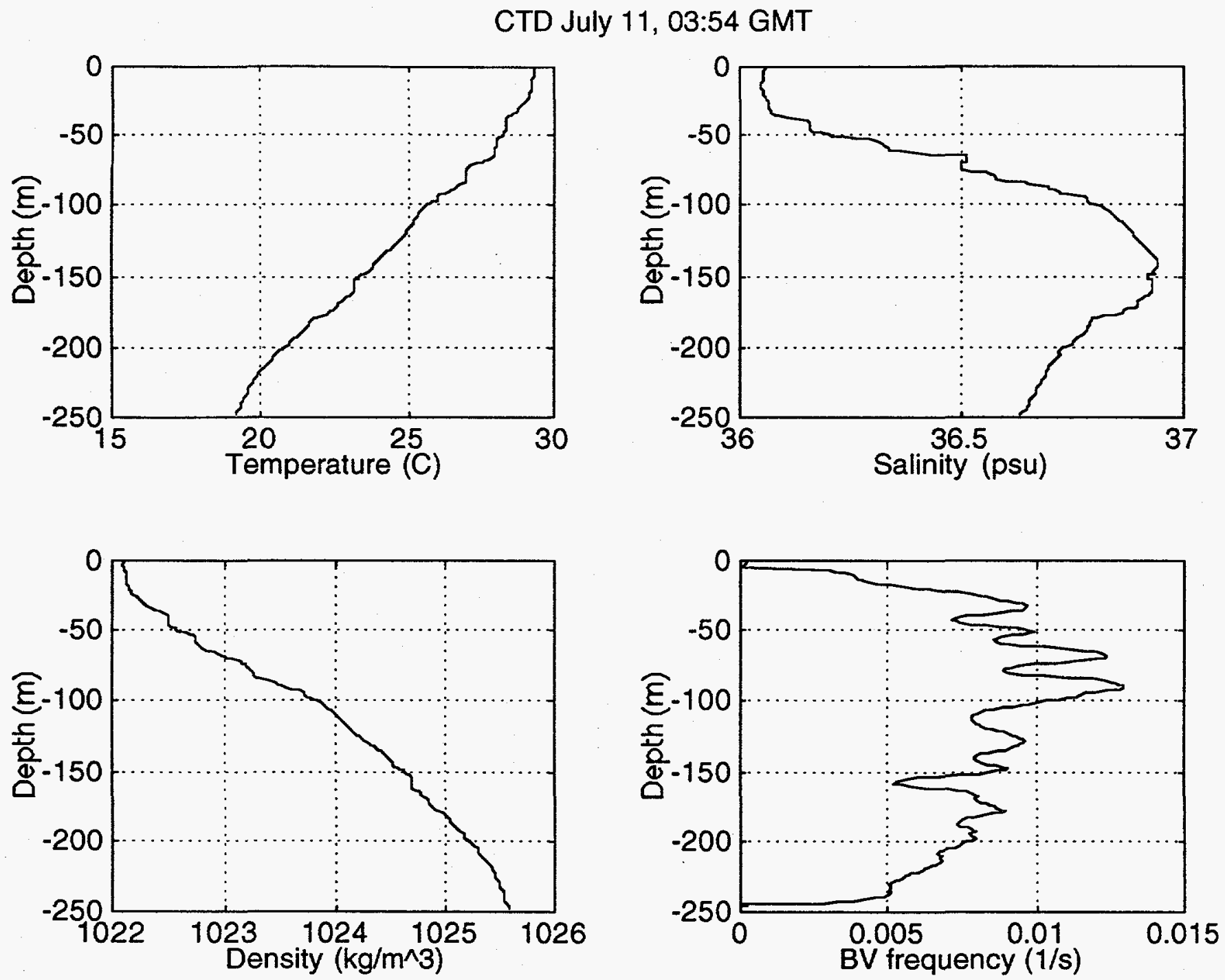


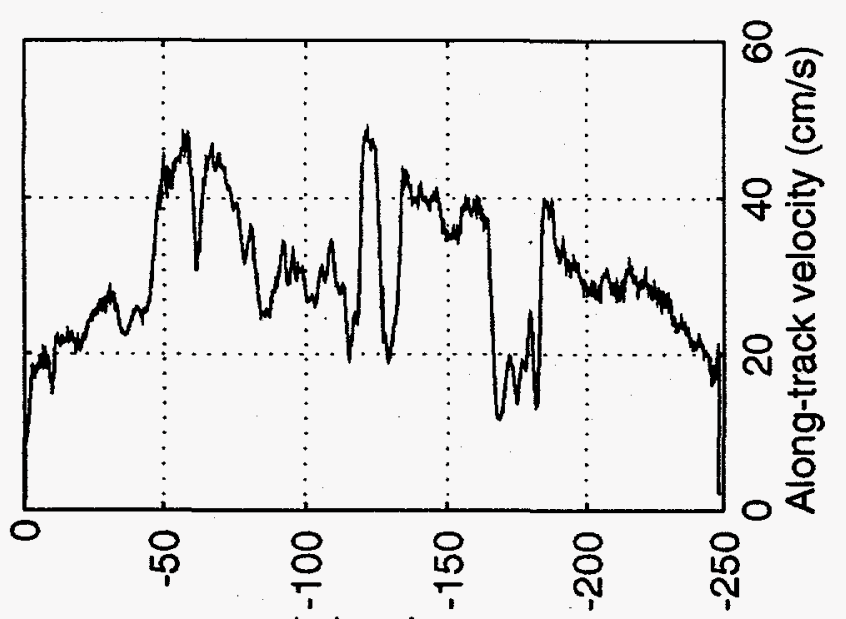

(ui) पұdəa

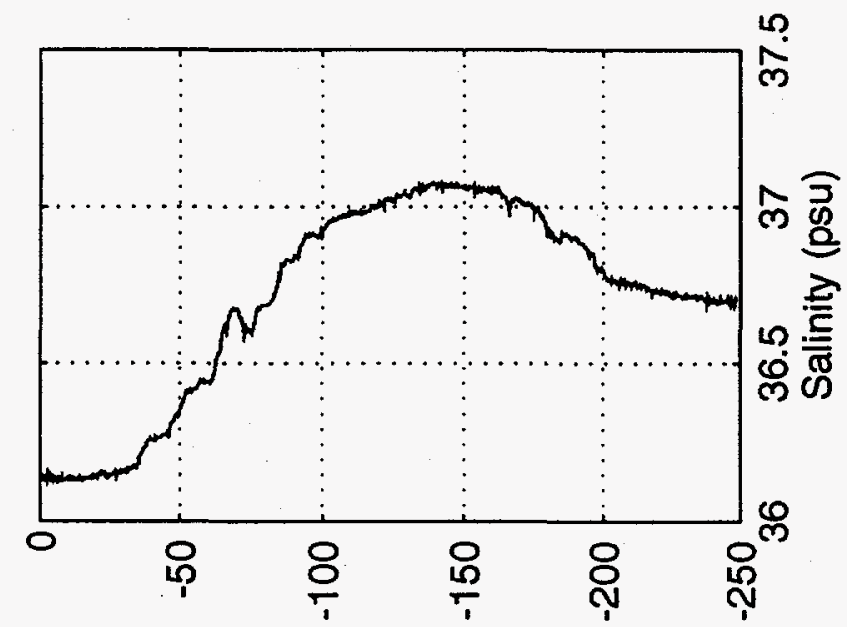

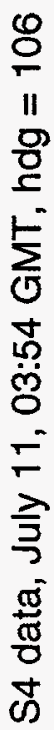

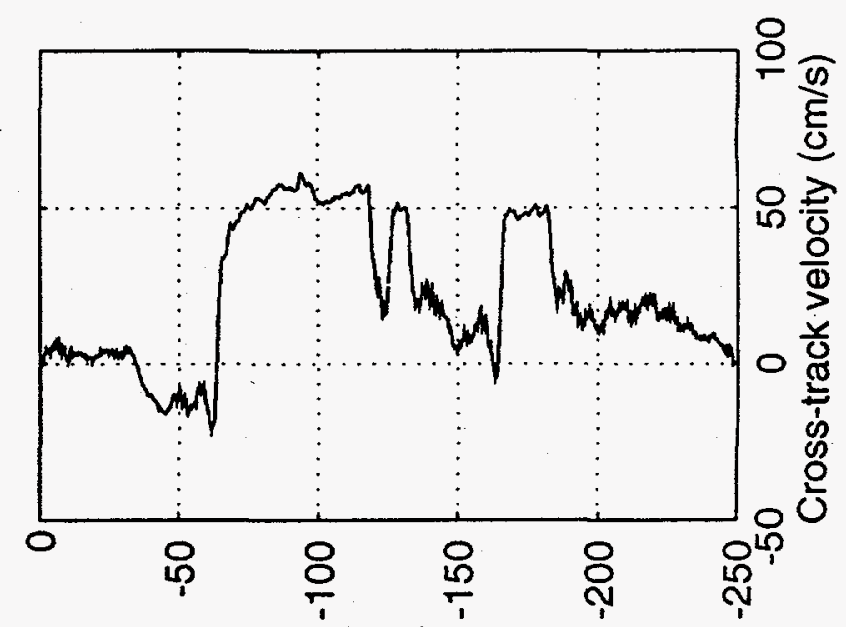

(w) पाdəa

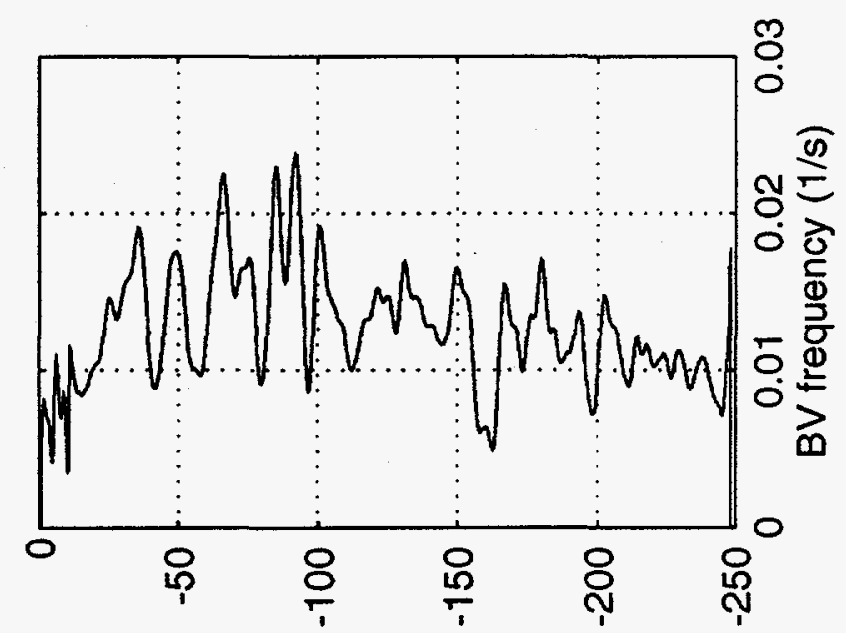

(ii) uldəg

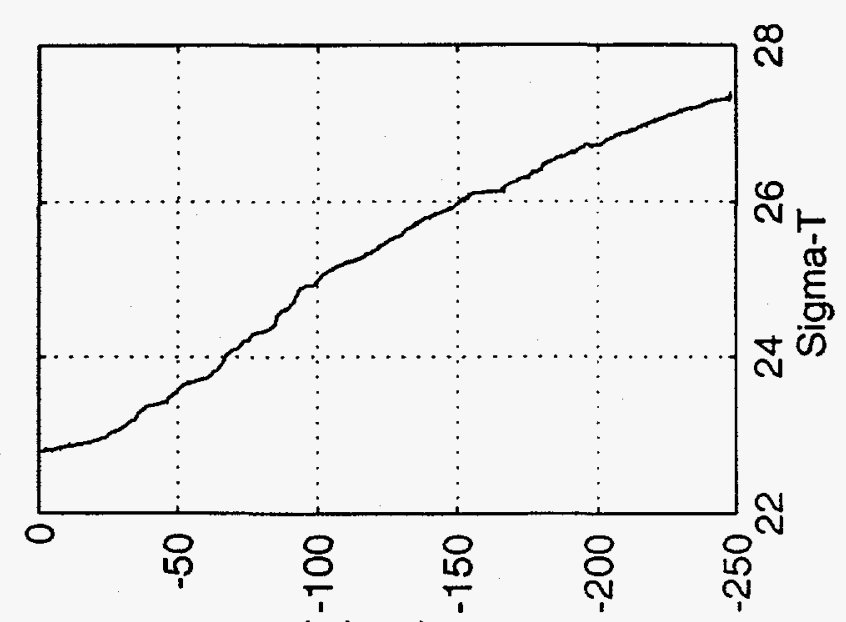

(w) प1dəव 


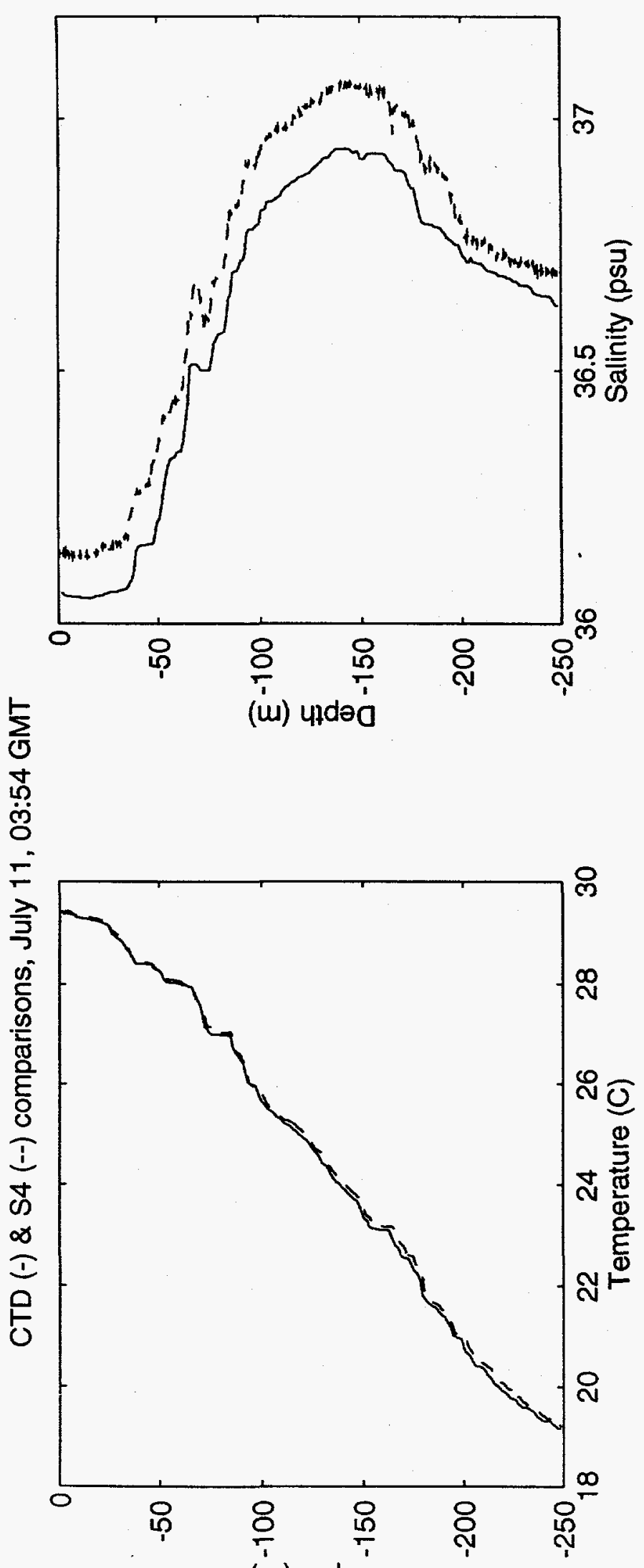

(w) पldəa

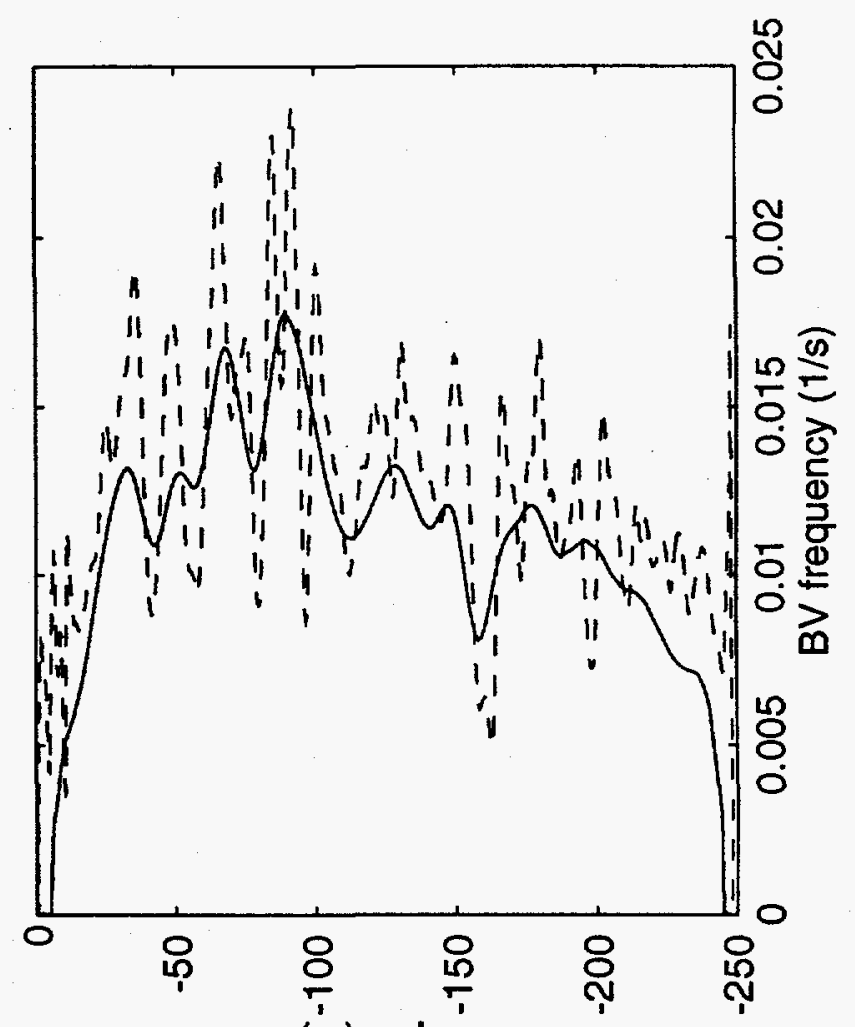

(wi) पıdəa

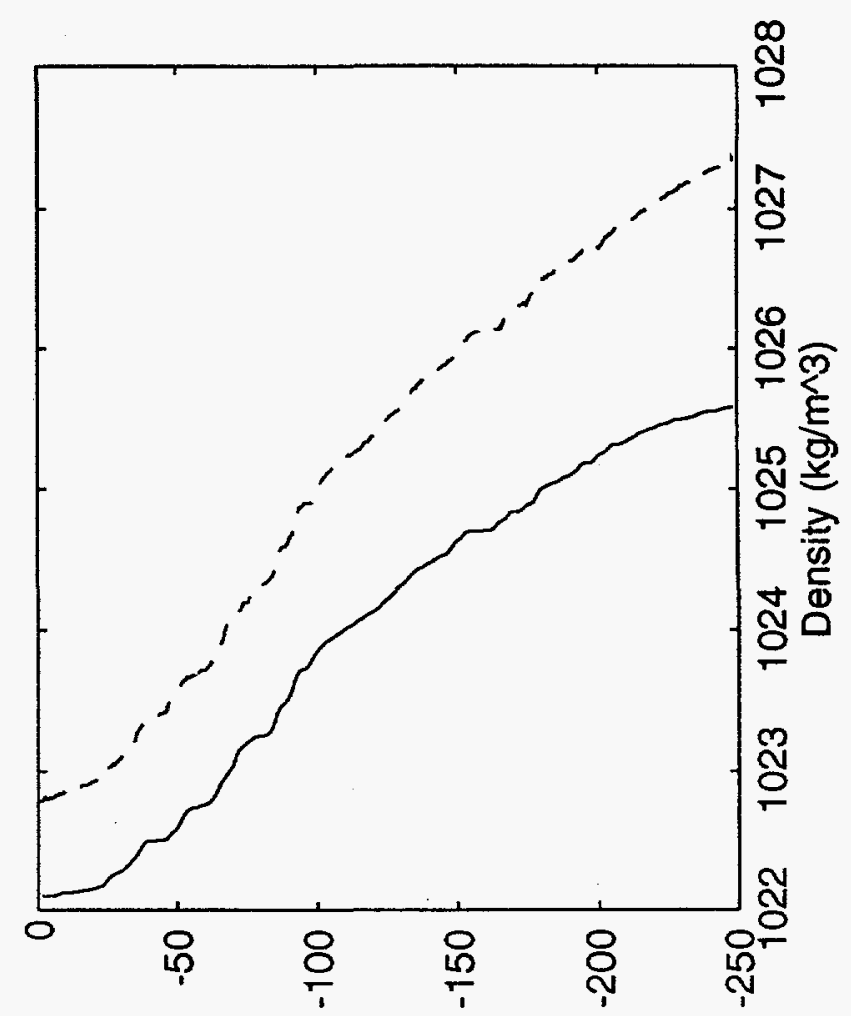

(ii) uldəa 


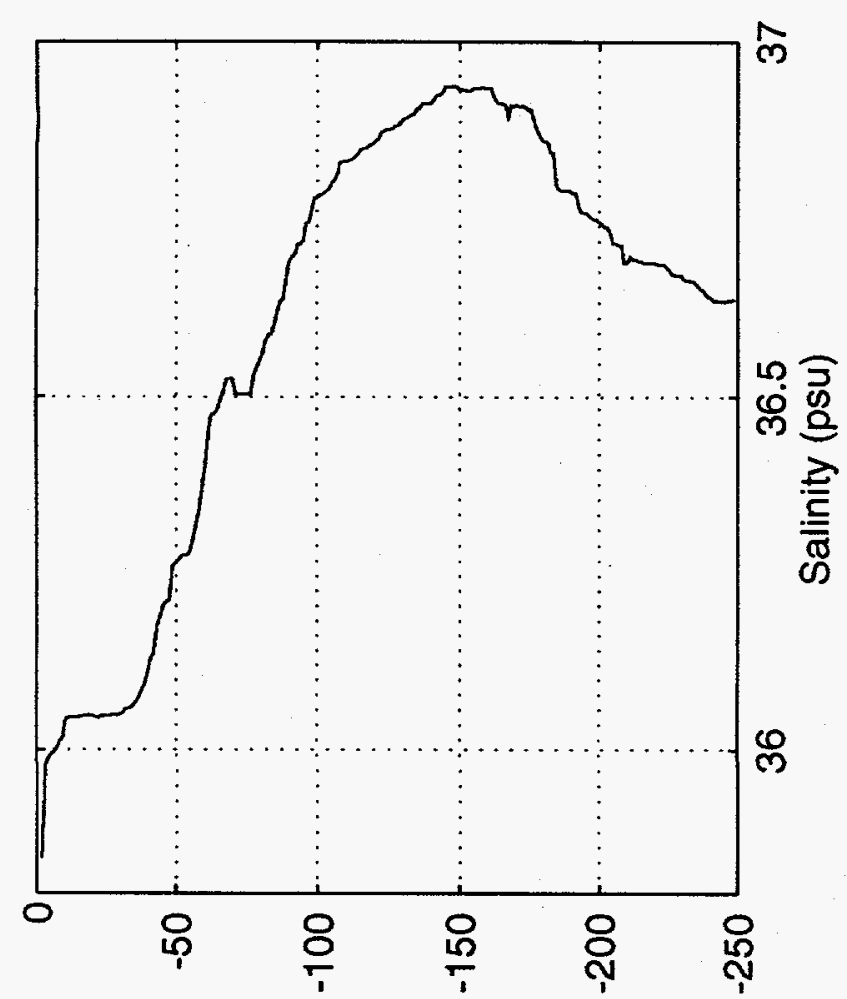

(ui) uाdəa

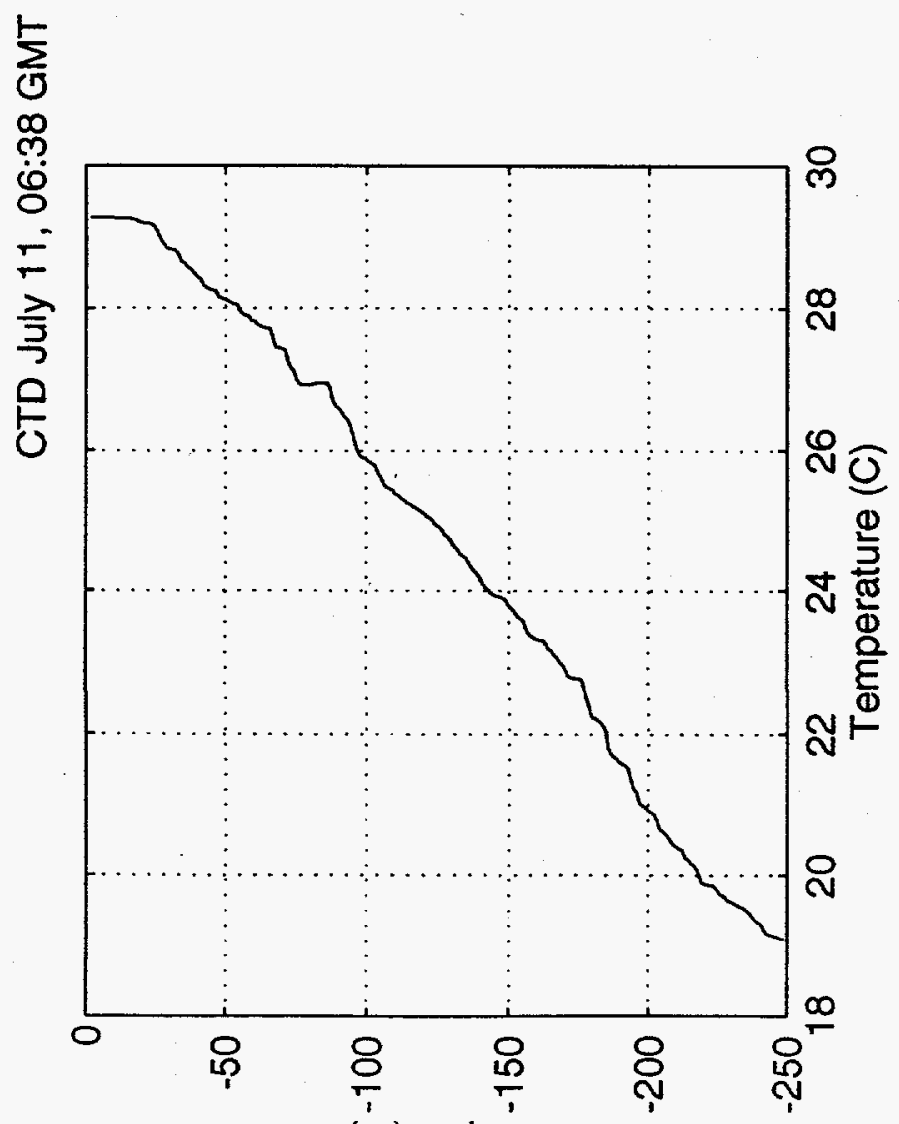

(ui) yłdəa

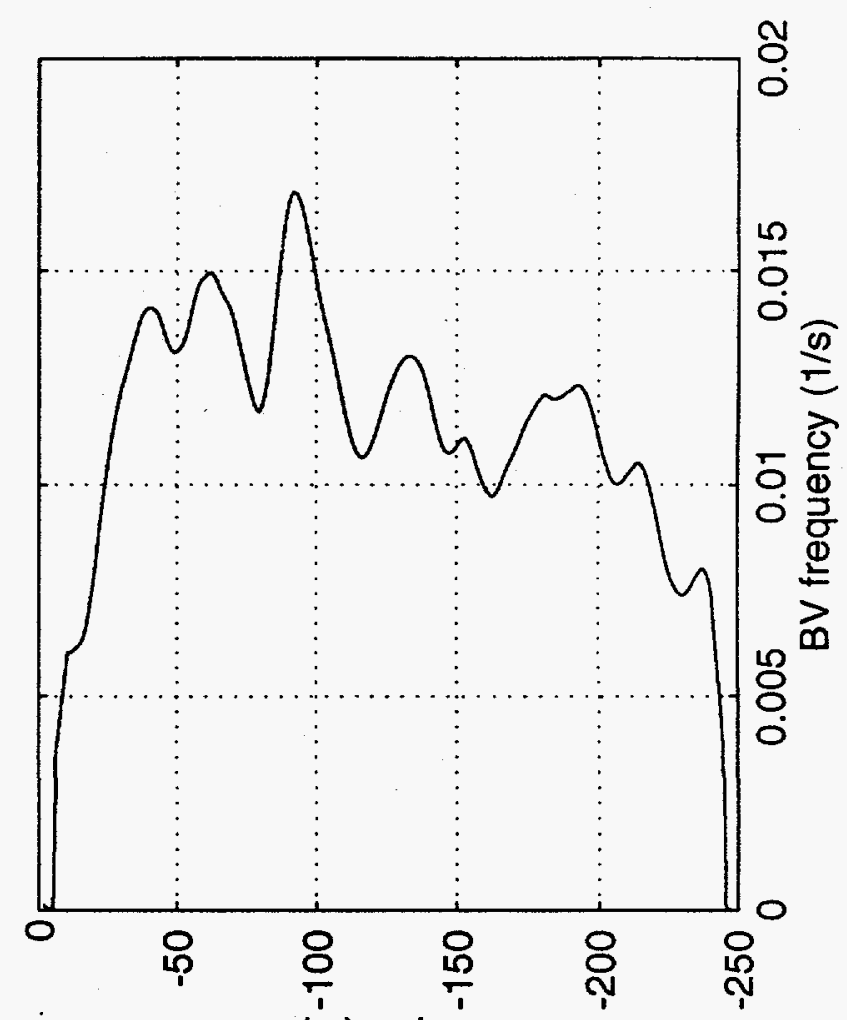

(u) uldəo

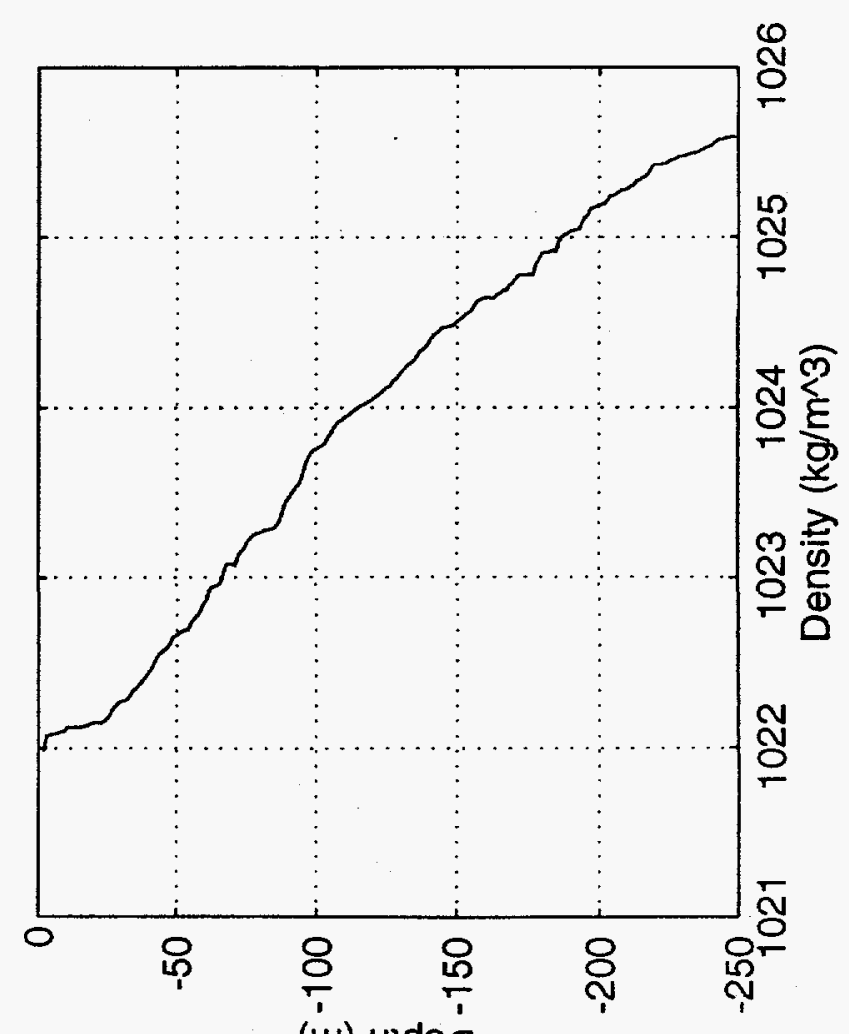

(u) yıdəo 


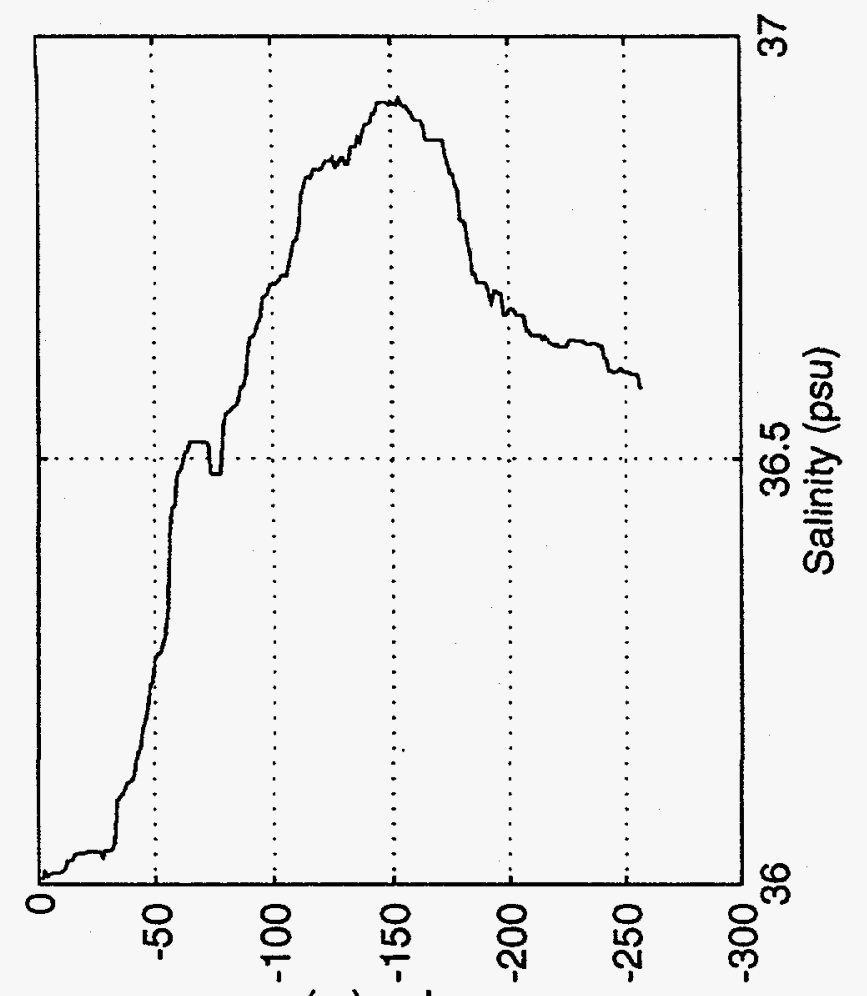

(u) uldəa

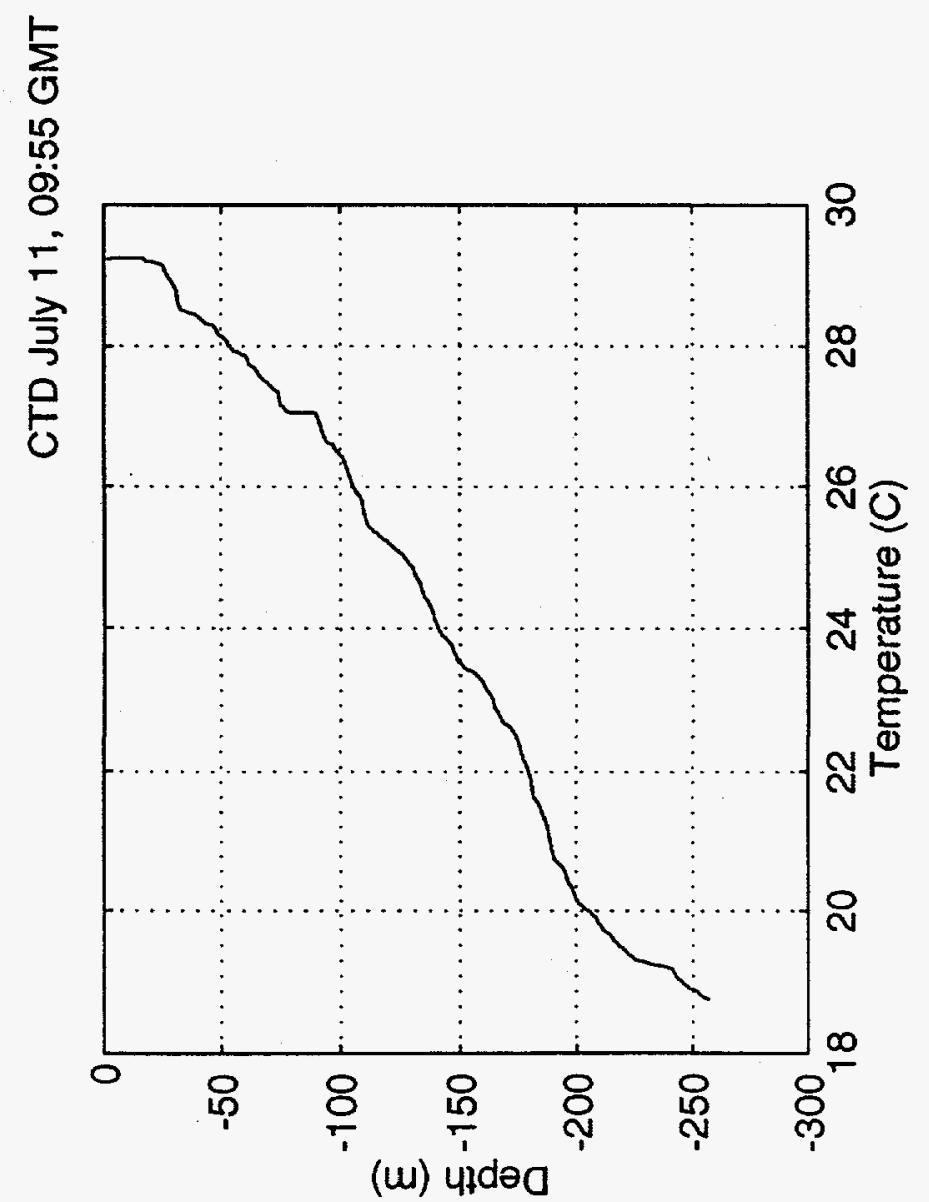

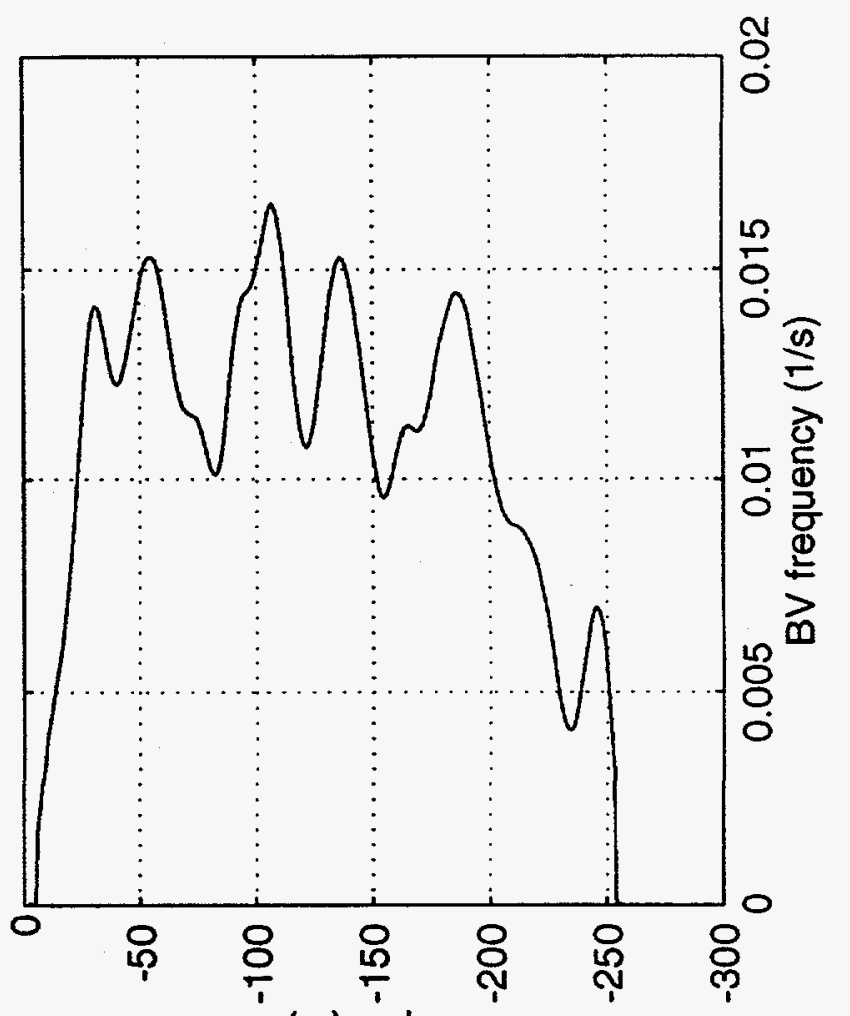

(ui) uideO

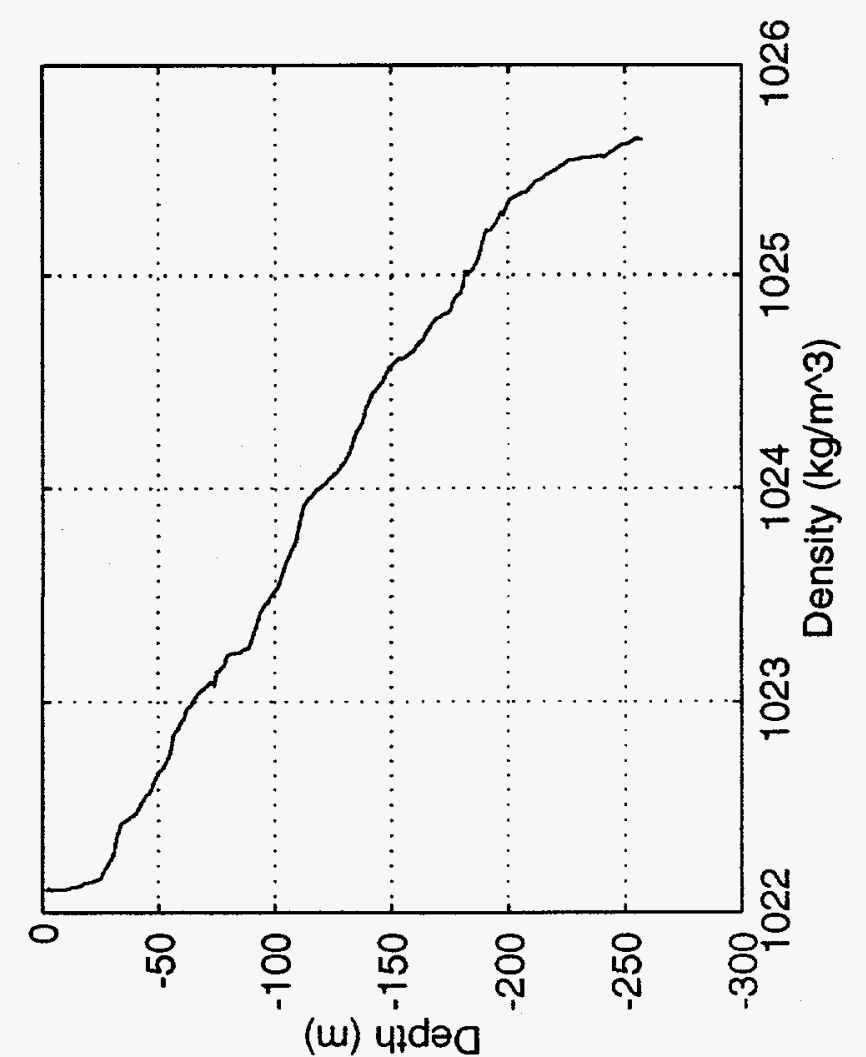



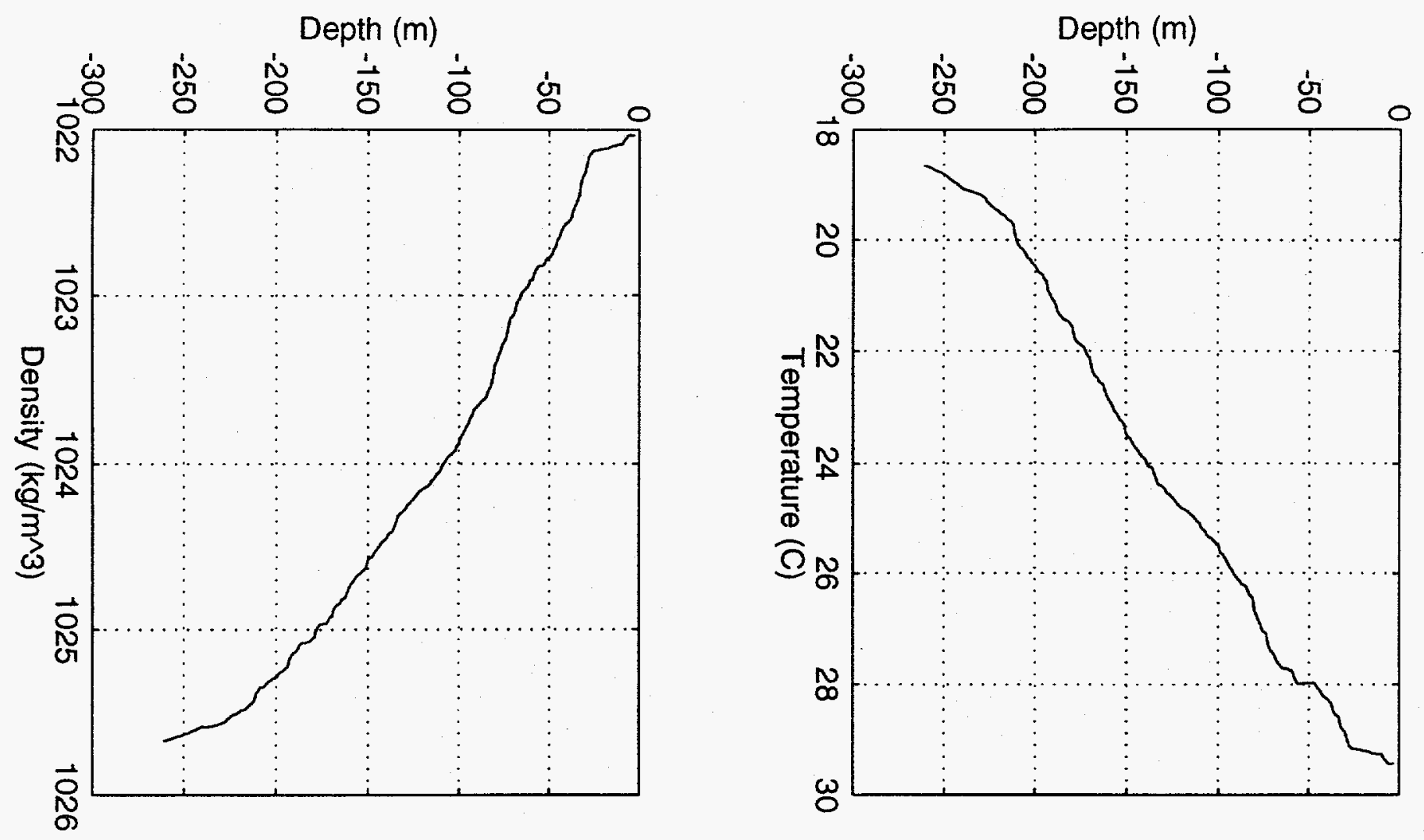

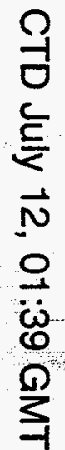
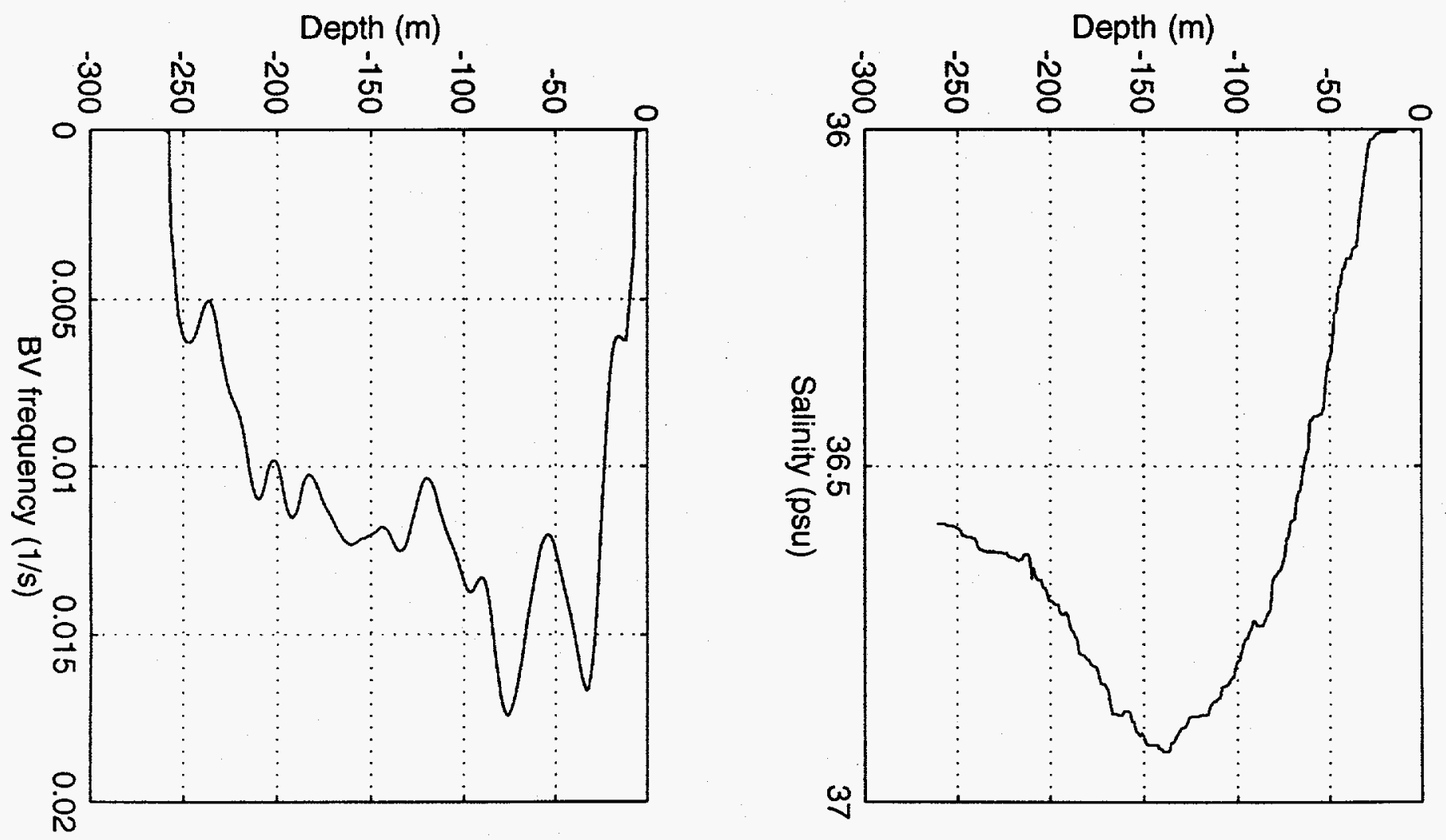
CTD (-) \& XBT (--) comparison, July 12, 01:35 GMT
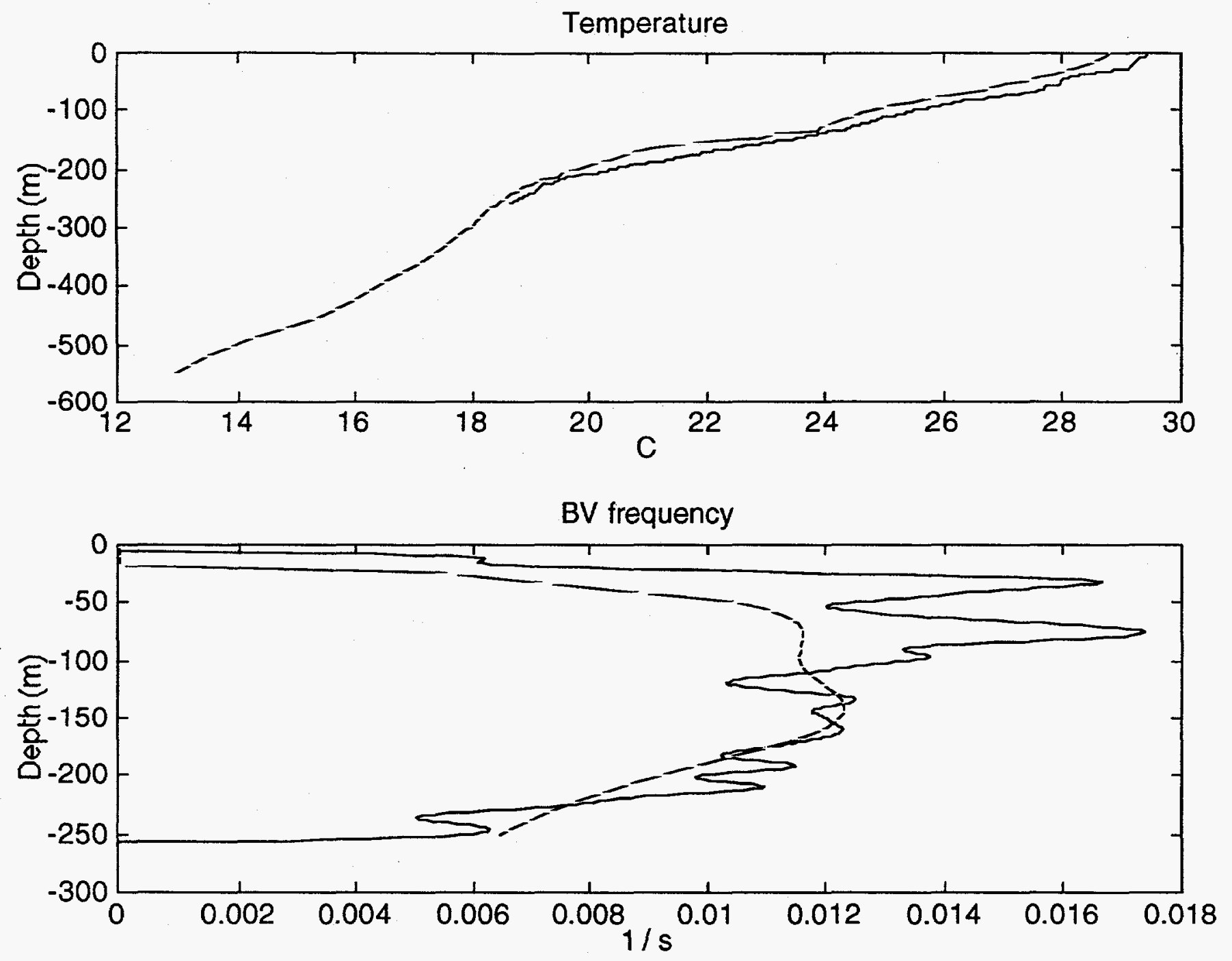


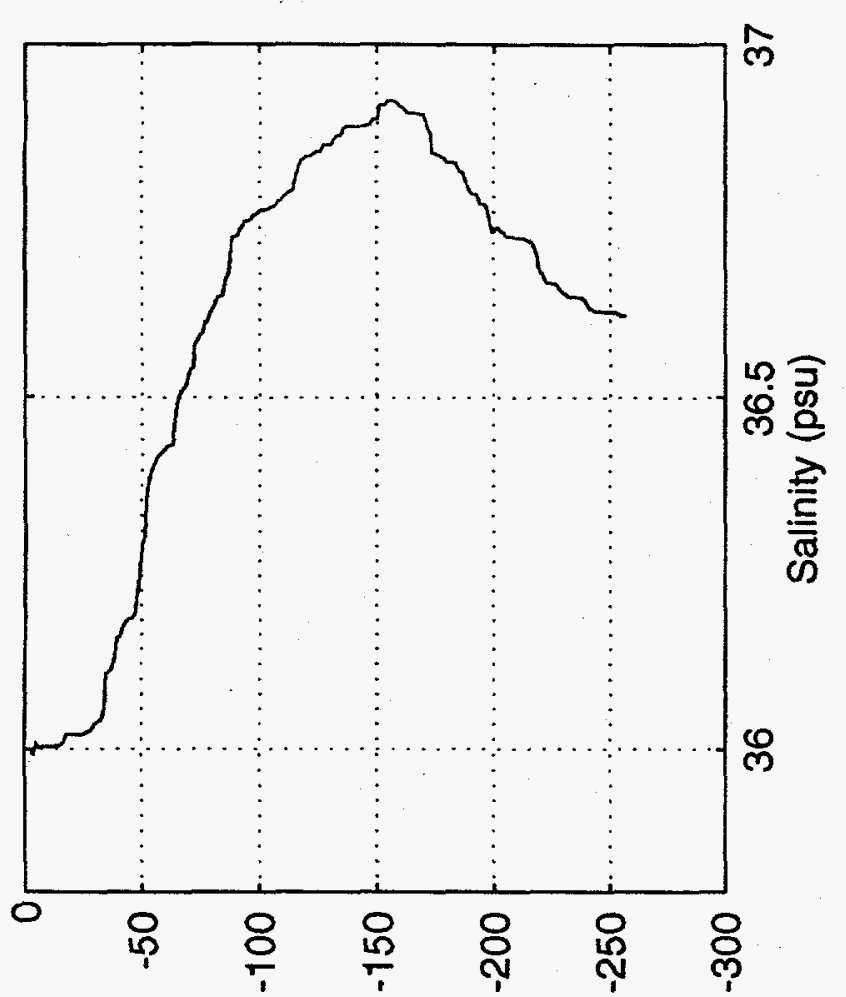

(u) प1 dəa

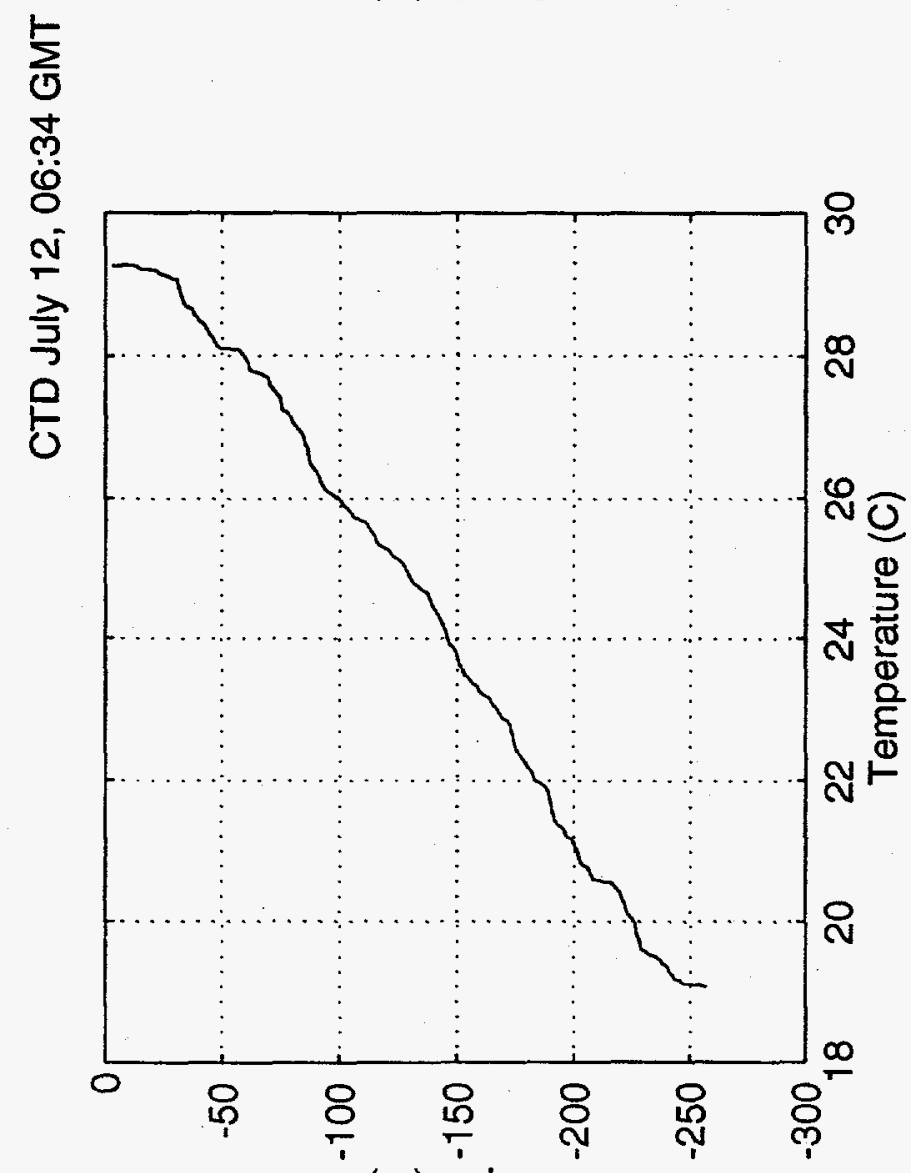

(u) पाdəo

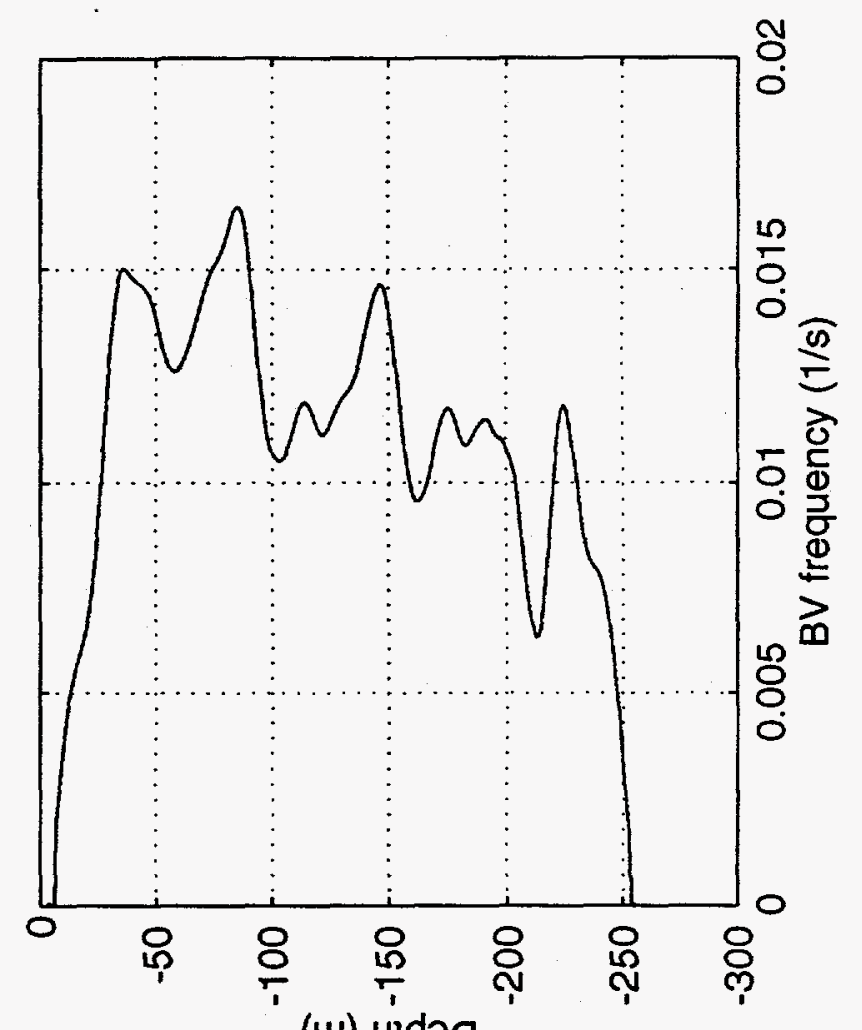

(w) 4idəa

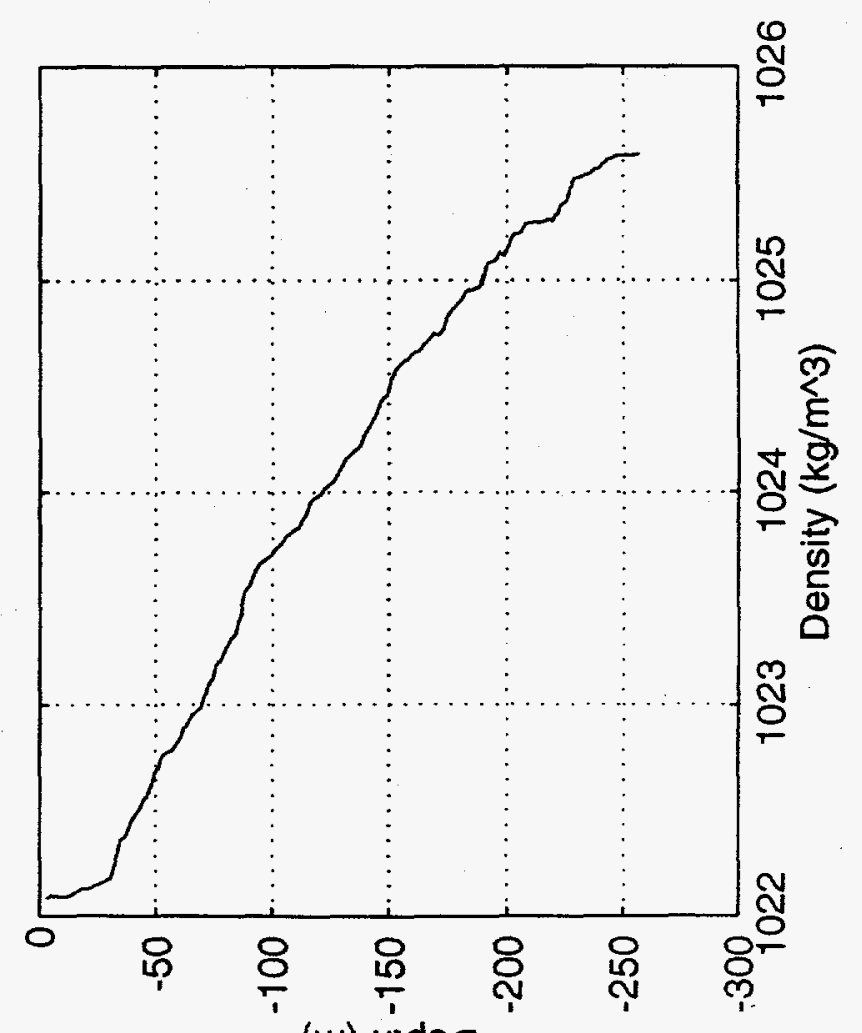

(u) uldəa 


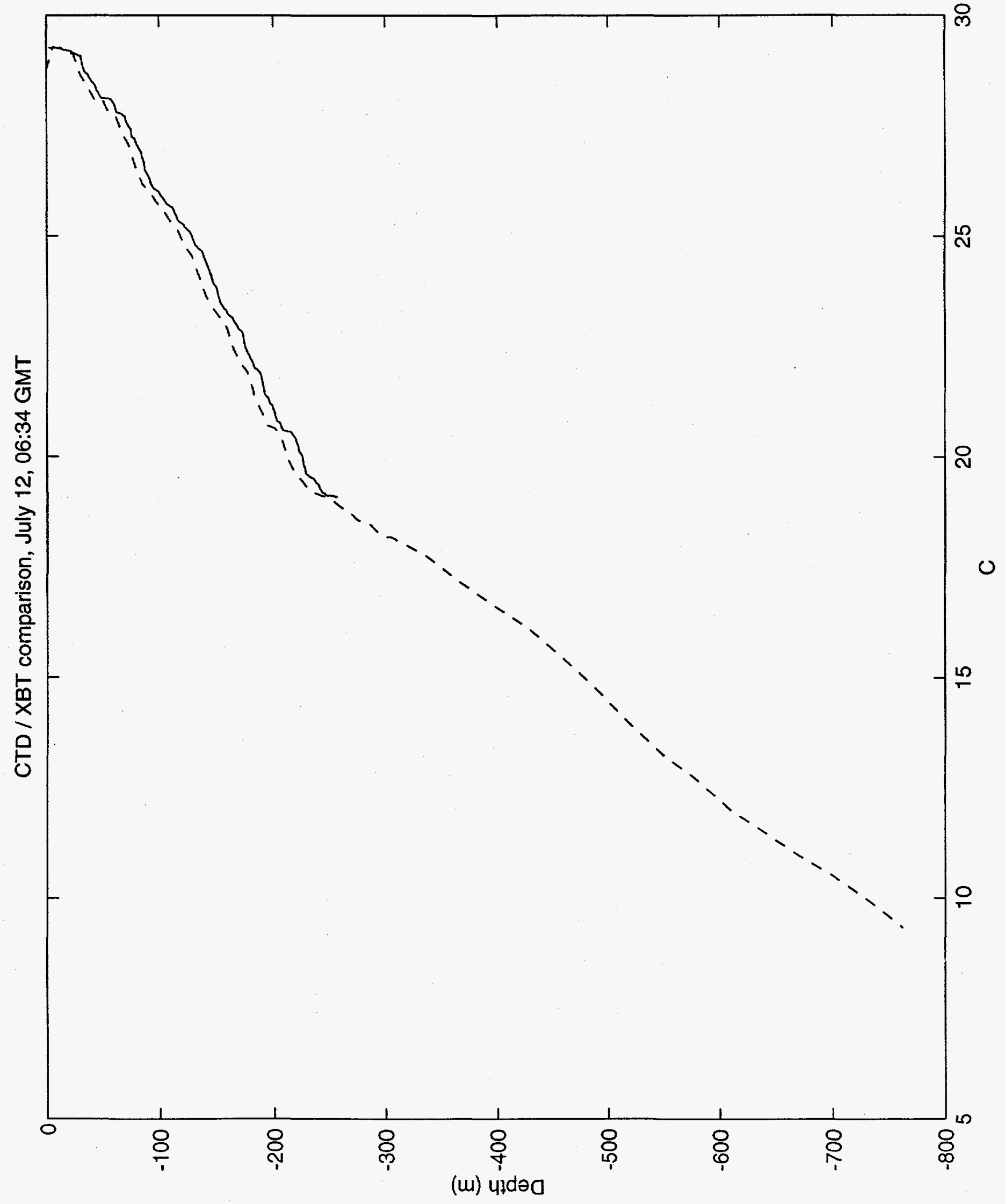




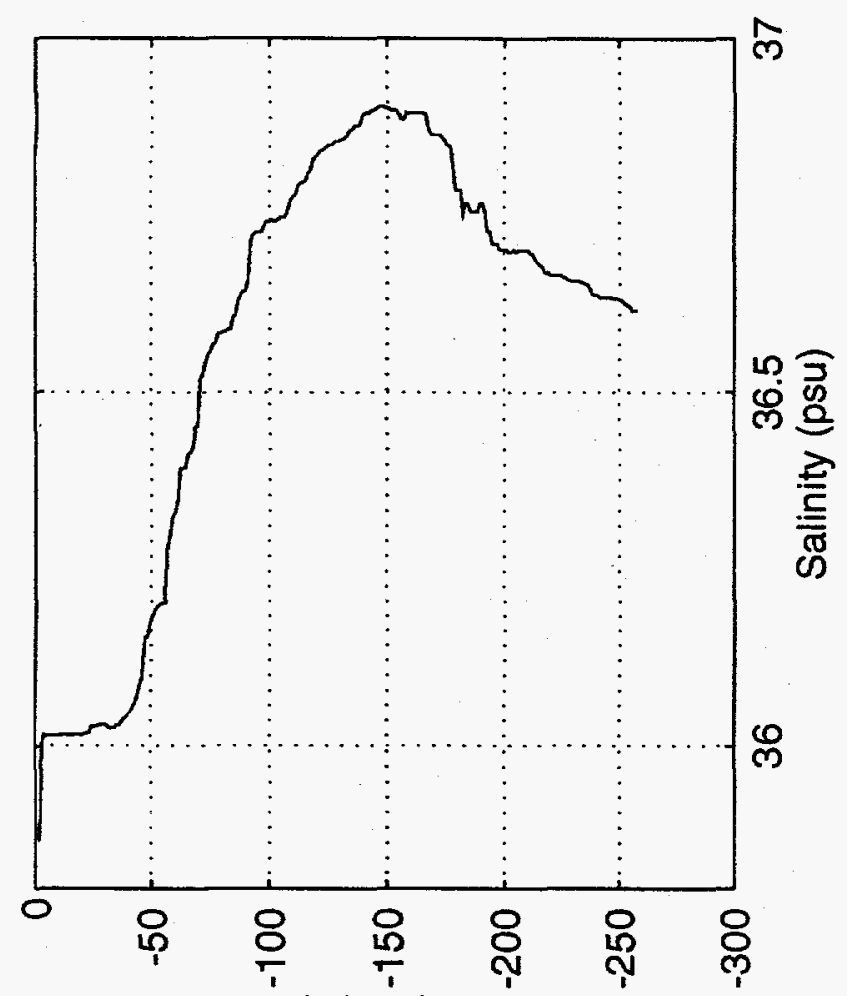

\begin{tabular}{l}
$\sum_{0}$ \\
0 \\
0 \\
0 \\
0 \\
2 \\
2 \\
3 \\
\hdashline \\
0
\end{tabular}

(w) uldag

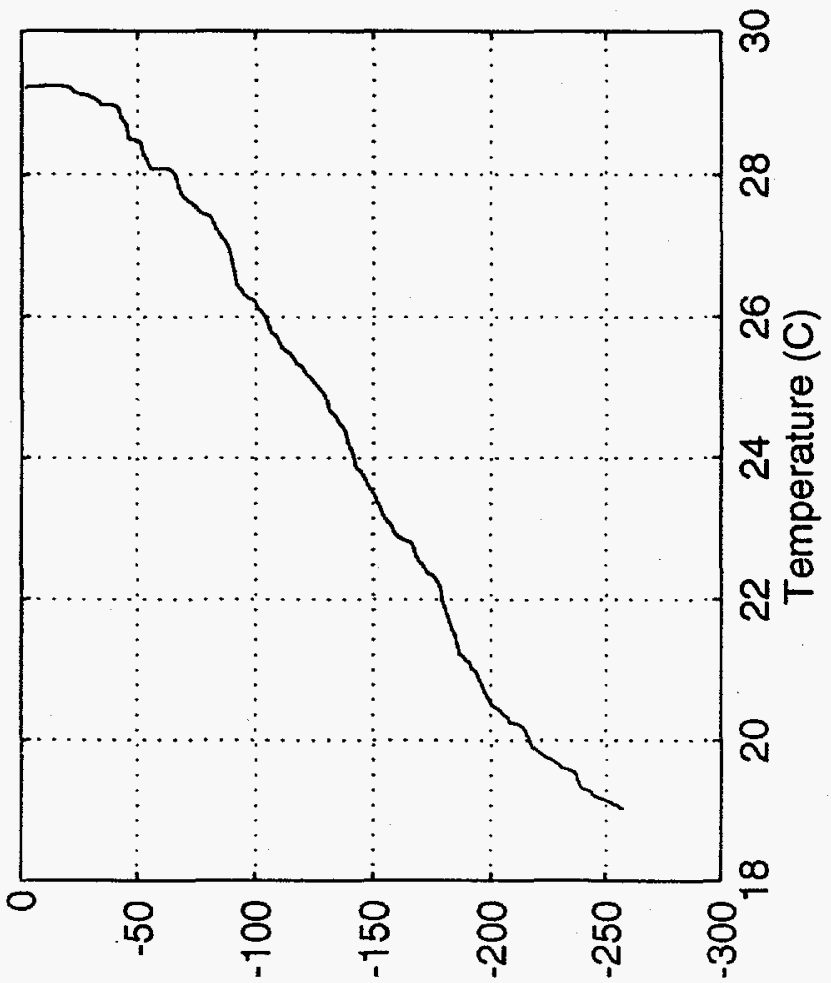

(w) 41dea

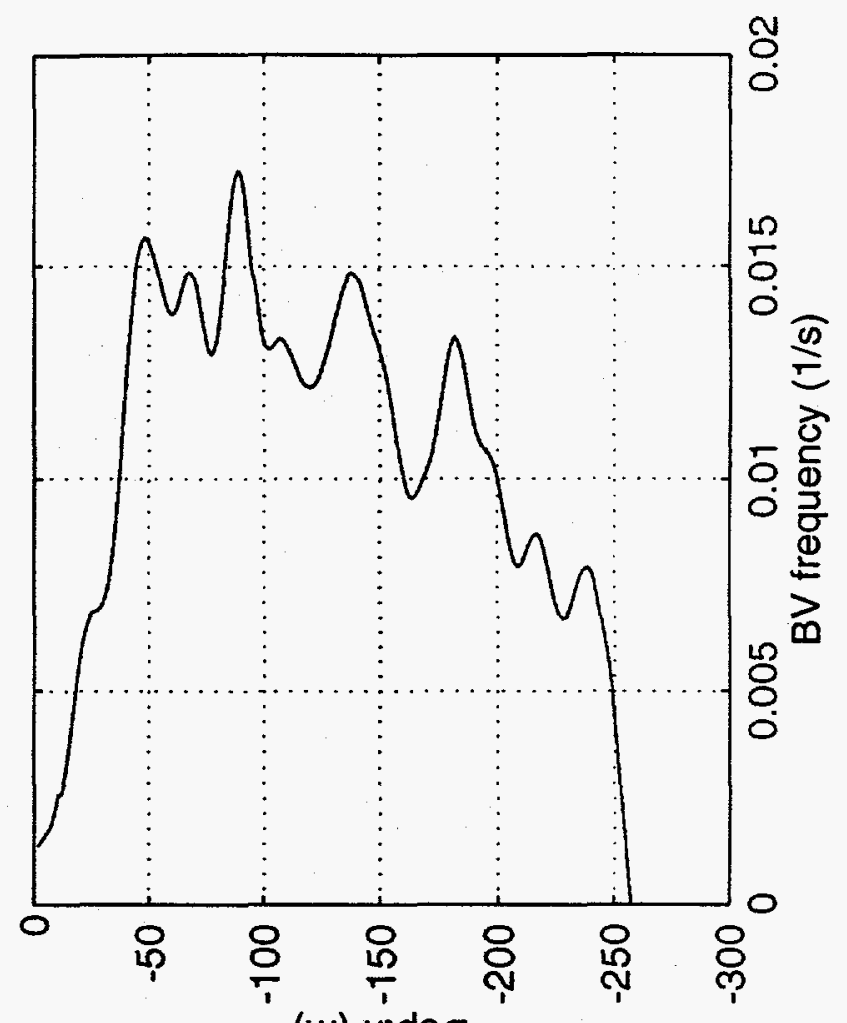

(u) ułdea

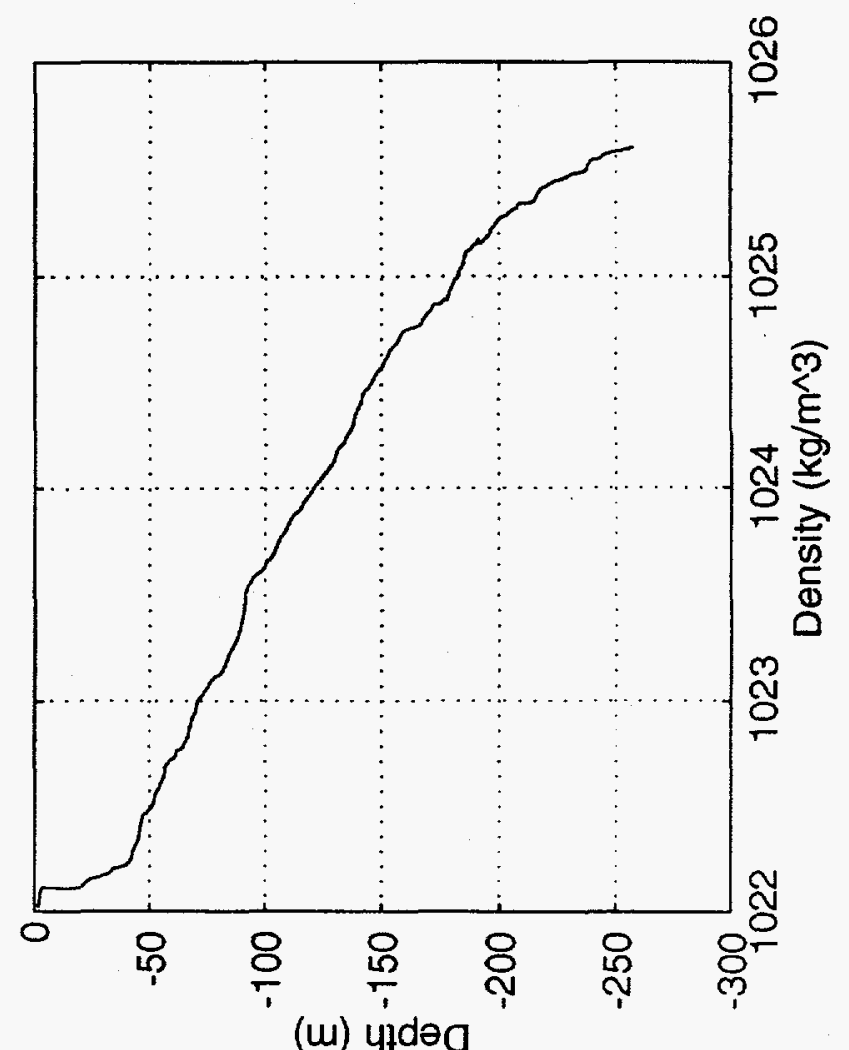




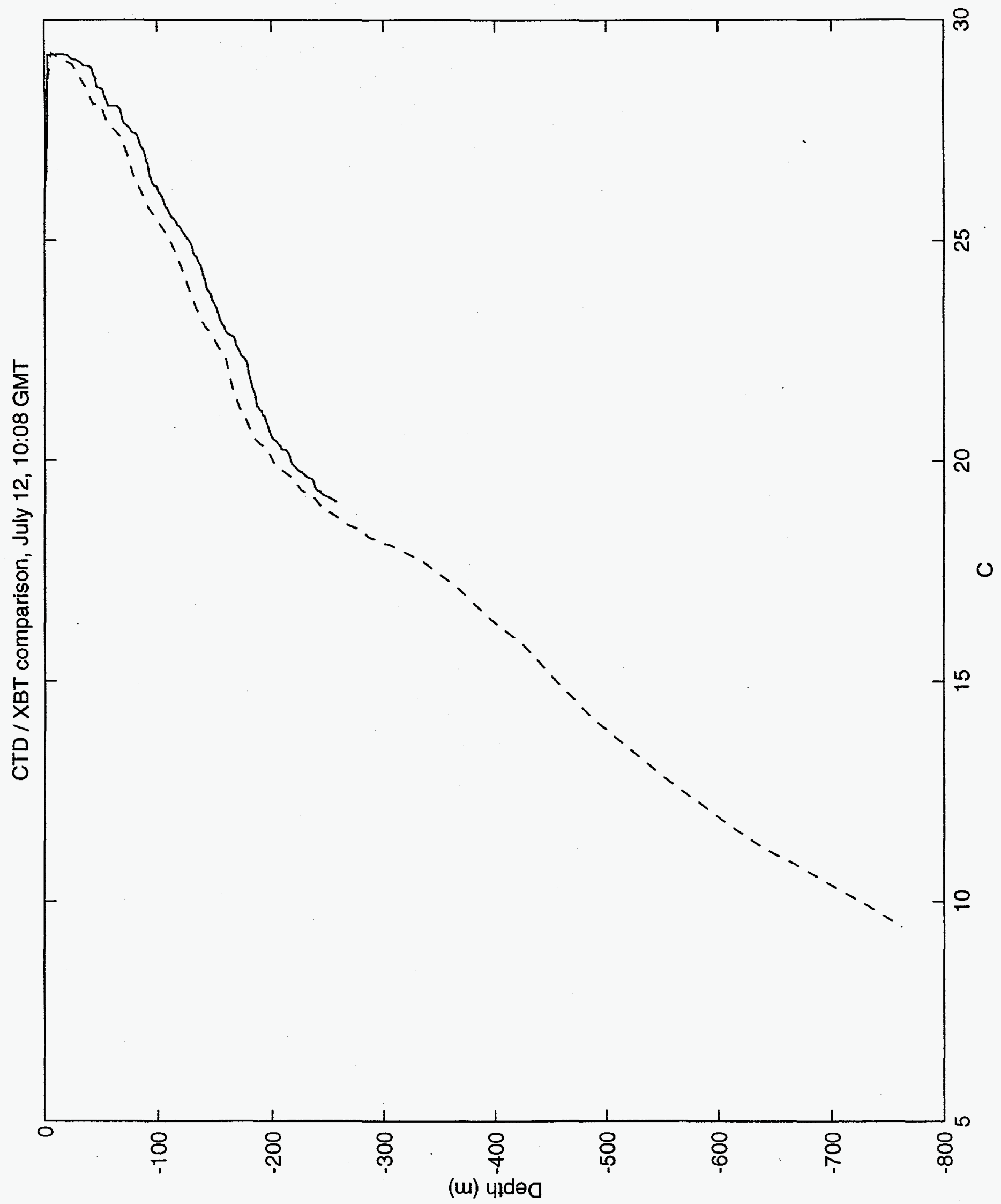



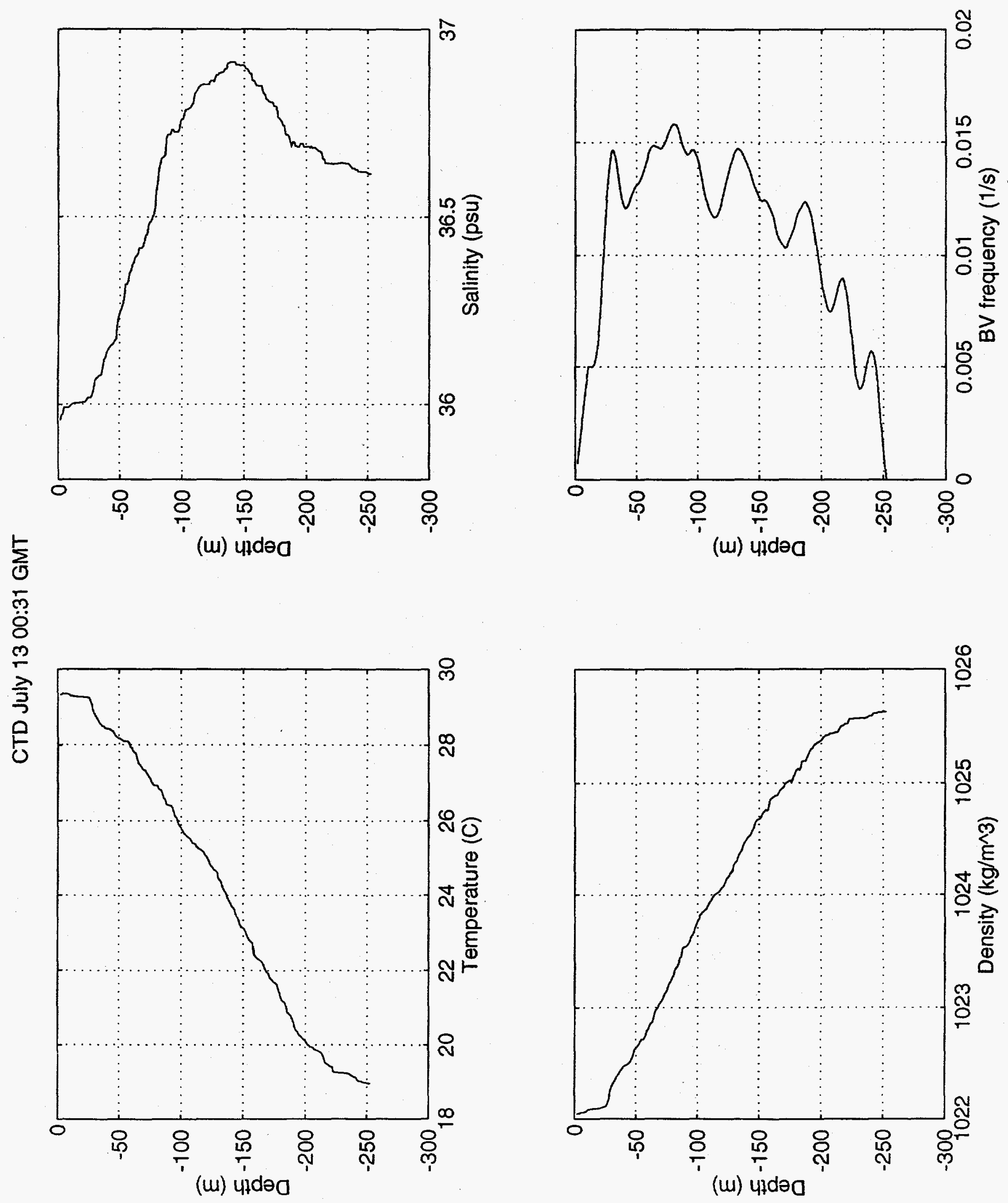

(w) पłdəa

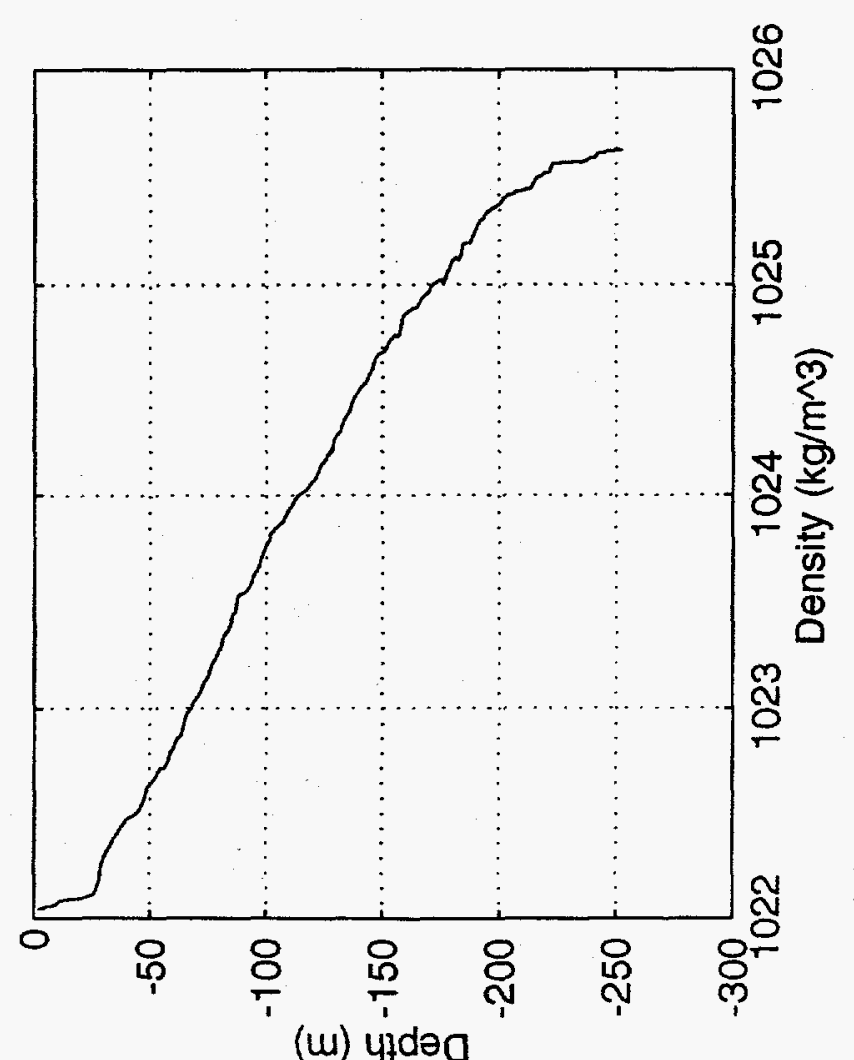




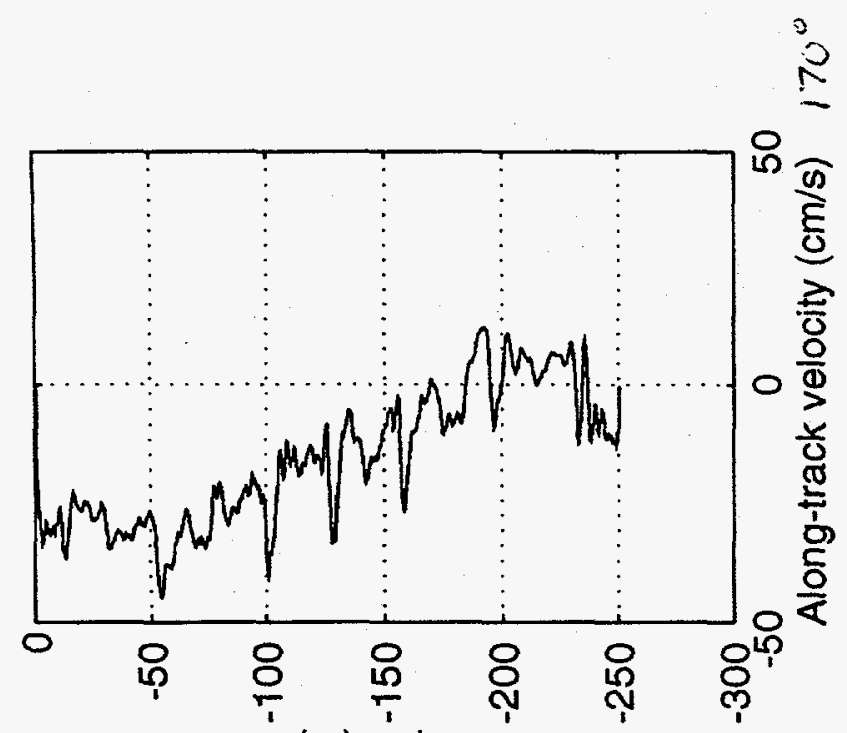

(w) प1də0

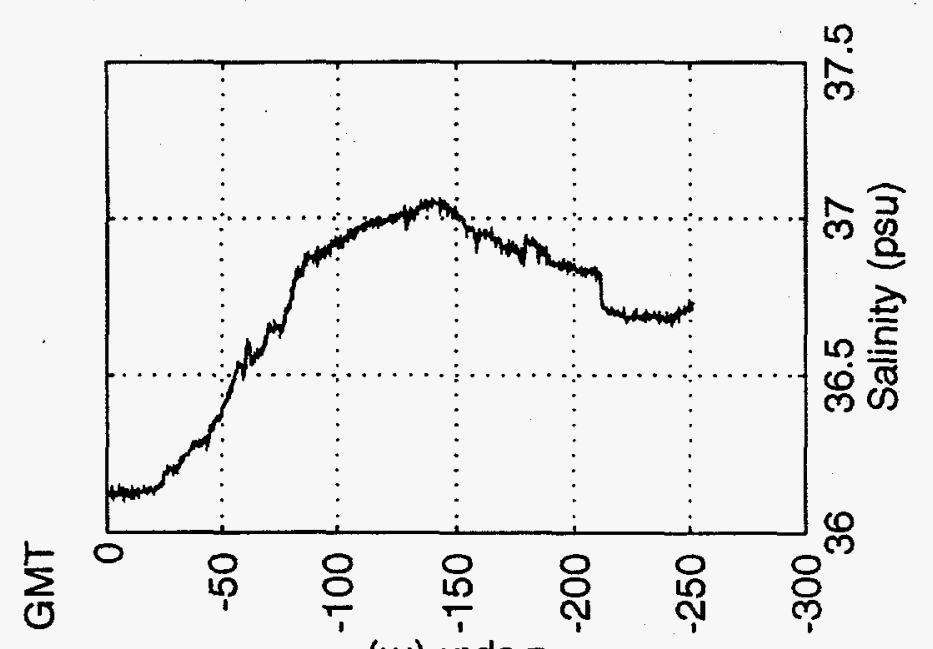

ตั

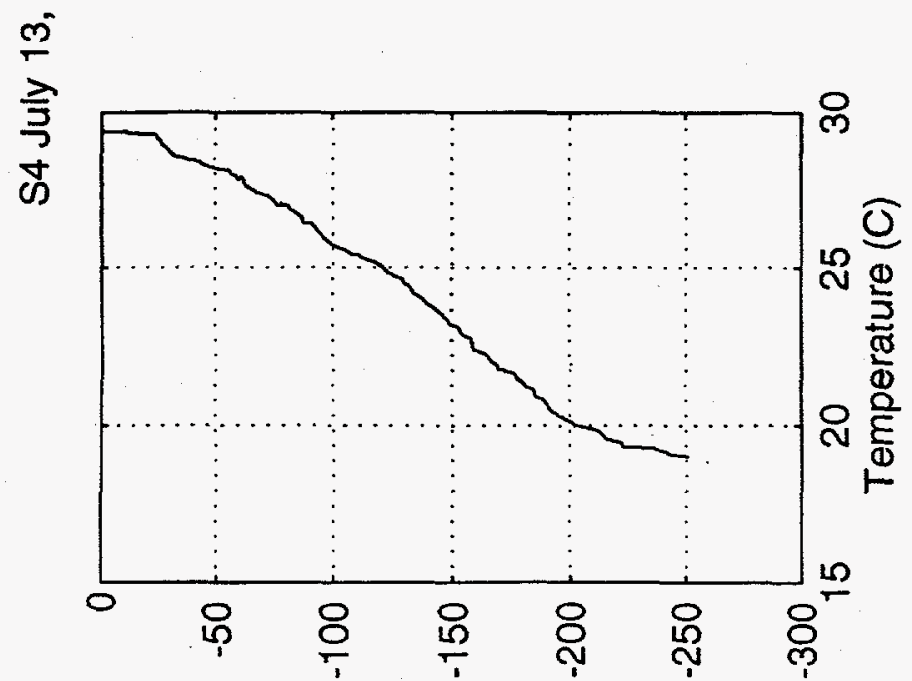

(u) पid dəa

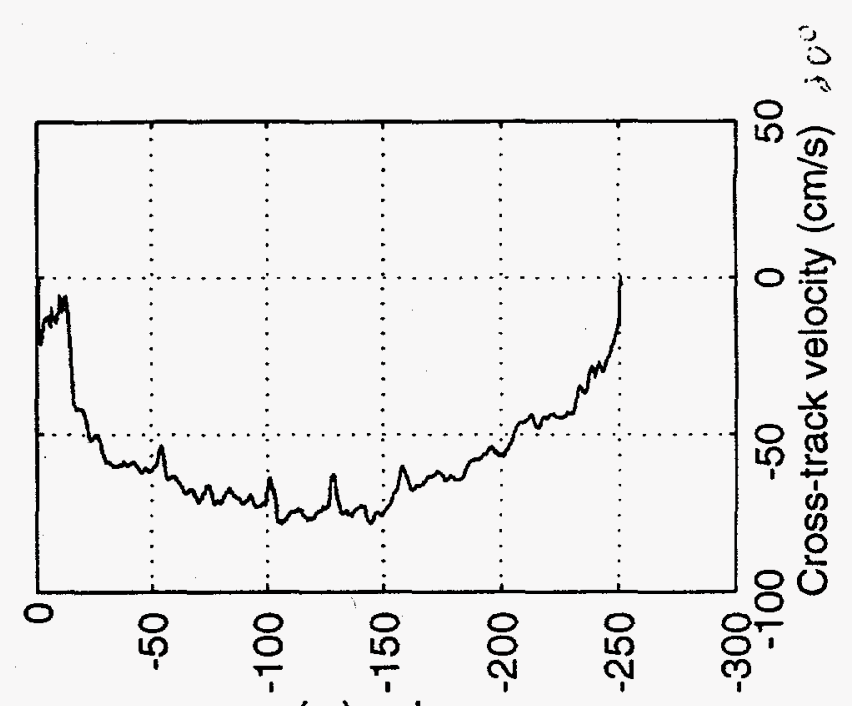

(ui) yıdəa

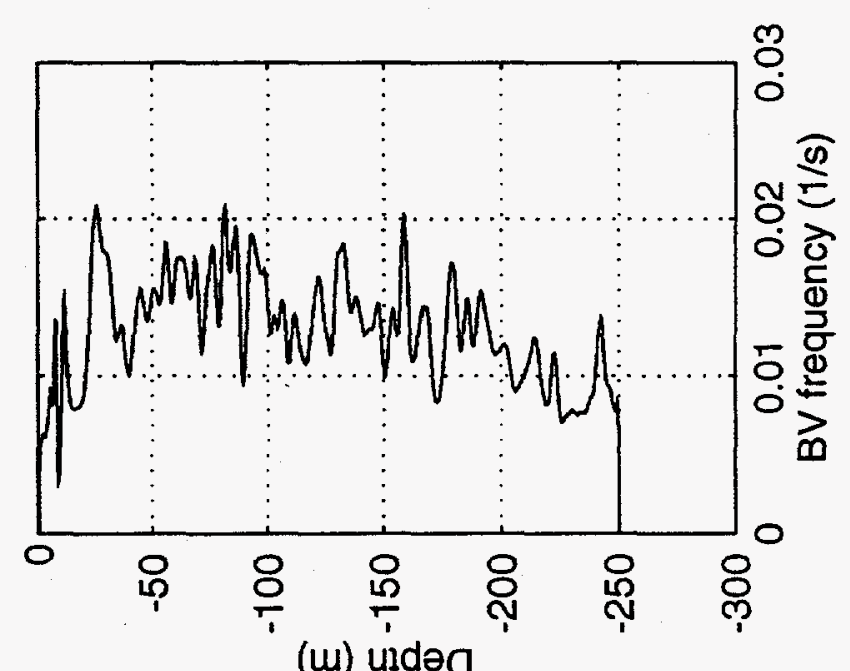

(u) uldəa

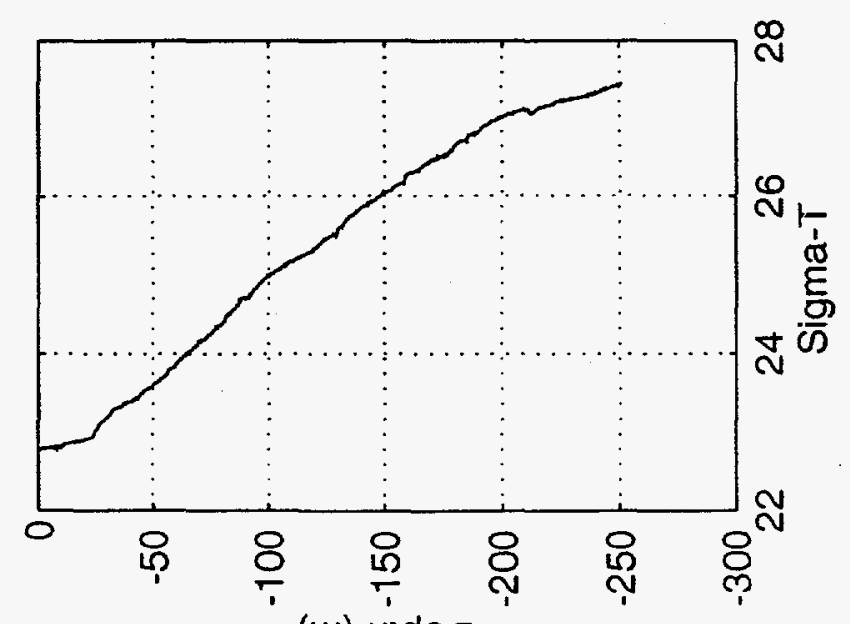

(w) पाdəa 


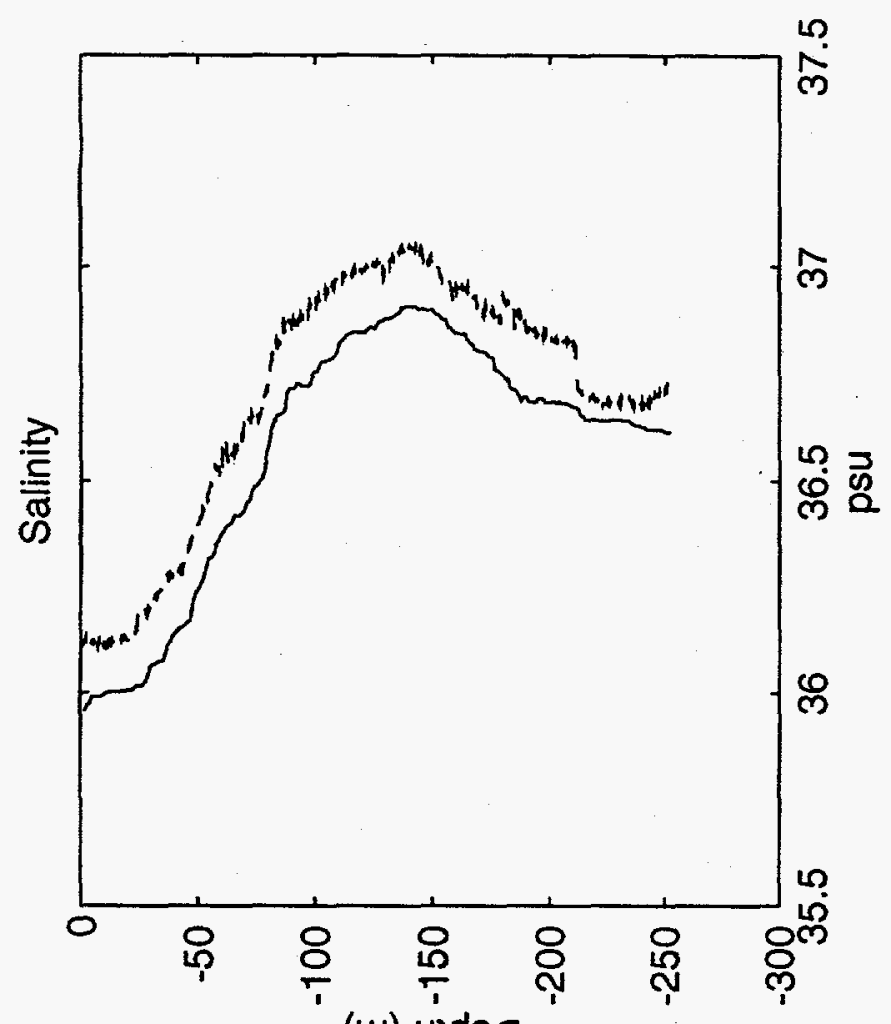

(w) uाdəa

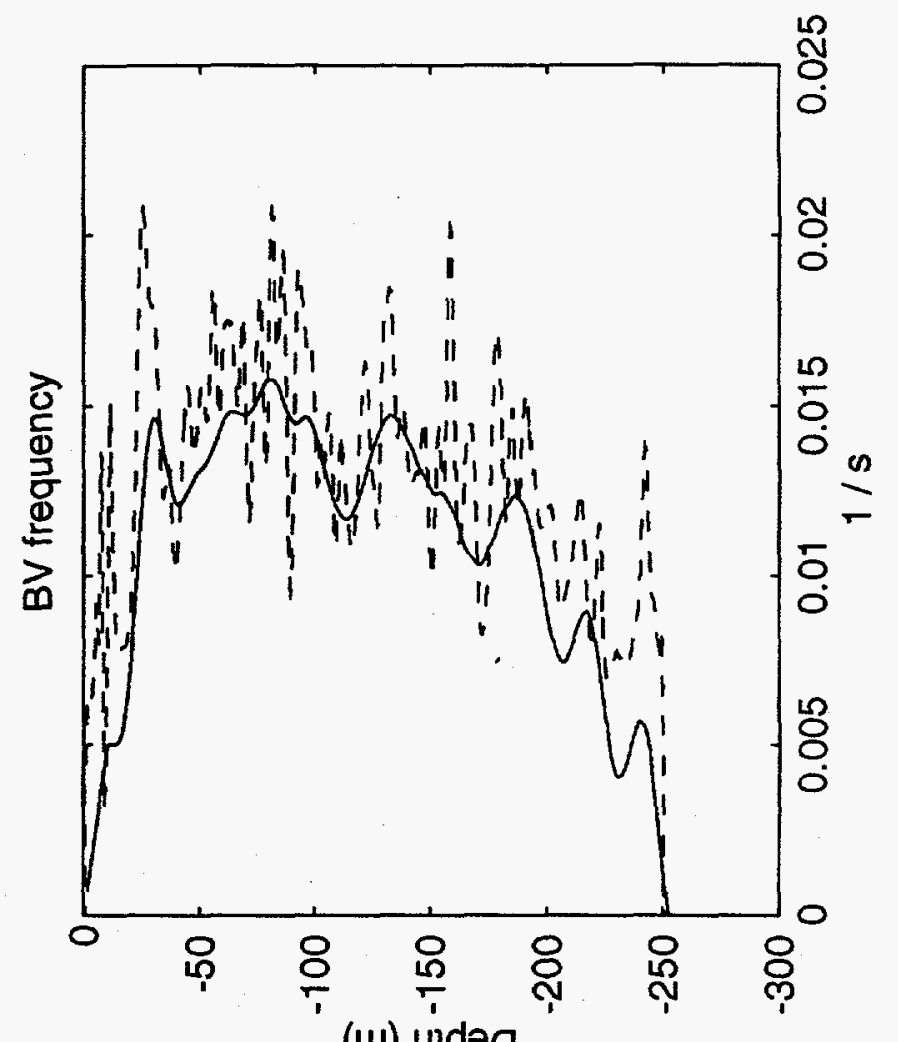

$\sum_{0}^{5}$
$\frac{5}{8}$

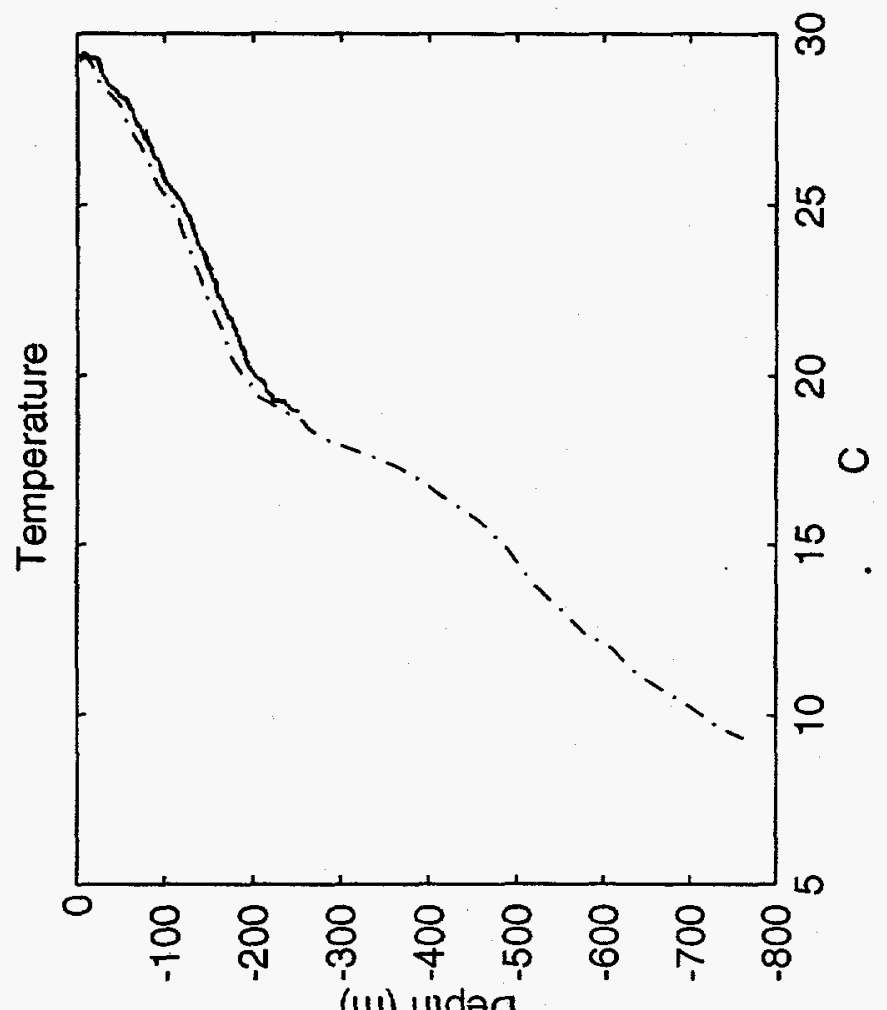

(iv) uldəo

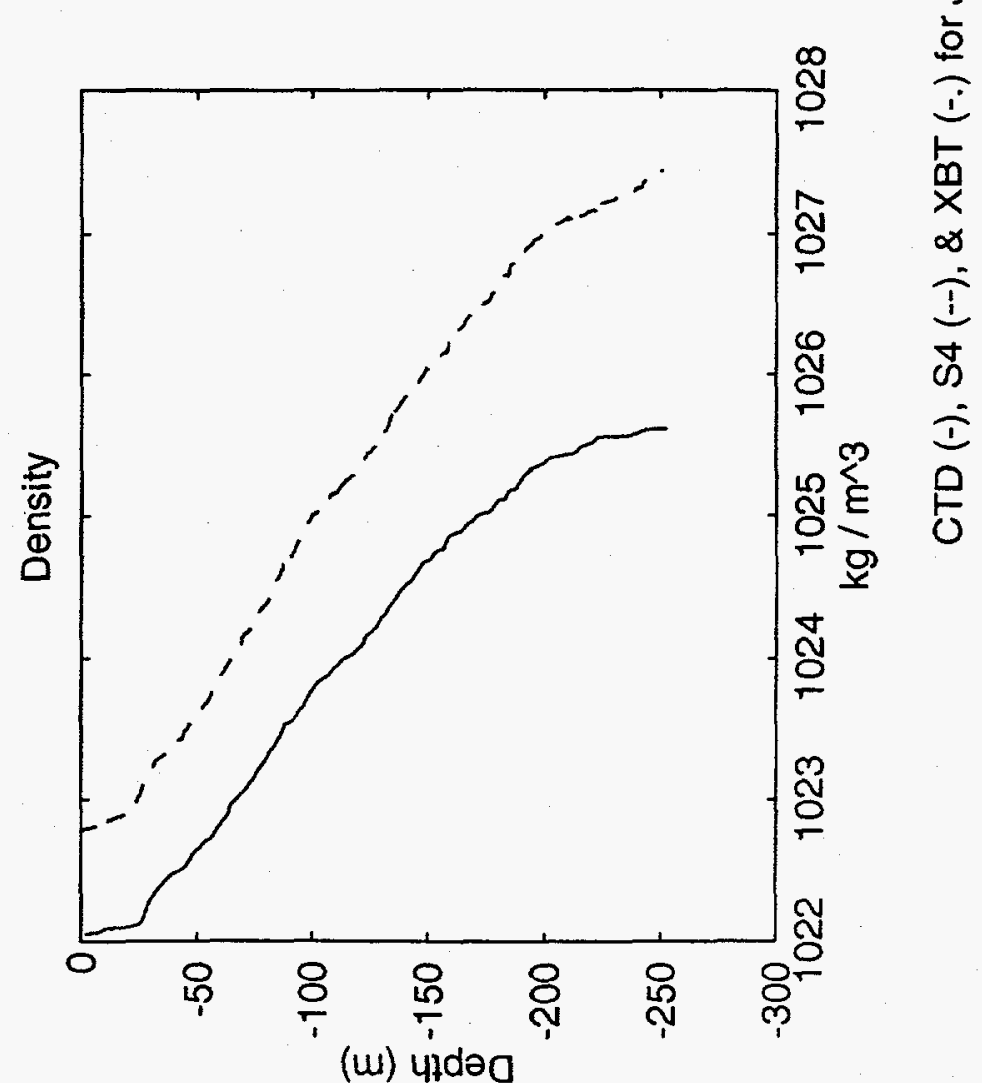



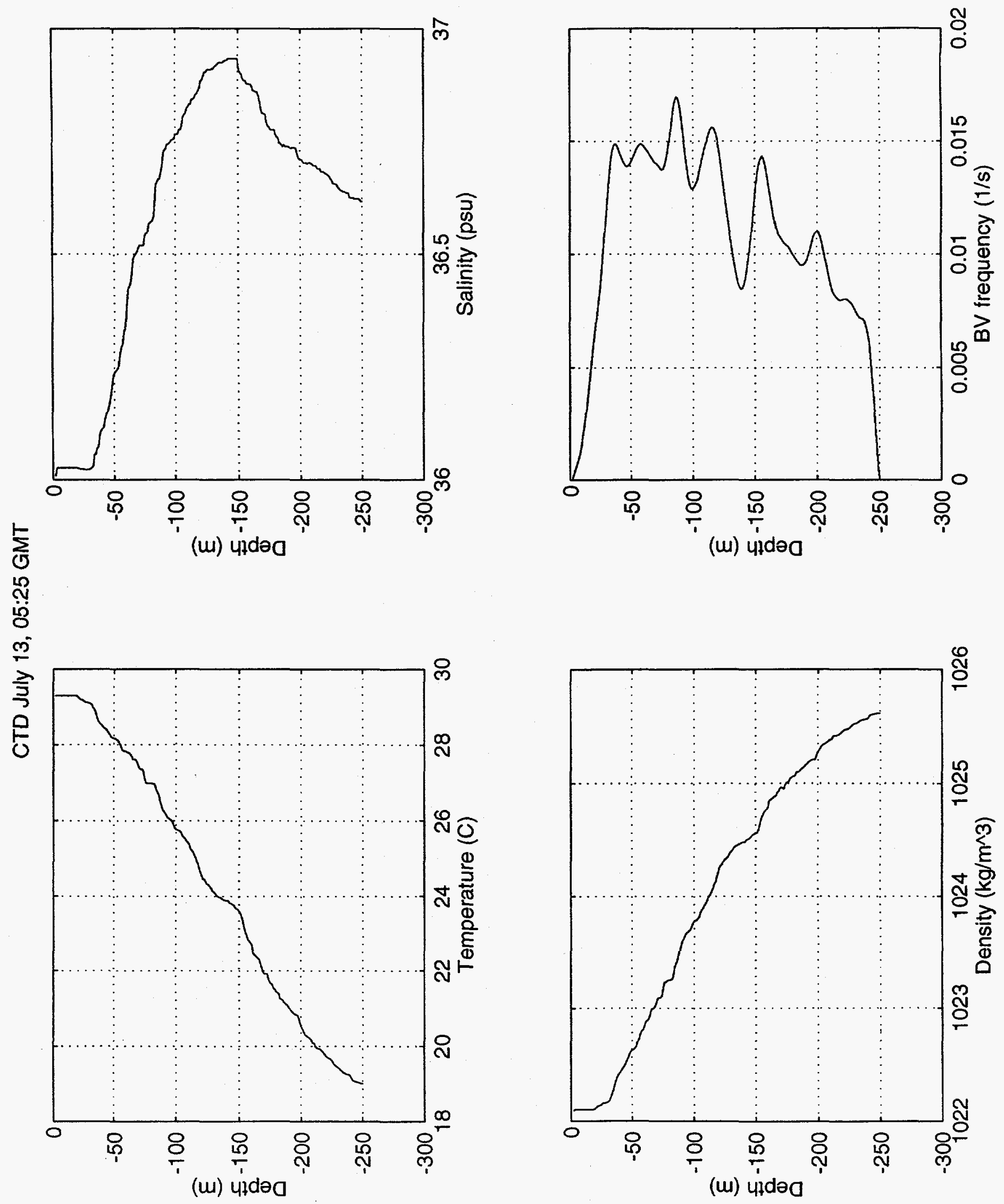


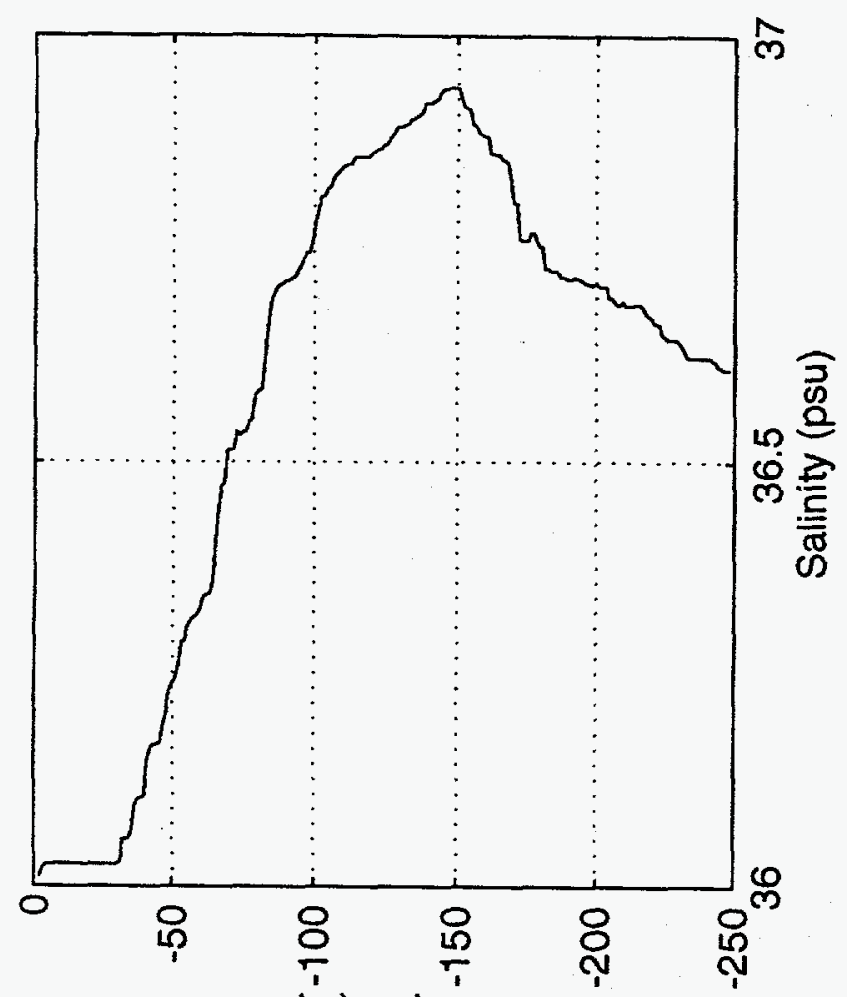

(ui) पldəa

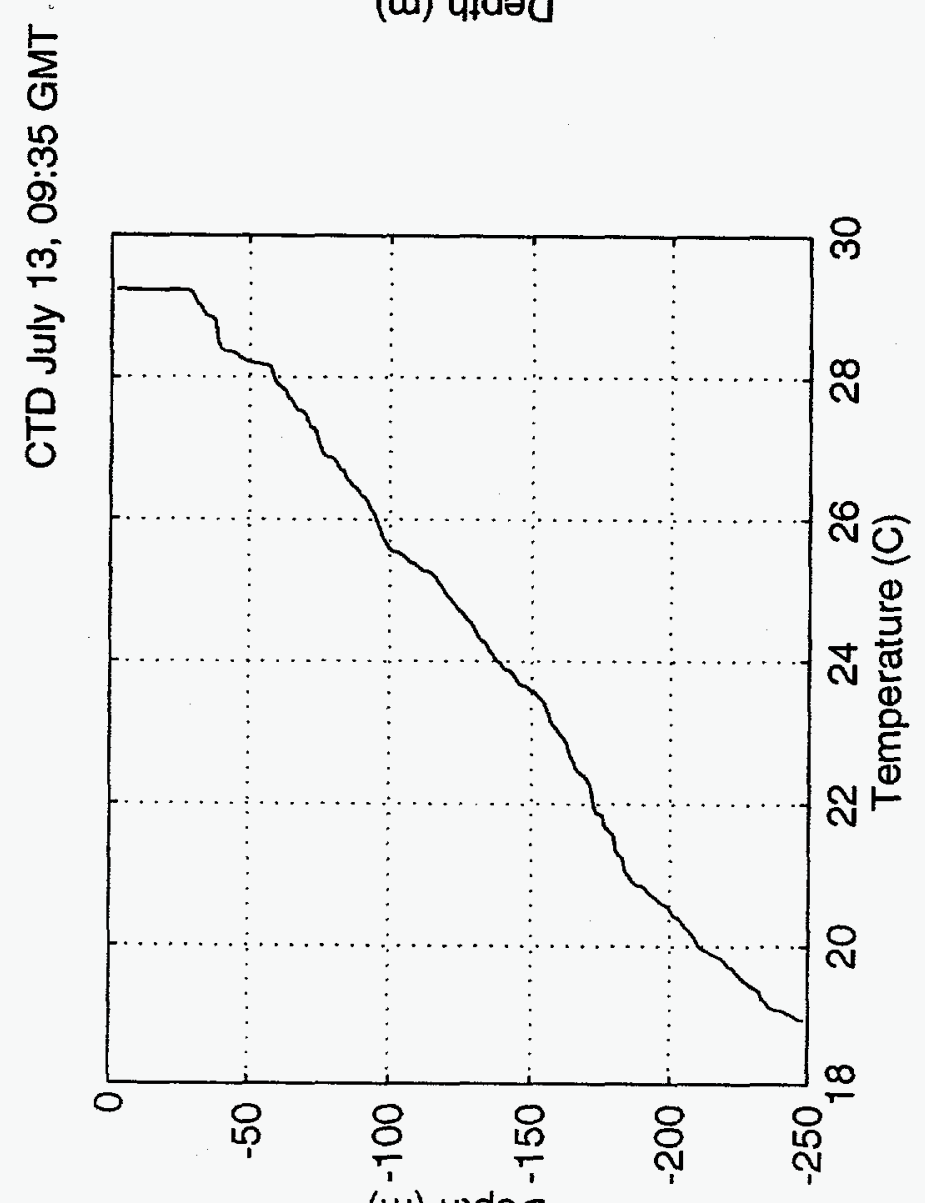

(ii) पाdəo'

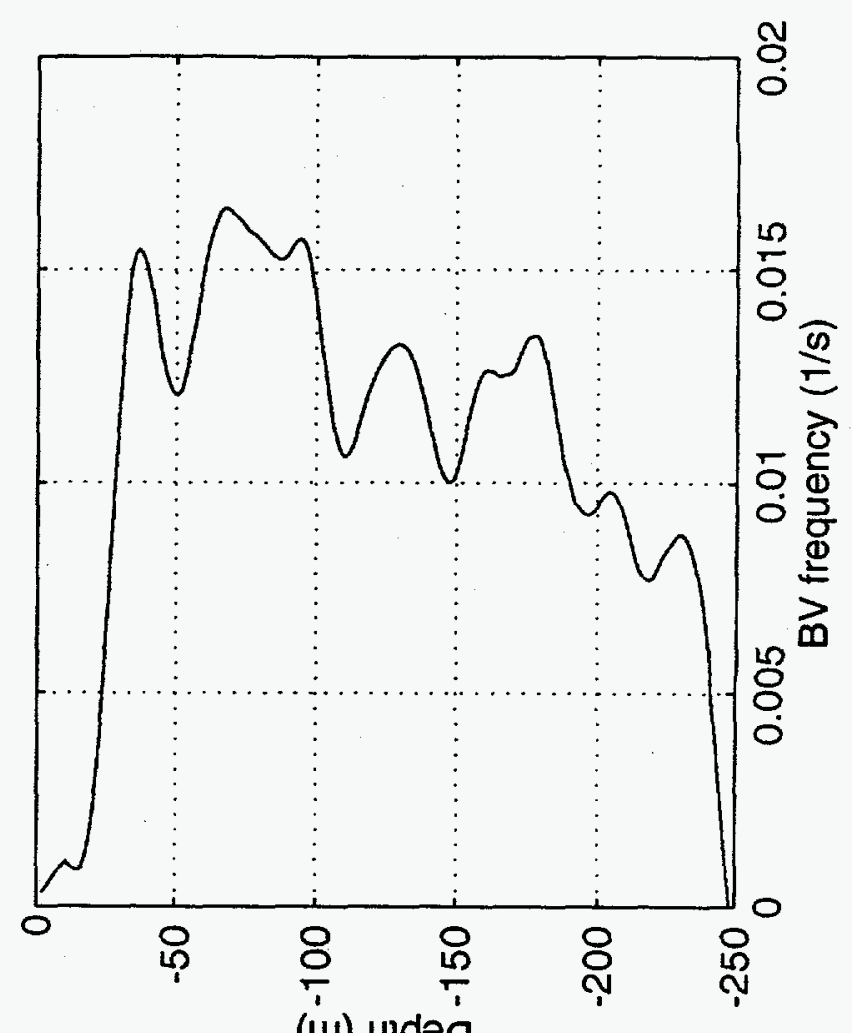

(u) uldəa

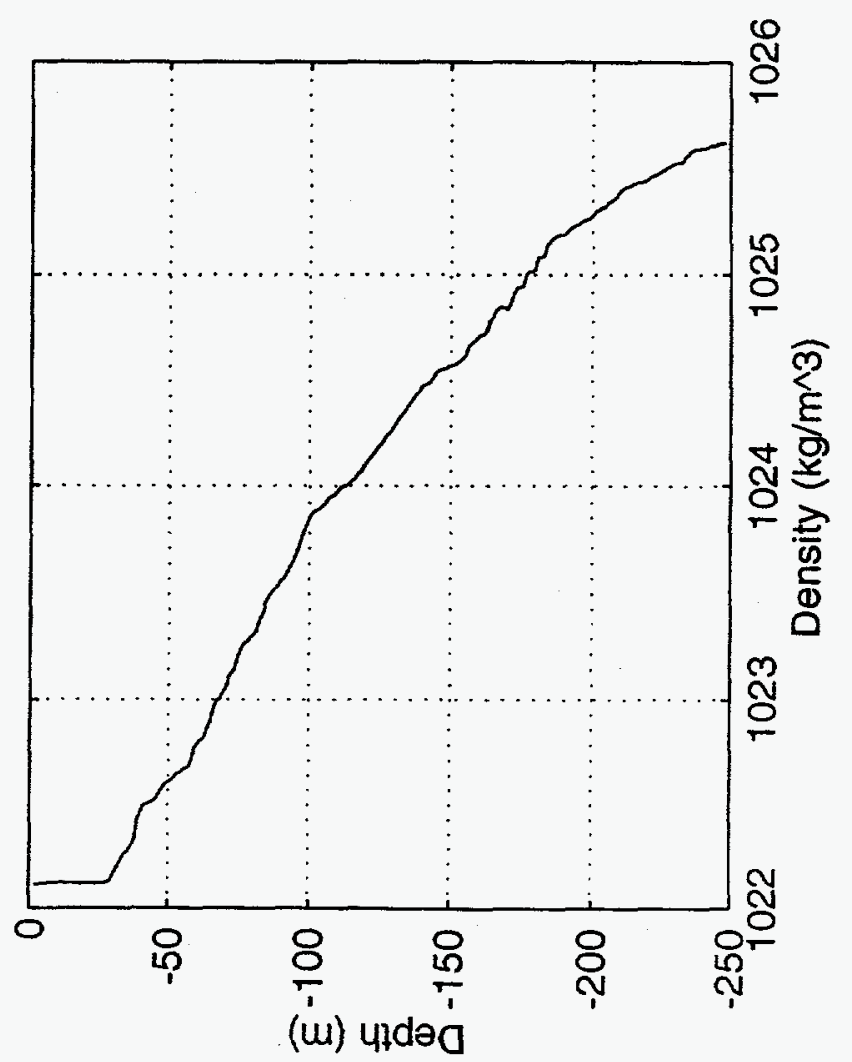




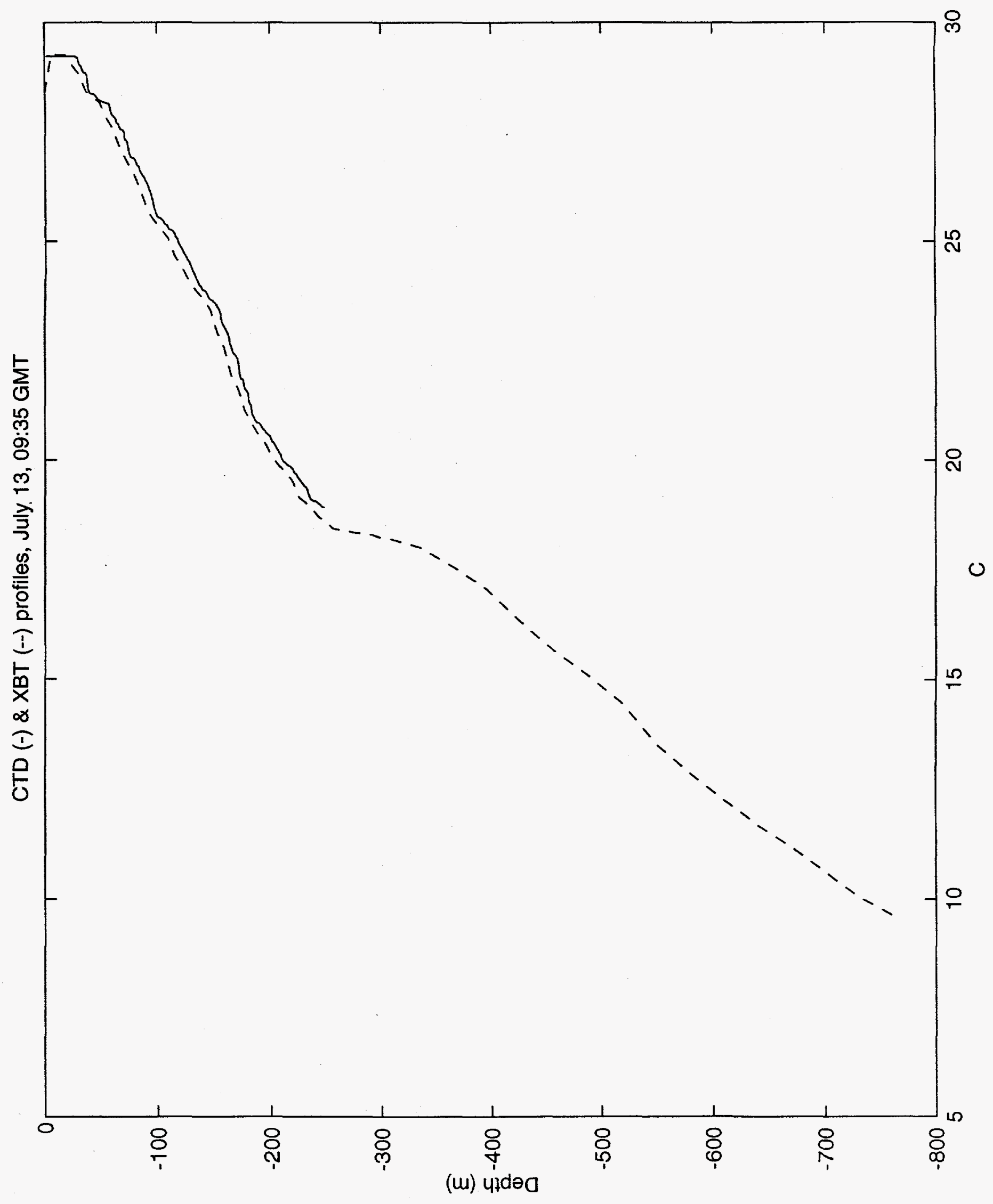



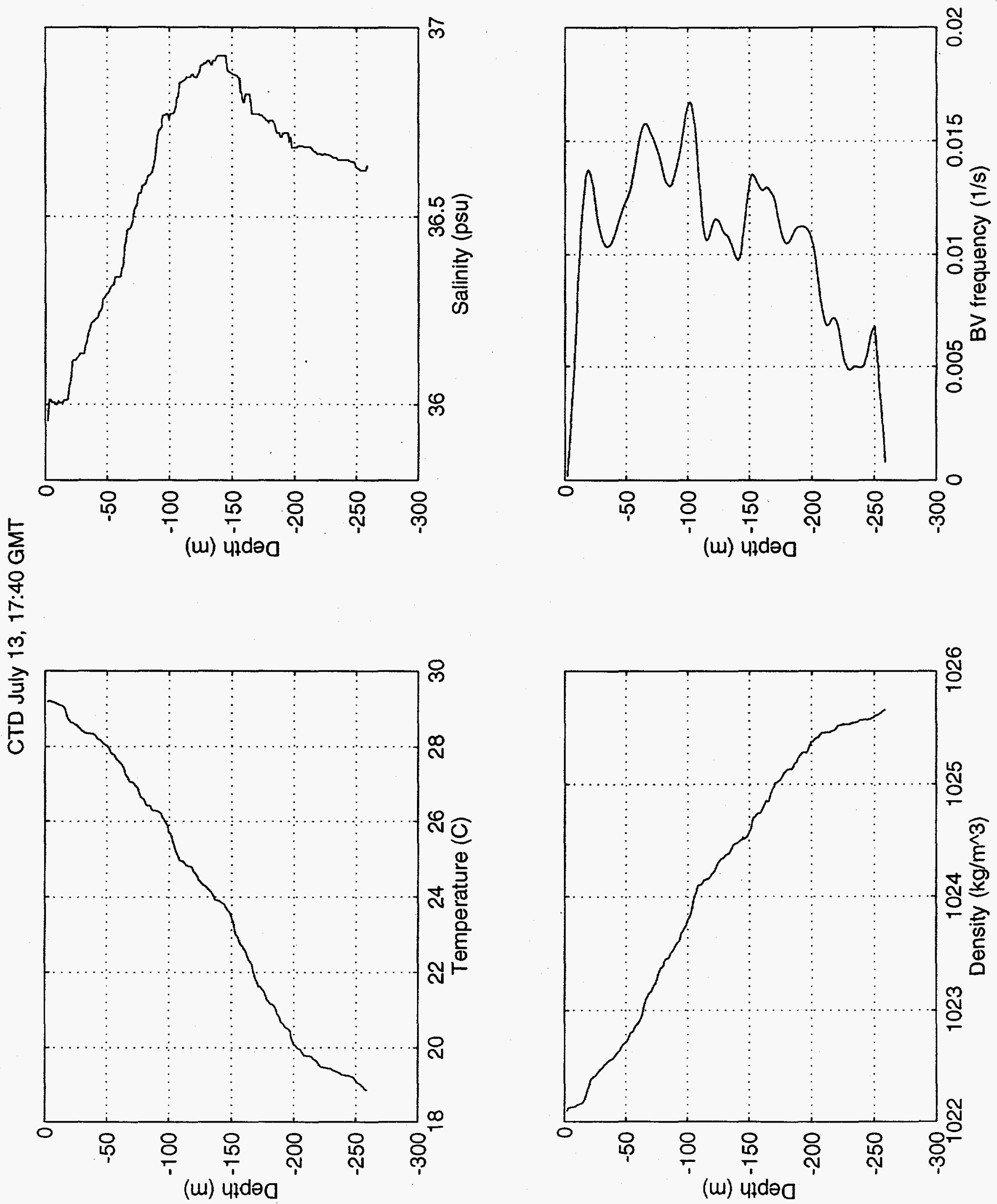


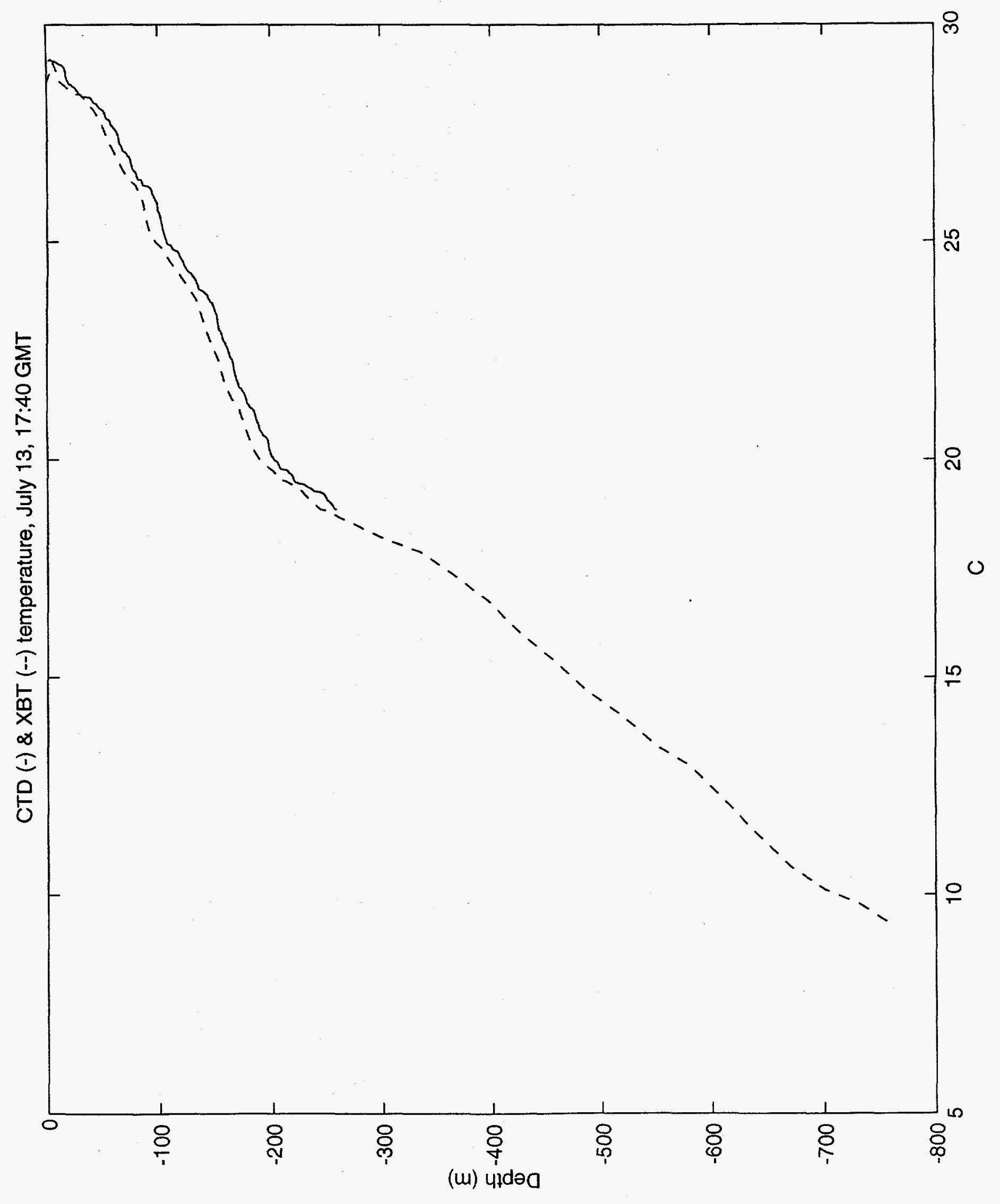




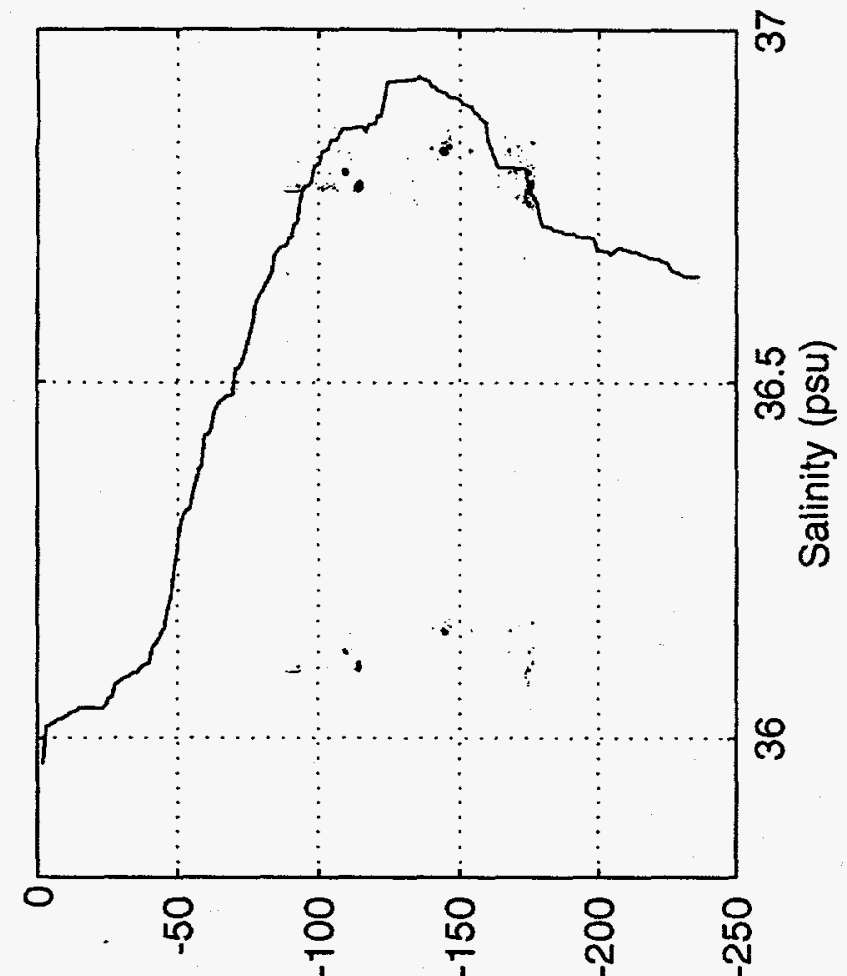

1
0
0
0
5
3
5
0

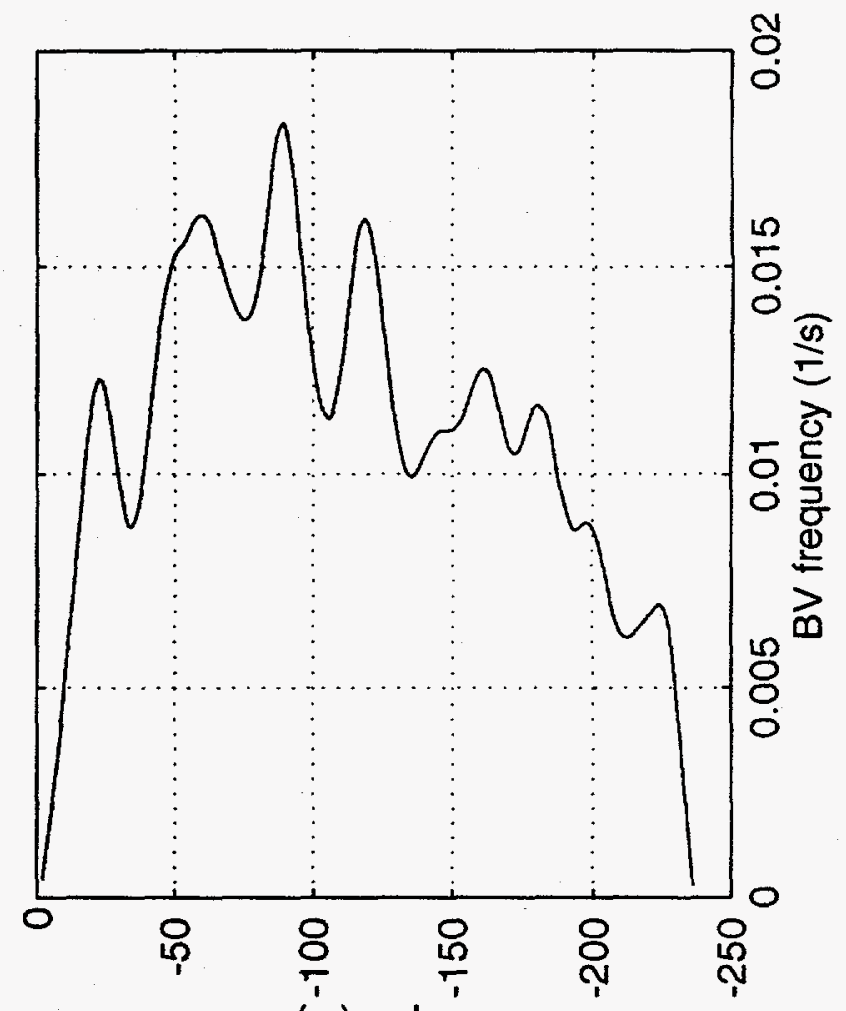

(u) uldəa

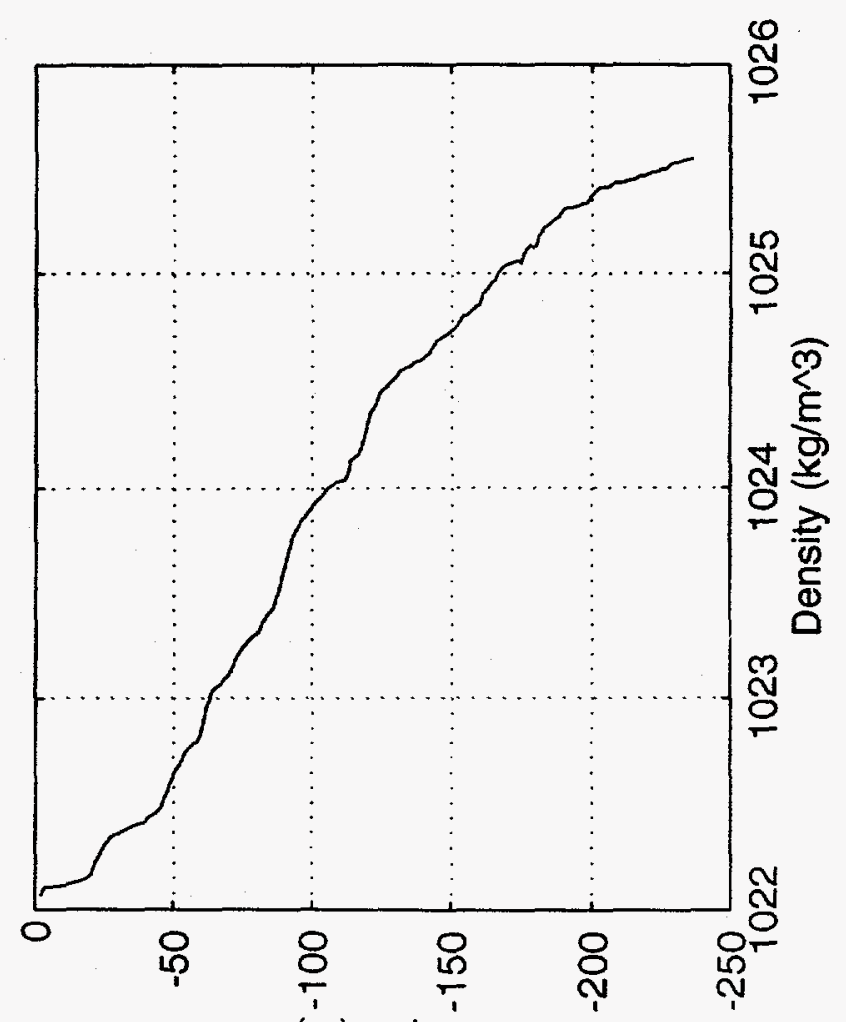

(w) पldəa 


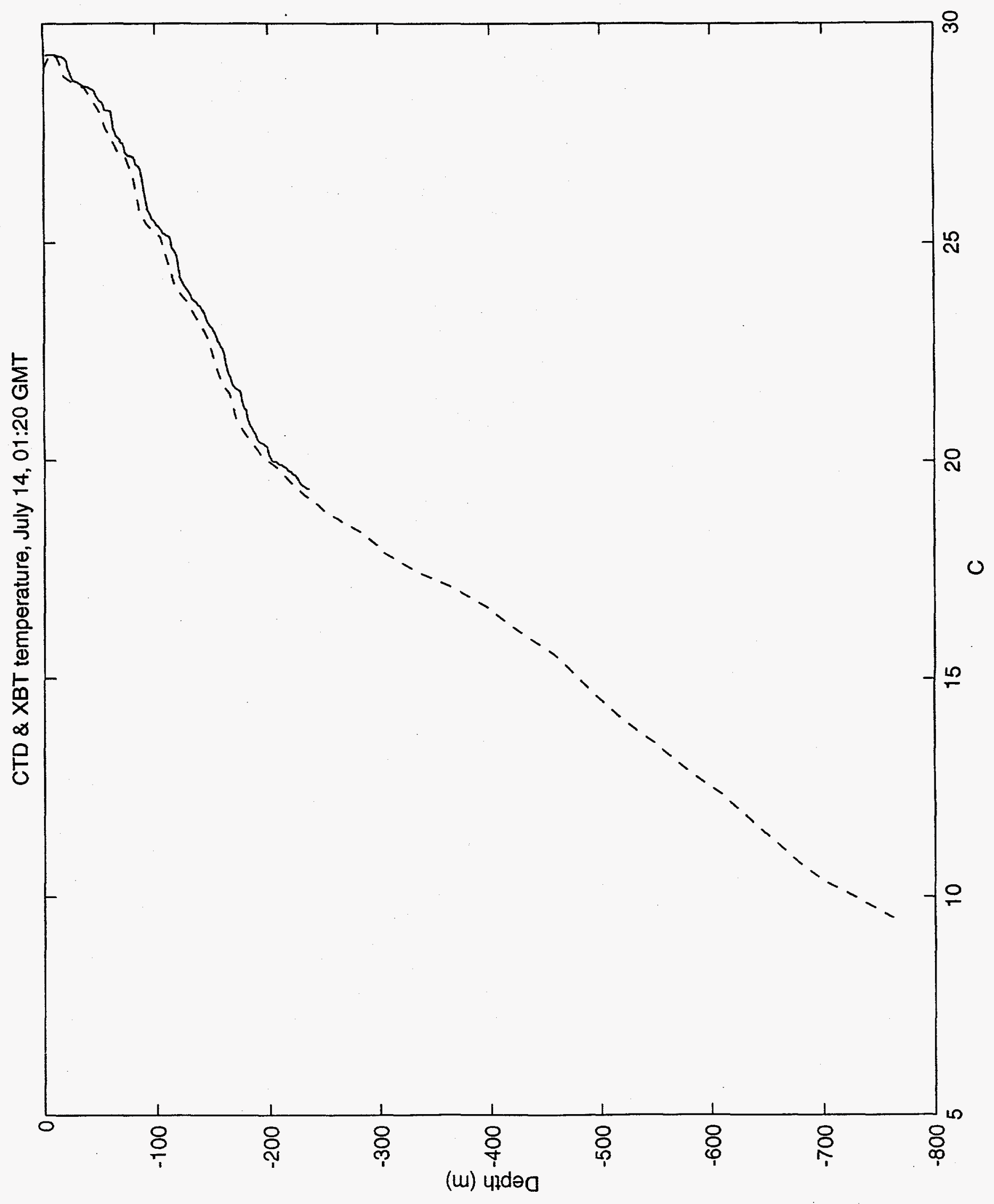



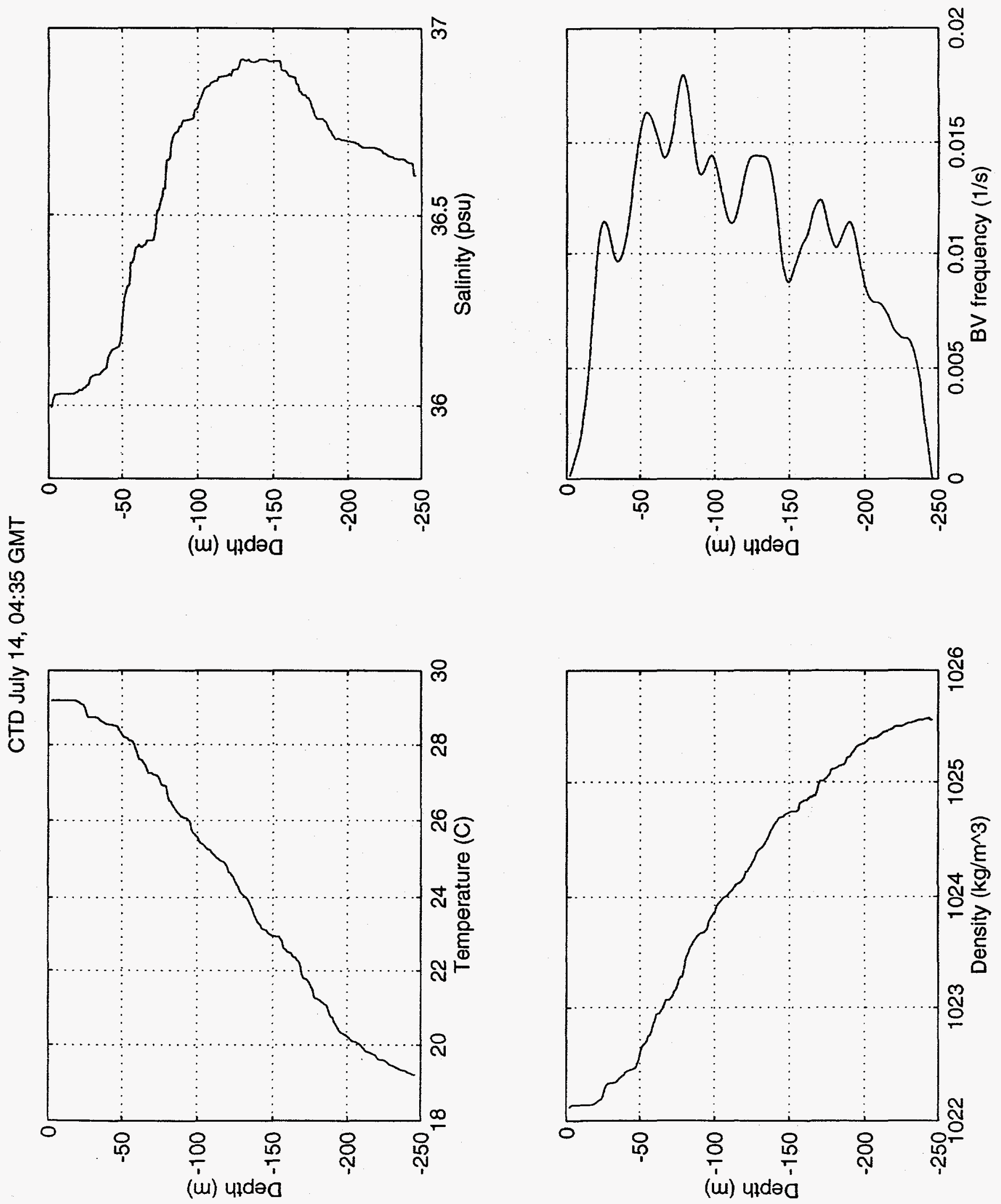


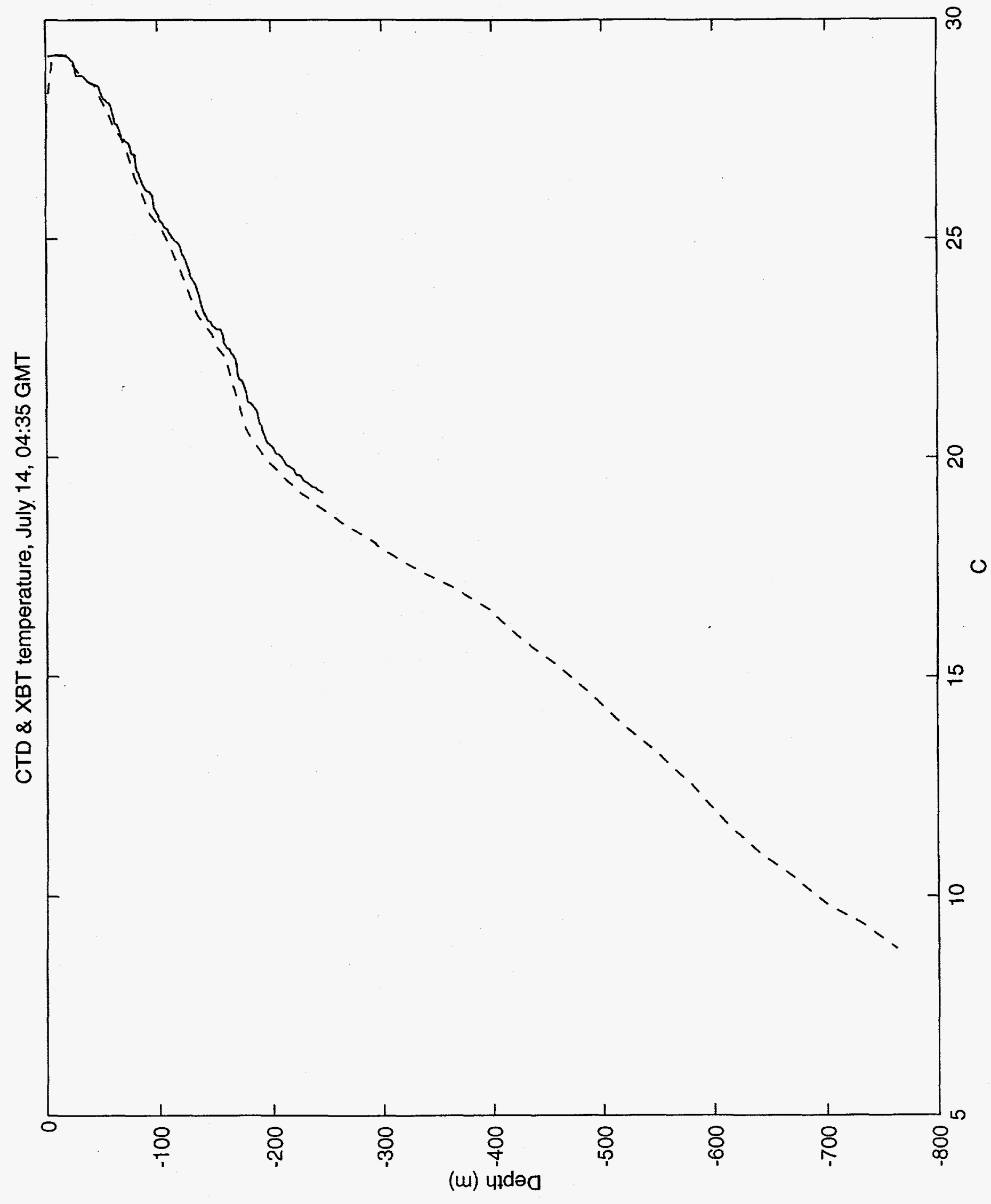




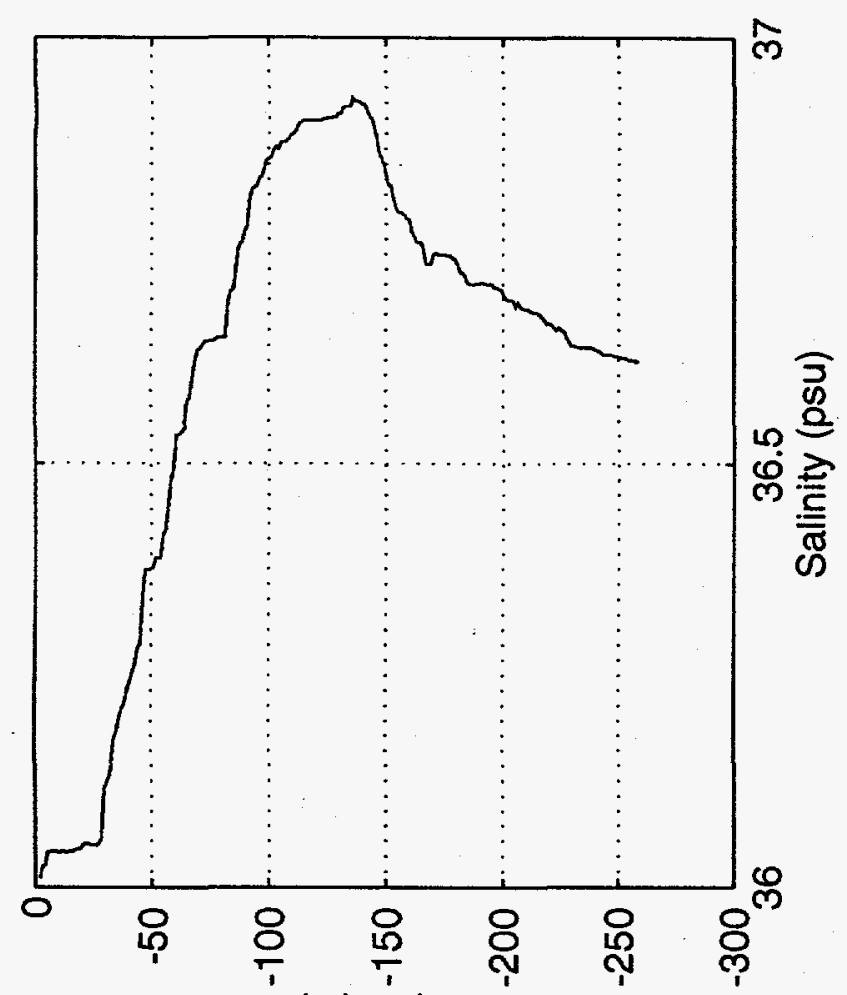

(u) yıdəo

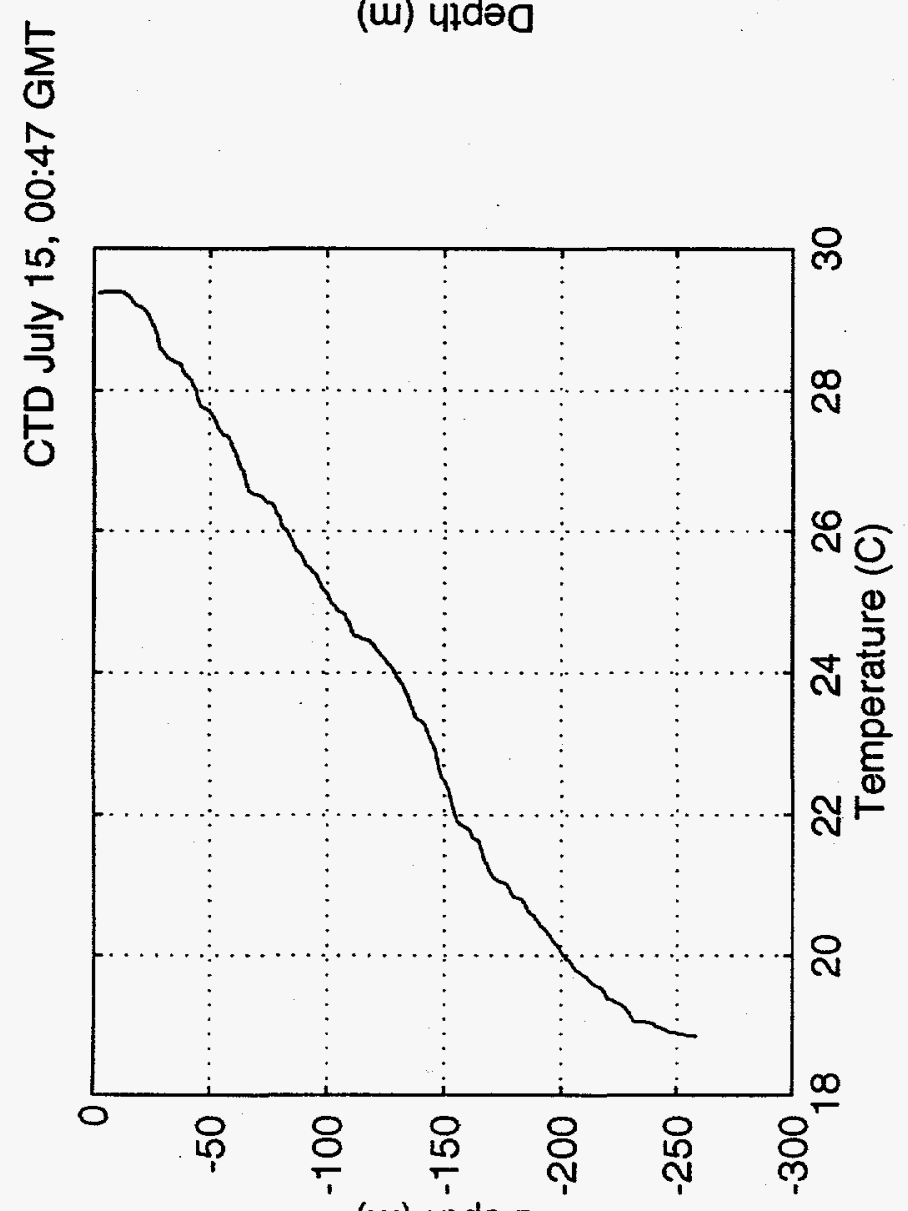

(w) पाdəo

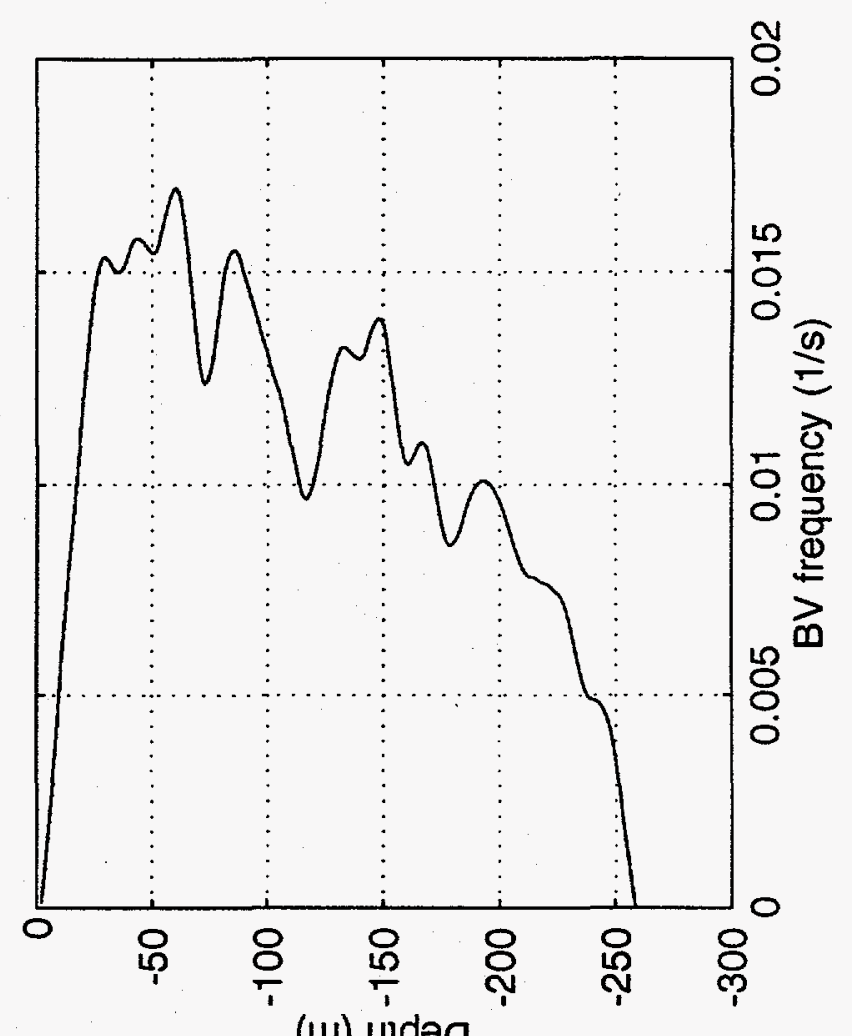

(us) प1dəa

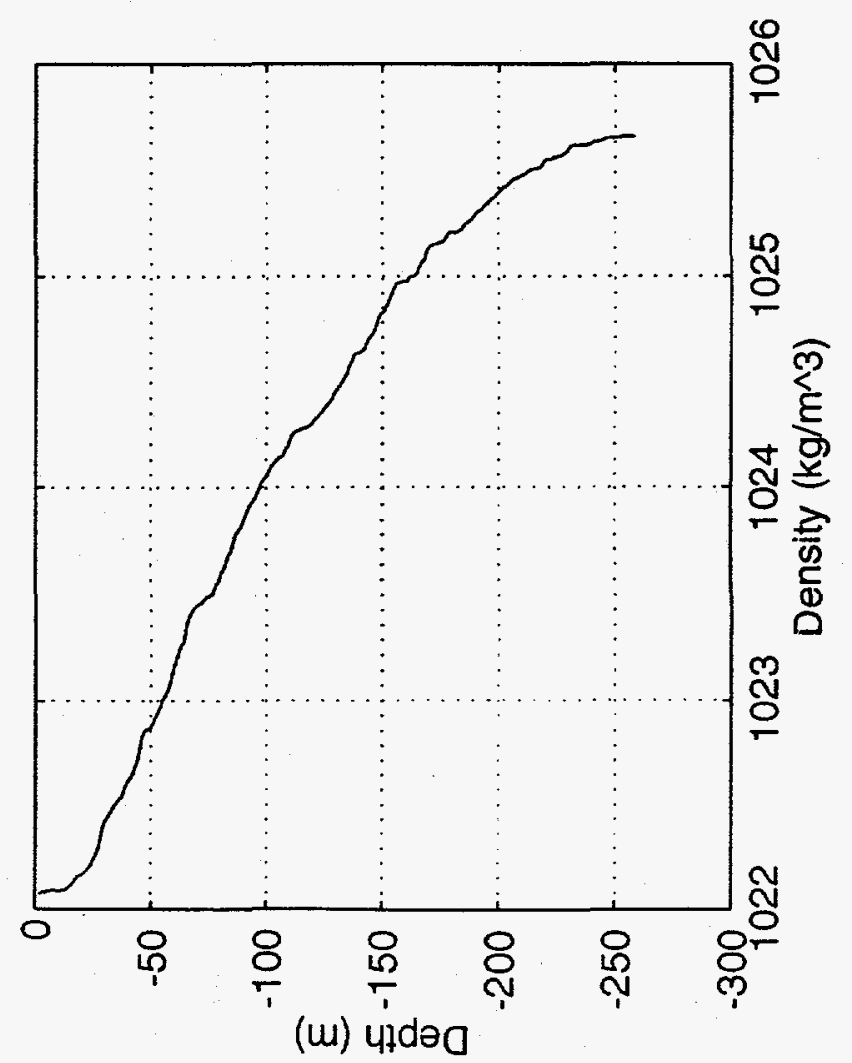




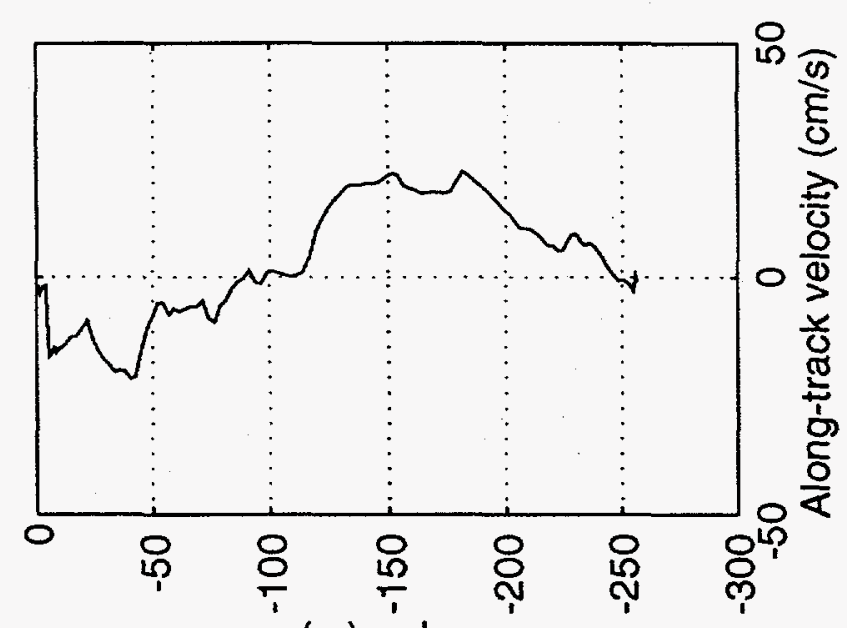

(w) पाdəo
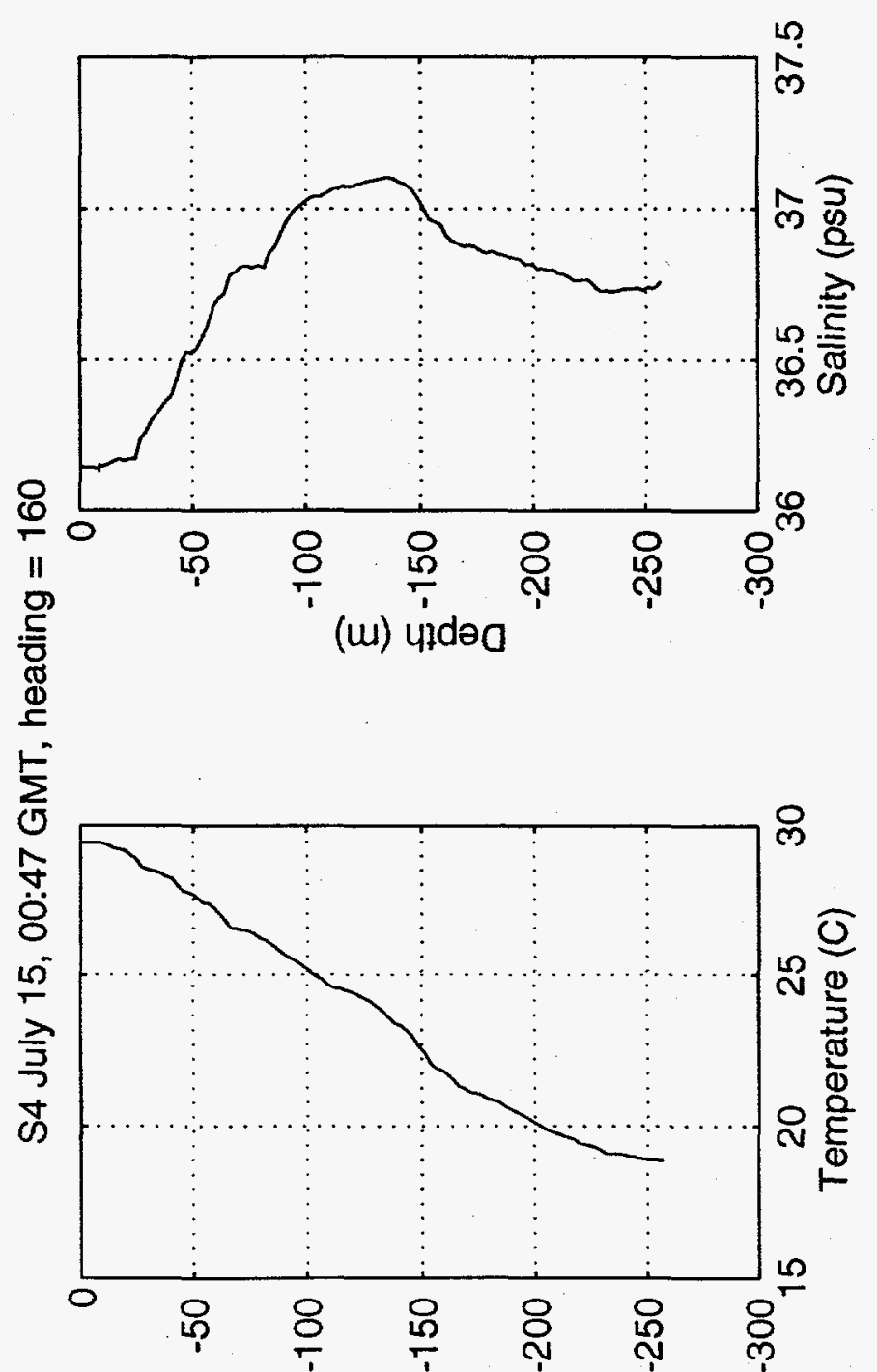

(u) पld dəa

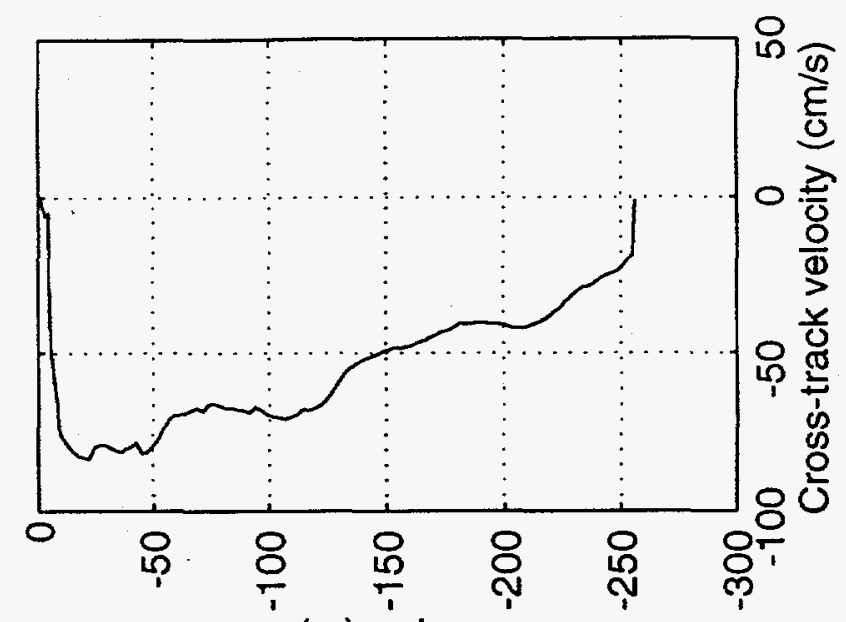

(u) yidəa

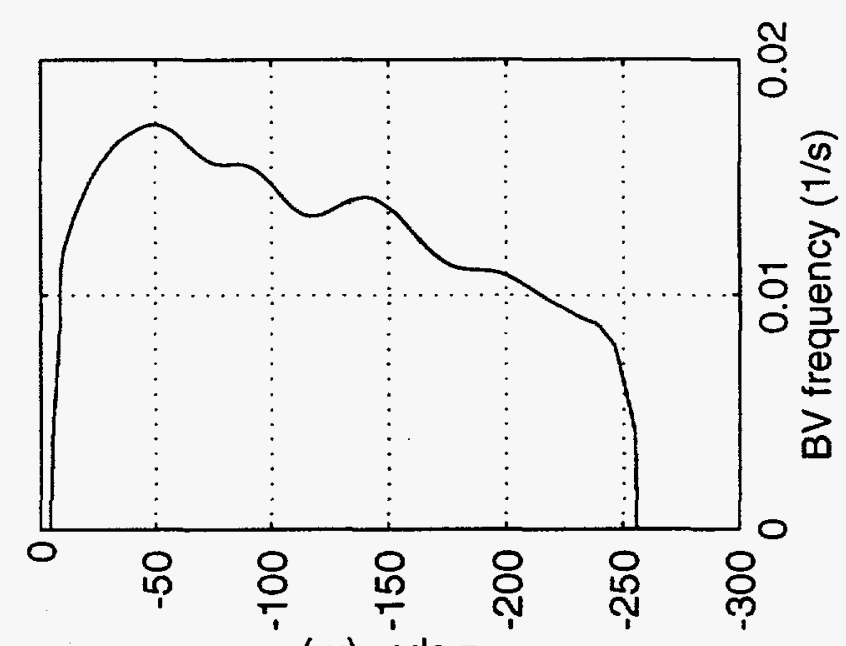

(u) पाdəa

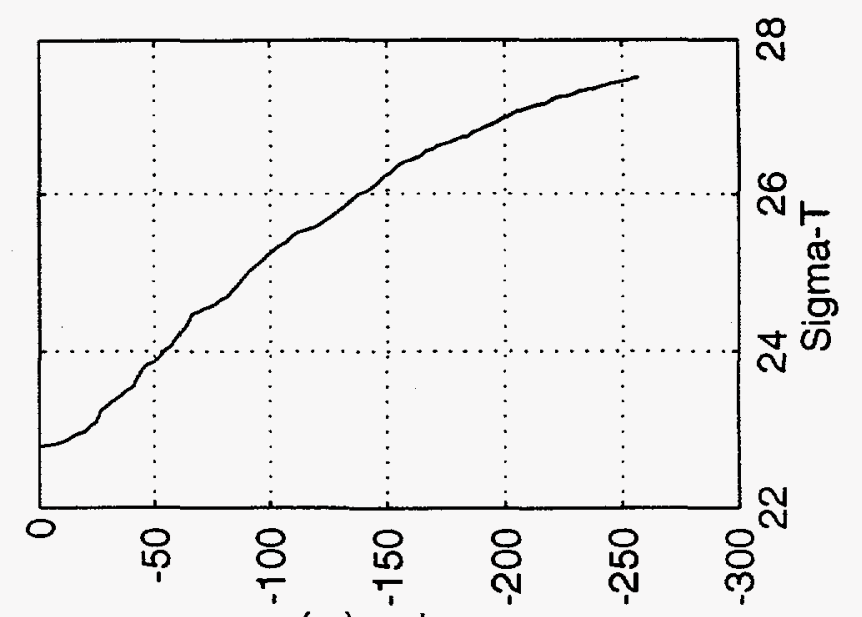

(u) uldəa 


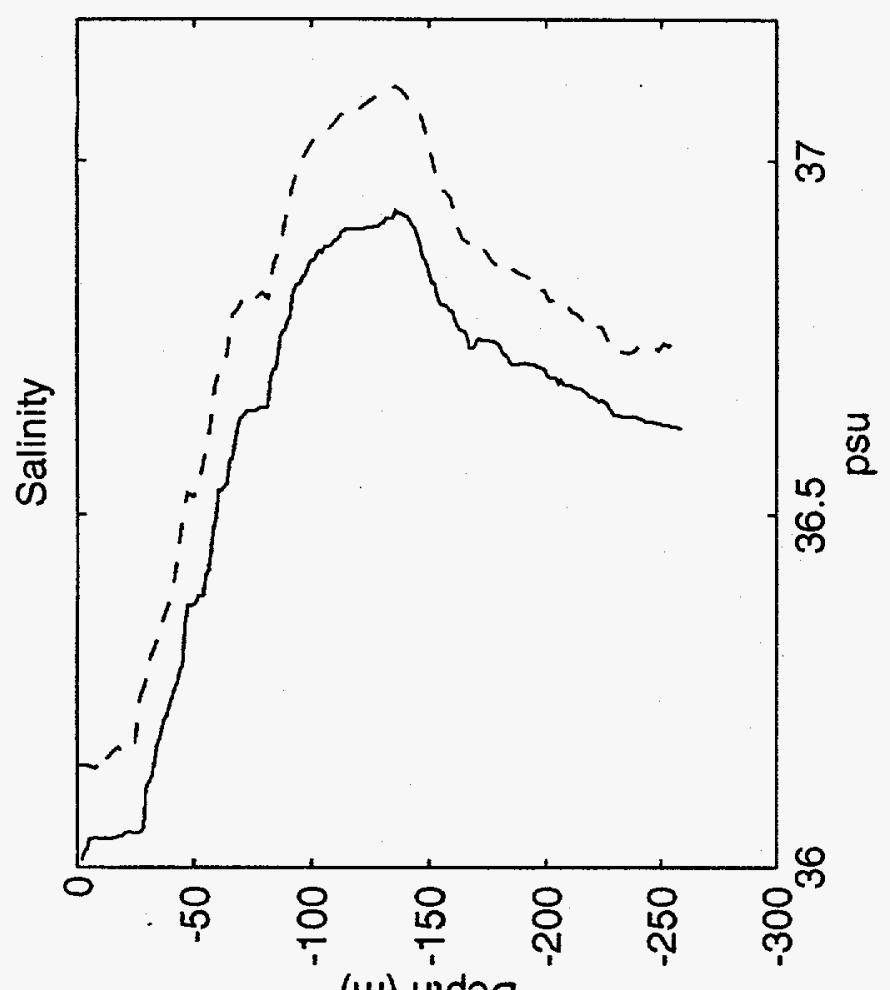

(w) पidəa

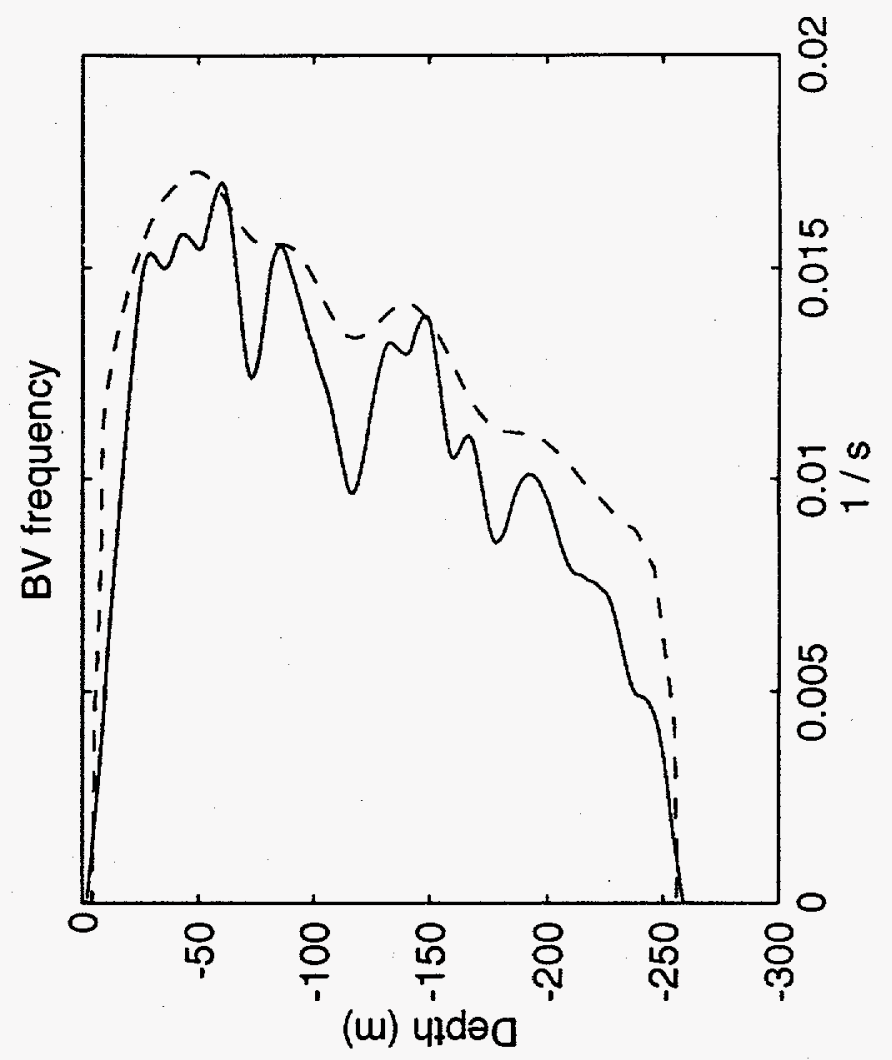

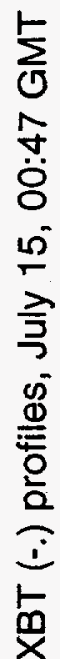

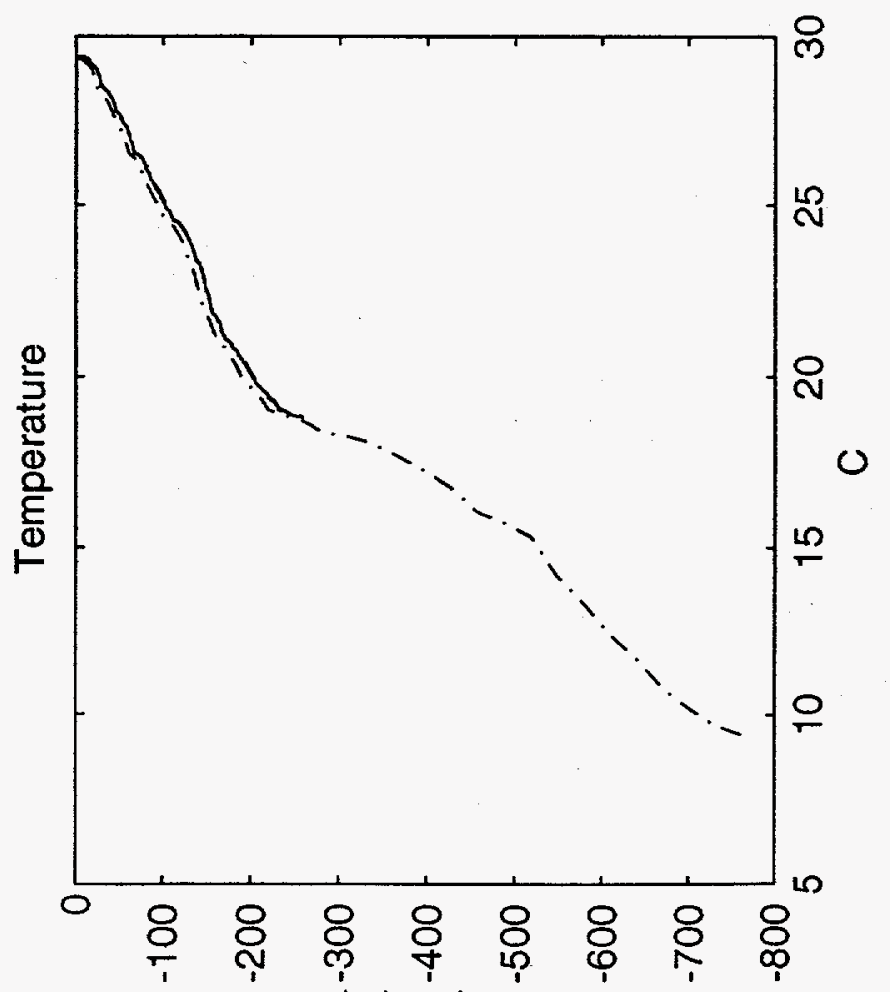

(ui) uाdeg

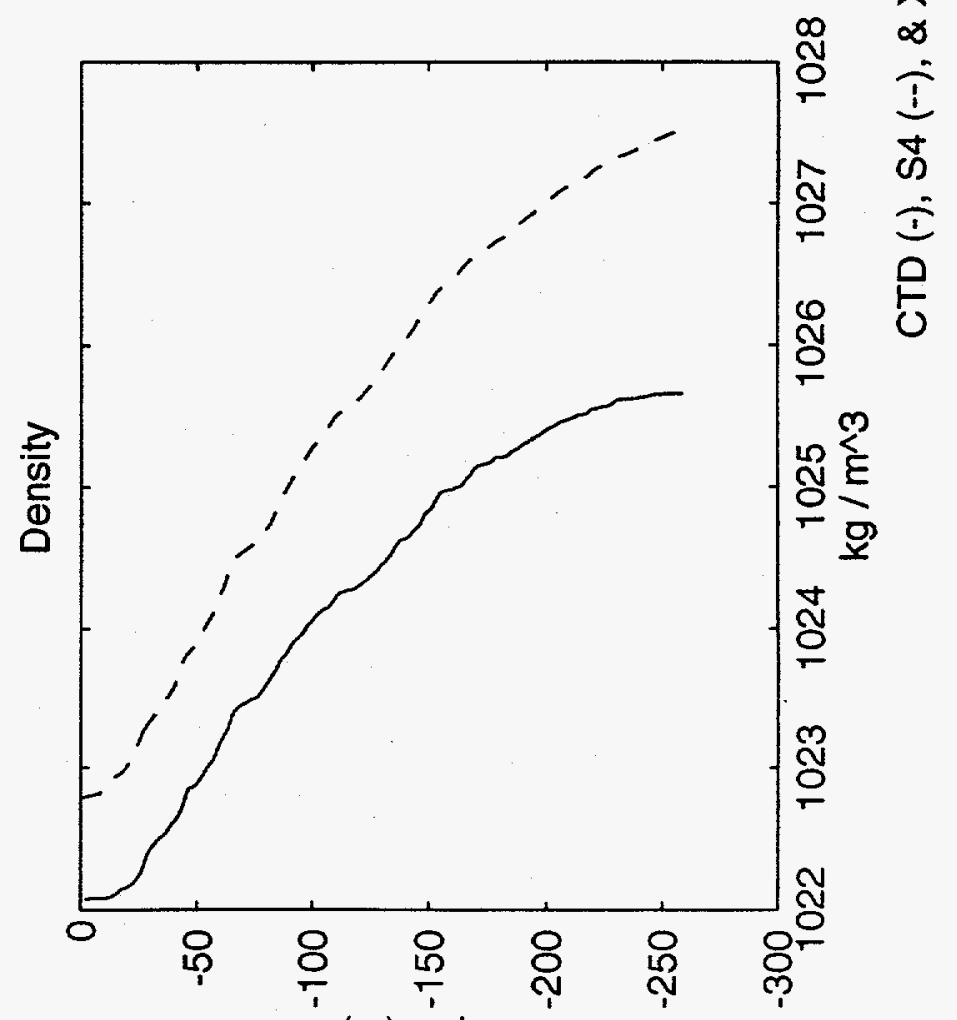

(u) प1də0 

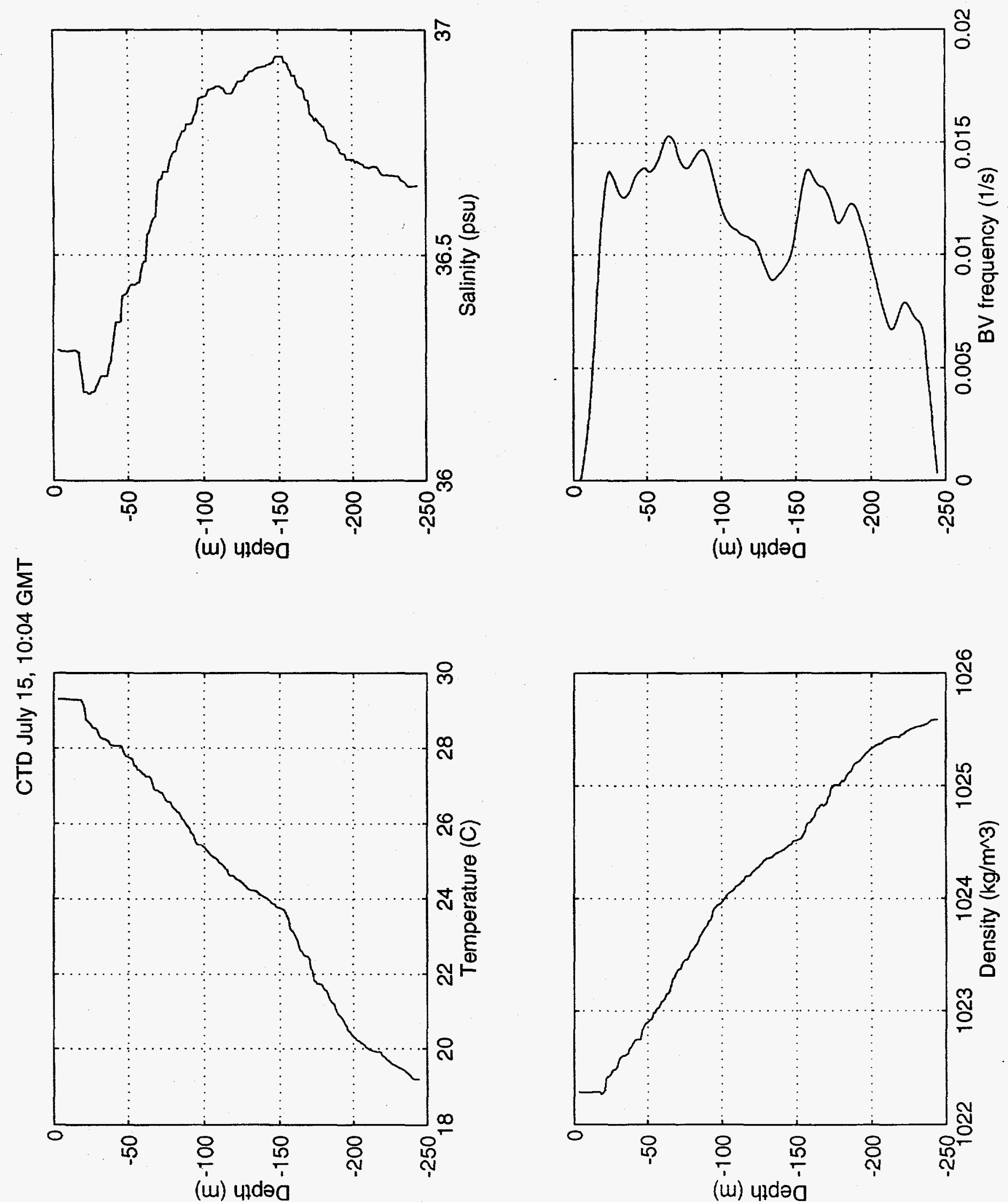

(w) yıdea 


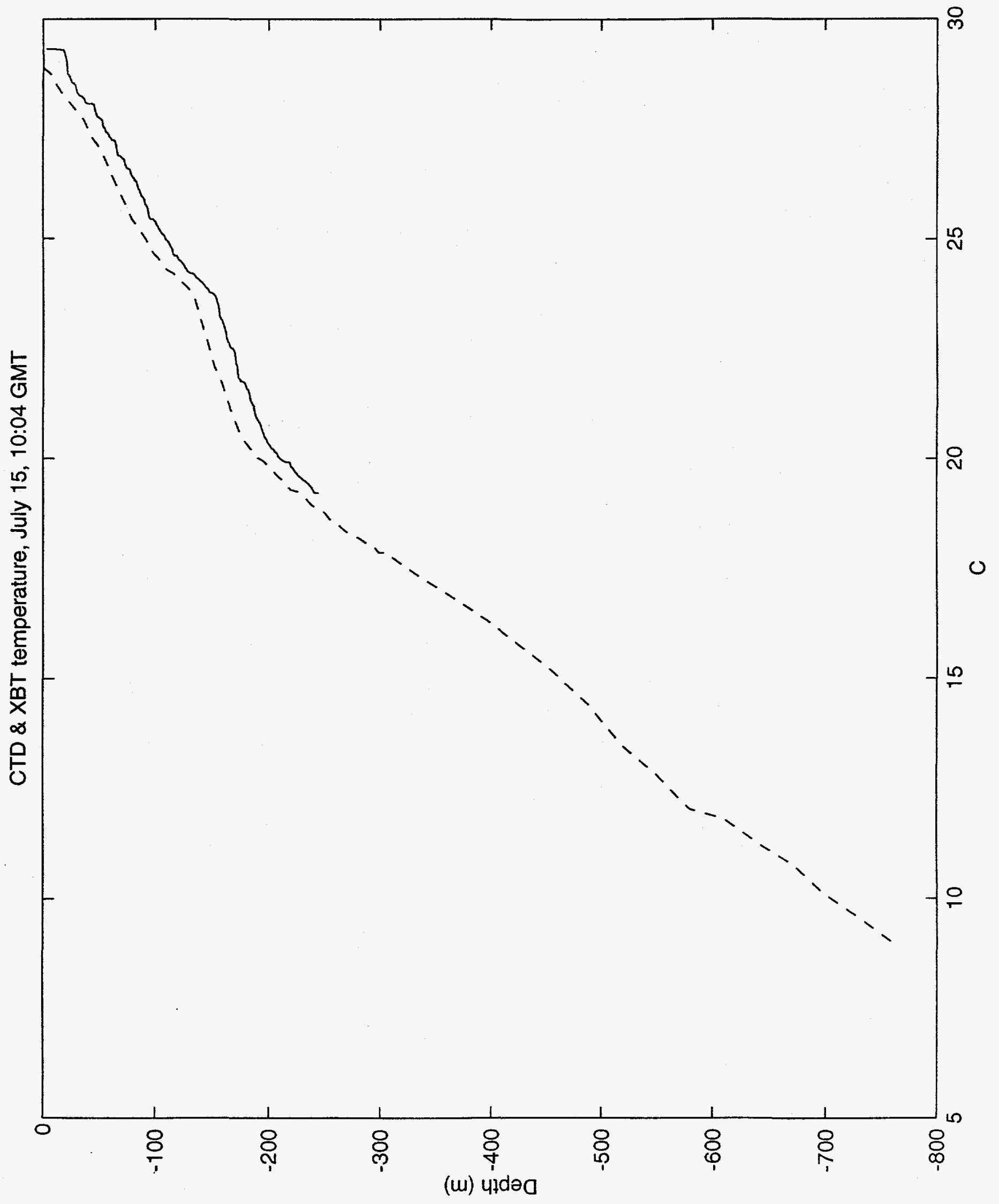



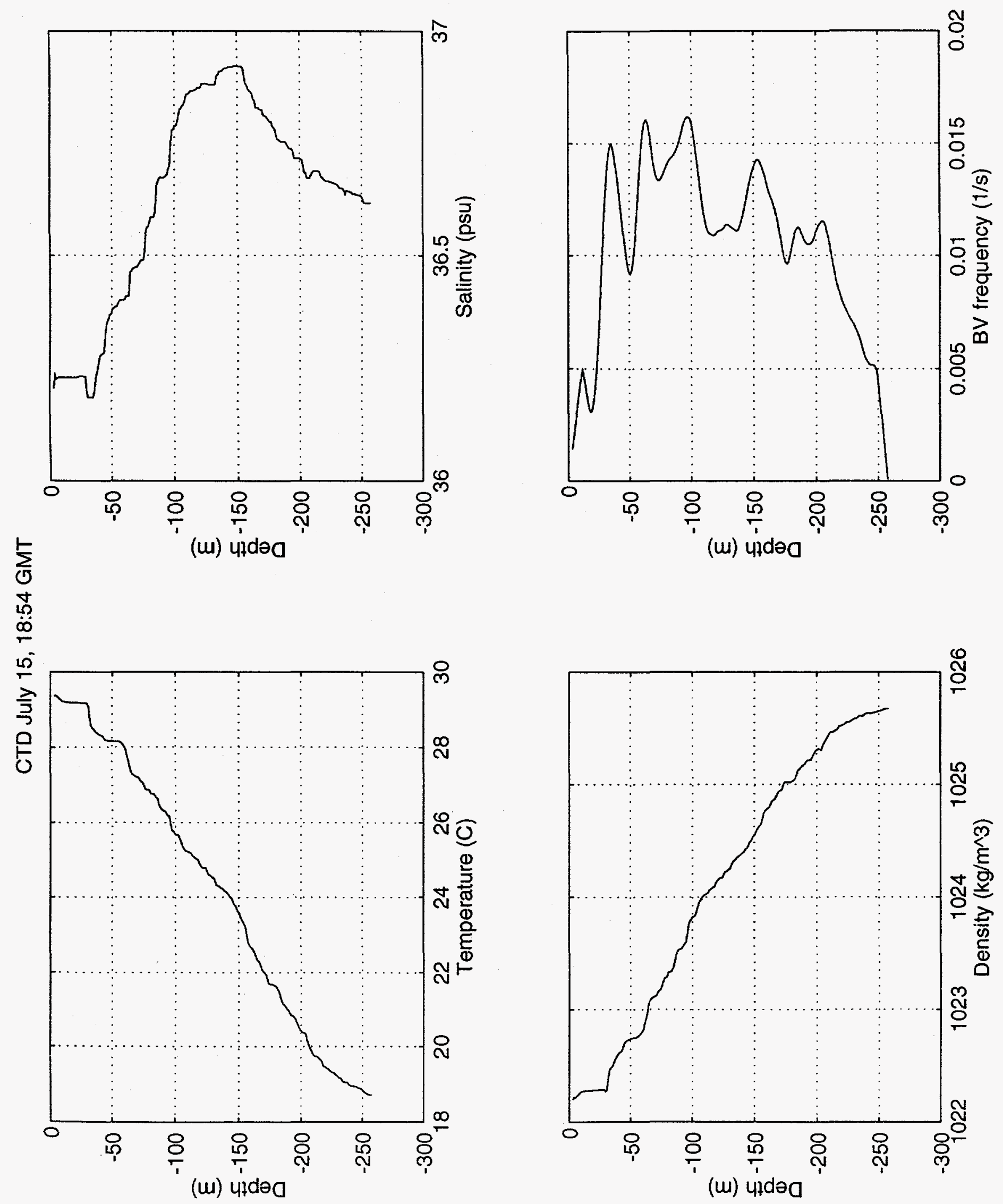


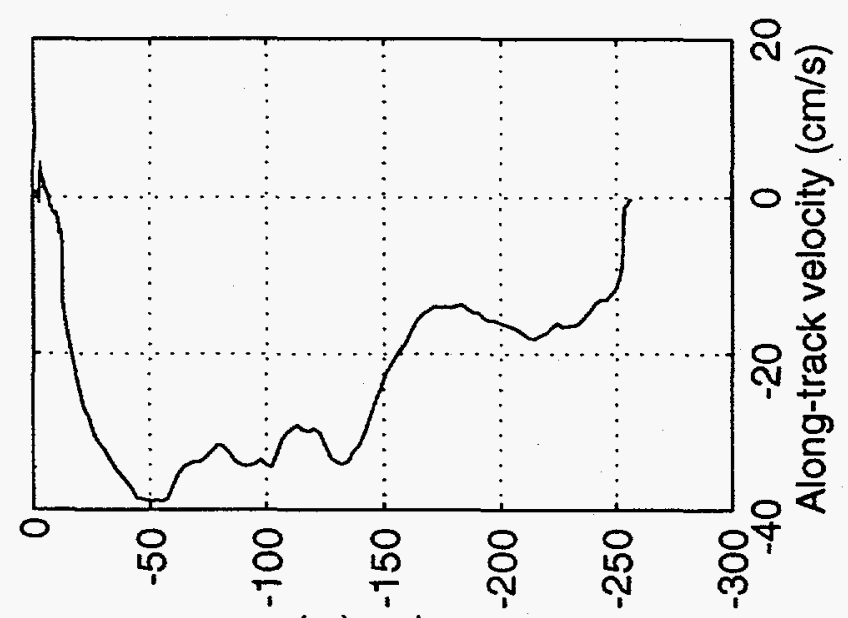

(u) uाdəo
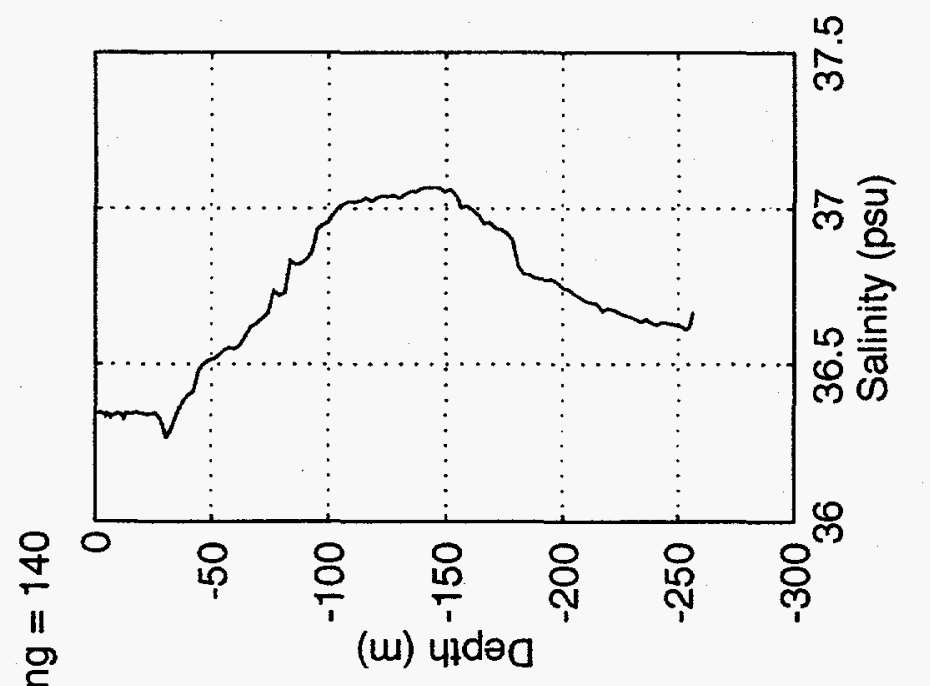

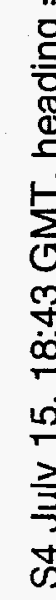

列

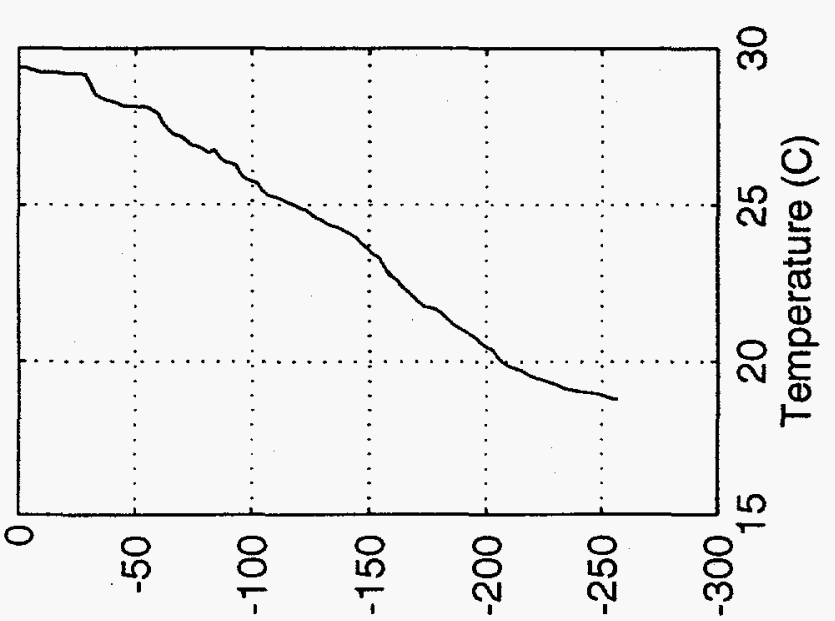

(ui) yıdəa

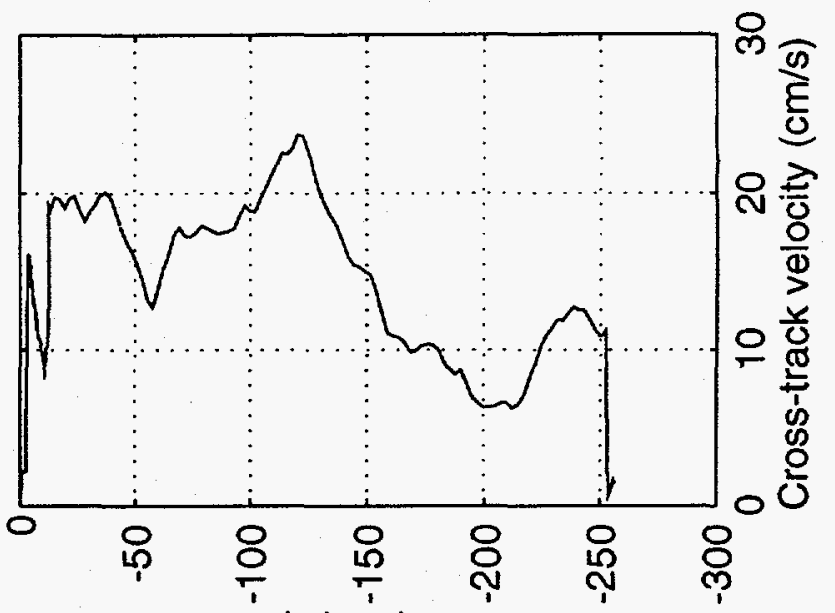

(w) utdea

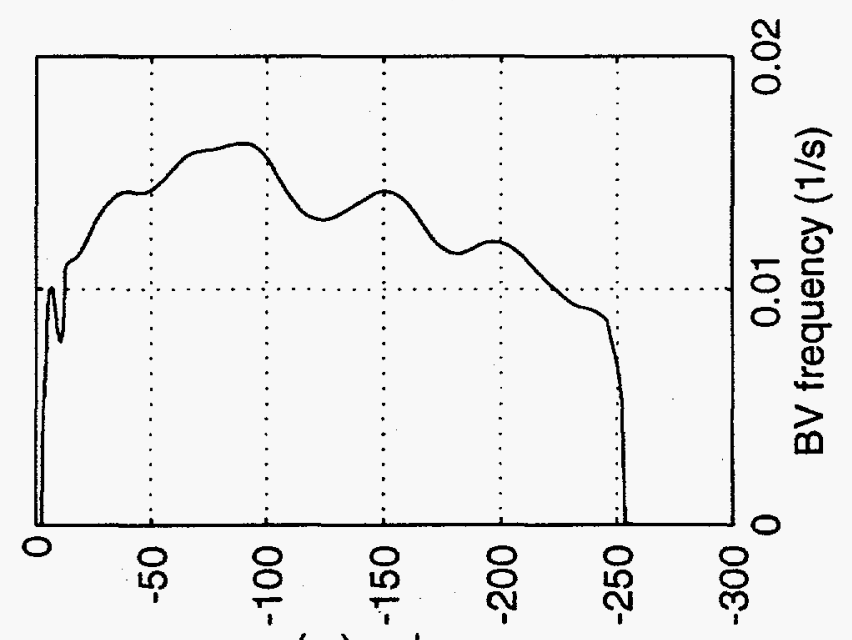

(w) uldeo

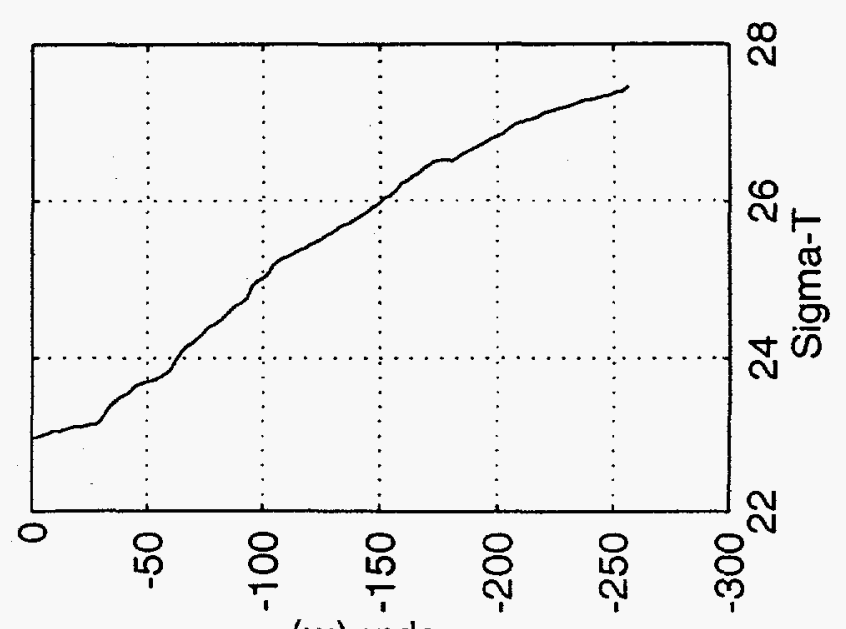

(w) undeo 

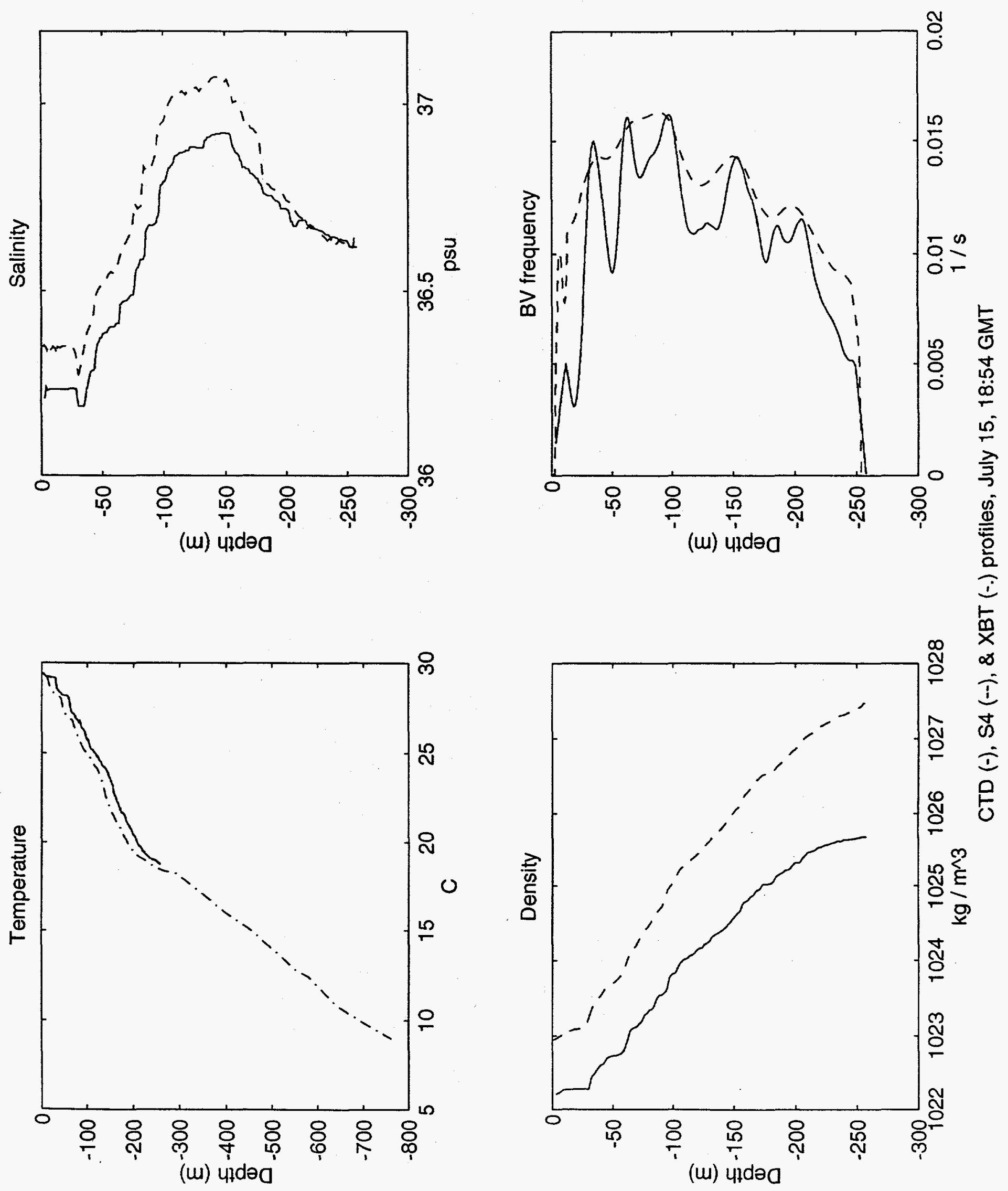


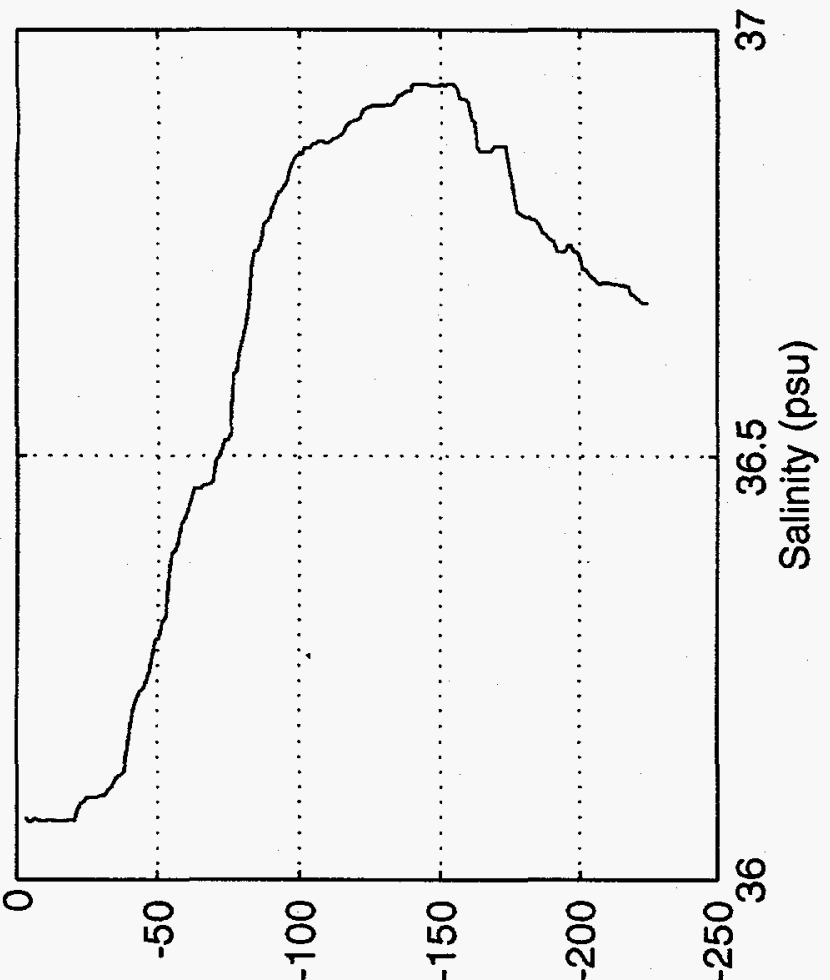

(ii) पld dəa

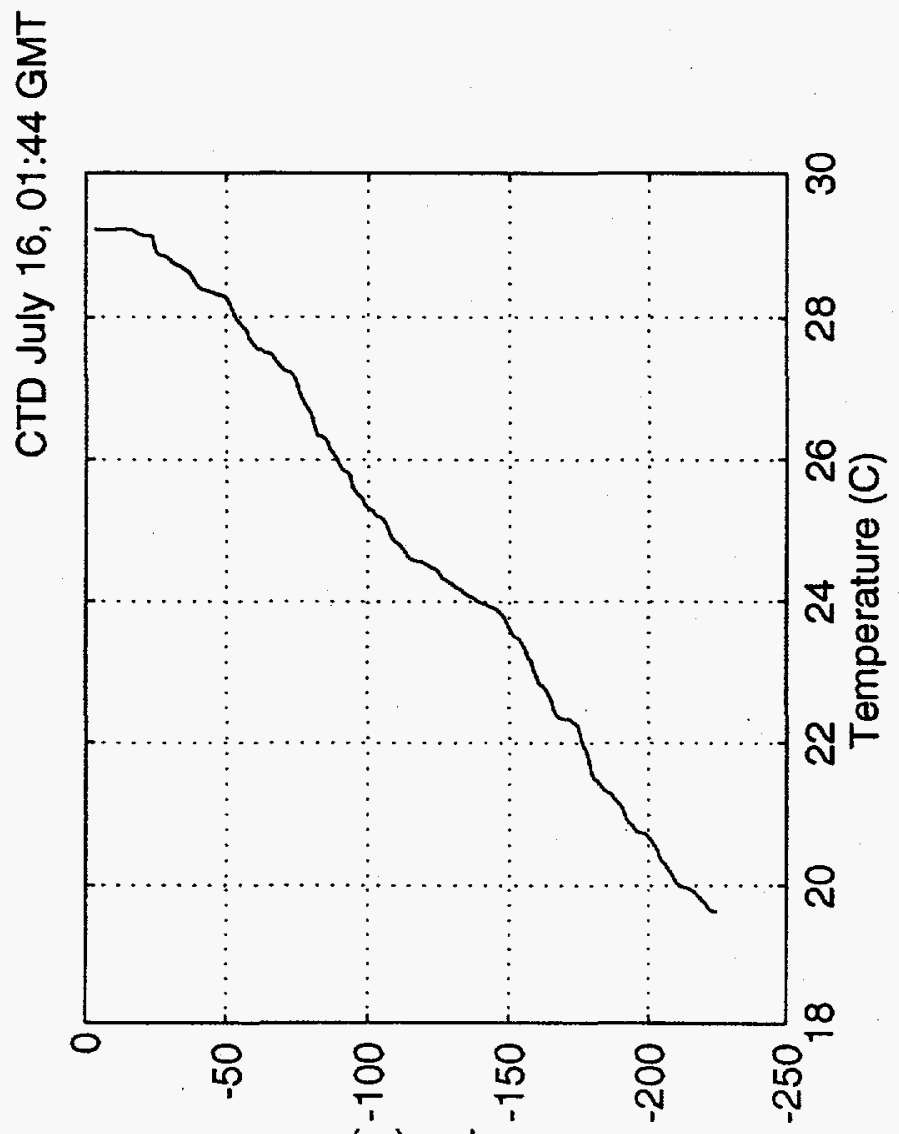

(iv) uldəa

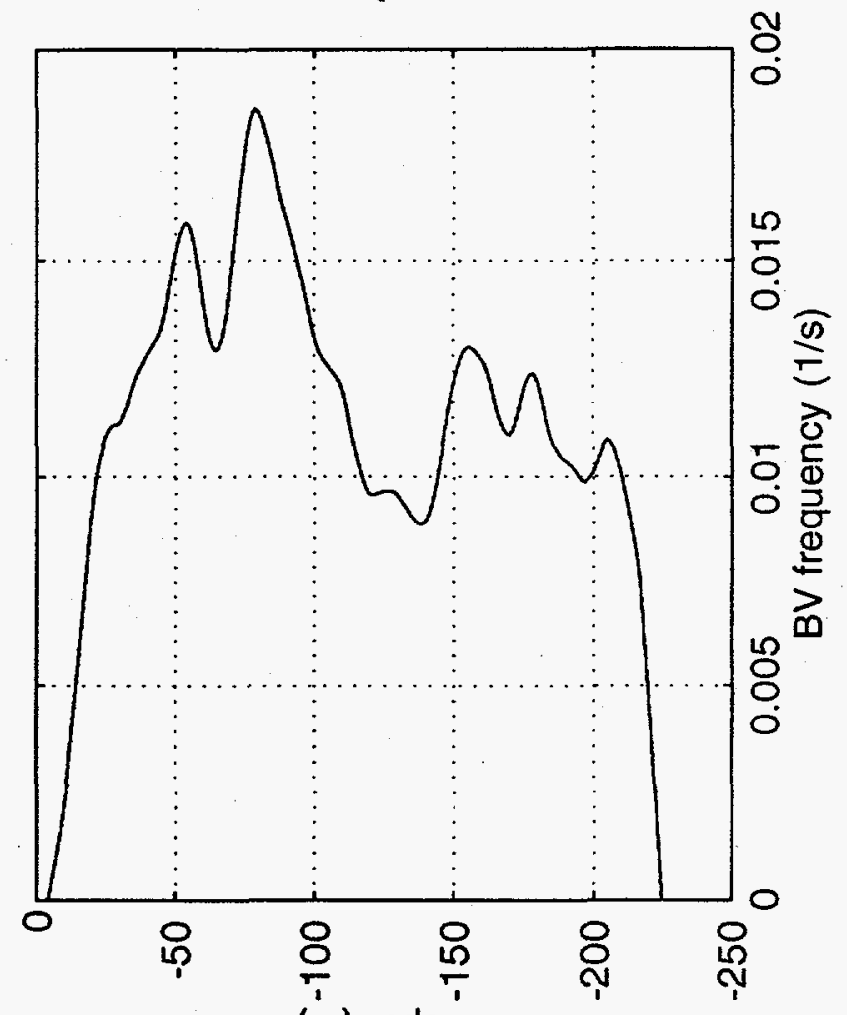

(w) updəa

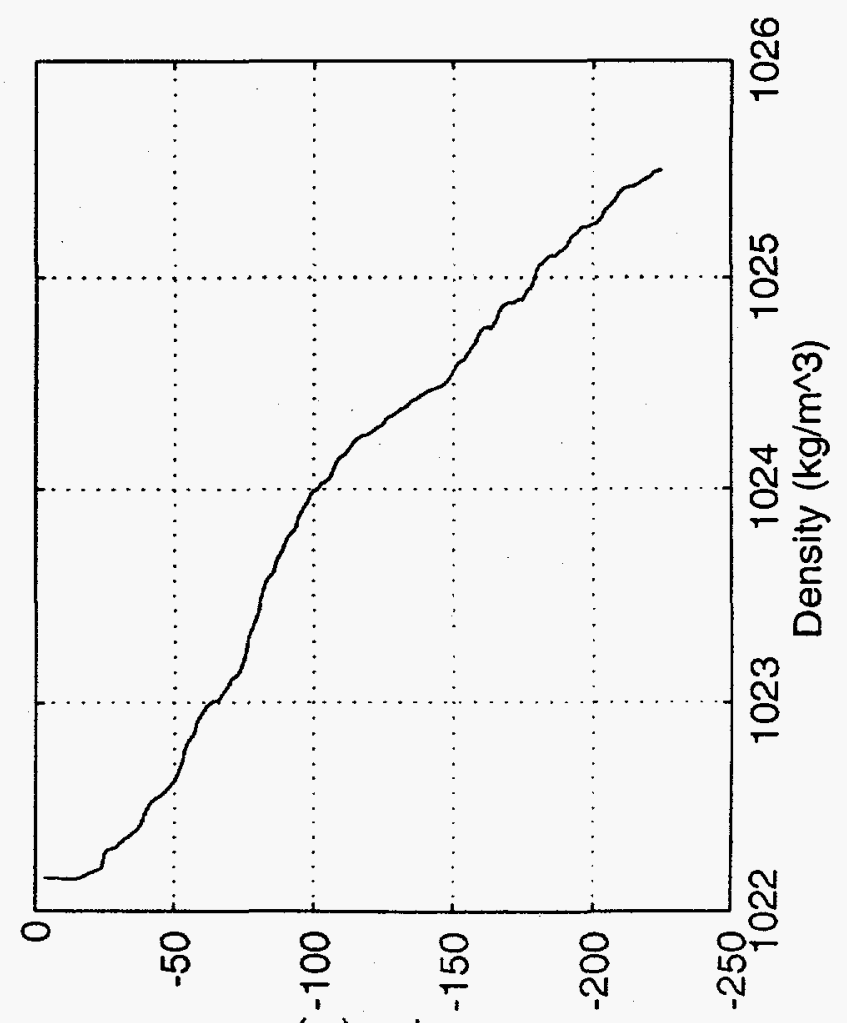

(w) पldəव 


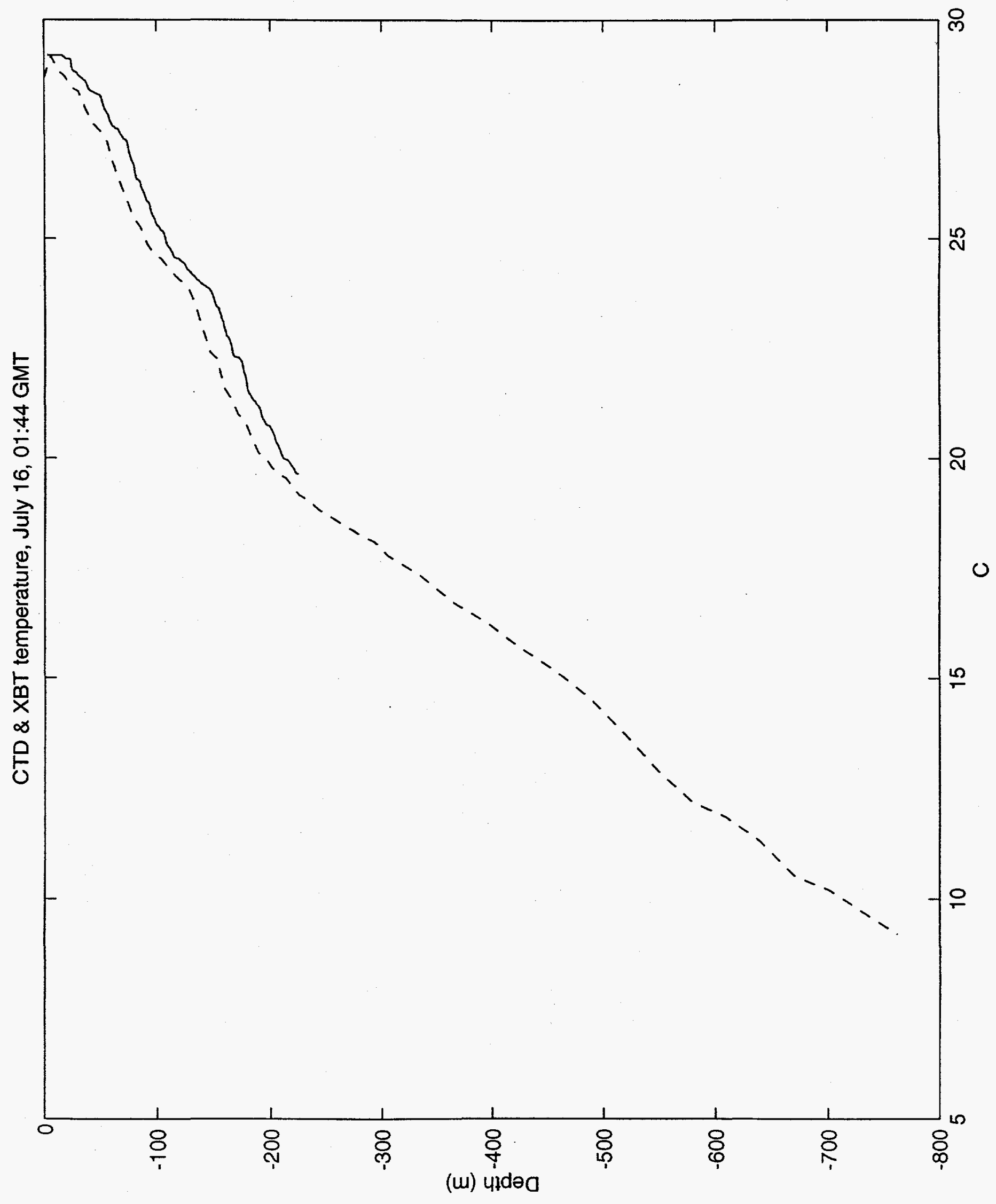



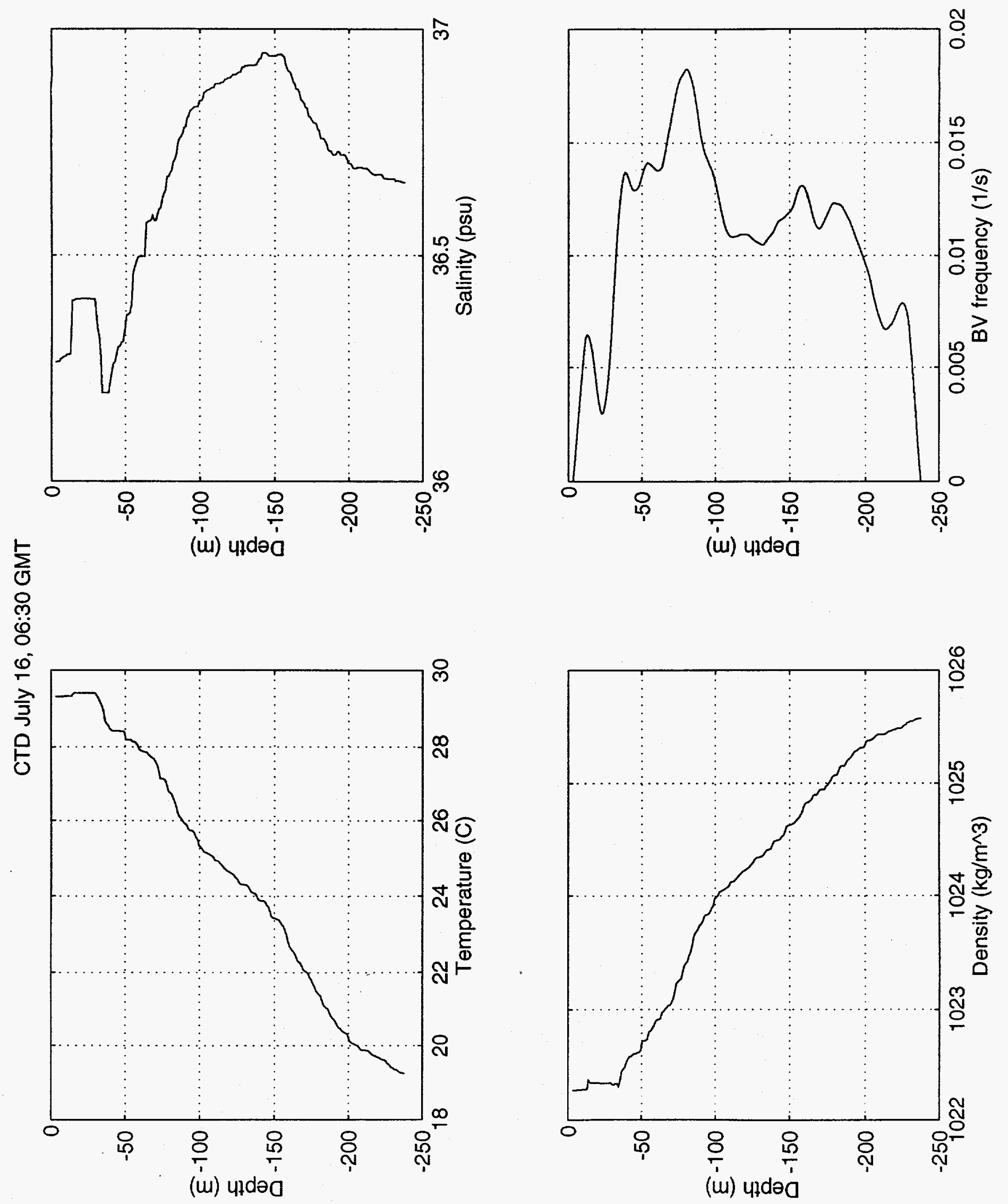


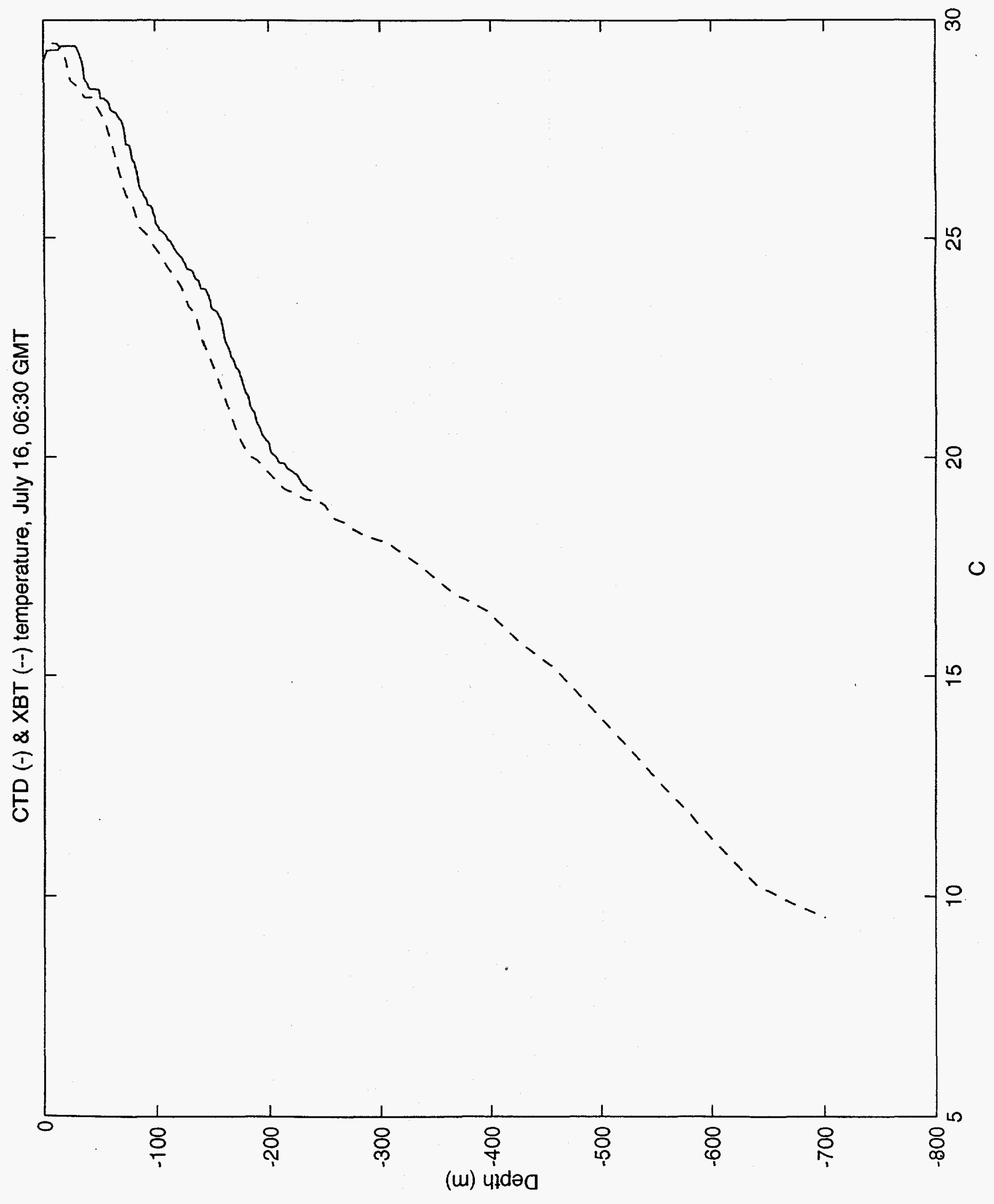



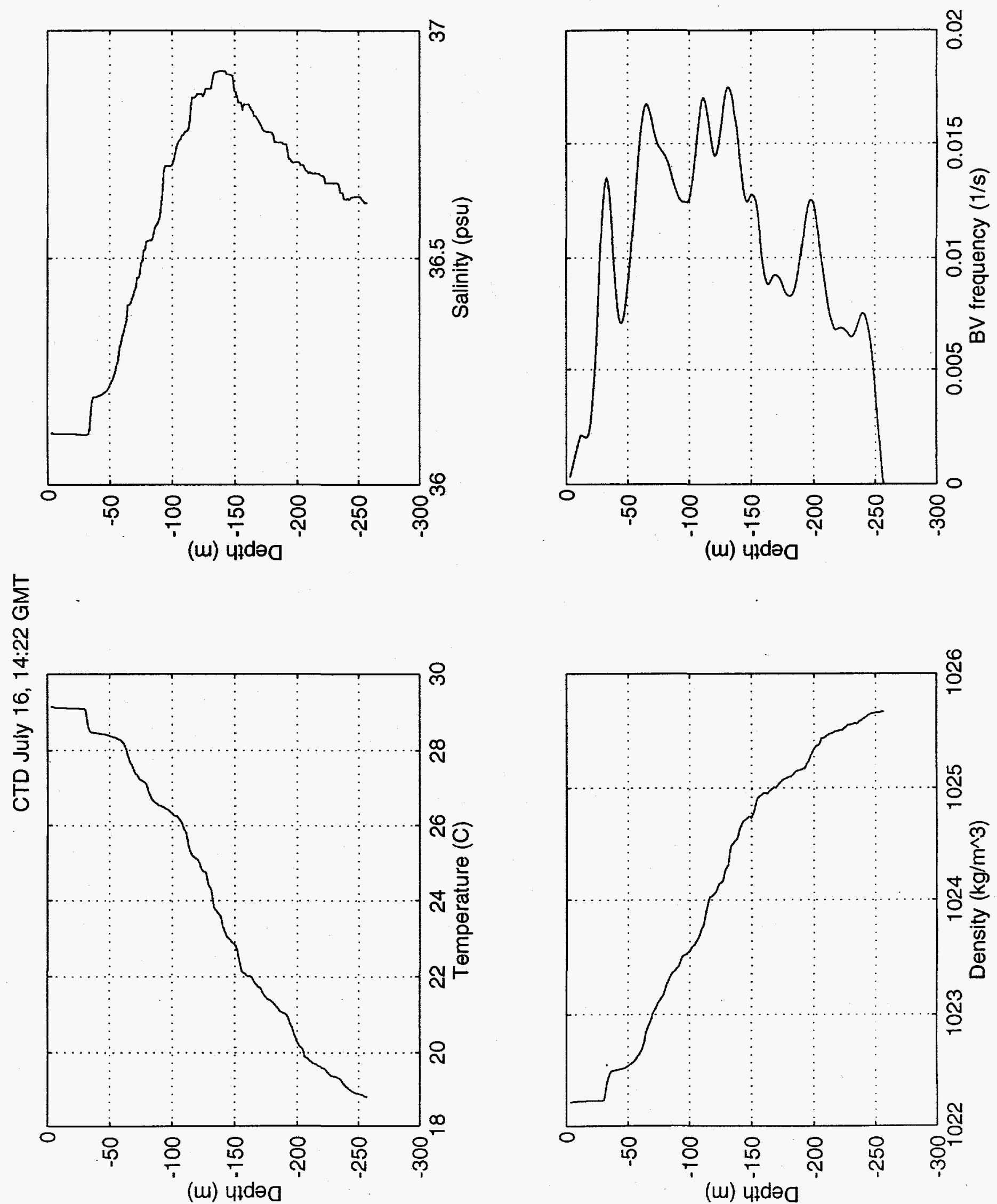


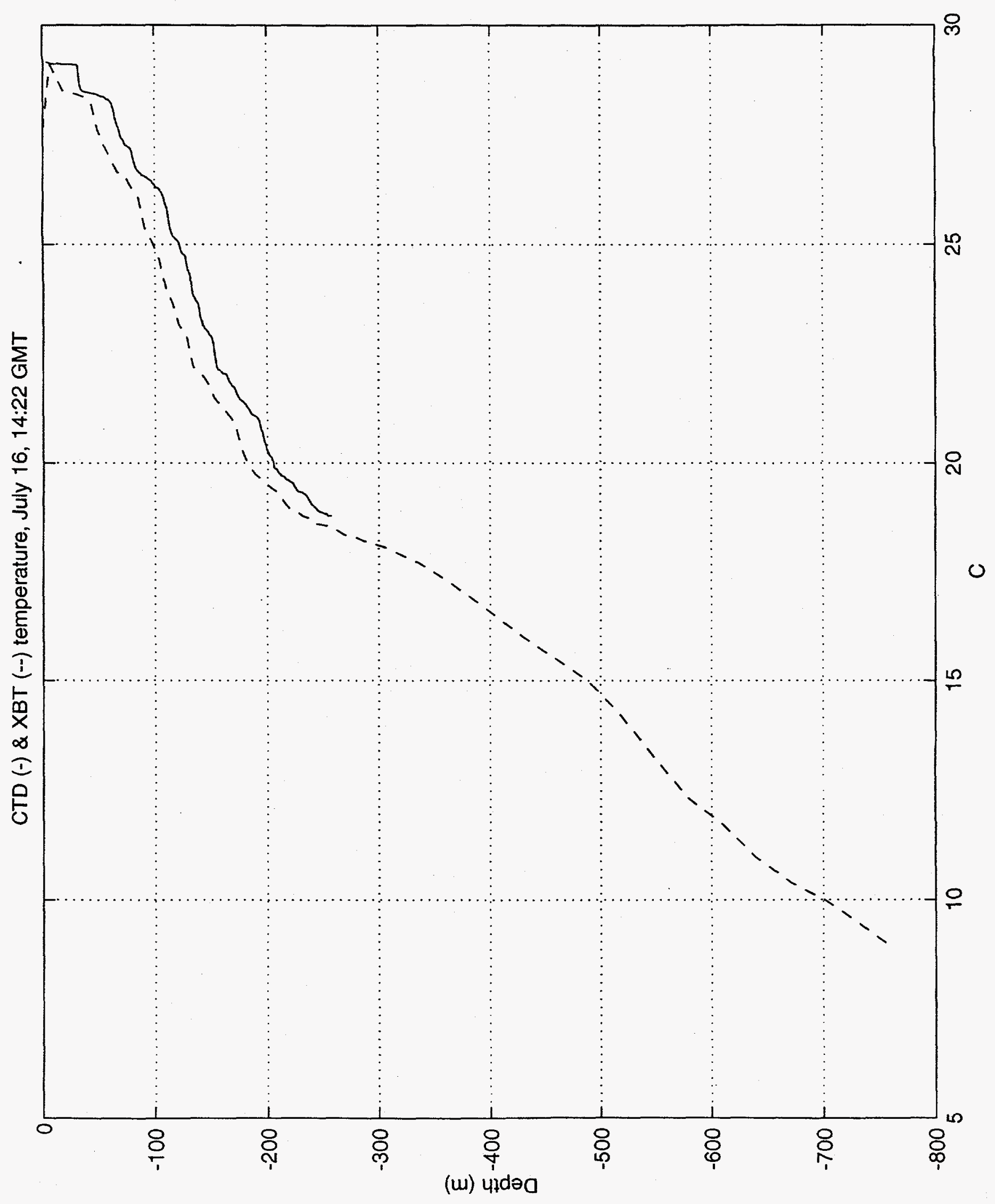


CTD deep July 16, 18:22 GMT
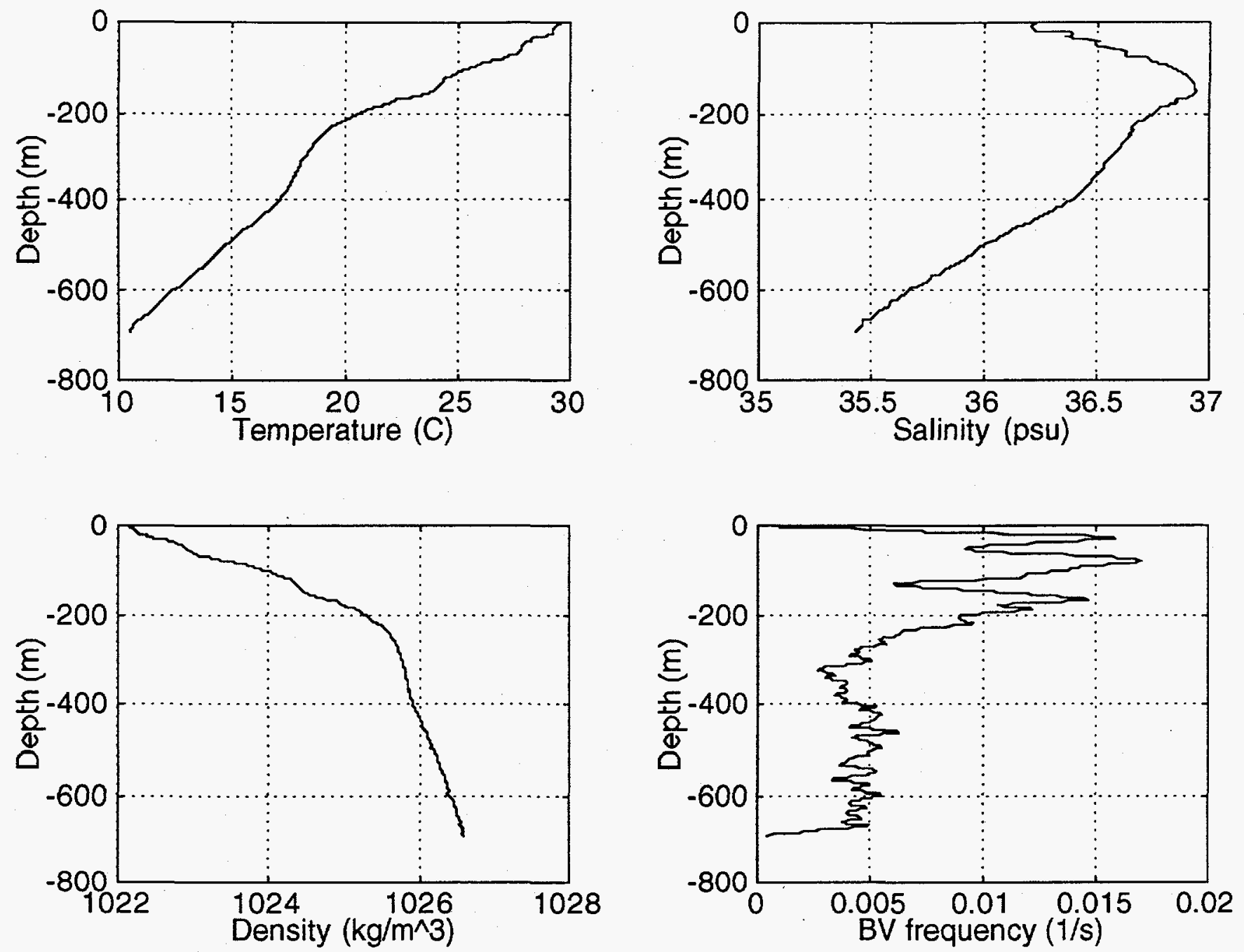
S4 deep, July $16,18: 22$ GMT, heading $=315$
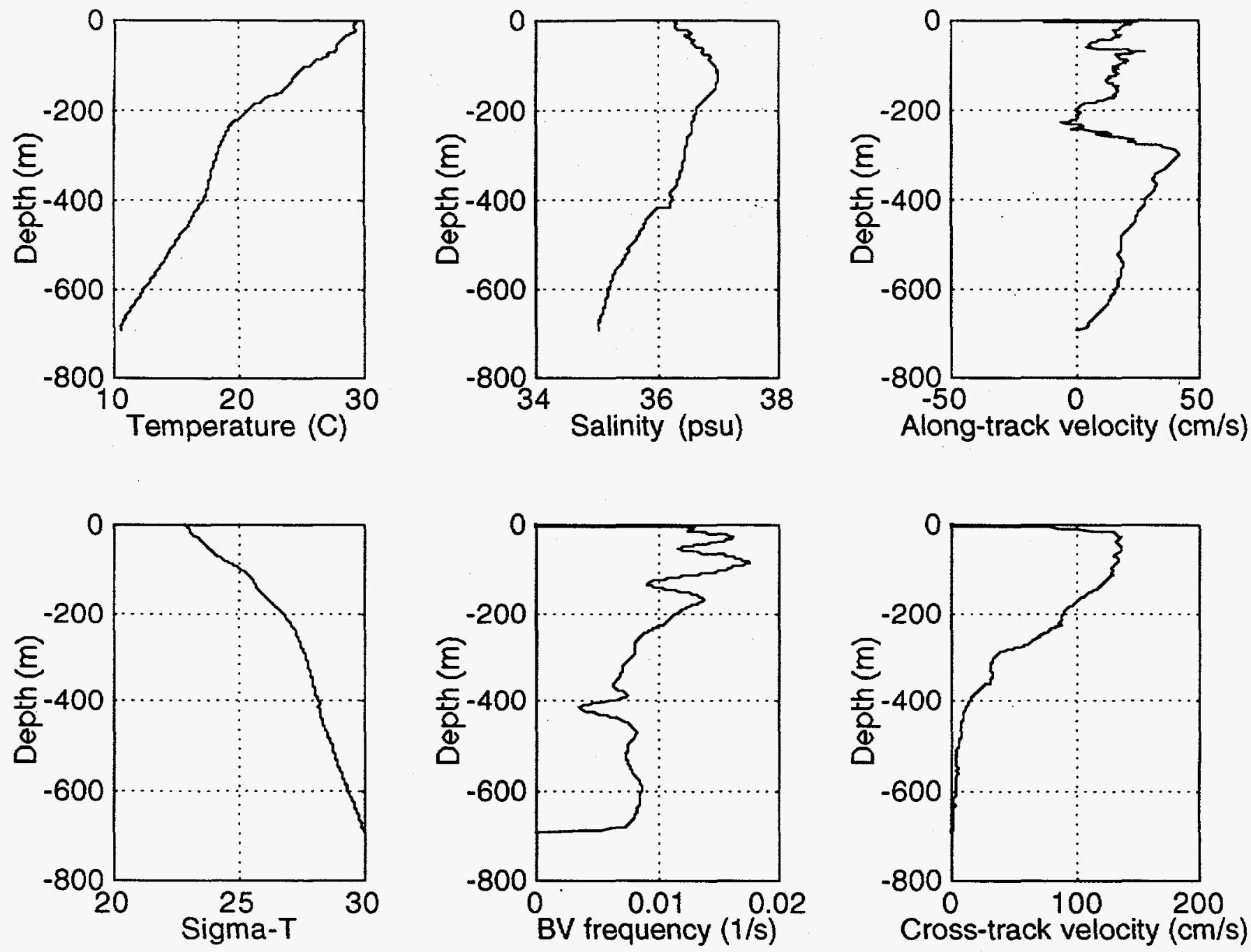
CTD (-), S4 (--), \& XBT (-.) profiles, July 16, 18:22 GMT
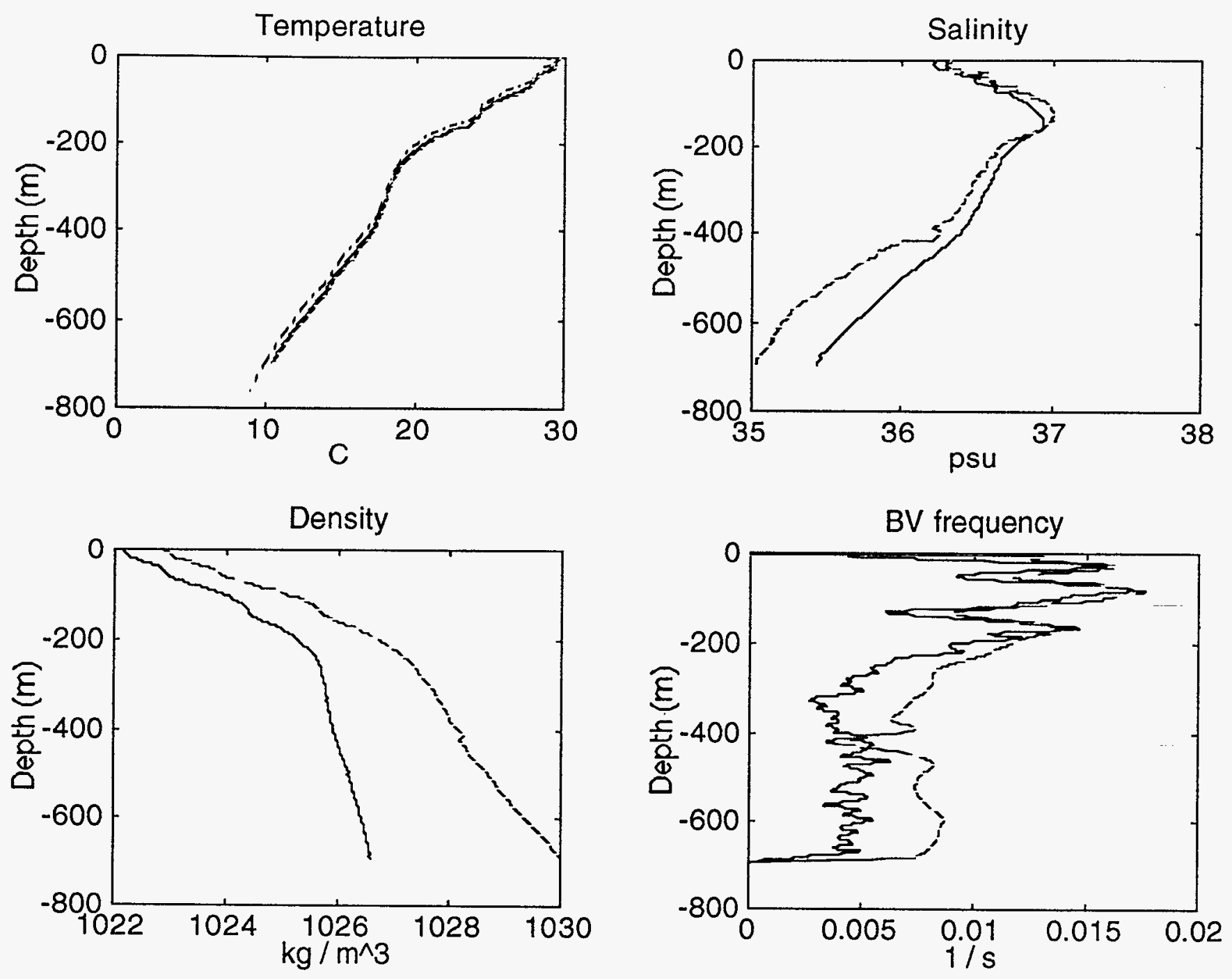

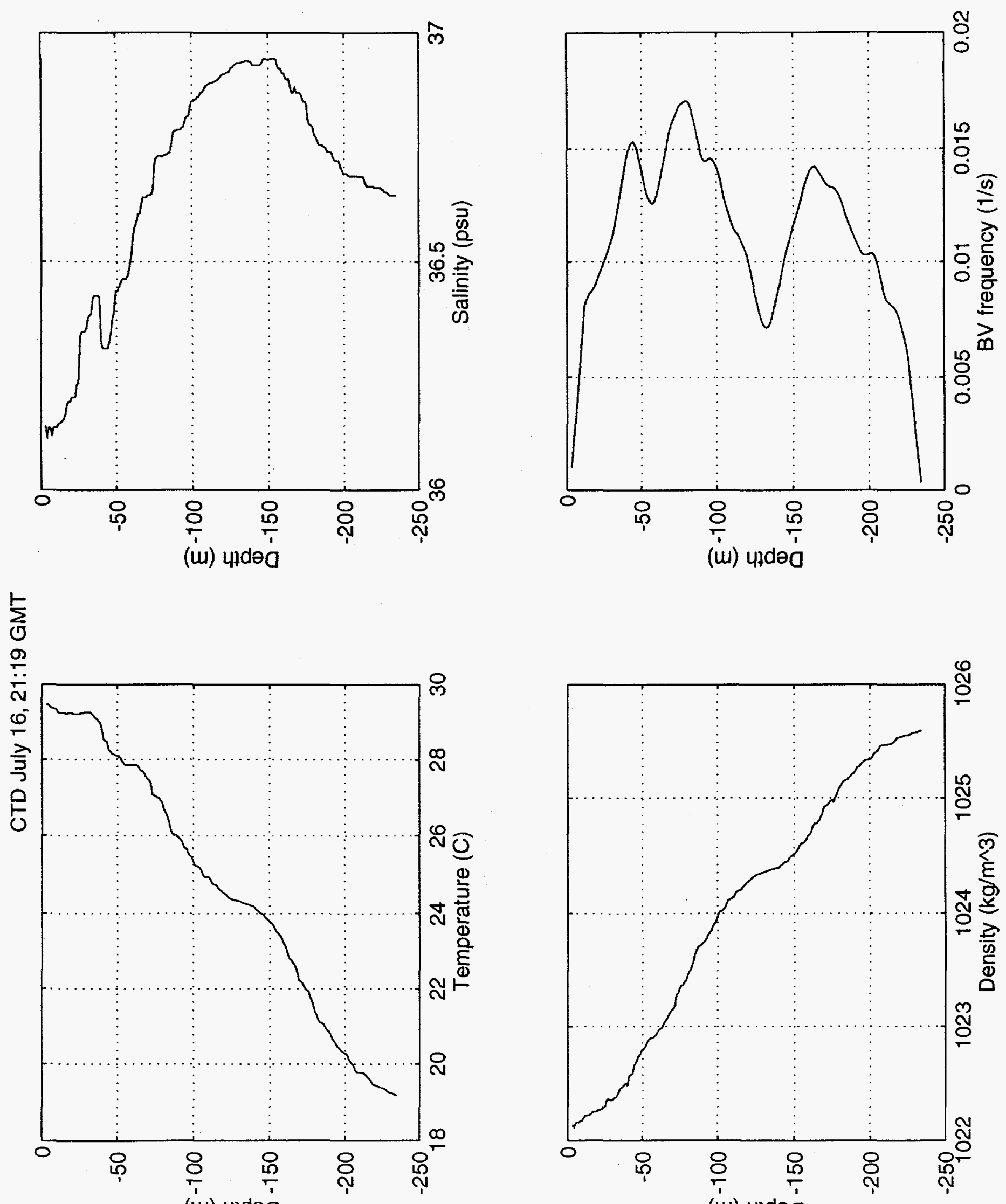

(u) utdaO

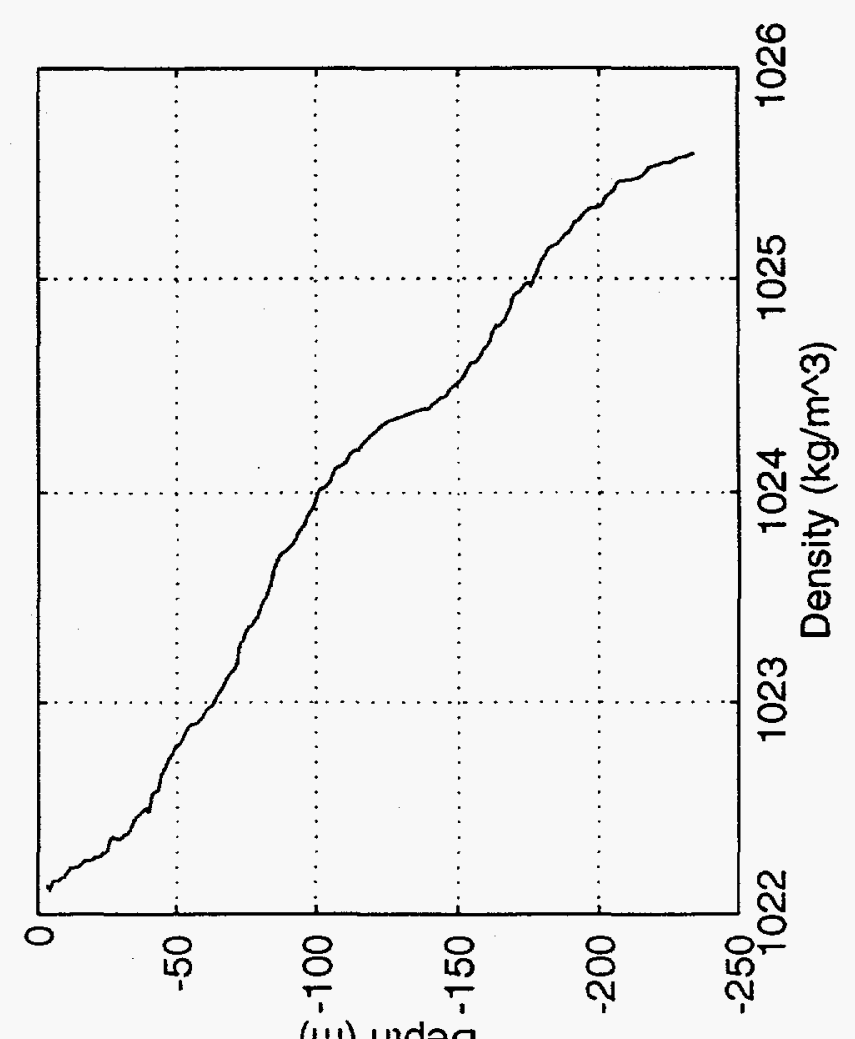

(ii) undea 


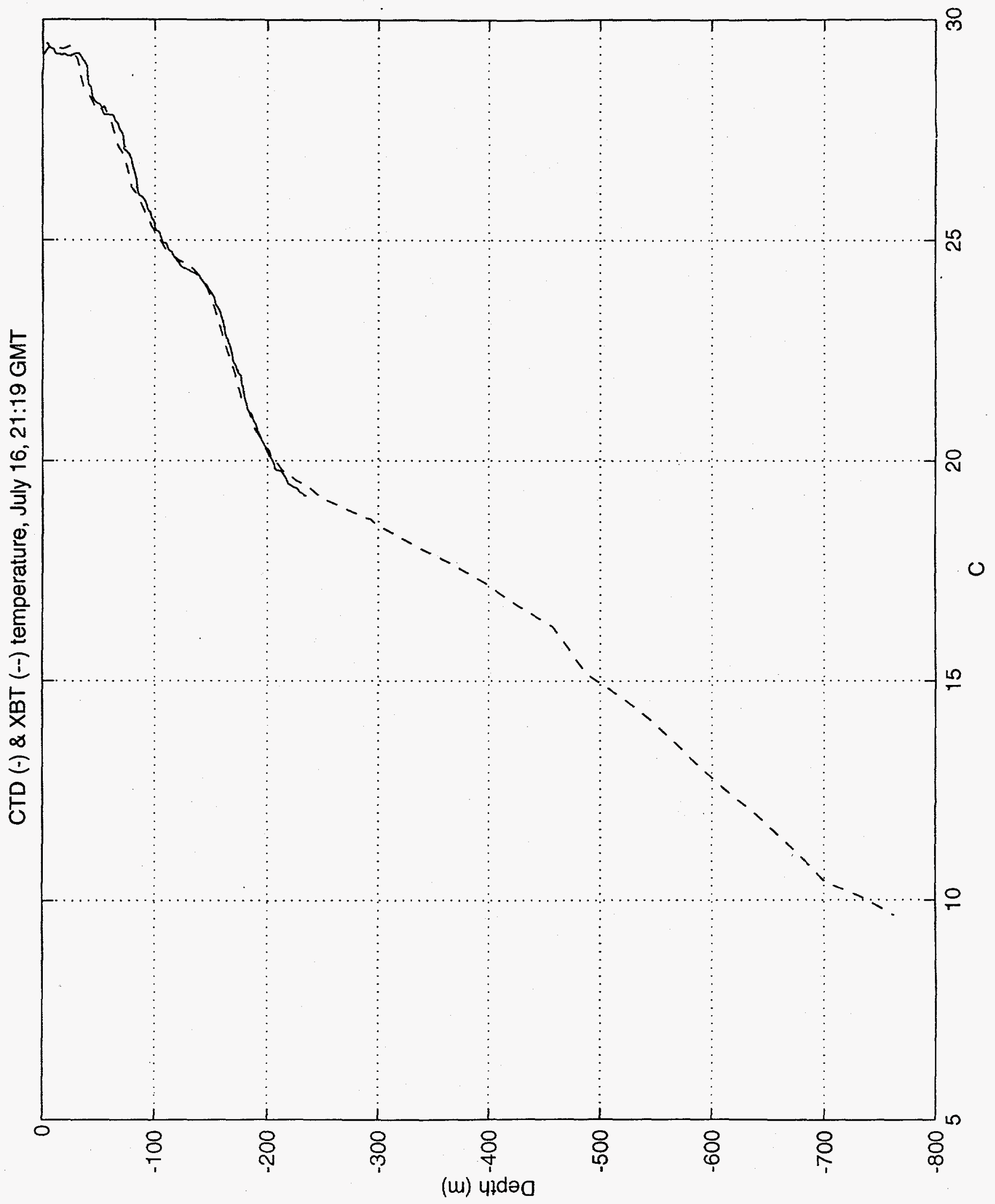



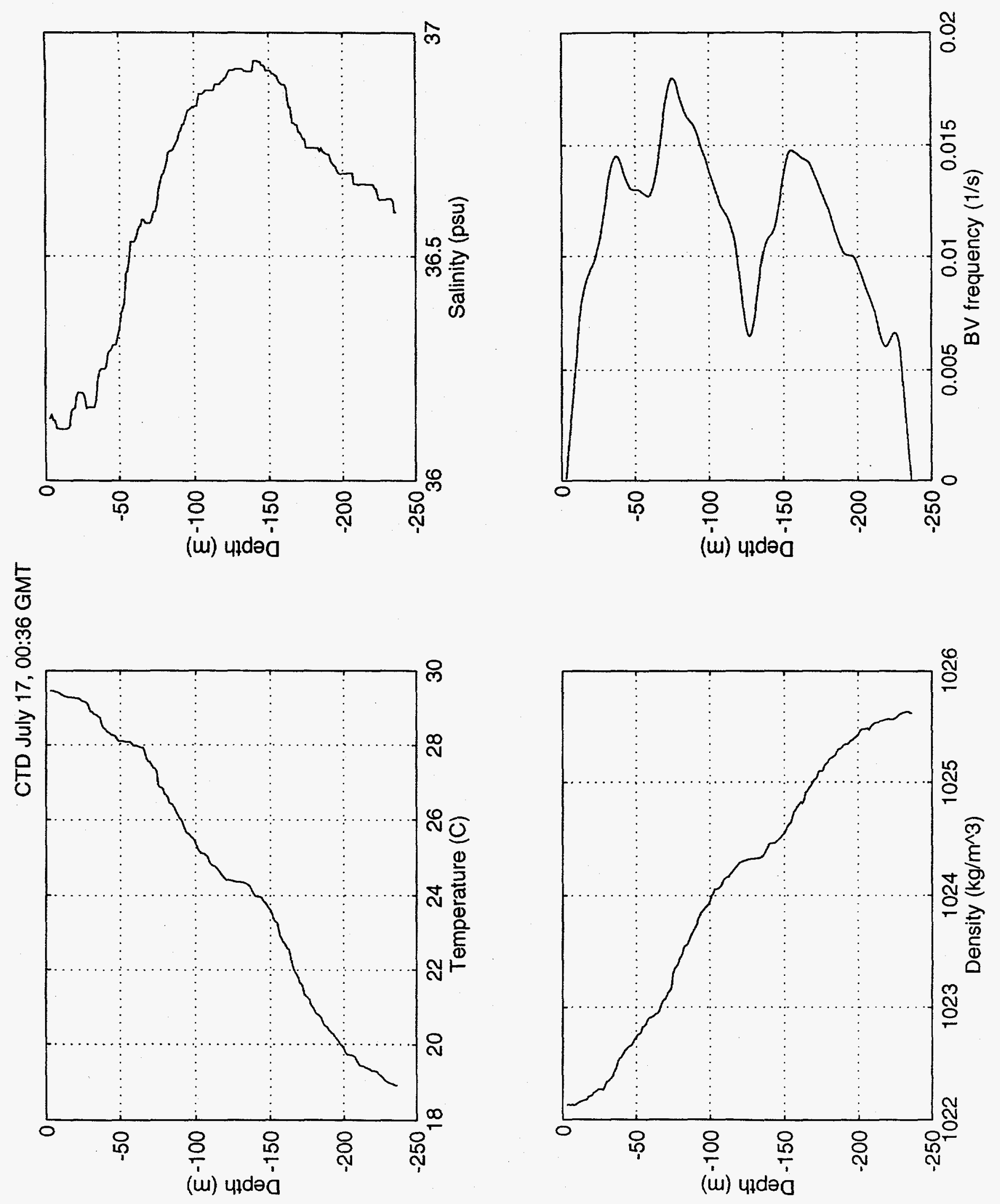


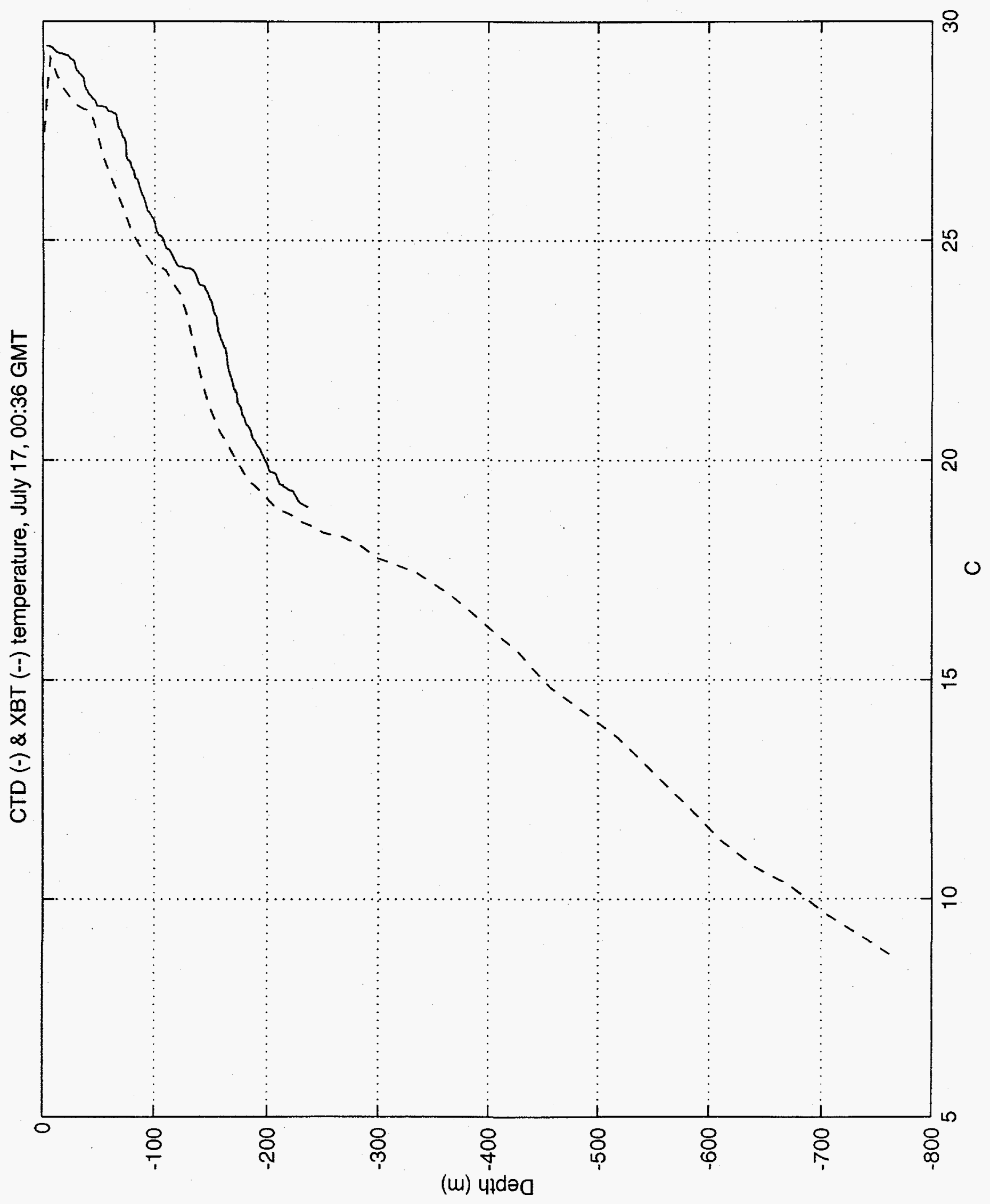



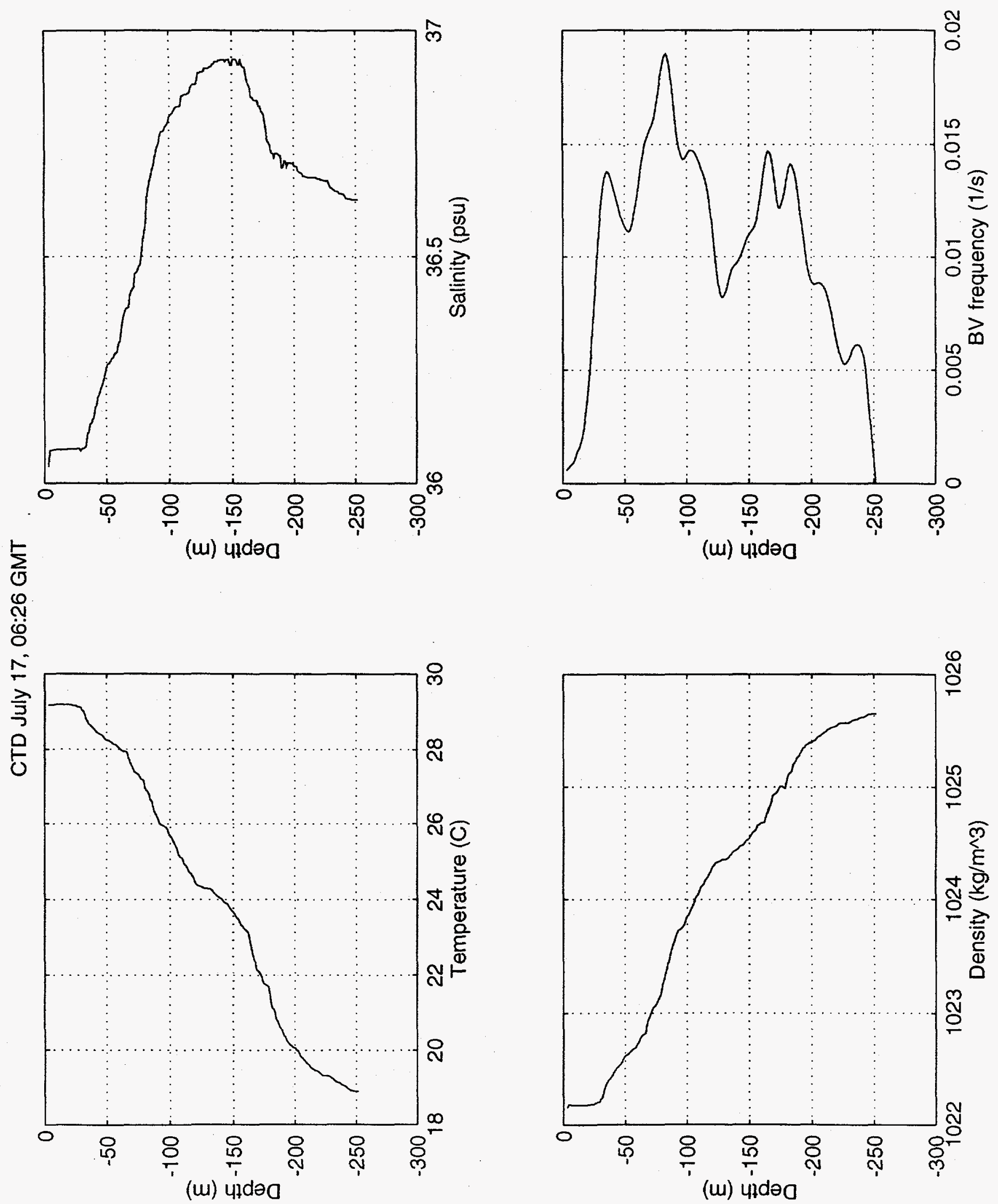


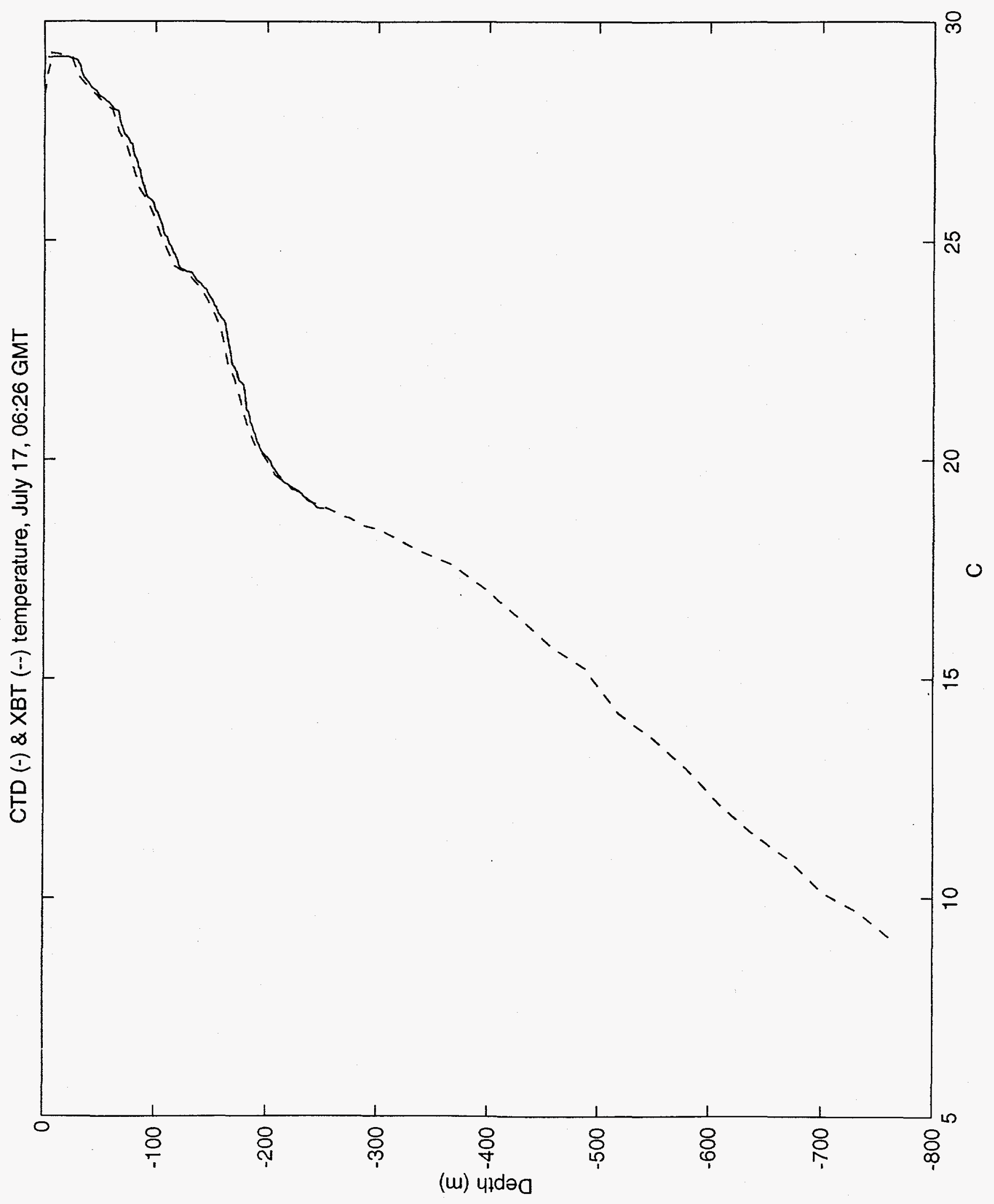


APPENDIX 3 

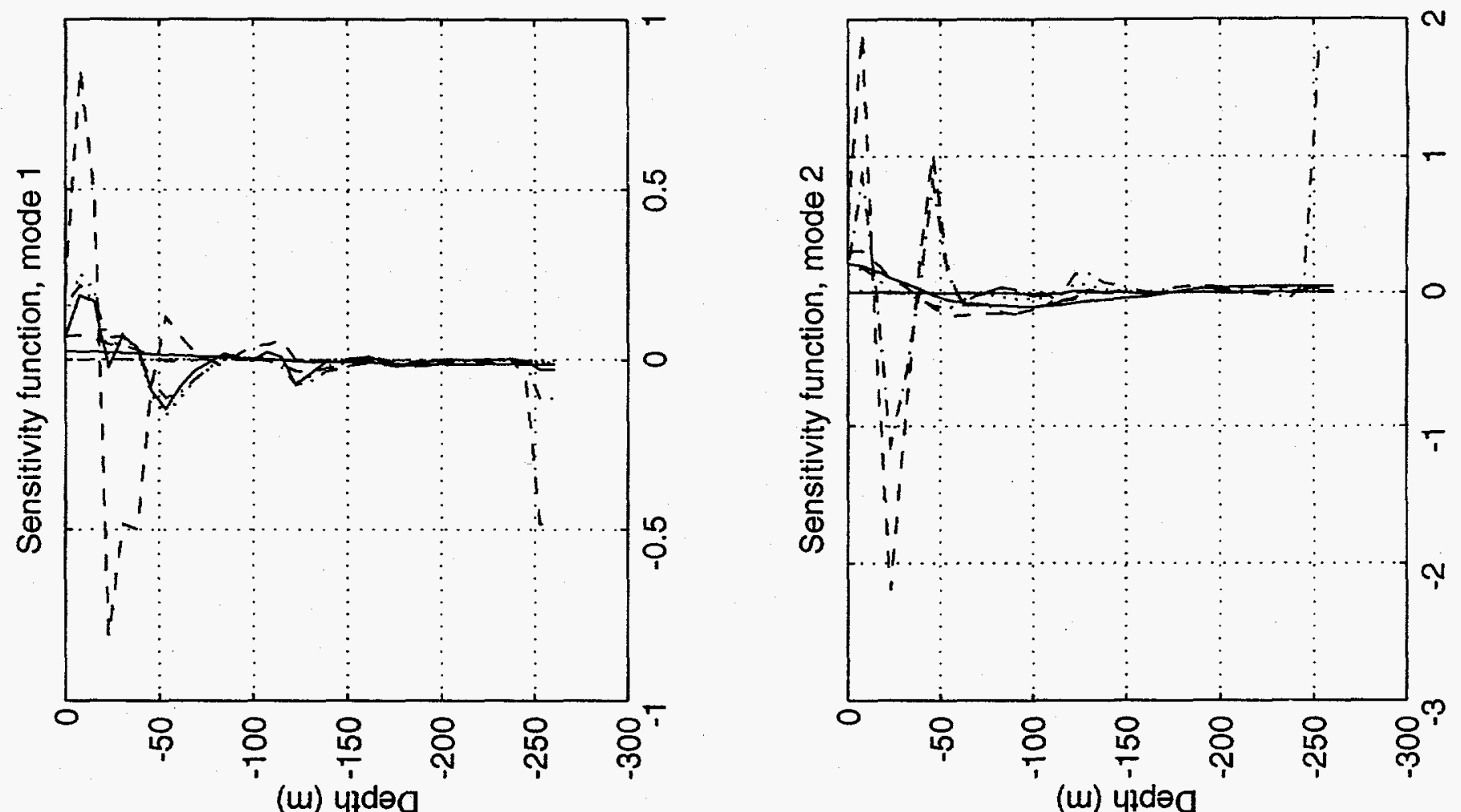

(w) uldəa
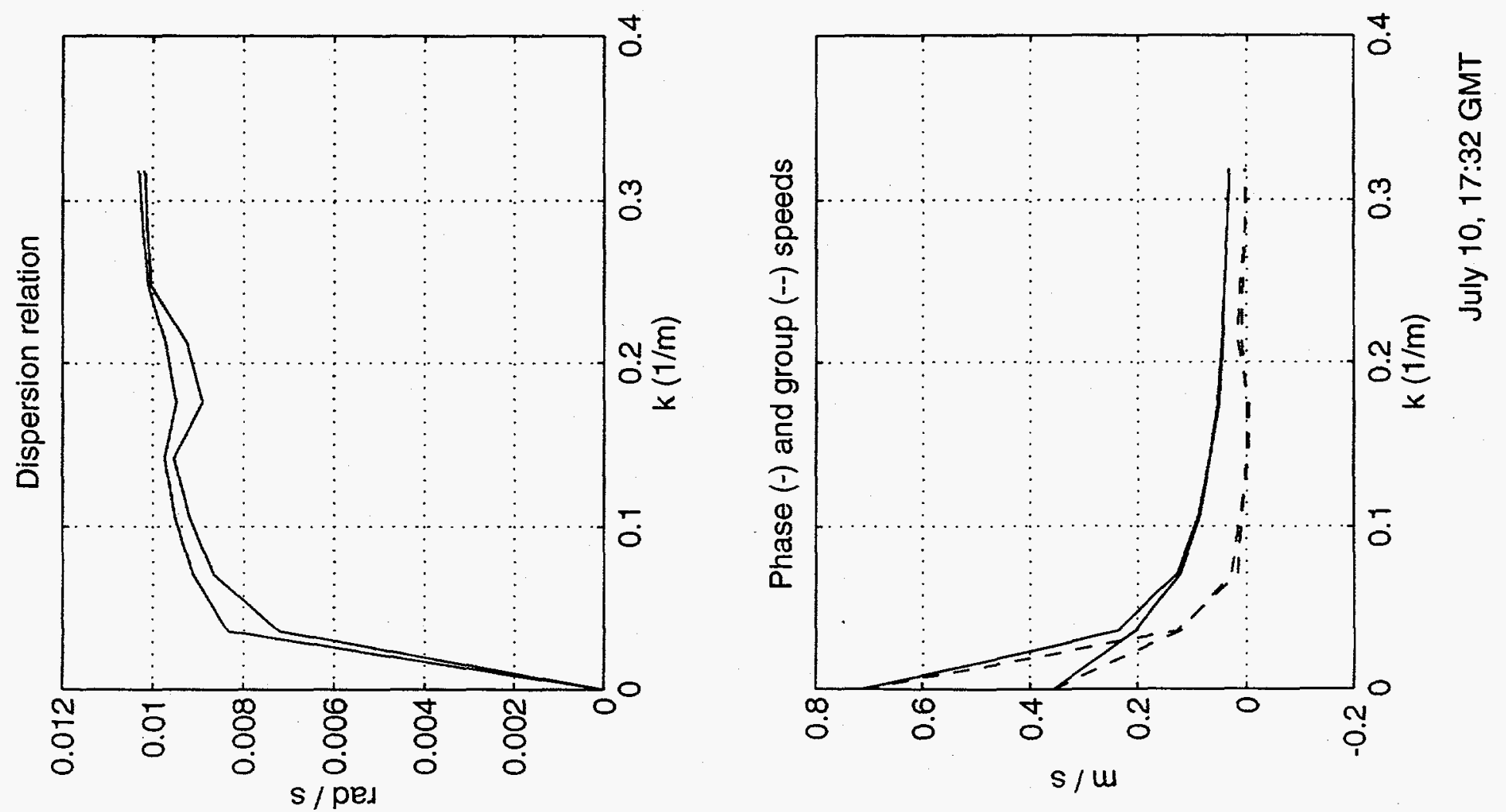

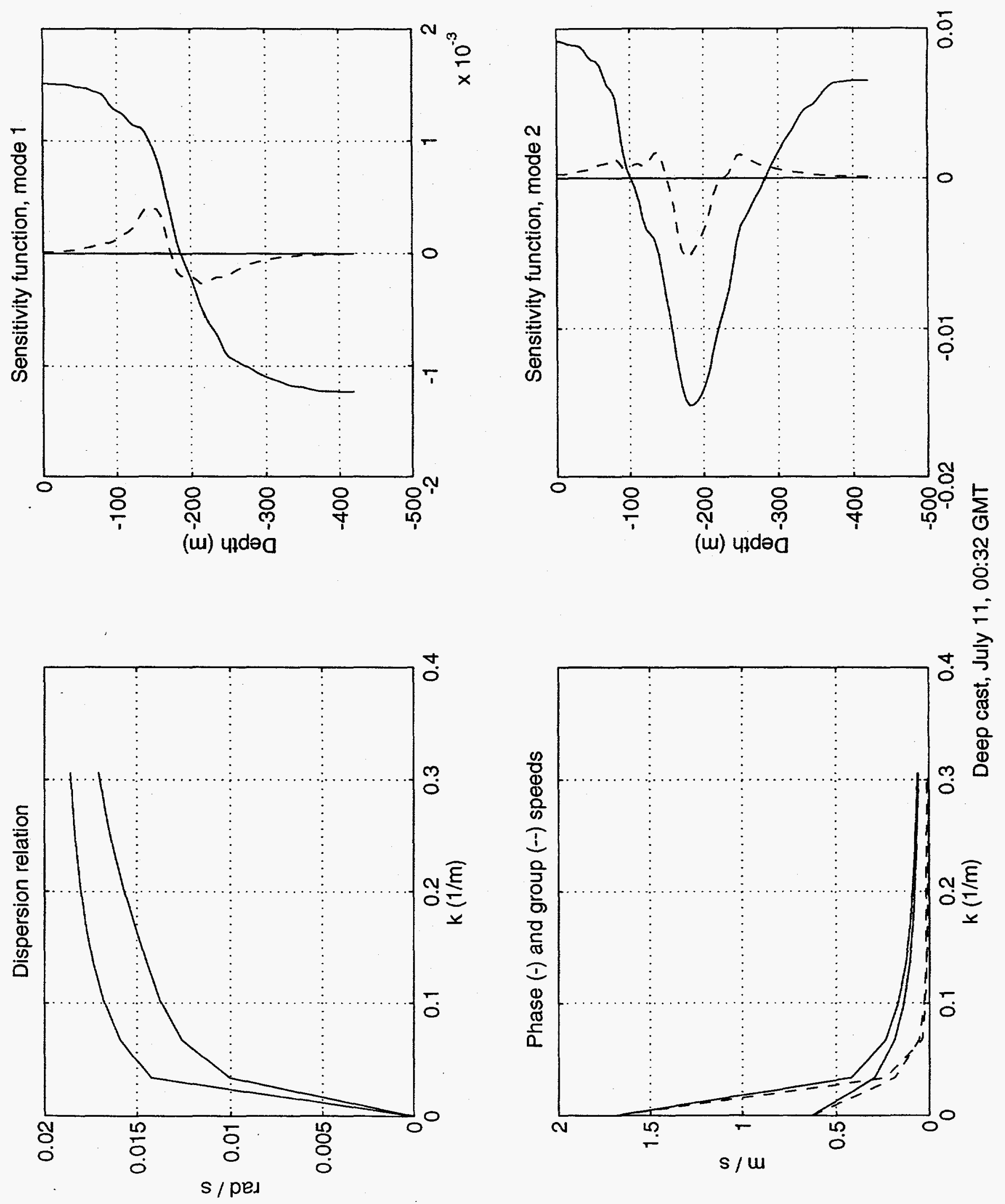


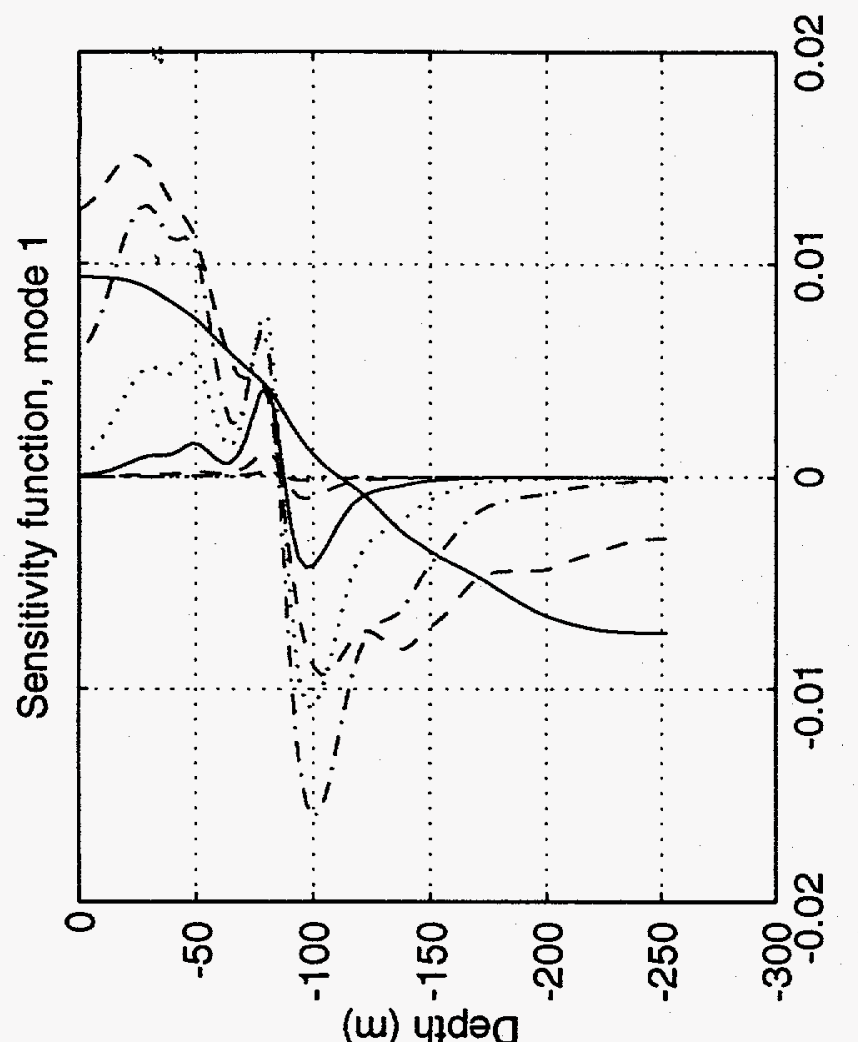

(w) 4zdəa

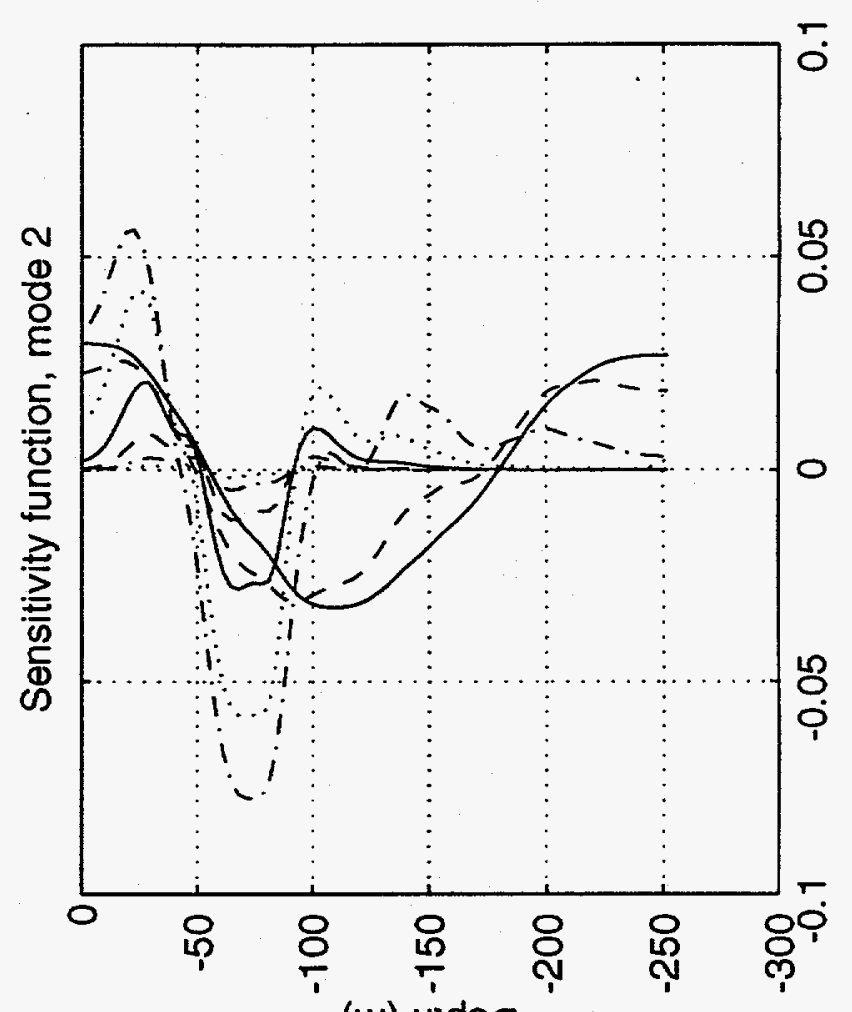

$\sum_{0}$

(w) uाdøa
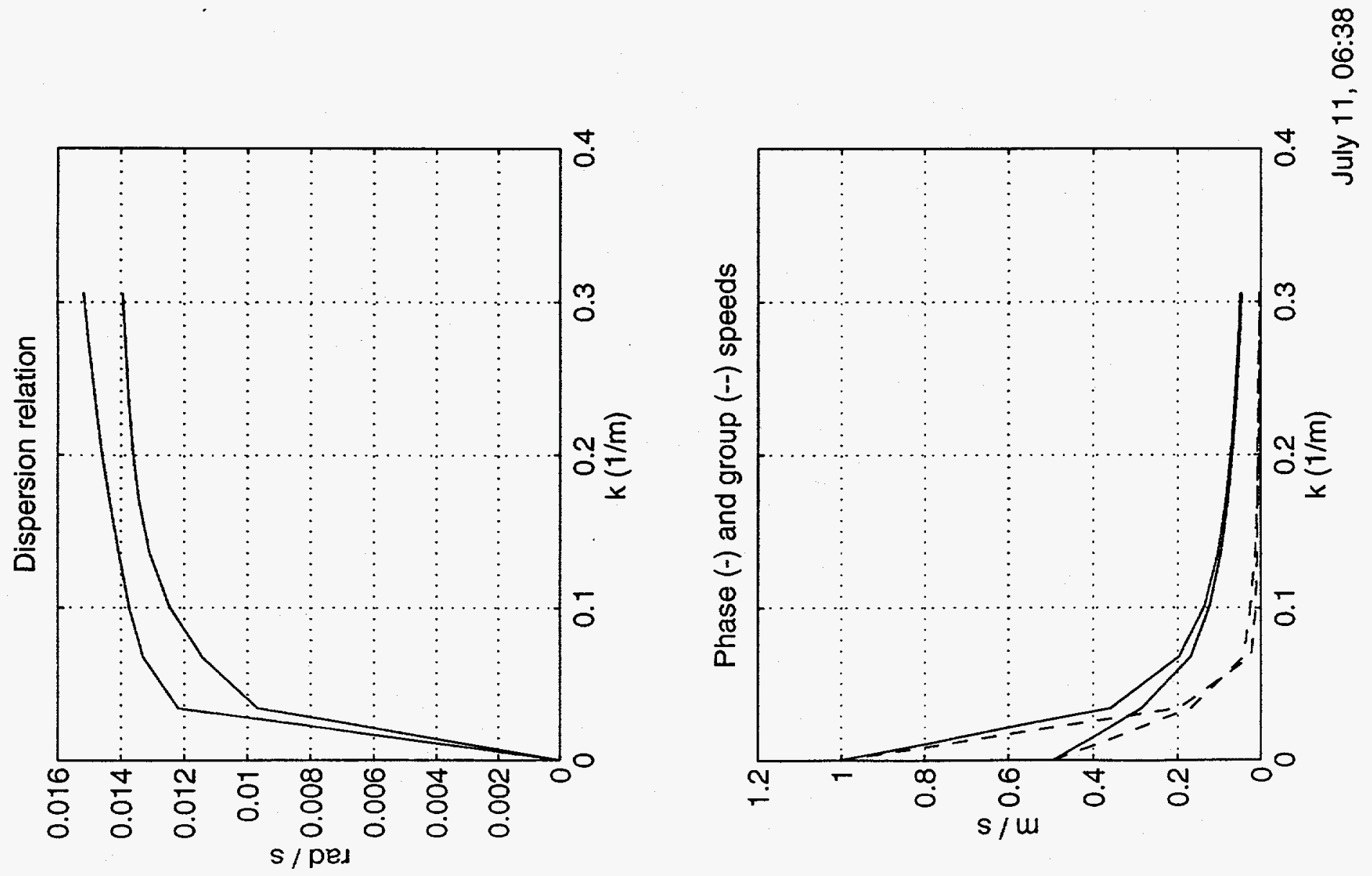

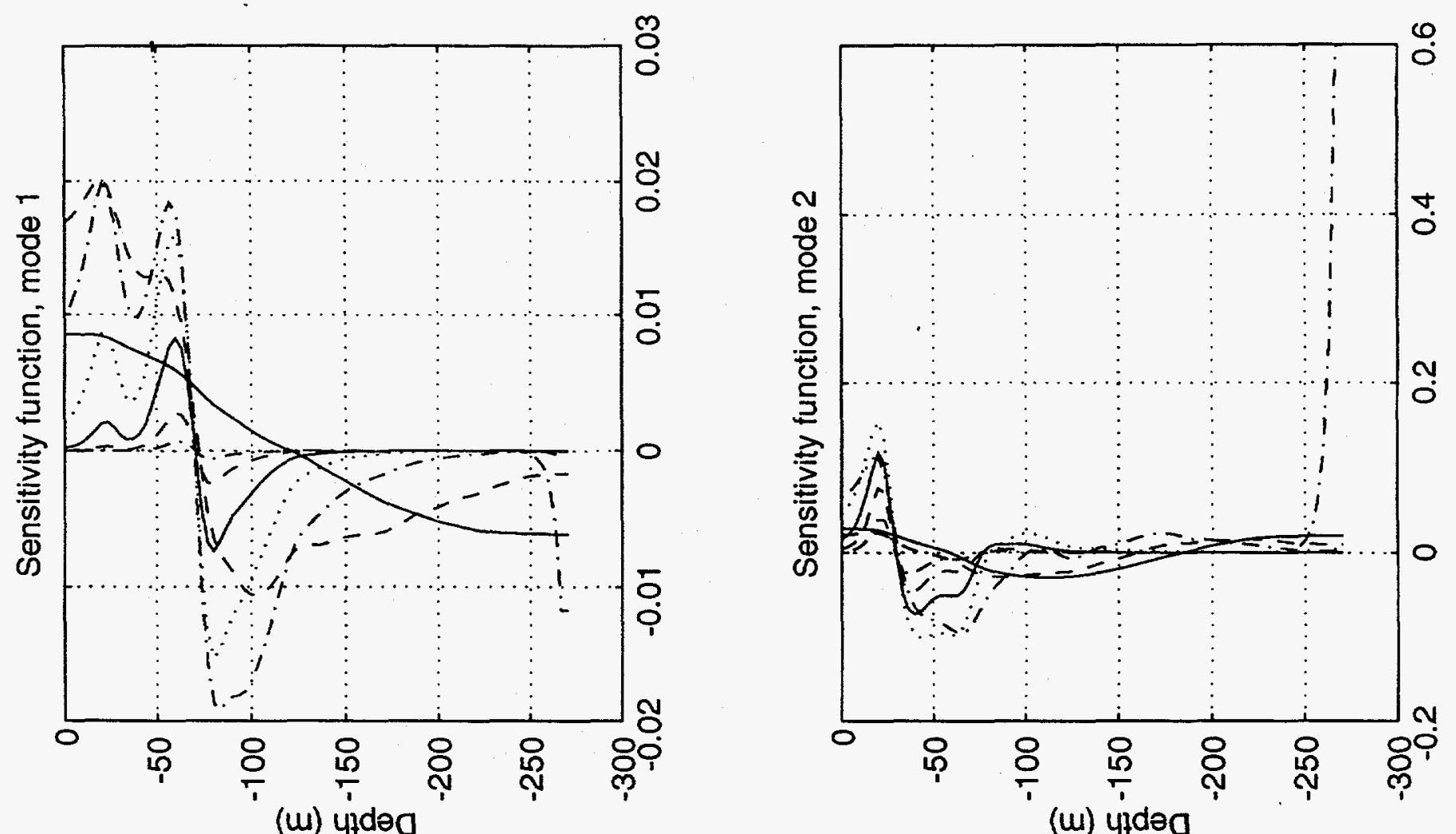

(u) yłdəo
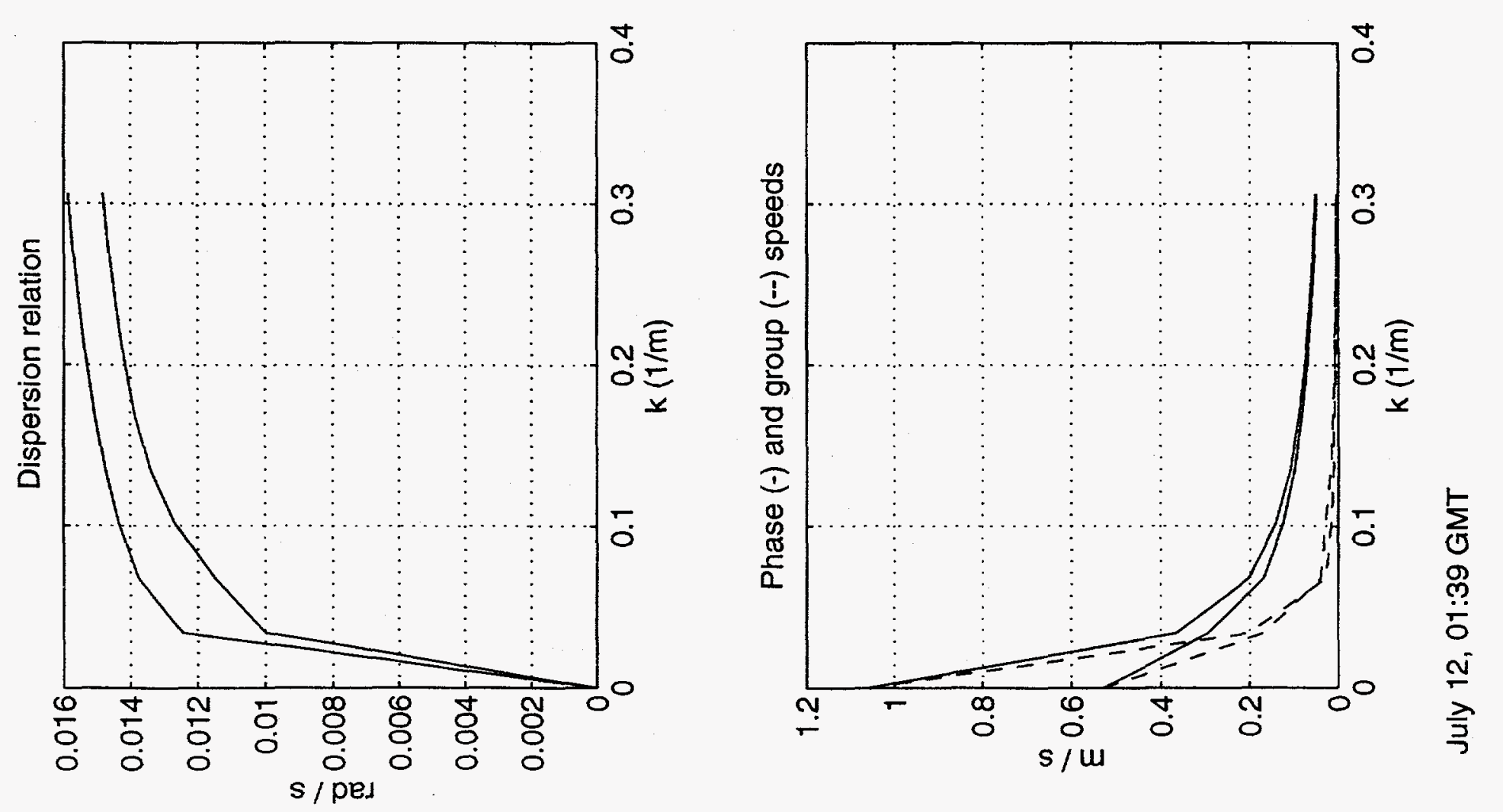

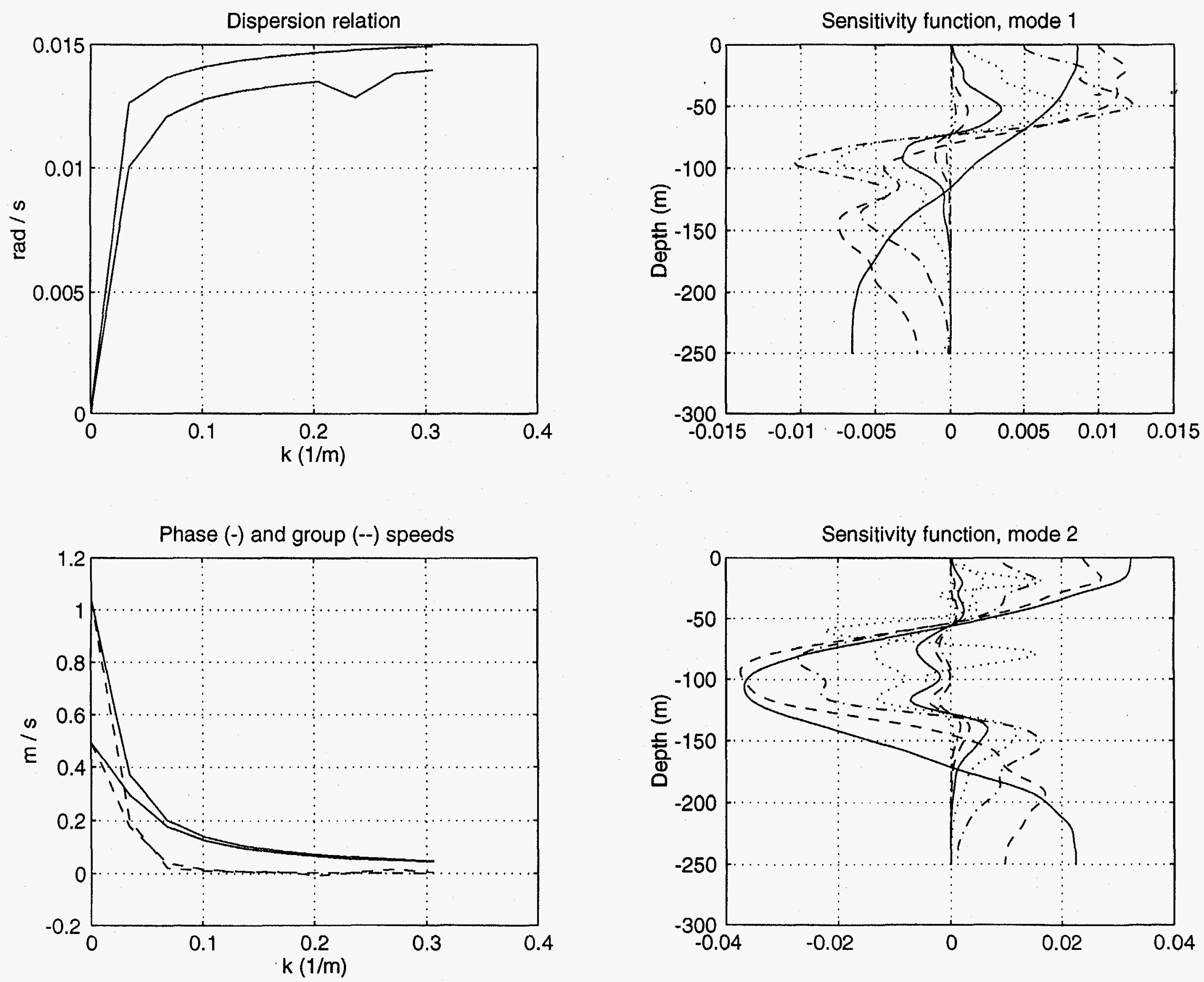

July 13, 00:31 GMT 

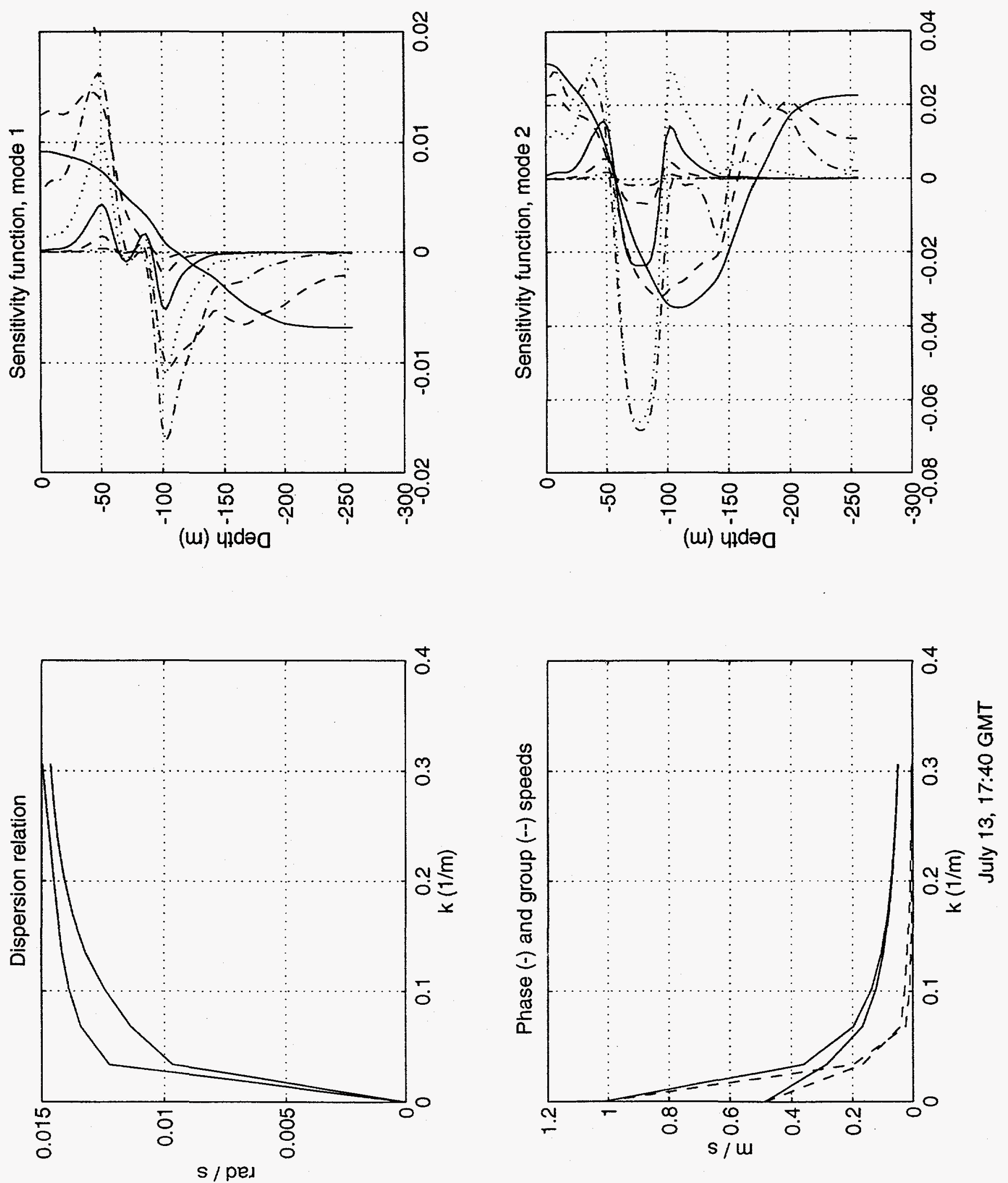

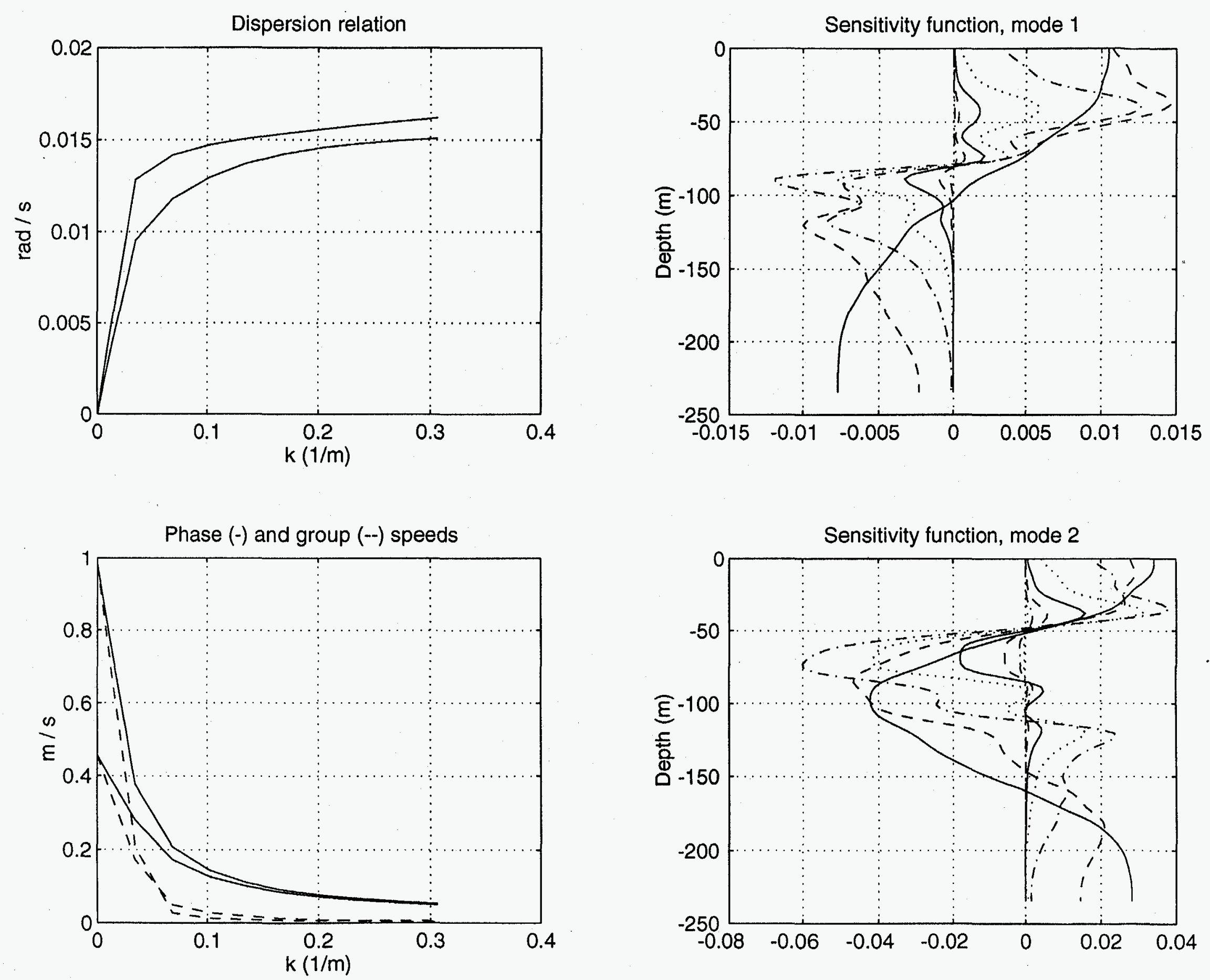

July 14, 01:20 GMT 


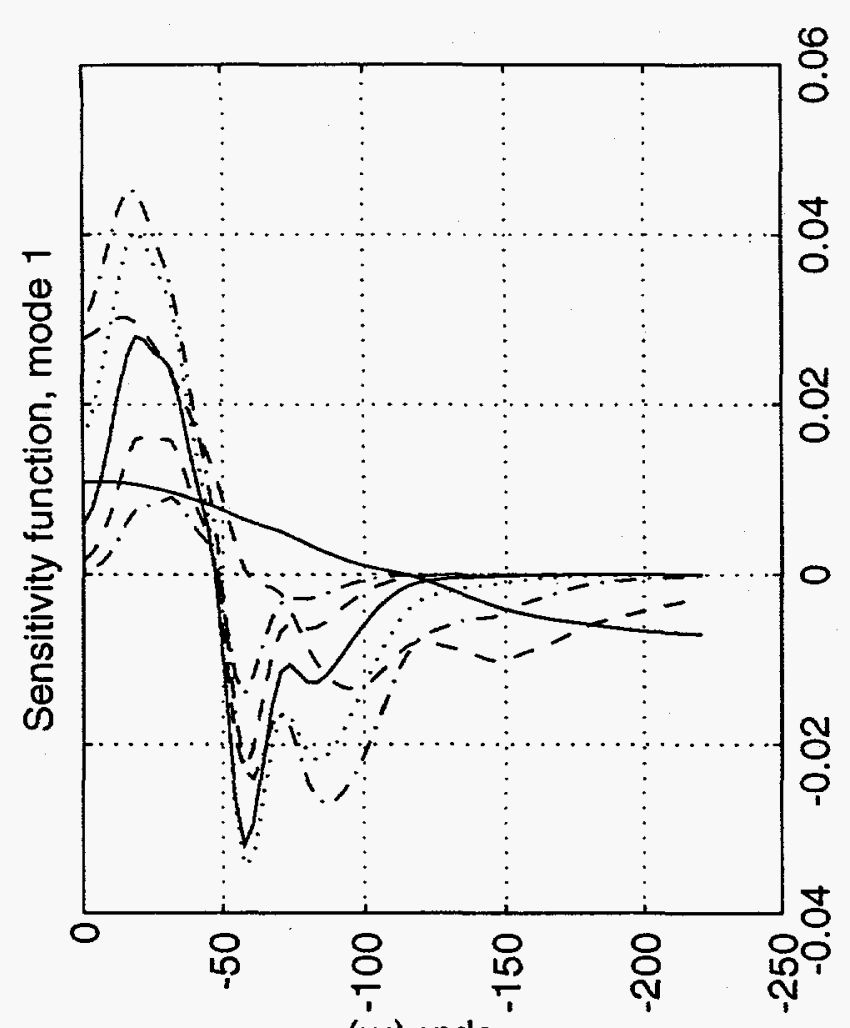

(ii) yıdəa

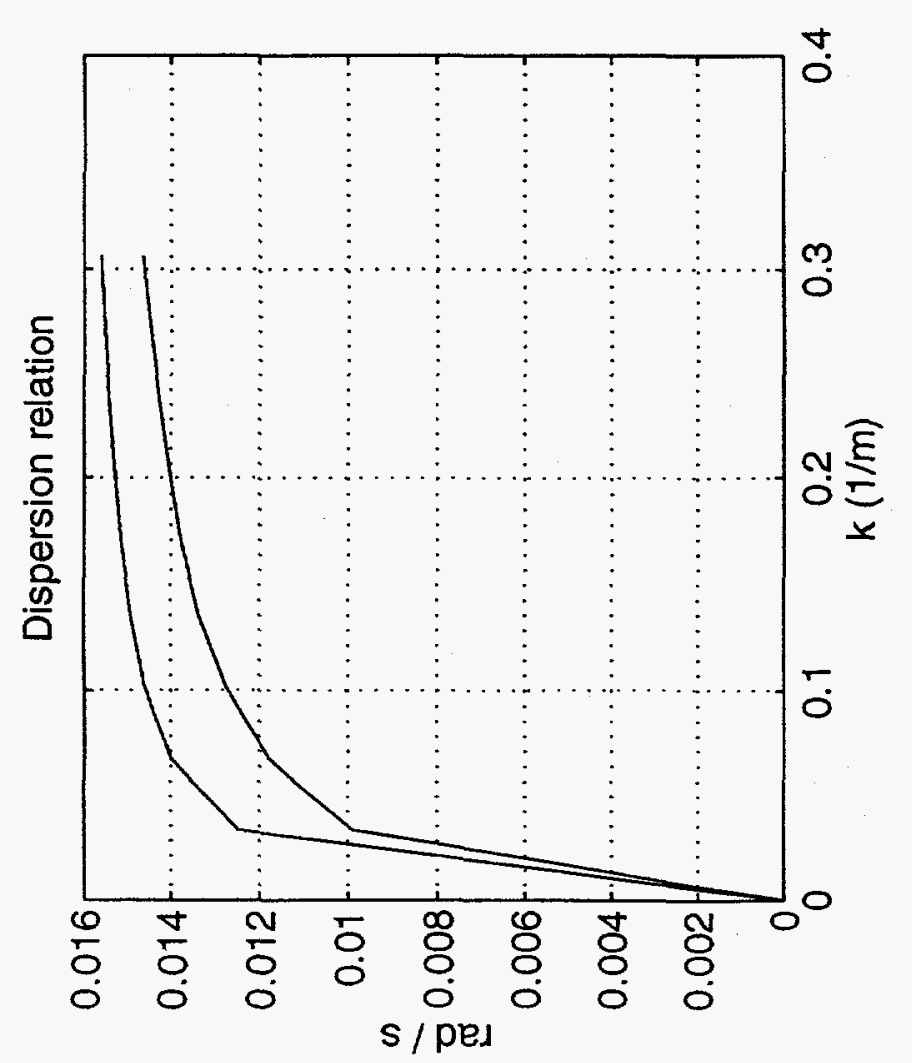

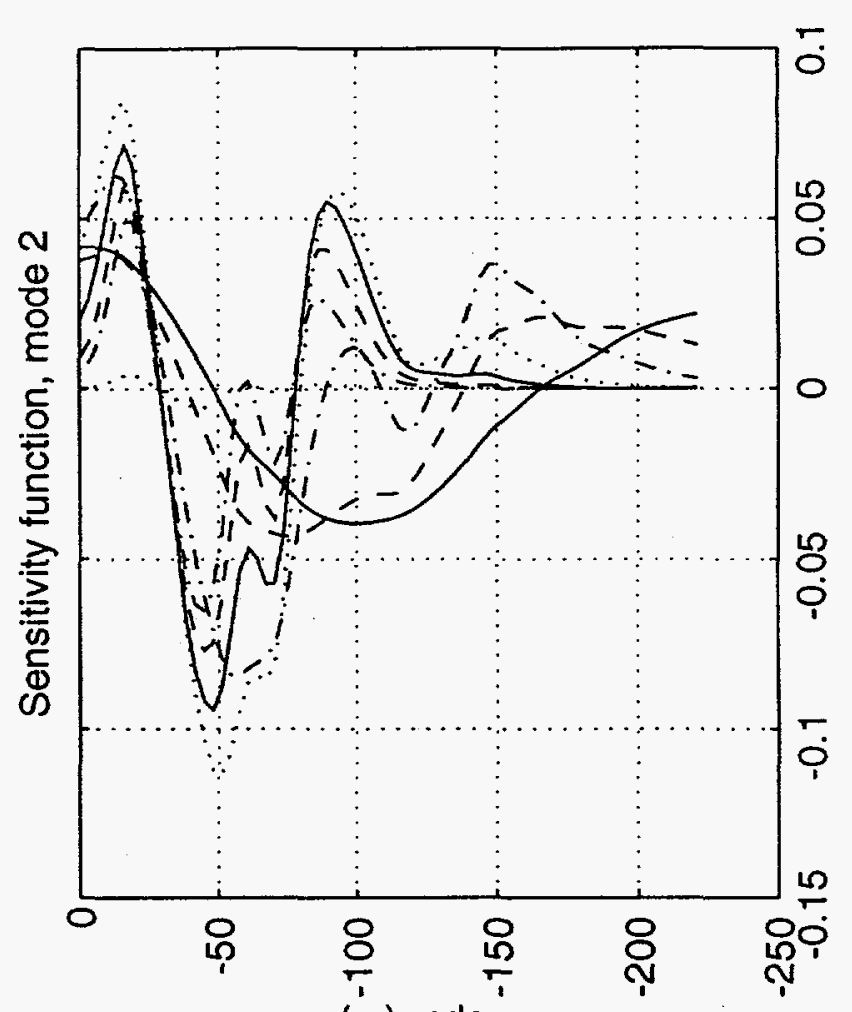

(ii) प1

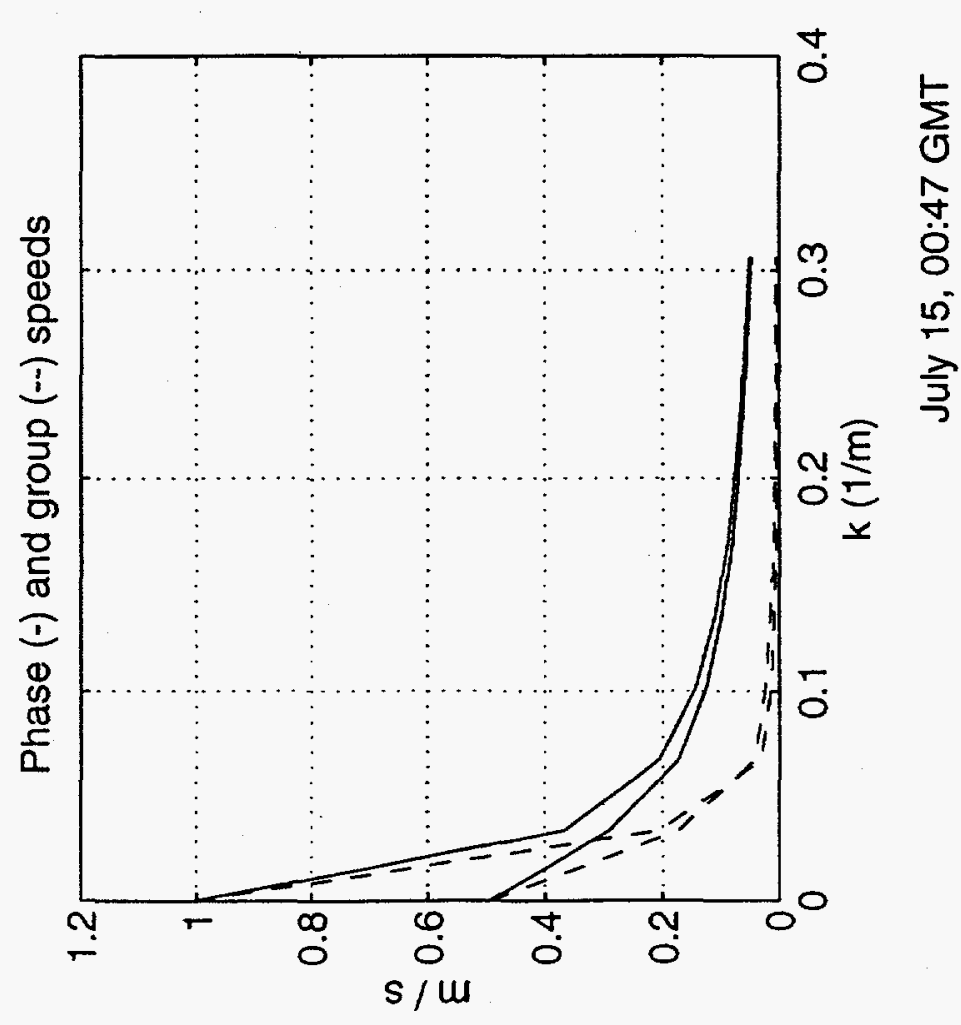



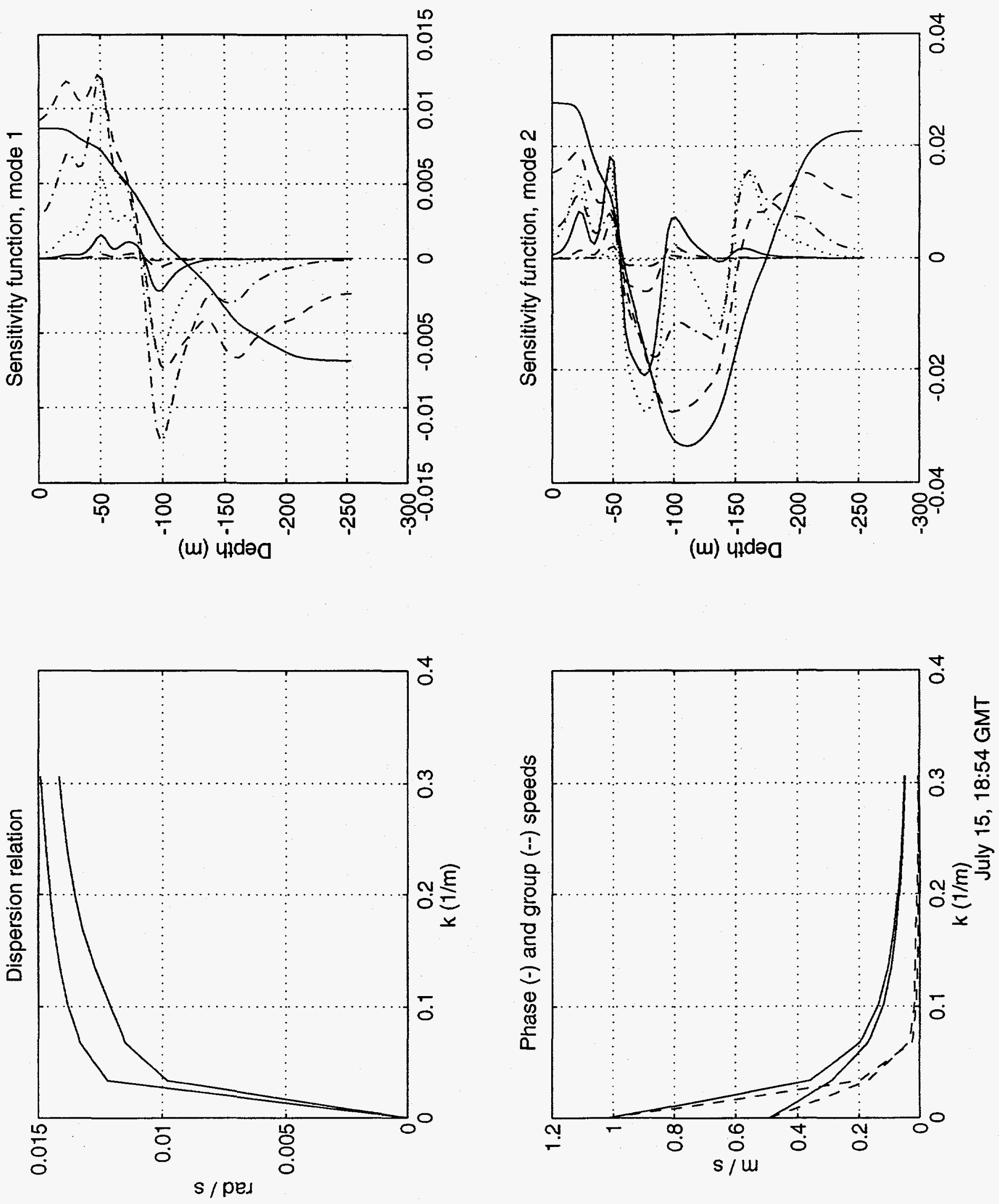

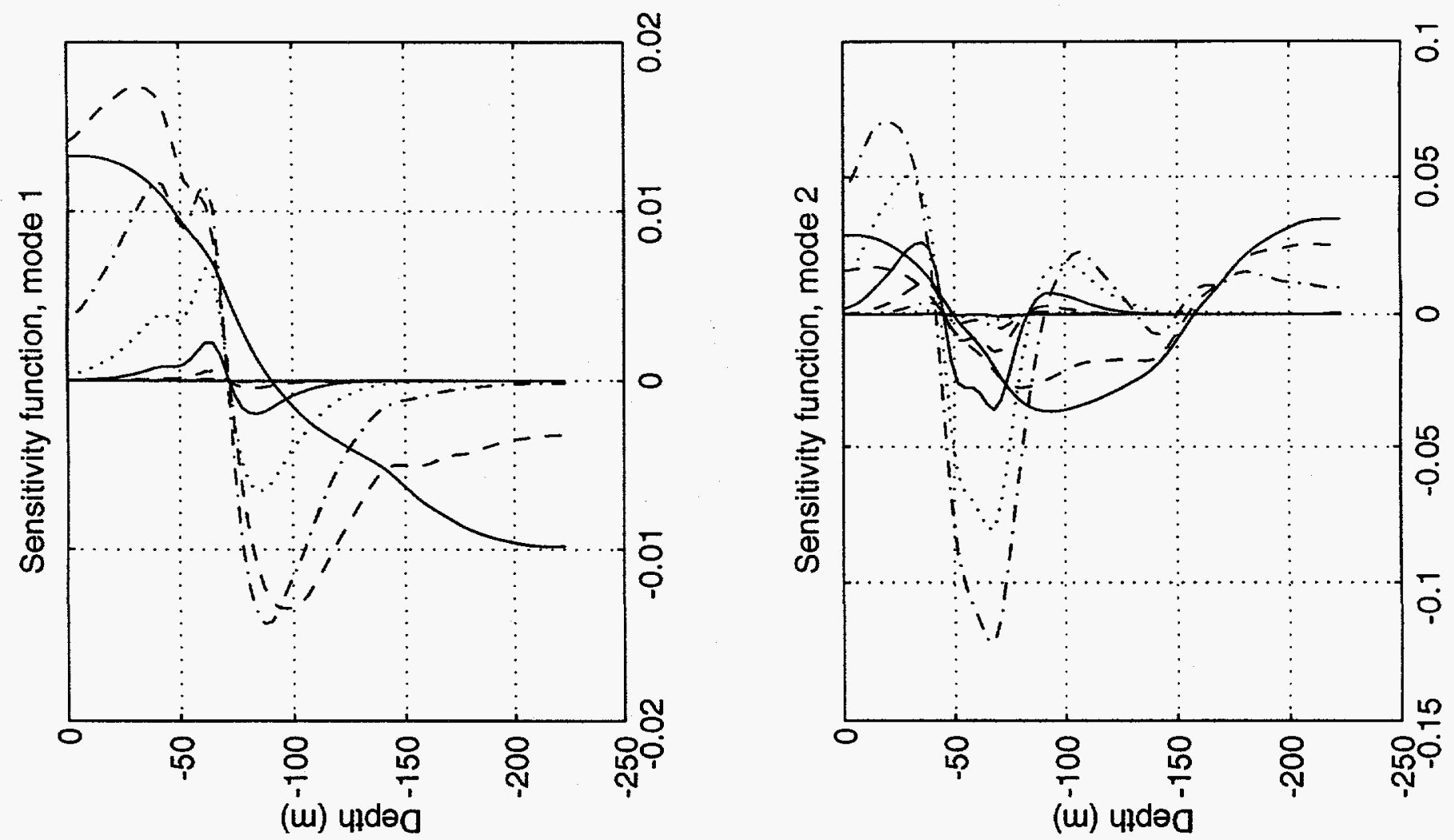

(u) पाdəa
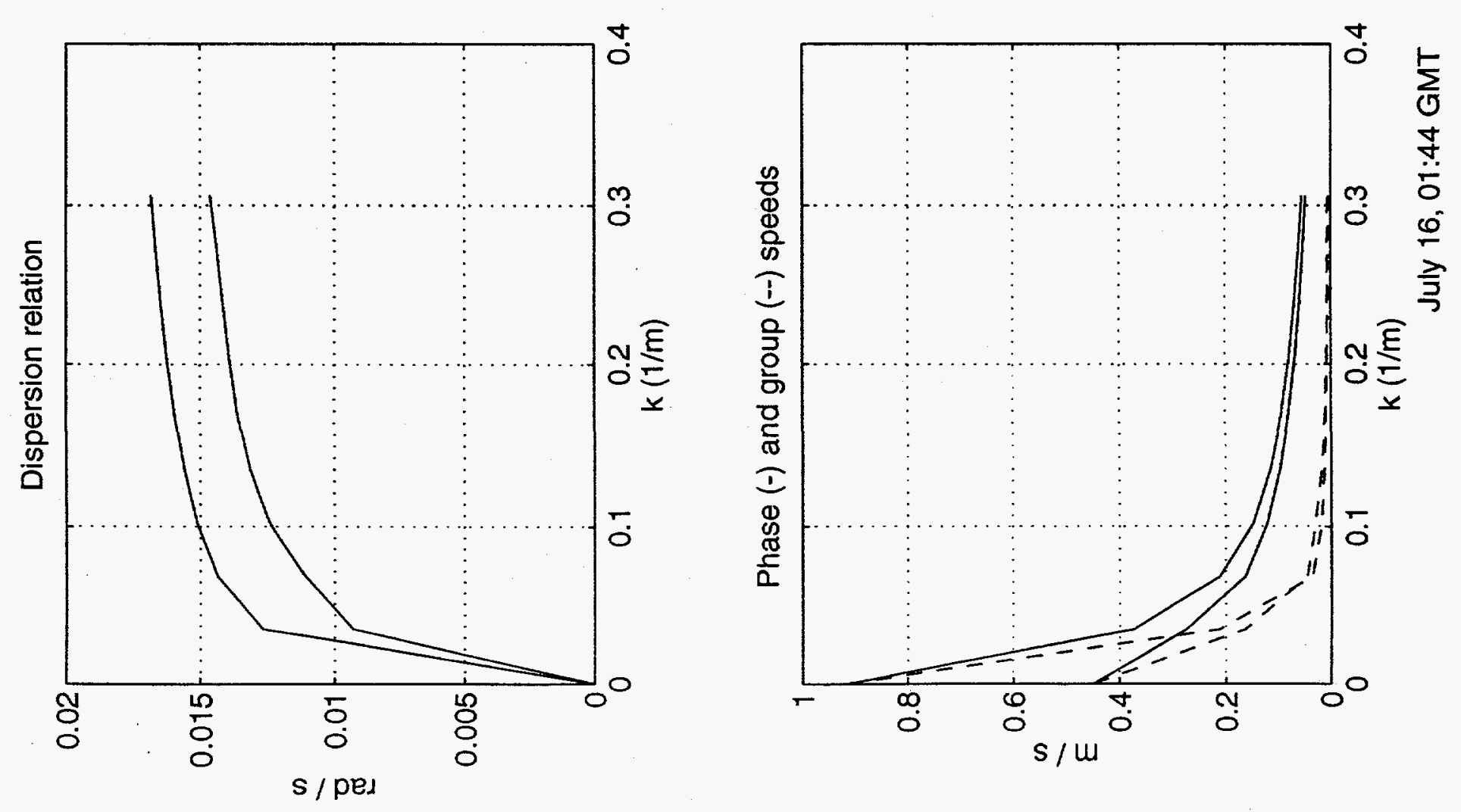


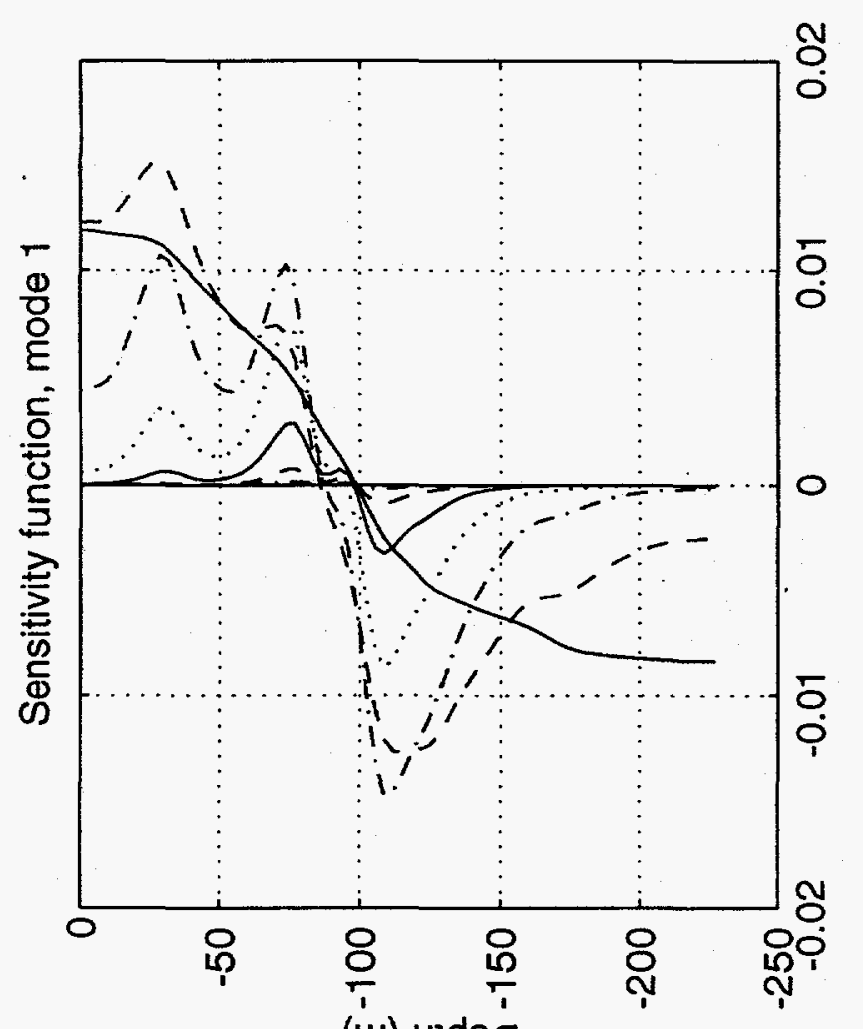

(w) yłdəa

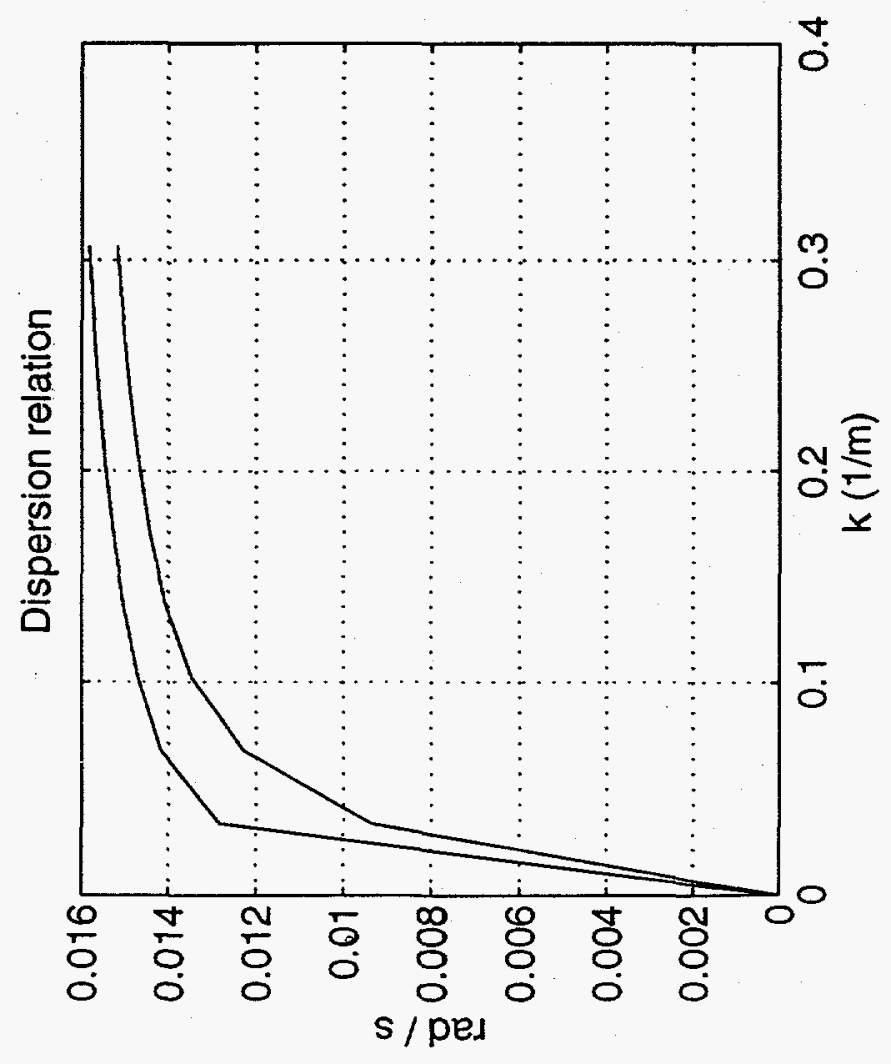

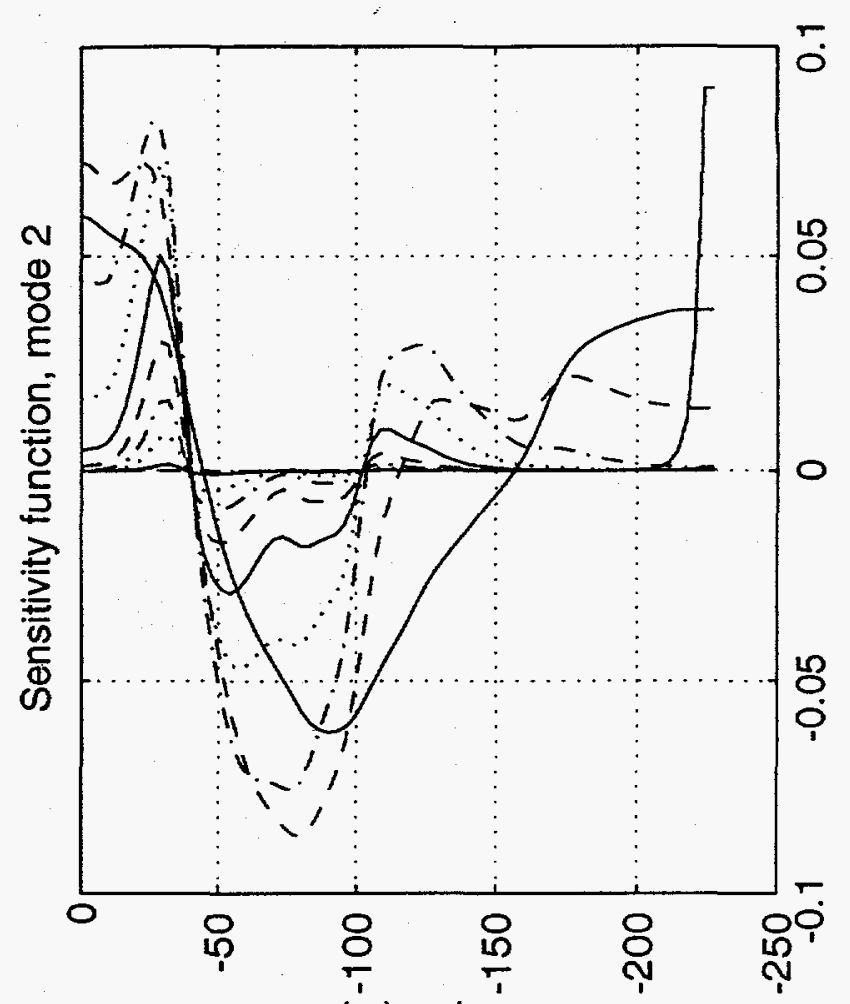

(u) yıdəa

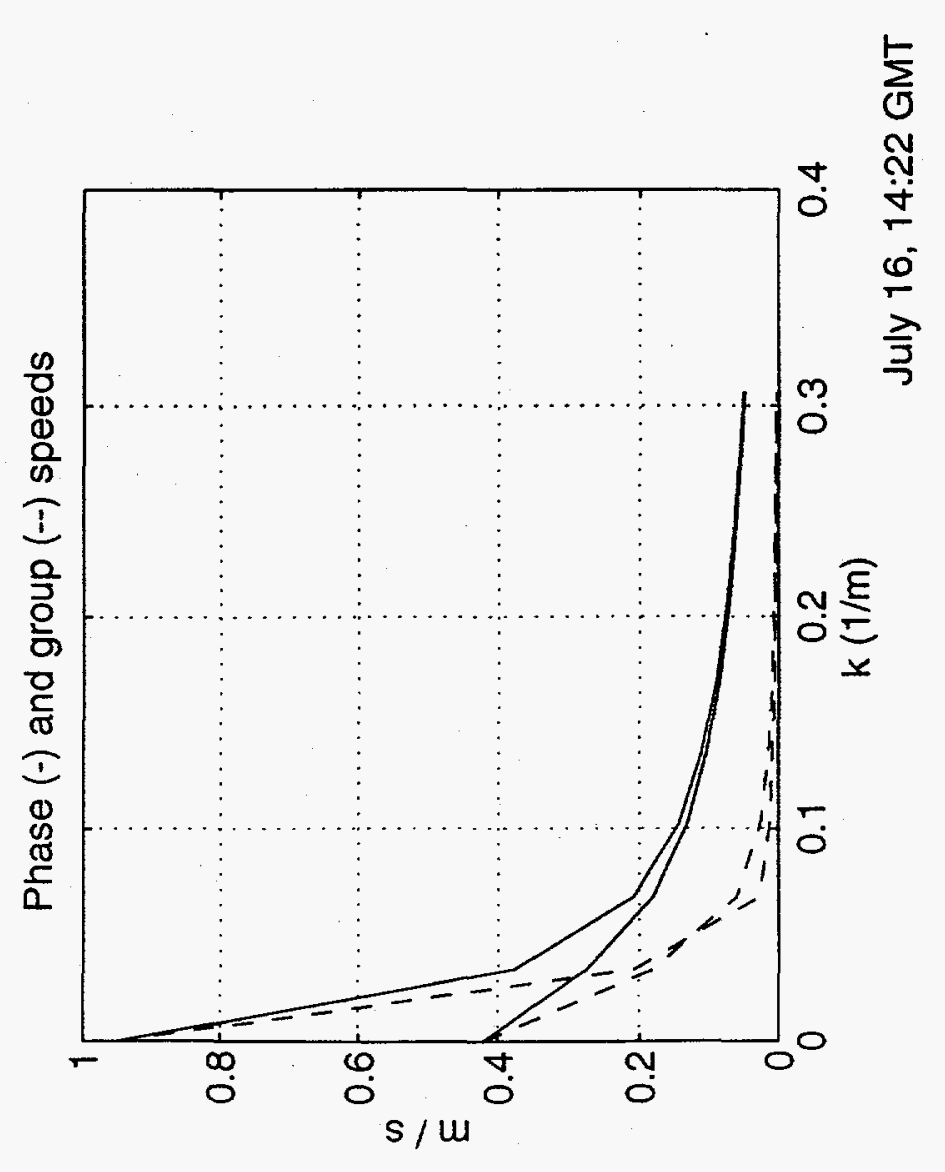




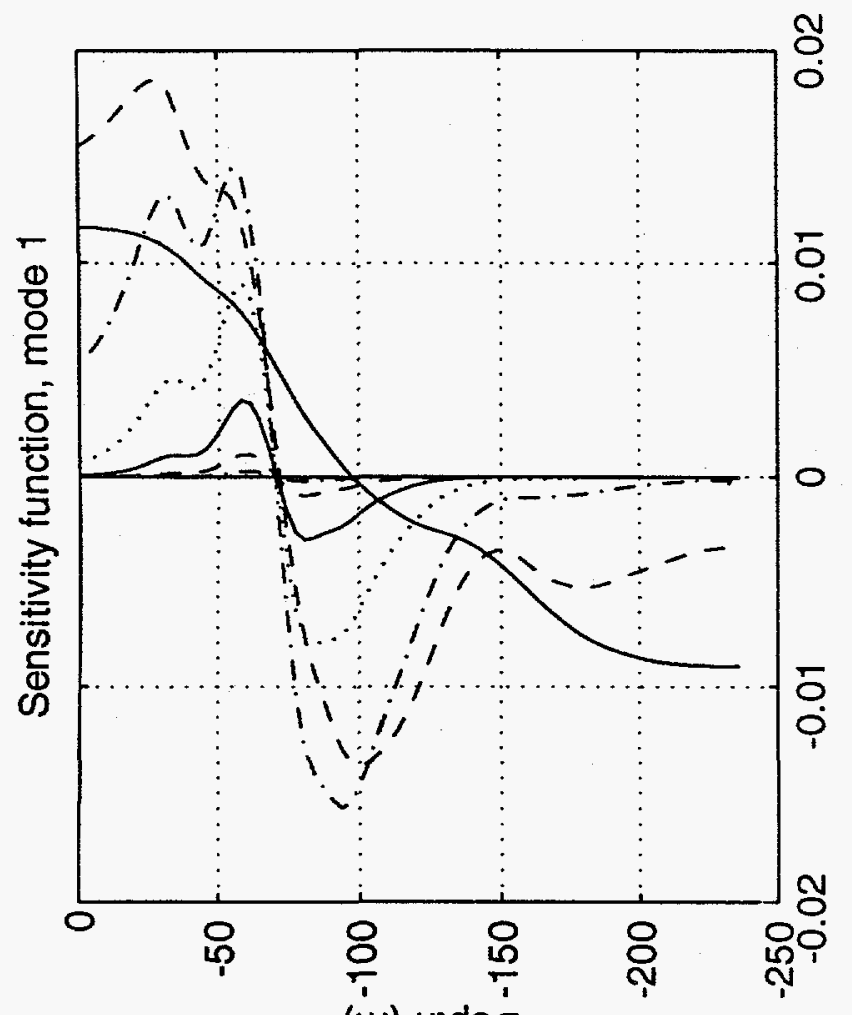

(iv) updəa

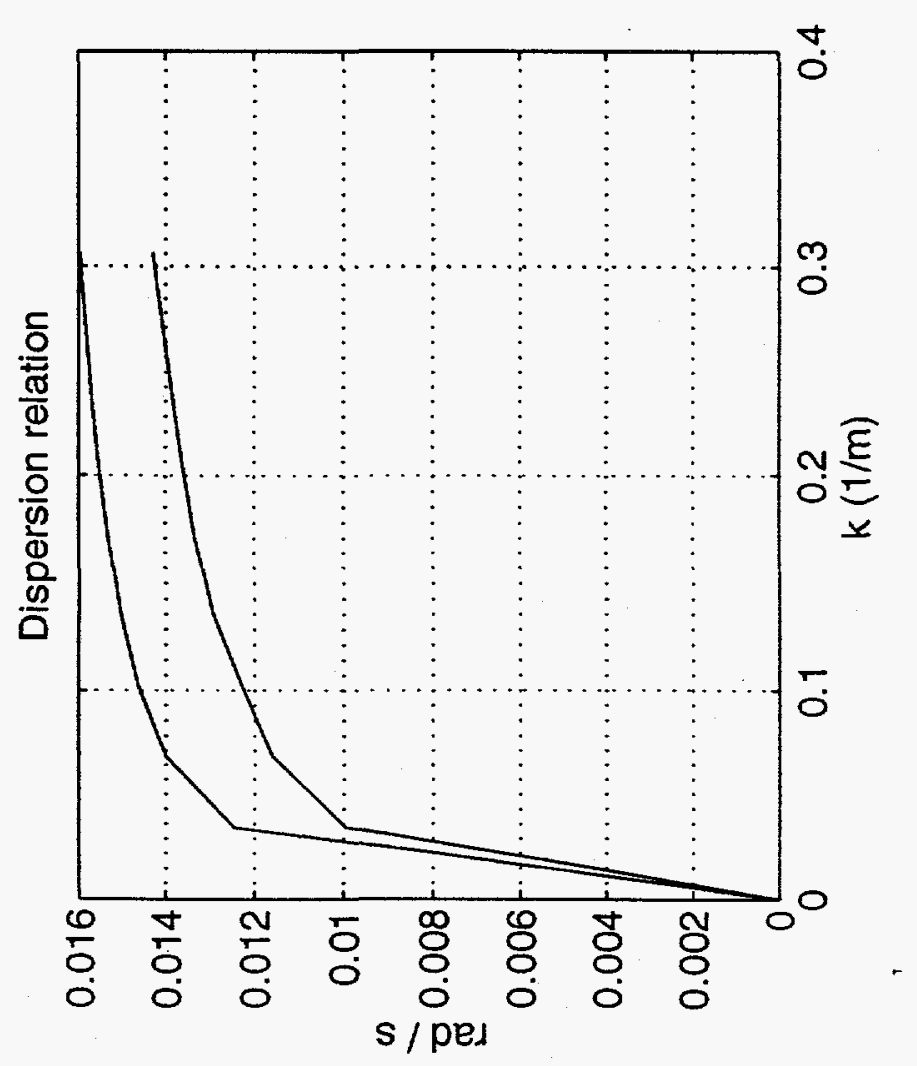

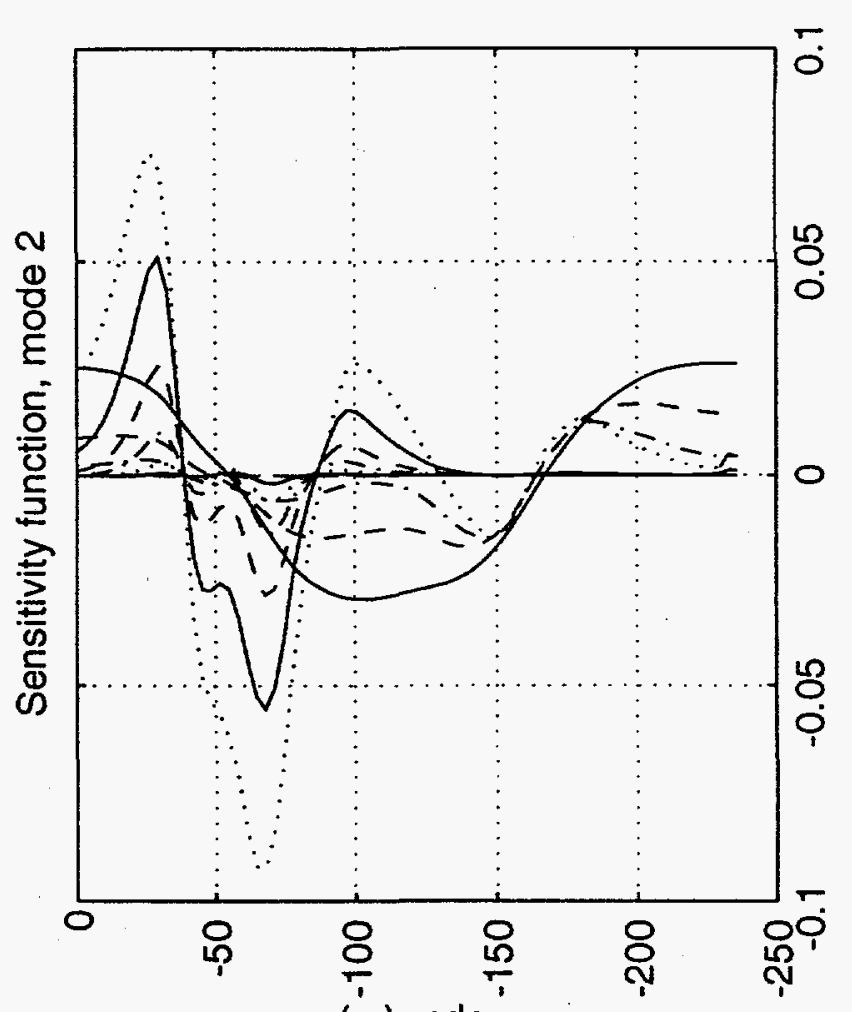

(ii) पıd dəa

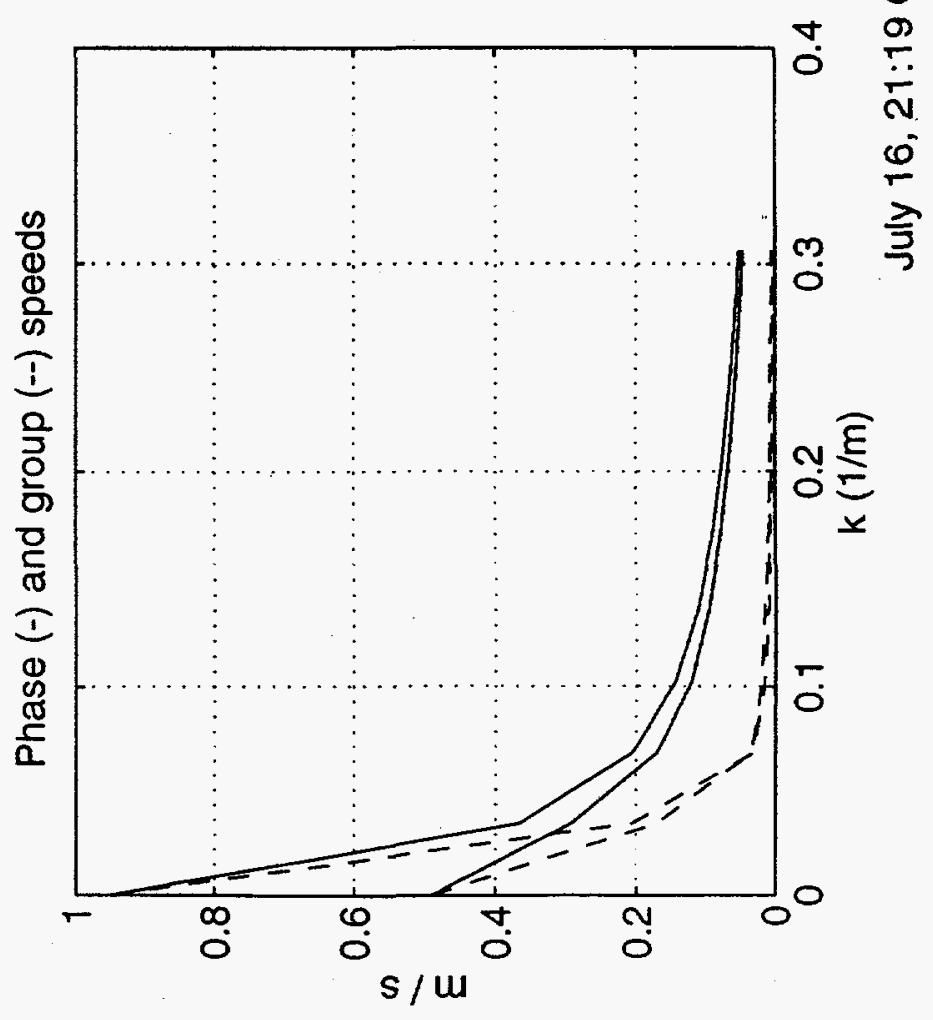

